\title{
WestVirginiaUniversity
}

THE RESEARCH REPOSITORY @ WVU

Graduate Theses, Dissertations, and Problem Reports

2006

\section{Durability of nanoclay FRP bars for concrete members}

\author{
Vijayarajan Krishnaswamy \\ West Virginia University
}

Follow this and additional works at: https://researchrepository.wvu.edu/etd

\section{Recommended Citation}

Krishnaswamy, Vijayarajan, "Durability of nanoclay FRP bars for concrete members" (2006). Graduate Theses, Dissertations, and Problem Reports. 4242.

https://researchrepository.wvu.edu/etd/4242

This Thesis is protected by copyright and/or related rights. It has been brought to you by the The Research Repository @ WVU with permission from the rights-holder(s). You are free to use this Thesis in any way that is permitted by the copyright and related rights legislation that applies to your use. For other uses you must obtain permission from the rights-holder(s) directly, unless additional rights are indicated by a Creative Commons license in the record and/ or on the work itself. This Thesis has been accepted for inclusion in WVU Graduate Theses, Dissertations, and Problem Reports collection by an authorized administrator of The Research Repository @ WVU. For more information, please contact researchrepository@mail.wvu.edu. 


\title{
Durability of Nanoclay FRP Bars for Concrete Members
}

\author{
By \\ Vijayarajan Krishnaswamy \\ Thesis submitted to the College of Engineering and Mineral Resources \\ at West Virginia University \\ in partial fulfillment of the requirements for the degree of
}

Master of Science

in

Civil Engineering

\author{
Dr. P.V.Vijay, Ph.D., Chair \\ Dr. Hota GangaRao, Ph.D., Co-Chair \\ Dr. Roger Chen, Ph.D.,
}

Department of Civil and Environmental Engineering

Morgantown, West Virginia - 26506

2006

Keywords: Bond, Beam flexure, Pullout, Durability, FRP, Nanoclay, Pultrusion, SEM, Shear, Tension, Moisture 


\section{ABSTRACT \\ Durability of Nanoclay FRP Bars for Concrete Members \\ Vijayarajan Krishnaswamy}

In this research, glass fiber reinforced polymer (GFRP) bars were manufactured with nanoclay at CFC-WVU laboratory to evaluate mechanical properties and durability. GFRP bars (0.5 in. and 0.75 in. dia.) were manufactured at room temperature by manual pultrusion. Vinyl ester resin was used with $4 \%$ exfoliated nanoclay by weight with a $44.7 \%$ glass fiber (roving) volume. Shear mixer was used to exfoliate nanoclay in the resin. GFRP bars measuring $12 \mathrm{ft}$. long were successfully manufactured with a low void content of $0.39 \%$.

GFRP bars manufactured with and without nanoclay were tested in tension, shear and bond prior to and after aging them in different conditioning schemes. Bars (\#4 dia.) with nanoclay showed $30.04 \%$ lower average strength as compared to those without nanoclay, which suggested that addition of higher percentage nanoclay (4\%) reduced the maximum failure stress of GFRP bars. Among different aging schemes (water at room temperature, water at $110^{\circ} \mathrm{F}$, water at $140^{\circ} \mathrm{F}$, and alkaline solution at room temperature), water at elevated temperature of $140^{\circ} \mathrm{F}$ was found to be more severe on strength reduction followed by alkaline aging (strength reduction of $36.51 \%$ without nanoclay vs. $18.52 \%$ with nanoclay at $140^{\circ} \mathrm{F}$ aging as compared to $16.35 \%$ without nanoclay and $13.58 \%$ with nanoclay in alkaline solution). GFRP bars with nanoclay exhibited better durability than those without nanoclay in all types of conditioning schemes considered in this research. Bars (\#4 dia.) with nanoclay showed 5.71\% lower average shear strength as compared to those without nanoclay (24.77 ksi vs. $26.27 \mathrm{ksi}$ ) and \#6 bars with nanoclay showed $12.77 \%$ lower average shear strength as compared to those without nanoclay (20.02 ksi vs. 22.95 ksi), which suggested that addition of nanoclay decreased the shear stress. GFRP bar with nanoclay conditioned at different aging schemes showed higher bond strength than the original bond strength, because increase in bond stress was noted due to post curing of concrete and rebars including bar swelling effects. Scanning Electron Microscopy (SEM) showed that many of the GFRP bars without nanoclay exhibited fiber pull-out near edges as compared to those with nanoclay. Bars subjected to $140^{\circ} \mathrm{F}$ and alkaline conditioning showed more number of fibers being pulled out and/or damaged from the matrix along the edges, which causes a reduction in bond strength.

Concrete beams reinforced with nanoclay GFRP bars showed better stiffness characteristics than those with regular GFRP bars (without nanoclay). GFRP reinforced beams were cast with \#4 and \#6 GFRP bars with and without nanoclay. Experimental to theoretical ultimate load ratios of all the beams varied between 0.91 and 1.08 (i.e., within 10\%). 


\section{DEDICATION}

THIS THESIS IS DEDICATED TO MY FAMILY

WHO HAVE MADE IT POSSIBLE FOR ME TO COMPLETE MY

MASTERS DEGREE IN WVU 


\section{ACKNOWLEDGEMENT}

I would like to extend my sincere gratitude to a number of people for their contributions towards this thesis and my master's degree.

The professors at West Virginia University have been wonderful source of guidance and encouragement. Dr. P. V. Vijay and Dr. Hota GangaRao, my thesis advisors, offered many helpful suggestions regarding the research and documentation of my master's thesis. My sincere thanks to them for being an integral part of this research work, their insights, guidance, time and most of all their patience. I also would like to thank Dr. Roger chen, member of my thesis committee, for his precious time and guidance.

My sincere thanks to Mr. Jerry Nester, Mr. Bill Comstock, and Mr. David Turner, at West Virginia University, who helped in the manufacturing of equipments and fixtures required for the completion of this work. I would also like to express my gratitude to Anu Viswanathan, Amarnath Varthakavi, Aneesh Bethi, and Imen Bathine, for lending me a helping hand whenever possible. 


\section{TABLE OF CONTENTS}

ABSTRACT ......................................................................................................................................ii

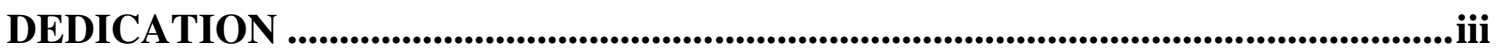

ACKNOWLEDGEMENT................................................................................................... iv

TABLE OF CONTENTS ........................................................................................................

LIST OF TABLES ............................................................................................................. ix

LIST OF FIGURES ...................................................................................................................... xii

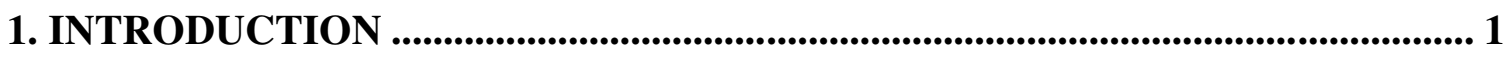

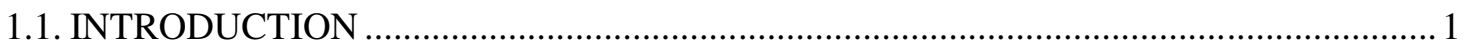

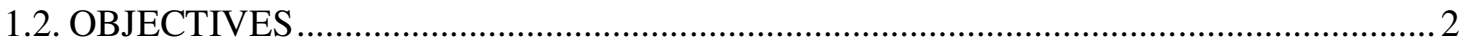

1.3. SCOPE

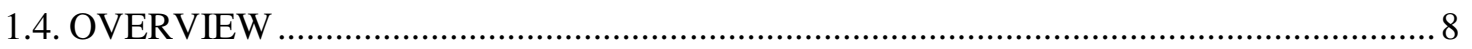

2. LITERATURE REVIEW ........................................................................................... 9

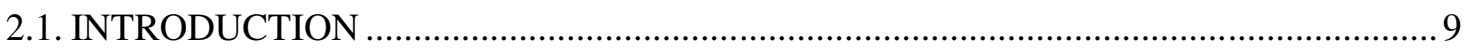

2.2. MECHANICAL PROPERTIES AND DURABILITY TESTS ON FRP BARS..................10

2.2.1. TENSION PROPERTIES OF GFRP ................................................................ 10

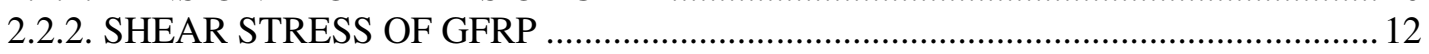

2.2.3. BOND STRENGTH OF GFRP WITH CONCRETE ……………………………..... 12

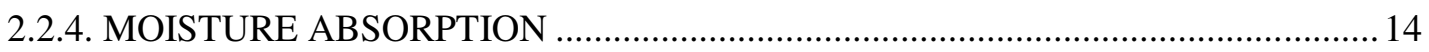

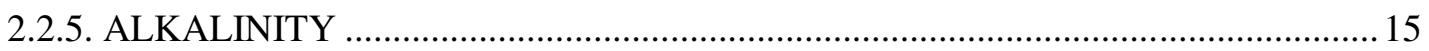

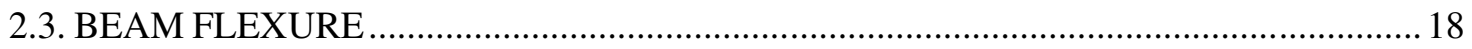

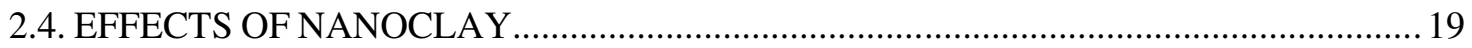

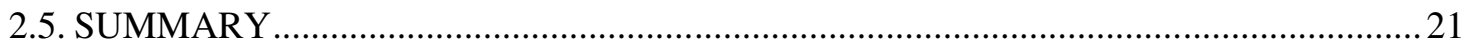

3. TEST PROCEDURES............................................................................................... 23

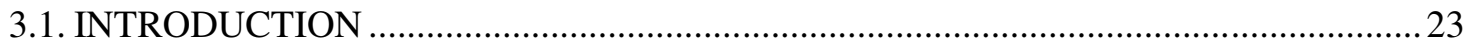

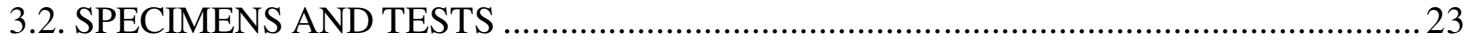

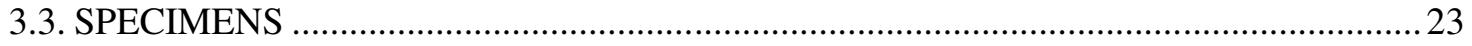

3.4. TESTS

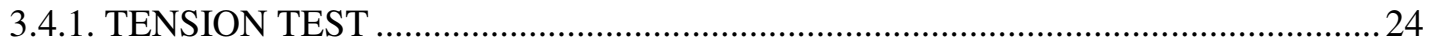

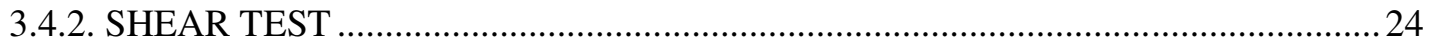

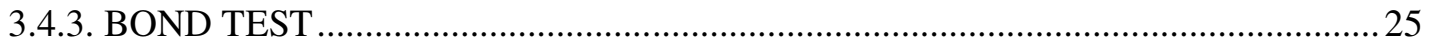

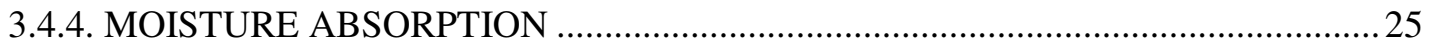

3.4.5. SEM

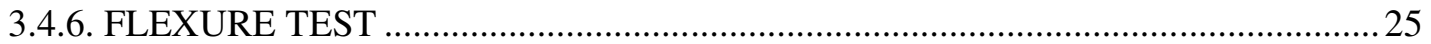

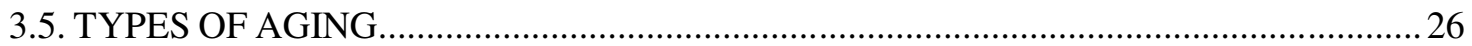

4. MATERIALS, MANUFACTURING, AND EQUIPMENTS................................... 27

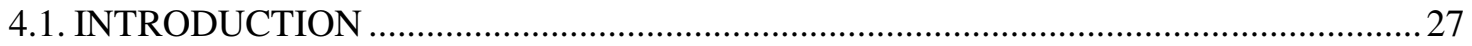

4.2. MATERIALS FOR MANUFACTURING GFRP REBAR ………………………........2

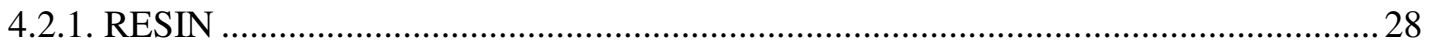

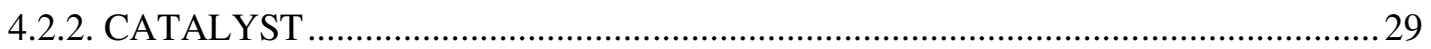

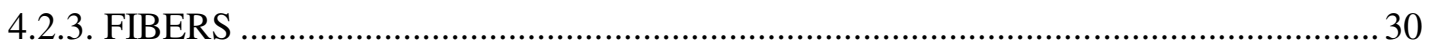

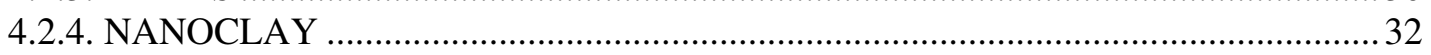

4.3. EQUIPMENTS FOR MANUFACTURING GFRP REBAR ………………………...... 34 


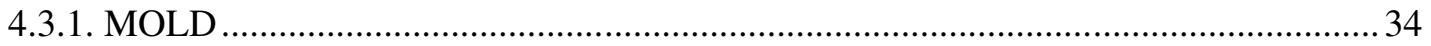

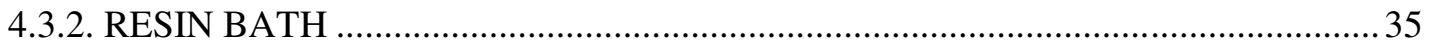

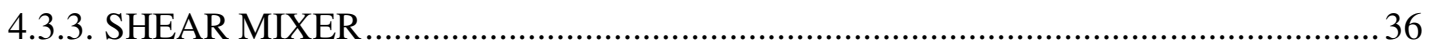

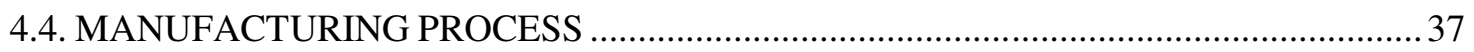

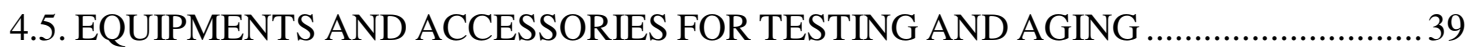

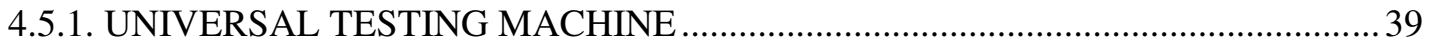

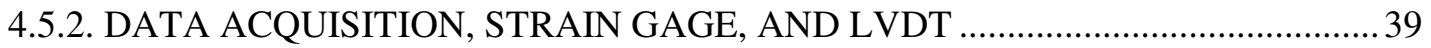

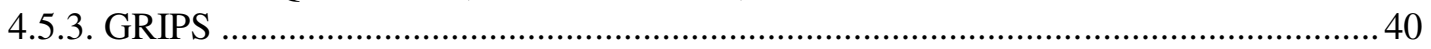

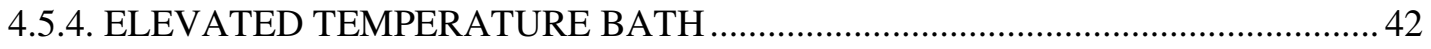

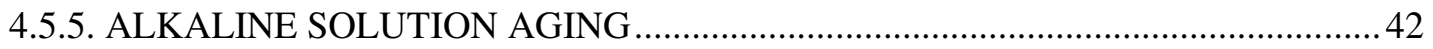

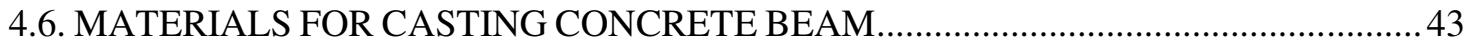

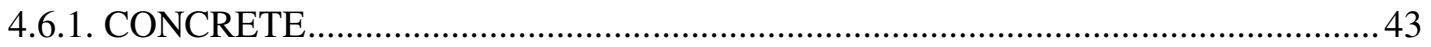

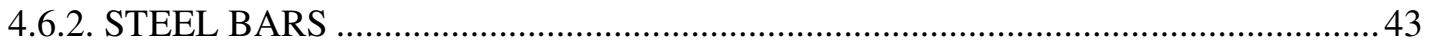

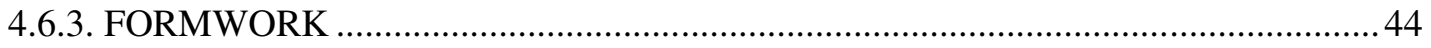

5. TENSION TESTS ................................................................................................................ 45

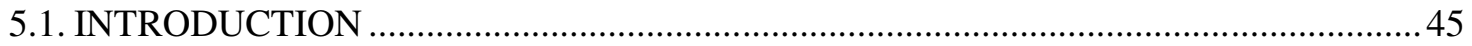

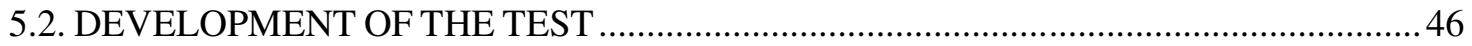

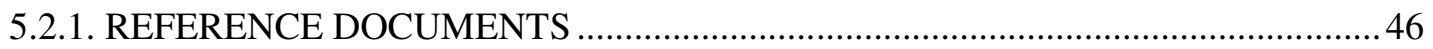

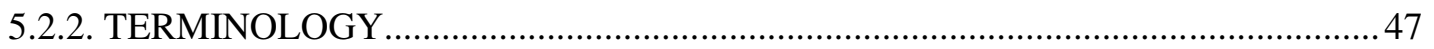

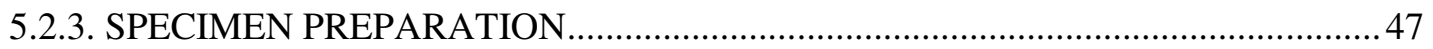

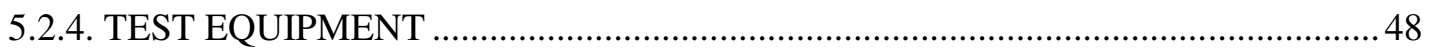

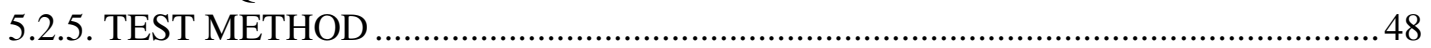

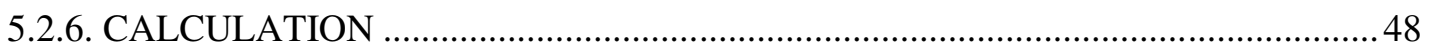

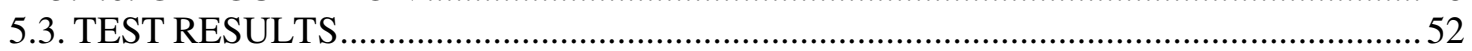

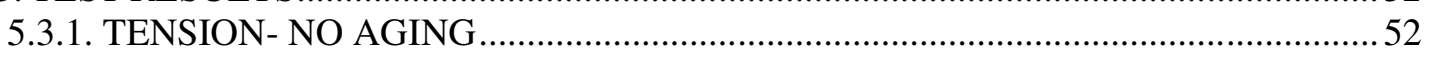

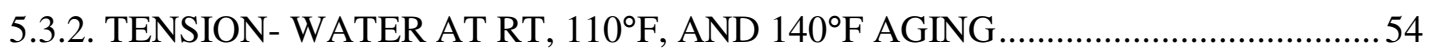

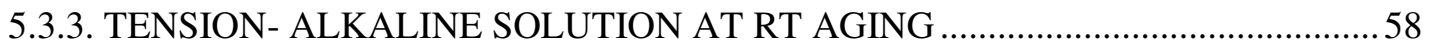

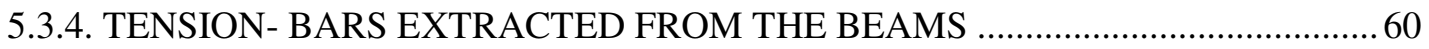

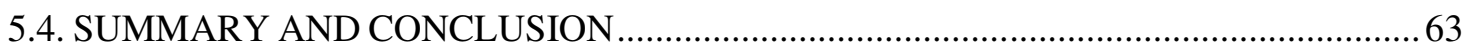

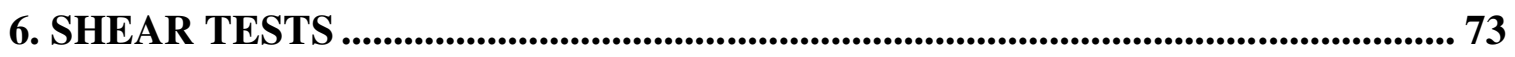

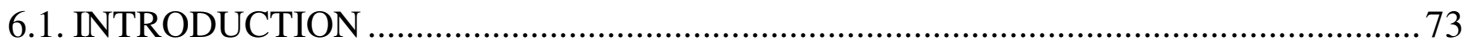

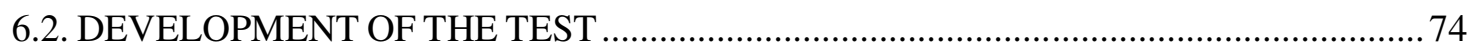

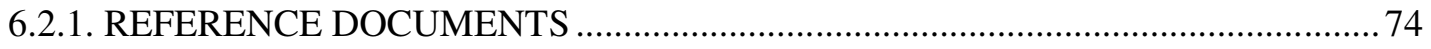

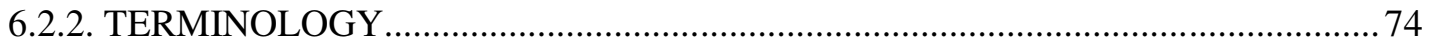

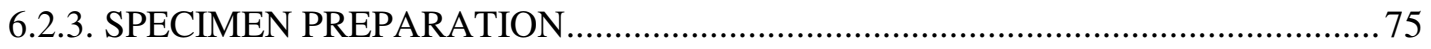

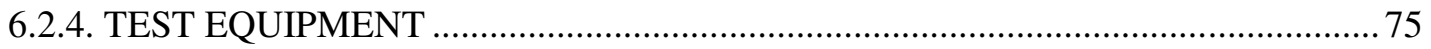

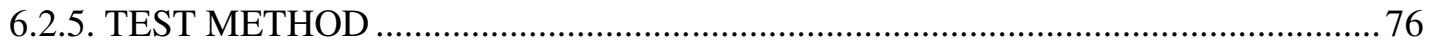

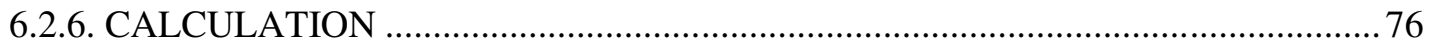

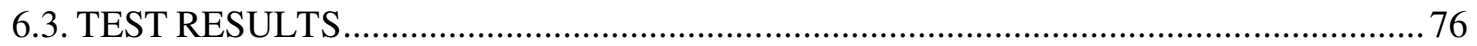

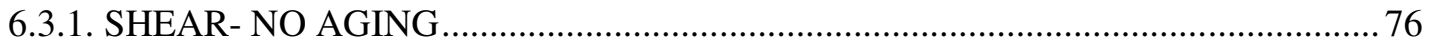

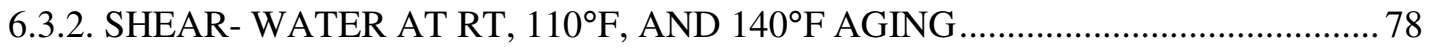

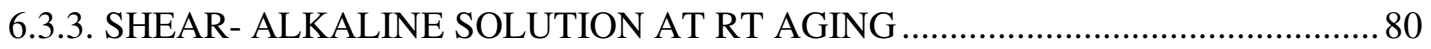

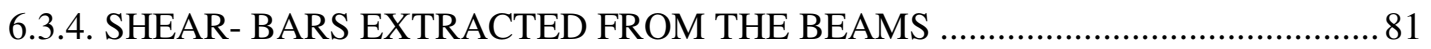

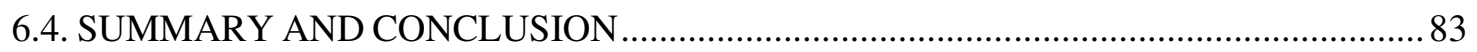

7. BOND TESTS ............................................................................................................................. 89

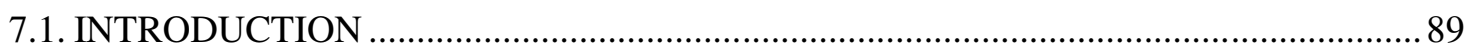

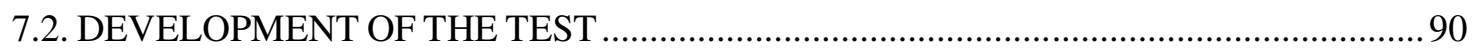




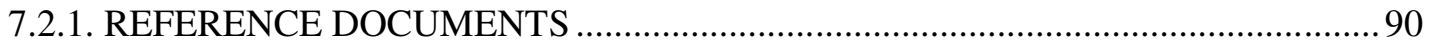

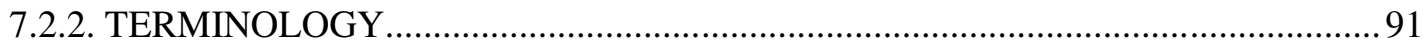

7.2.3. SPECIMEN PREPARATION ...................................................................... 91

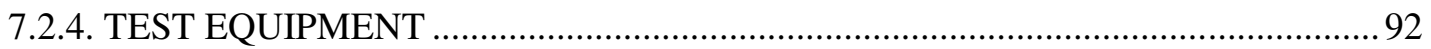

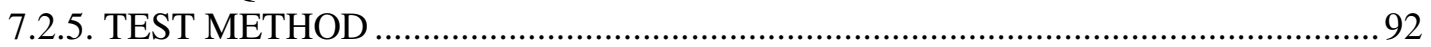

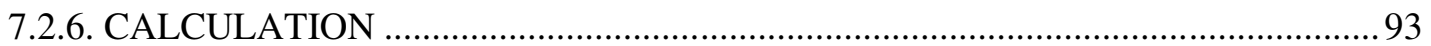

7.3. TEST RESULTS

7.3.1. BOND- NO AGING...……………………………………………………... 94

7.3.2. BOND- WATER AT RT, $110^{\circ} \mathrm{F}, 140^{\circ} \mathrm{F}$, AND ALKAINE SOLUTION AT RT ......95

7.4. SUMMARY AND CONCLUSION ........................................................................97

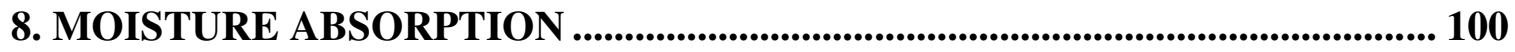

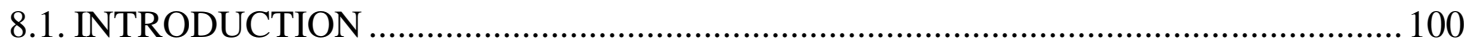

8.2. SPECIMEN PREPARATION AND TEST METHOD .............................................. 100

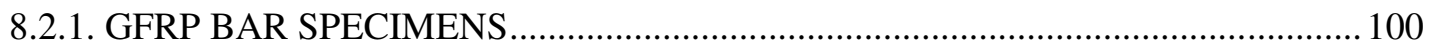

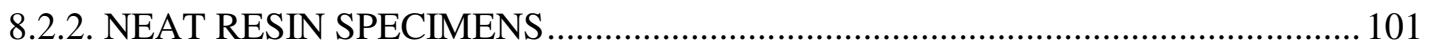

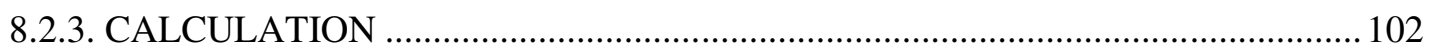

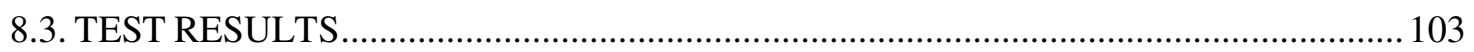

8.3.1. GFRP BAR WITH AND WITHOUT NANOCLAY....................................................... 103

8.3.2. NEAT RESIN WITH AND WITHOUT NANOCLAY ..................................................... 104

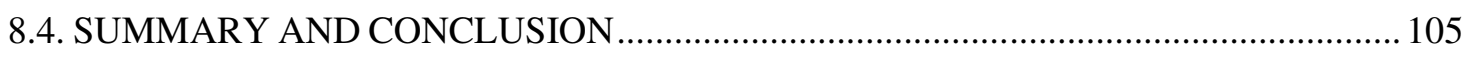

9. SCANNING ELECTRON MICROSCOPE (SEM) .............................................. 106

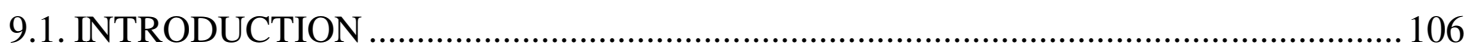

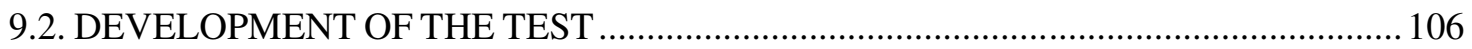

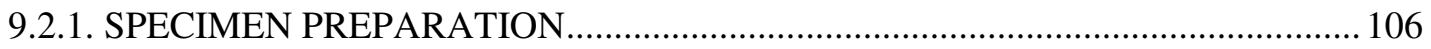

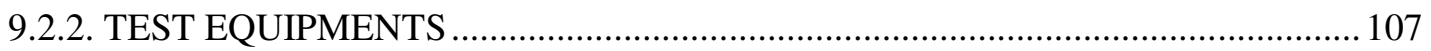

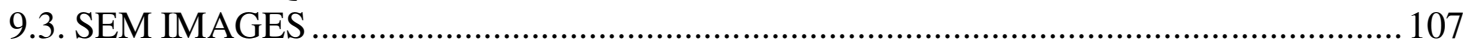

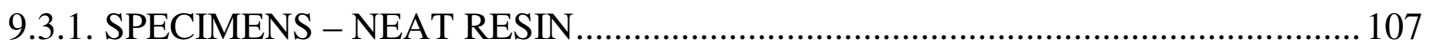

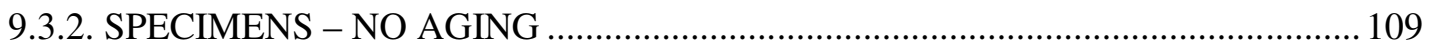

9.3.3. SPECIMENS - WATER AT RT, $110^{\circ} \mathrm{F}$, AND $140^{\circ} \mathrm{F}$ AGING ………………......... 110

9.3.4. SPECIMENS - ALKALINE SOLUTION AT RT AGING …………………….......... 118

9.3.5. SPECIMENS - EXTRACTED FROM CONCRETE BEAMS …………………….... 122

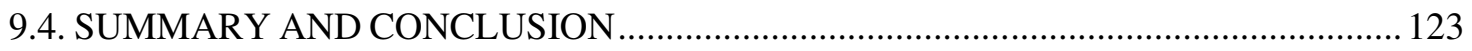

10. BEAM FLEXURE ................................................................................................... 124

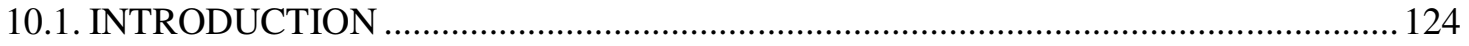

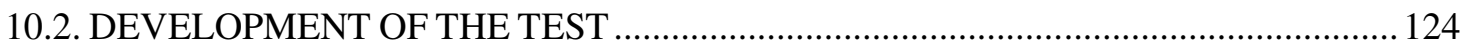

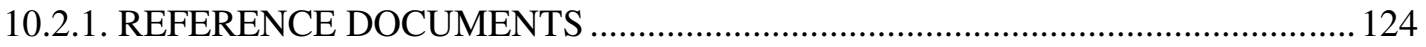

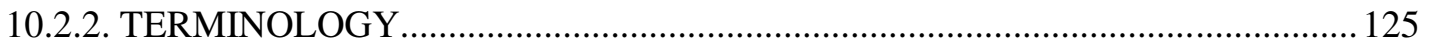

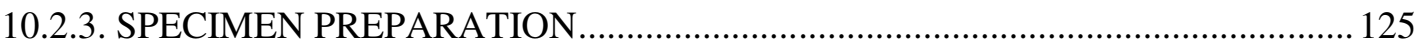

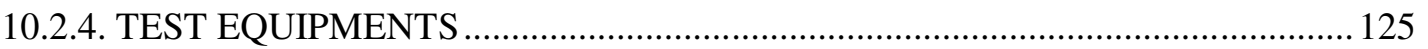

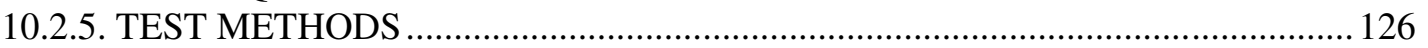

10.3. COMPRESSION TESTS ON CONCRETE CYLINDERS ......................................... 128

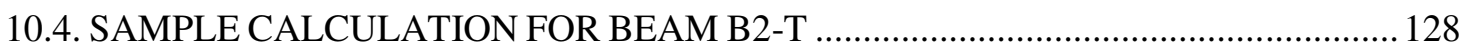

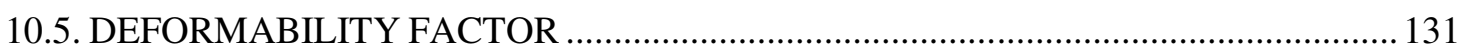

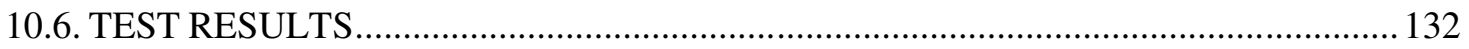

10.6.1. BEAM WITH AND WITHOUT NANOCLAY (5 FT LONG) ............................. 132

10.6.2. BEAM WITH \# 4 BARS WITH AND WITHOUT NANOCLAY (10 FT LONG) 136

10.6.3. BEAM WITH \# 6 BARS WITH AND WITHOUT NANOCLAY (10 FT LONG) 141 


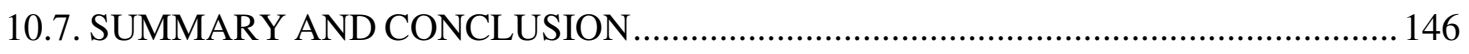

11. SUMMARY AND CONCLUSION ................................................................... 147

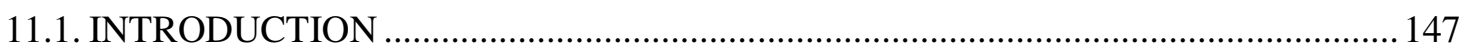

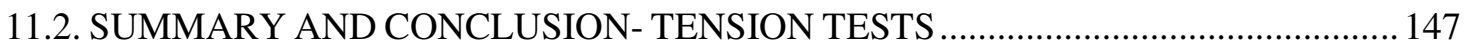

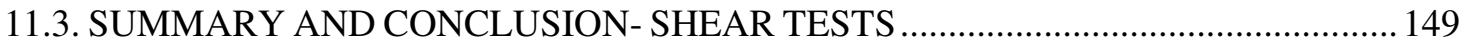

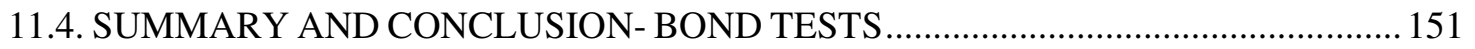

11.5. SUMMARY AND CONCLUSION - MOISTURE ABSORPTION ............................. 152

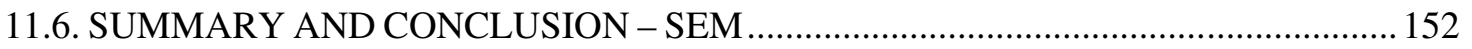

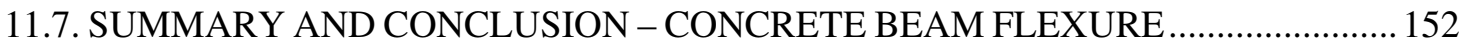

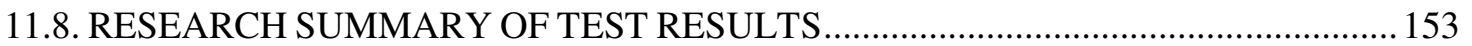

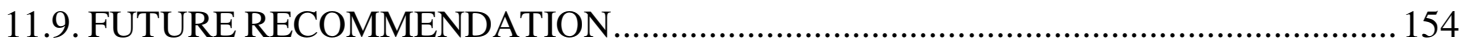

REFERENCES............................................................................................................... 155

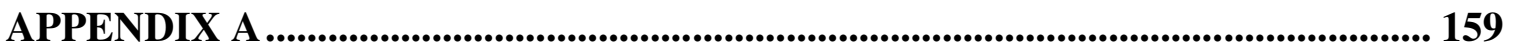

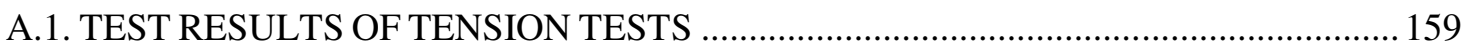

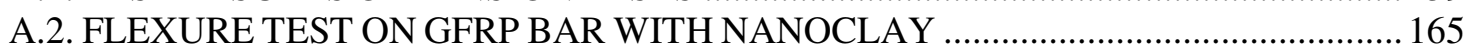

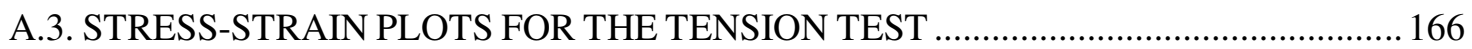

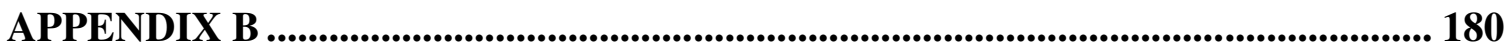

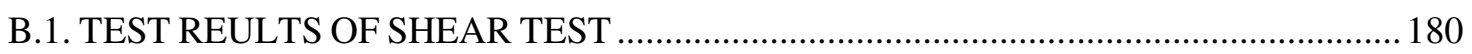

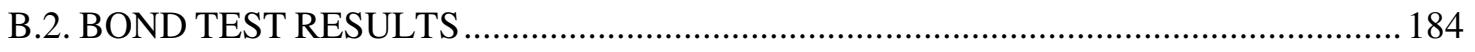

APPENDIX C............................................................................................... 187

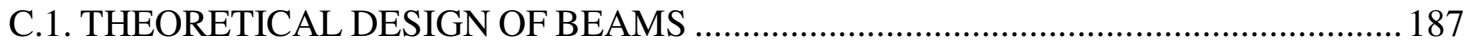

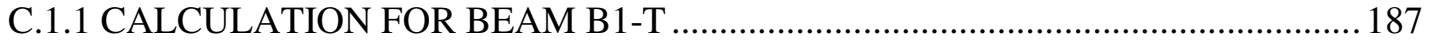

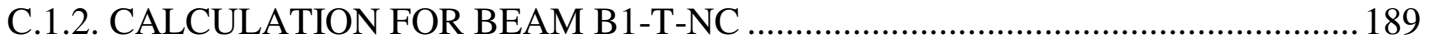

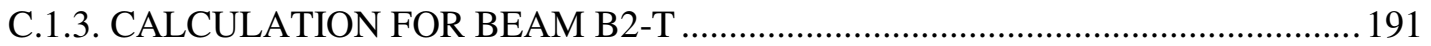

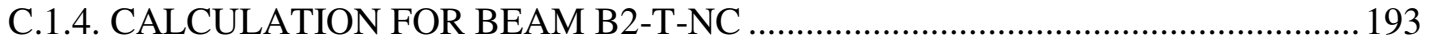

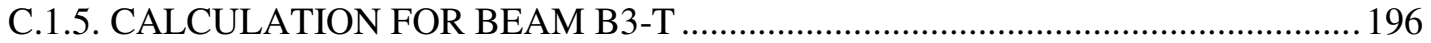

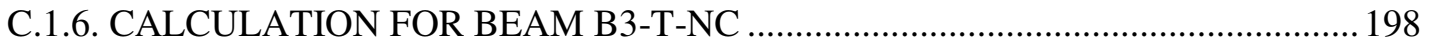

APPEDNDIX D .................................................................................................................. 201

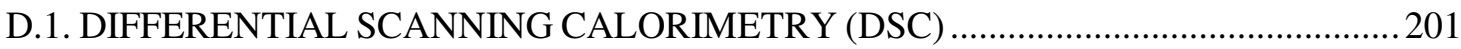

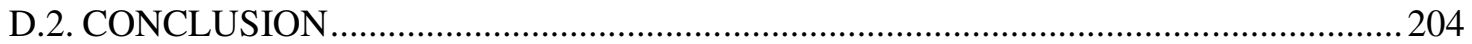




\section{LIST OF TABLES}

Table 1-1 Number and aging schemes of GFRP bars tested in tension .............................. 5

Table 1-2 Number and aging schemes of GFRP bars tested in shear ................................. 6

Table 1-3 Number and aging schemes of GFRP bars tested in bond ............................... 6

Table 1-4 Number and aging schemes of GFRP bars tested in SEM ............................... 7

Table 1-5 Number of moisture absorption specimens ....................................................... 7

Table 1-6 Number of concrete beams cast with GFRP bars ............................................ 7

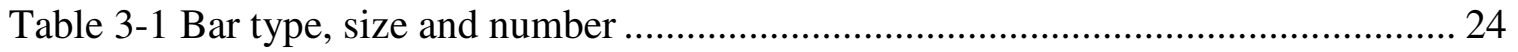

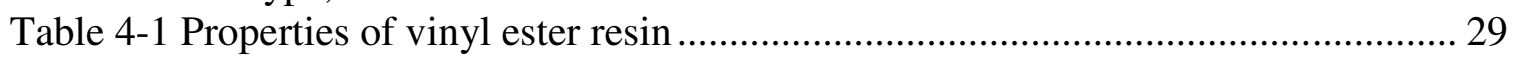

Table 4-2 Properties of MEKP catalyst ..................................................................... 29

Table 4-3 Guidelines for use of MEKP with vinyl ester resin......................................... 30

Table 4-4 Properties of E-glass fibers..................................................................... 31

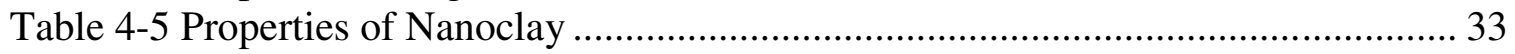

Table 5-1 Number and aging schemes of GFRP bars tested in tension............................. 46

Table 5-2 Length of steel grips used for tension test........................................................ 47

Table 5-3 Summary of test results of \#4 and \#6 bars with and without nanoclay subjected to no aging.................................................................................................... 52

Table 5-4 Summary of test results of \#4 bars with and without nanoclay aged in water at RT for 3, 6, and 9 months ................................................................................. 55

Table 5-5 Summary of test results of \#4 bars with and without nanoclay aged in water at

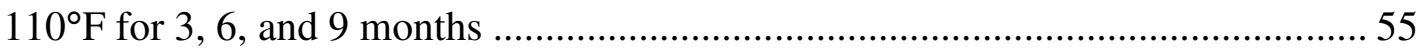

Table 5-6 Summary of test results of \#4 bars with and without nanoclay aged in water at

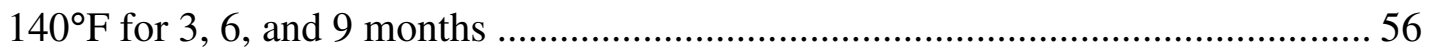

Table 5-7 Summary of test results of \#4 bars with and without nanoclay aged in alkaline solution at RT for 3, 6, and 9 months ................................................................. 59

Table 5-8 Summary of test results of bars extracted from the concrete beam................... 61

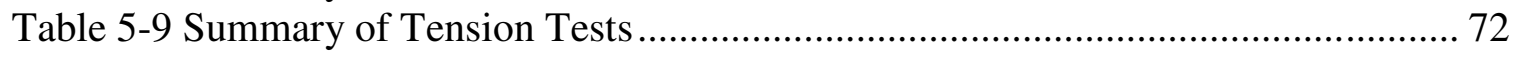

Table 6-1 Number and aging schemes of GFRP bars tested in shear ............................... 74

Table 6-2 Summary of test results of \#4 and \#6 bar with and without nanoclay subjected

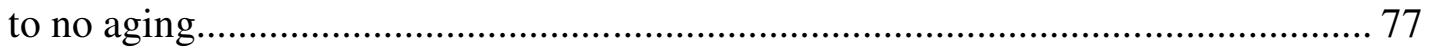

Table 6-3 Summary of test results of bar with and without nanoclay aged in water at RT,

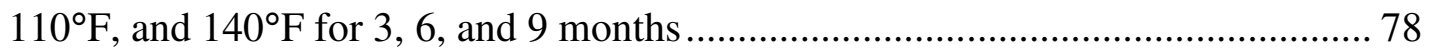

Table 6-4 Summary of test results of bar with and without nanoclay aged in alkaline solution at RT for 3, 6, and 9 months ............................................................... 80

Table 6-5 Summary of test results of \#4 and \#6 bar with and without nanoclay extracted

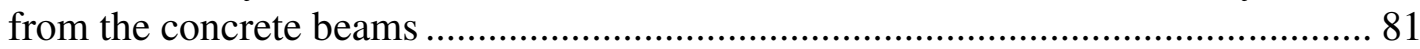

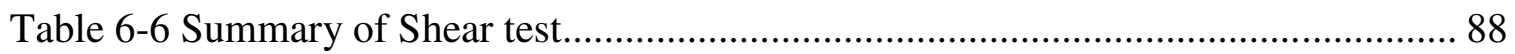

Table 7-1 Number and aging schemes of GFRP bars tested in bond ............................... 90

Table 7-2 Summary of test results of \#4 and \#6 bars with and without nanoclay subjected

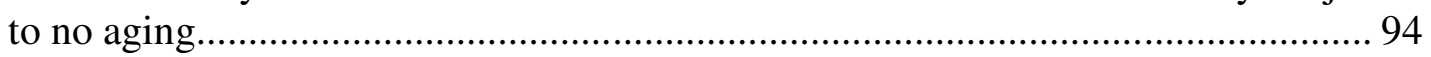

Table 7-3 Summary of test results of bars with nanoclay aged in Water at RT, $110^{\circ} \mathrm{F}$, $140^{\circ} \mathrm{F}$, and alkaline solution at RT for 3, 6, and 9 months ..................................... 95

Table 7-4 Summary of Bond Test............................................................................. 99

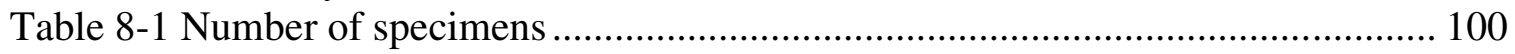

Table 8-2 Percentage weight gain of GFRP bars with and without nanoclay ................. 103

Table 8-3 Percentage weight gain of neat resin with and without nanoclay ................... 104 
Table 9-1 Number and aging schemes of GFRP bars tested in SEM ........................... 106

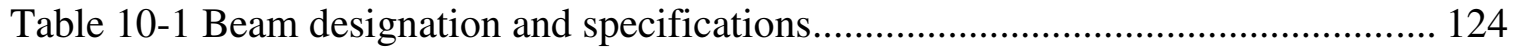

Table 10-2 Compressive strength of concrete cylinders ........................................... 128

Table 10-3 Test results of beams B1-T \& B1-T-NC ................................................. 132

Table 10-4 Max (Exptl./Theor) load (moment) ratios for beams B1-T \& B1-T-NC ... 134

Table 10-5 Loads at different limiting deflection values of beams B1-T \& B1-T-NC .. 135

Table 10-6 Ratio of load at serviceability deflection to maximum load for the beams.. 135

Table 10-7 Load at crack width limit (0.016 in.) for the beams B1-T \& B1-T-NC ...... 135

Table 10-8 Test results of beams B2-T \& B2-T-NC ................................................ 137

Table 10-9 Max (Exptl./Theor) load (moment) ratios for beams B2-T \& B2-T-NC ... 139

Table 10-10 Loads at different limiting deflection values of beams B2-T \& B2-T-NC 140

Table 10-11 Ratio of load at serviceability deflection to maximum load for the beams B2-

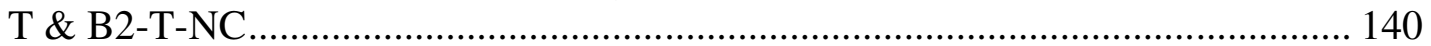

Table 10-12 Load at crack width limit (0.016 in.) for the beams B2-T \& B2-T-NC ..... 140

Table 10-13 Test results of beams B3-T \& B3-T-NC ................................................ 142

Table 10-14 Max (Exptl./Theor ) load (moment) ratios for beams B3-T \& B3-T-NC .. 144

Table 10-15 Loads at different limiting deflection values of beams B3-T \& B3-T-NC 144

Table 10-16 Ratio of load at serviceability deflection to maximum load for the beams B3-

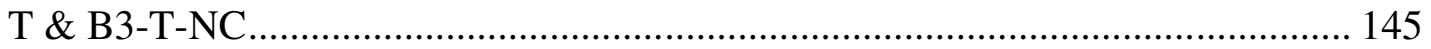

Table 10-17 Load at crack width limit (0.016 in.) for the beams B3-T \& B3-T-NC ..... 145

Table A-1 Test results of \#4 and \#6 bars with and without nanoclay subjected to no aging

159

Table A-2 Test results of \#4 and \#6 bars with and without nanoclay extracted from the concrete beams 160

Table A-3 Test results of \#4 bars with and without nanoclay aged in water at room temperature for 3,6 , and 9 months ................................................................. 161

Table A-4 Test results of \#4 bars with nanoclay aged in water at $110^{\circ} \mathrm{F}$ for 3,6 , and 9 months.....

Table A-5 Test results of bars with and without nanoclay aged in water at $140^{\circ} \mathrm{F}$ for 3,6 , and 9 months 163

Table A-6 Test results of bars with and without nanoclay aged in alkaline solution at room temperature for 3,6 , and 9 months 164

Table A-7 Flexure test results of GFRP bars with nanoclay 165

Table B-1 Test results of \#4 and \#6 bar with and without nanoclay subjected to no aging 180

Table B-2 Test results of bar with and without nanoclay aged in water at room temperature for 3, 6, and 9 months 181

Table B-3 Test results on bar with and without nanoclay aged in water at $110^{\circ} \mathrm{F}$ for 3,6 , and 9 months 181

Table B-4 Test results on bar with and without nanoclay aged in water at $140^{\circ} \mathrm{F}$ for 3,6 , and 9 months 182

Table B-5 Test results on bar with and without nanoclay aged in alkaline solution at room temperature for 3,6 , and 9 months 182

Table B-6 Test results of \#4 and \#6 bar with and without nanoclay extracted from concrete beams 183 
Table B-7 Test results of \#4 and \#6 bars with and without nanoclay subjected to no aging Table B-8 Test results of \#4 bars with and without nanoclay aged in water at room temperature, water at $110^{\circ} \mathrm{F}$, and water at $140{ }^{\circ} \mathrm{F}$

Table B-9 Test results of \#4 bars with nanoclay aged in alkaline solution at room

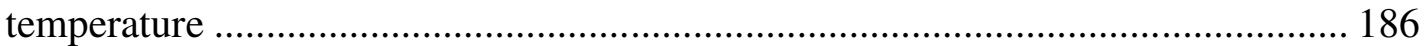

Table D-1 Glass transition temperature of samples with and without nanoclay ........... 203 


\section{LIST OF FIGURES}

Figure 2-1 Rough estimate of alkali penetration in GFRP rods....................................... 17

Figure 4-1 Synthesis of vinyl ester by the reaction of a bisphenol-A glycidylether......... 28

Figure 4-2 Montmorillonite's unique platey particle structure ....................................... 32

Figure 4-3 Nanoclay-resin interaction before and after exfoliation.................................... 33

Figure 4-4 FRP bar mold (4 ft.) with drum type pulley ................................................... 34

Figure 4-5 FRP bar mold (12 ft.) with drum type pulley ............................................... 35

Figure 4-6 Teflon plates drilled with holes................................................................... 35

Figure 4-7 Teflon plates drilled with holes in resin bath tray ............................................. 36

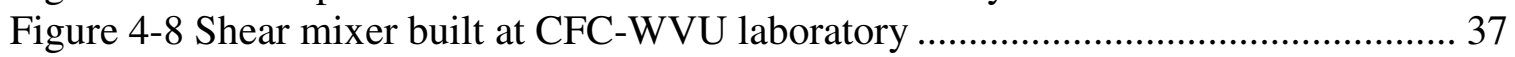

Figure 4-9 Schematic diagram showing pultrusion of GFRP bar.................................... 37

Figure 4-10 Fibers passing through Teflon plate ............................................................ 38

Figure 4-11 Fibers passing through resin bath into the mold ........................................... 39

Figure 4-12 Schematic diagram showing bar attached with grips .................................... 41

Figure 4-13 GFRP bar and grips .............................................................................. 41

Figure 4-14 GFRP bar attached with steel grips ............................................................. 41

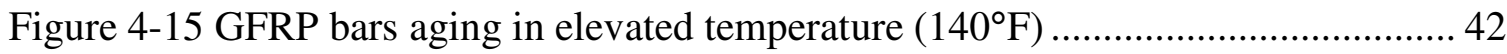

Figure 4-16 GFRP bars aging in Alkaline solution ....................................................... 43

Figure 4-17 Formwork and reinforcement for 5 in. x 8 in. x 60 in. beam ....................... 44

Figure 4-18 Formwork and reinforcement for 8 in. x 16 in. x 120 in. beam ................... 44

Figure 5-1 Schematic Diagram of a Tension Test Specimen ......................................... 45

Figure 5-2 GFRP bar fixed with strain gage ................................................................. 49

Figure 5-3 Tension test setup using UTM ………………........................................ 50

Figure 5-4 Diagram showing GFRP bar held between wedge grips of UTM .................. 50

Figure 5-5 Typical stress-strain plot from a tension test of GFRP bar .............................. 51

Figure 5-6 GFRP bar after testing.............................................................................. 51

Figure 5-7 Comparison of tensile stress of GFRP bars without nanoclay aged in different

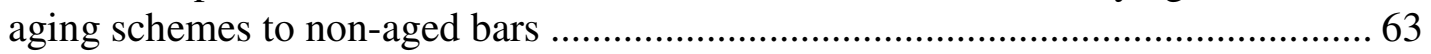

Figure 5-8 Comparison of tensile stress of GFRP bars with nanoclay aged in different

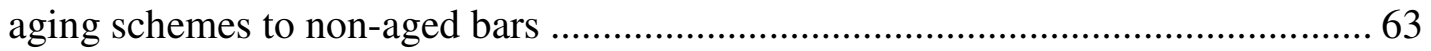

Figure 5-9 Comparison of stiffness of GFRP bars without nanoclay aged in different aging schemes to non-aged bars ............................................................................... 64

Figure 5-10 Comparison of stiffness of GFRP bars with nanoclay aged in different aging

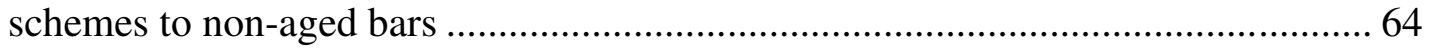

Figure 5-11 Comparison of tensile stress of GFRP bars with and without nanoclay aged in different aging schemes to non-aged bars........................................................... 65

Figure 5-12 Comparison of percentage tensile stress reduction of GFRP bars with and without nanoclay aged in different aging schemes to non-aged bars ........................ 66

Figure 5-13 Comparison of stiffness of GFRP bars with and without nanoclay aged in different aging schemes to non-aged bars...

Figure 5-14 Comparison of percentage tensile stiffness change of GFRP bars with and without nanoclay aged in different aging schemes to non-aged bars ........................ 68

Figure 6-1 Shear Testing Apparatus ........................................................................... 73

Figure 6-2 Comparison of shear stress of GFRP bars without nanoclay aged in different

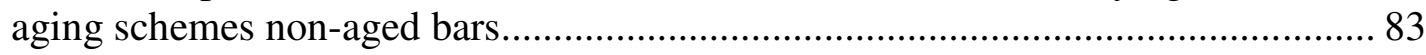


Figure 6-3 Comparison of shear stress of GFRP bars with nanoclay aged in different

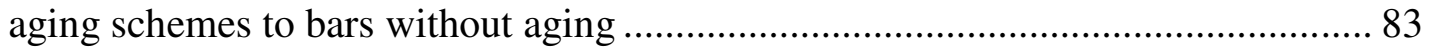

Figure 6-4 Comparison of shear stress of GFRP bars with and without nanoclay aged in different aging schemes to non-aged bars........................................................ 84

Figure 6-5 Comparison of percentage shear stress reduction of GFRP bars with and without nanoclay aged in different aging schemes to non-aged bars ..................... 85

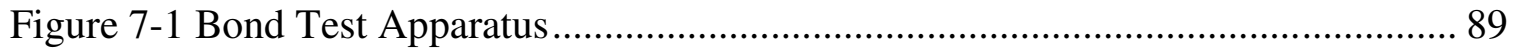

Figure 7-2 Schematic Diagram of the Bond Test Setup ............................................ 91

Figure 7-3 Typical stress vs. slip (unloading end) plot for GFRP bars without nanoclay in

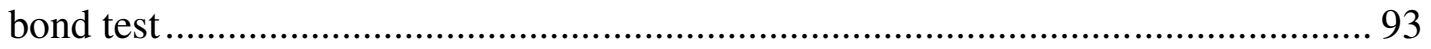

Figure 7-4 Comparison of bond stress of GFRP bars with nanoclay aged in different

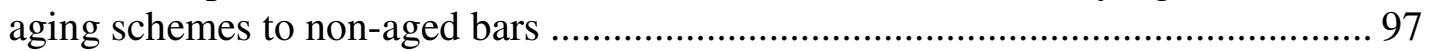

Figure 7-5 Comparison of percentage bond stress increase of GFRP bars with nanoclay aged in different aging schemes to non-aged bars ............................................... 97

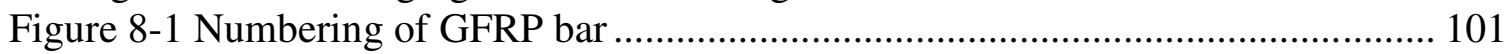

Figure 8-2 GFRP bars immersed in water ............................................................ 101

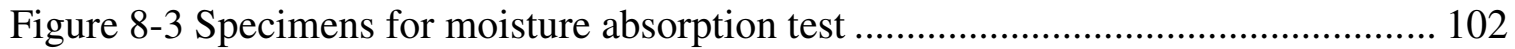

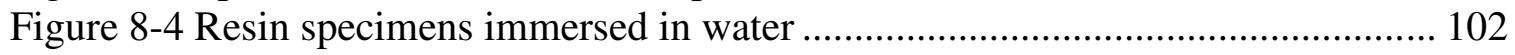

Figure 8-5 Moisture gain of GFRP bars (a) without and (b) with nanoclay.................. 103

Figure 8-6 Moisture gain of neat resin (a) without and (b) with nanoclay .................... 105

Figure 9-1 SEM image of vinyl ester resin partially exfoliated with (a) $2 \%$ nanoclay and (b) $3.5 \%$ nanoclay showing scattered nanoclay ............................................... 108

Figure 9-2 SEM image of vinyl ester resin partially exfoliated with (a) $4 \%$ nanoclay and

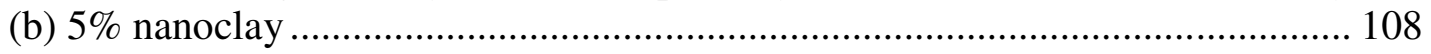

Figure 9-3 SEM image showing (a) glass fibers densely packed with the resin at the center of the bar (b) resin fiber interaction at edge ........................................... 109

Figure 9-4 SEM image showing (a) glass fibers densely packed with the resin exfoliated with clay at the center of the bar (b) cracks formed in the rib of the bars allowing path for moisture entry. 110

Figure 9-5 SEM images showing (a) glass fibers densely packed with the resin at the center of the bar (b) fiber-resin isolation/pullout at the edges ............................ 111

Figure 9-6 SEM image showing (a) glass fibers densely packed with the resin exfoliated with clay at the center of the bar (b) crack formed in edge of the bar leading to moisture ingression

Figure 9-7 SEM image showing (a) fiber- resin interface at the edge of the bar (b) fibers

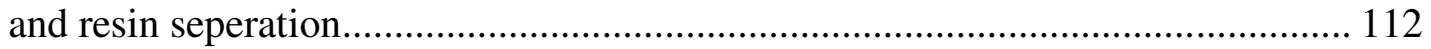

Figure 9-8 SEM image showing (a) glass fibers densely packed with the resin exfoliated with clay at the center of the bar (b) crack formation in the bars at the edge leading to moisture ingression ..... 112

Figure 9-9 SEM image showing (a) fiber- resin interface at the edge of the bar (b) fiberresin isolation/pullout at the edges................................................................ 113

Figure 9-10 SEM image showing (a) cavity formation near the edge of bars with fiberrein isolation (b) fiber-resin isolation/pullout at the edges ............................... 113

Figure 9-11 SEM image showing (a) fiber-resin isolation at the edge of bar (b) fiber-resin

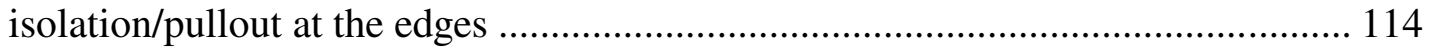


Figure 9-12 SEM image showing (a) fiber and resin interaction in the center of the bar (b)

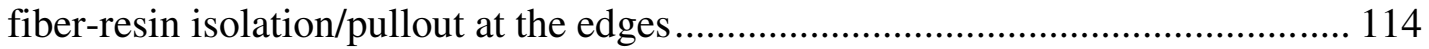

Figure 9-13 SEM image showing (a) glass fibers densely packed with the resin at the center of the bar (b) fiber-resin isolation/pullout at the edges ............................ 115

Figure 9-14 SEM image showing (a) damage/pullout at the resin and fibers interface (b) fiber-resin isolation/pullout at the edges....

Figure 9-15 SEM image showing (a) resin damaged at the edge due to conditioning (b) cavity formation and fiber-resin damage in edge ............................................... 116

Figure 9-16 SEM image showing (a) fiber damage and resin isolation at edge of the bar (b) resin damage at the edge of the bar ........................................................... 116

Figure 9-17 SEM imaging showing (a) fiber-resin interaction at the center of the bar (b) fiber-rein interaction at the edge of the bar..................................................... 117

Figure 9-18 SEM imaging showing (a) fiber-resin interaction at the center of the bar (b) fiber-rein interaction at the edge of the bar..................................................... 117

Figure 9-19 SEM imaging showing (a) fiber-resin isolation/pullout at the edges (b) crack formation in the rib of the bar 118

Figure 9-20 SEM image showing (a) resin damage and cavity formation over the bars edge (b) fiber isolation and cavity formation.................................................... 119

Figure 9-21 SEM image showing (a) damage resin in the edges there by reducing the fiber-resin interaction (b) cavity formation and resin damage in the edge ............. 119

Figure 9-22 SEM image showing (a) fiber-resin isolation leading to decreased stress distribution (b) disturbance of fiber-resin isolation and fibers ........................... 120

Figure 9-23 SEM image showing (a) fiber-resin interaction at the center of the bar (b) fiber-resin interaction is decreasing at the edge of the bar ............................... 120

Figure 9-24 SEM image showing (a) fiber-resin interaction at the center of the bar (b) fiber-resin interaction is decreasing at the edge of the bar ................................ 121

Figure 9-25 SEM image showing (a) fiber-resin interaction at the center of the bar (b) fiber-resin interaction is decreasing at the edge of the bar ................................. 121

Figure 9-26 SEM image showing (a) resin damage over the edge of the bar (b) resin damage over the bars edge

Figure 9-27 SEM image showing (a) fiber and resin interaction in the center of the bar (b) resin damage and cavity formation in the edge of the bar .................................... 123

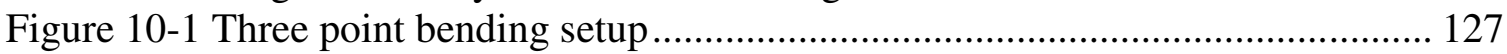

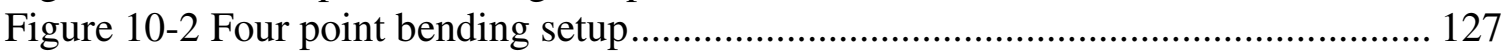

Figure 10-3 Schematic diagram of four point bending test .................................... 128

Figure 10-4 Schematic diagram of beams B1-T \& B1-T-NC ..................................... 132

Figure 10-5 Load vs. deflection curve for beam B1-T ............................................ 133

Figure 10-6 Load vs. deflection curve for beam B1-T-NC ........................................ 133

Figure 10-7 Comparison of load vs. deflection of beams B1-T and B1-T-NC ............. 134

Figure 10-8 Schematic diagram of beam B2-T \& B2-T-NC ....................................... 137

Figure 10-9 Load vs. deflection curve for beam B2-T ............................................... 138

Figure 10-10 Load vs. deflection curve for beam B2-T-NC .................................... 138

Figure 10-11 Comparison of load vs. deflection of beams B2-T and B2-T-NC (up to 30

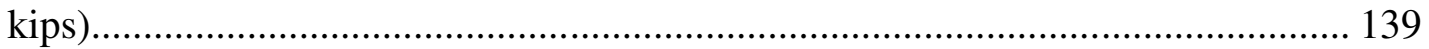

Figure 10-12 Schematic diagram of beam B3-T \& B3-T-NC …................................ 142

Figure 10-13 Load vs. deflection curve for beam B3-T .............................................. 143 
Figure 10-14 Load vs. deflection curve for beam B3-T-NC 143

Figure A-1 Stress-strain plot of \#4 bars without nanoclay subjected to no aging (Table A1)

Figure A-2 Stress-strain plot of \#4 bars with nanoclay subjected to no aging 166

Figure A-3 Stress-strain plot of \#6 bars with nanoclay subjected to no aging (TableA-1) 167

Figure A-4 Stress-strain plot of \#4 bars without nanoclay extracted from the concrete beam (Table A-2) 167

Figure A-5 Stress-strain plot of \#4 bars with nanoclay extracted from the concrete beam (Table A-2). 168

Figure A-6 Stress-strain plot of \#6 bars with and without nanoclay extracted from the concrete beam (Table A-2) 168

Figure A-7 Stress-strain plot of \#4 bars without nanoclay aged in water at room temperature for 3 months (Table A-3) .......................................................... 168

Figure A-8 Stress-strain plot of \#4 bars with nanoclay aged in water at room temperature for 3 months (Table A-3) 169

Figure A-9 Stress-strain plot of \#4 bars without nanoclay aged in water at room temperature for 6 months (Table A-3) 169

Figure A-10 Stress-strain plot of \#4 bars with nanoclay aged in water at room temperature for 6 months (Table A-3). 170

Figure A-11 Stress-strain plot of \#4 bars without nanoclay aged in water at room temperature for 9 months (Table A-3)

Figure A-12 Stress-strain plot of \#4 bars with nanoclay aged in water at room temperature for 9 months (Table A-3) . 171

Figure A-13 Stress-strain plot of \#4 bars with nanoclay aged in water at $110^{\circ} \mathrm{F}$ for 3 months (Table A-4). 172

Figure A-14 Stress-strain plot of \#4 bars with nanoclay aged in water at $110^{\circ} \mathrm{F}$ for 6 months (Table A-4).... 172

Figure A-15 Stress-strain plot of \#4 bars with nanoclay aged in water at $110^{\circ} \mathrm{F}$ for 9 months (Table A-4). 173

Figure A-16 Stress-strain plot of \#4 bars without nanoclay aged in water at $140^{\circ} \mathrm{F}$ for 3 months (Table A-5)....

Figure A-17 Stress-strain plot of \#4 bars with nanoclay aged in water at $140^{\circ} \mathrm{F}$ for 3 months (Table A-5) 174

Figure A-18 Stress-strain plot of \#4 bars without nanoclay aged in water at $140^{\circ} \mathrm{F}$ for 6 months (Table A-5). 174

Figure A-19 Stress-strain plot of \#4 bars with nanoclay aged in water at $140^{\circ} \mathrm{F}$ for 6 months (Table A-5). 175

Figure A-20 Stress-strain plot of \#4 bars without nanoclay aged in water at $140^{\circ} \mathrm{F}$ for 9 months (Table A-5).... 175

Figure A-21 Stress-strain plot of \#4 bars with nanoclay aged in water at $140^{\circ} \mathrm{F}$ for 9 months (Table A-5).

Figure A-22 Stress-strain plot of \#4 bars without nanoclay aged in alkaline solution at room temperature for 3 months (Table A-6). 176

Figure A-23 Stress-strain plot of \#4 bars with nanoclay aged in alkaline solution at room temperature for 3 months (Table A-6). 177 
Figure A-24 Stress-strain plot of \#4 bars without nanoclay aged in alkaline solution at room temperature for 6 months (Table A-6) .................................................... 178

Figure A-25 Stress-strain plot of \#4 bars with nanoclay aged in alkaline solution at room

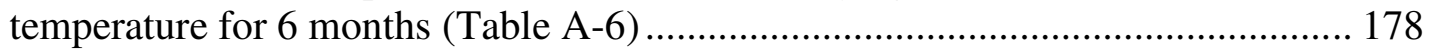

Figure A-26 Stress-strain plot of \#4 bars without nanoclay aged in alkaline solution at room temperature for 9 months (Table A-6) .................................................. 178

Figure A-27 Stress-strain plot of \#4 bars with nanoclay aged in alkaline solution at room temperature for 9 months (Table A-6) .............................................................. 179

Figure D-1 Glass transition temperature plot for sample without nanoclay subjected to no

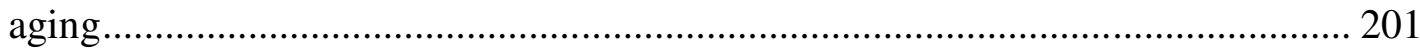

Figure D-2 Glass transition temperature plot for sample with nanoclay subjected to no

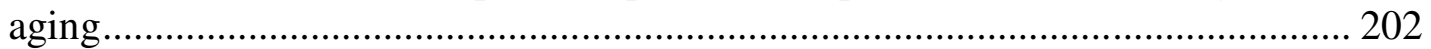

Figure D-3 Glass transition temperature plot for sample without nanoclay subjected to 9

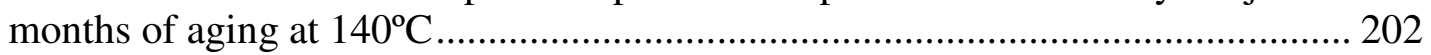

Figure D-4 Glass transition temperature plot for sample with nanoclay subjected to 9

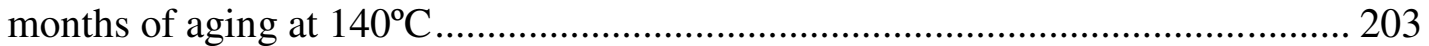




\section{INTRODUCTION}

\subsection{INTRODUCTION}

Fiber Reinforced Polymer (FRP) bars are used as reinforcement for concrete structures in which corrosion protection, magnetic transparency, and electrical non-conductivity are of primary concern. Glass FRP (GFRP) materials are corrosion resistant, electrically and magnetically non-conductive, and exhibit several other advantages that make them suitable as reinforcement for concrete structures. Some of the advantages of FRP composites are high strength-to-weight ratio, high stiffness-to-weight ratio, excellent durability, non-corrosiveness, low coefficient of thermal expansion, and low density to FRP, which, in turn, make them a potential substitute for metals. The modulus-to-weight ratio and tensile strength-to-weight ratio for fiber reinforced polymer composites are much higher than those for metals or alloys (Mallick, 1993).

During their service life, FRP rebars in concrete structures are exposed to varying environments consisting of moisture, temperature variations, freeze-thaw cycles, and $\mathrm{pH}$ (acid, salt, and alkali). Reduction in GFRP bar properties subjected to different exposure conditions is noted during their service life. It is important to evaluate the nature of interaction of these environments with FRP materials and their effect on the material properties of FRP bars. In concrete applications, FRP bars are exposed to different conditions such as i) concrete pore solution which is alkaline in nature, ii) salts used to melt the snow on pavements during the winter season, and iii) chemicals in waste water plants and others. Such environmental exposure adversely affects the properties of FRP bars and leads to their aging, i.e. strength and stiffness reduction.

Moisture ingress into GFRP reinforced concrete is detrimental to mechanical properties of FRP reinforcement due to high alkalinity of concrete $(\approx \mathrm{pH} 12.8)$. Chemical reaction between silica in glass and alkaline ions produces fiber damage, matrix embrittlement, and fiber-resin interface damage due to chemical attack and growth of hydration resulting in loss of tensile strength and inter-laminar shear properties (Vijay and GangaRao, 1999). To control aging of FRP composites, alkaline resistant glass fibers and improved resin system with organic polymer and inorganic fillers have been attempted. In this research, 
montmorillonite nanoclay was exfoliated in the resin to provide improved durability to GFRP bars. Nanoclay is naturally occurring clay, which has one dimension at a nanoscale

$\left(\mathrm{x} 10^{-9} \mathrm{~m}\right)$. Nanoclays are treated with organophylic resins to make them compatible with resin. When mixed and exfoliated in the resin, millions of these nano particles are spread throughout the resin.

Nanoclay exfoliation in a resin retards easy moisture movement in a rebar by creating innumerable tortuous paths at nanoscale; thereby improving the durability of GFRP bar. Objectives and scope of this research are described in sections 1.2 and 1.3.

\subsection{OBJECTIVES}

Objectives of this study are to:

1. Manufacture GFRP rebars with and without nanoclay with proper fiber volume fraction $(>40 \%)$, fiber placement, fiber wetting, shape of lugs, reduction in void content, and bar dimensions.

2. Compare tension, shear, and bond strength values of bars subjected to aging (water at room temperature and elevated temperature and alkaline solution) for 3 , 6 , and 9 months with non-aged bars.

3. Evaluate the effect of addition of nanoclay on the tensile and shear strength of GFRP bars and their durability with aging.

4. Evaluate the effect of aging on bond-strength of GFRP bars with and without nanoclay.

5. Study flexure behavior of concrete beams reinforced with GFRP bars with and without nanoclay.

6. Evaluate the effect of addition of nanoclay on moisture absorption of the bar and neat resin.

7. Evaluate the effect of addition of nanoclay on durability and moisture pick up of GFRP bars using Scanning Electron Microscope (SEM) imaging. 


\subsection{SCOPE}

GFRP bars with and without nanoclay were manufactured at WVU laboratory and tested in this research. Laboratory manufacturing of GFRP bars with nanoclay was necessary due to complexity and cost considerations in prototype manufacturing of these bars with several parameters, i.e., variations and refinements in a manufacturing plant. Significant amount of planning and revisions were made to manufacturing aspects of GFRP bars with nanoclay having superior properties and performance using durable vinyl ester resins and nanoclay at room temperature. Significant emphasis was placed on exfoliation of nanoclay. Short-term tests were carried out to determine the basic strength properties of FRP bars that included tensile, shear, and bond strength. Long-term tests were carried out to determine the strength reduction under various aging schemes for 3, 6, and 9 months of aging. Different aging schemes considered were: water at room temperature, water at $110^{\circ} \mathrm{F}$, water at $140^{\circ} \mathrm{F}$, and alkaline solution at room temperature. Beams were cast using GFRP bars manufactured with and without nanoclay and tested under three and four point bending loads.

Scope of this study on GFRP bars with and without nanoclay subjected to aging is to conduct several mechanical tests and evaluate micrographs. Details of this testing can be found in Table 1-1 through 1-6:

- Tension test: This test comprised of monotonic tensile loading up to failure for establishing ultimate strength and stiffness of GFRP bars with a gage length of 40 times diameter. Strain gage, load cell, and data acquisition system were used for recording the test data.

- Shear test: Double shear tests were conducted on GFRP bars with and without nanoclay of 6 in. length using $1 / 2$ in. wide cutting tool.

- Bond test: Cylinder (6 in. x 12 in.) pullout tests were conducted on specimens, embedded with FRP bars to evaluate the bond strength between FRP bar and concrete. Slip measurements at the unloading end were noted.

- Moisture absorption test: Three inch long \#4 GFRP bars (0.5 in. dia.) with and without nanoclay were sealed at the ends with thin resin coatings and immersed in water for monitoring weight gain up to 400 days and beyond. For comparison 
purposes, cylindrical neat resin specimens without fibers were prepared and cured. Neat resin specimens measuring $1 / 2$ in. diameter and $1 / 2$ in. height were sealed at the ends and immersed in water.

- SEM: GFRP bars of $1 / 2$ in. high were ground and coated with conductive medium and SEM images of GFRP bars were taken and investigated for the moisture diffusion path, fiber damage, presence of voids and cracks.

Scope of flexure tests conducted on concrete beams reinforced with GFRP bars that consisted of nanoclay is as follows:

- Flexure test on beams: Beams reinforced with GFRP rebar manufactured in CFCWVU laboratory were cast. The beams were subjected to three point and four point bending test. 
Different types of tests conducted in this research and number of specimens are shown in Tables 1-1 to1-6.

Table 1-1 Number and aging schemes of GFRP bars tested in tension

\begin{tabular}{|c|c|c|c|c|c|c|}
\hline \multirow[b]{2}{*}{ Aging schemes } & \multirow{2}{*}{$\begin{array}{l}\text { Bar } \\
\text { size }\end{array}$} & \multirow[b]{2}{*}{ Nanoclay } & \multicolumn{4}{|c|}{ Number of specimens } \\
\hline & & & $\begin{array}{c}\text { Without } \\
\text { aging } \\
\end{array}$ & $\begin{array}{c}3 \text { months } \\
\text { aging }\end{array}$ & $\begin{array}{c}6 \text { months } \\
\text { aging }\end{array}$ & $\begin{array}{c}9 \text { months } \\
\text { aging }\end{array}$ \\
\hline \multirow{4}{*}{ Non-aged } & \multirow{2}{*}{ \#4 } & Yes & 3 & - & - & - \\
\hline & & No & 3 & - & - & - \\
\hline & \multirow{2}{*}{ \#6 } & Yes* & 2 & - & - & - \\
\hline & & Yes & 2 & - & - & - \\
\hline \multirow{4}{*}{$\begin{array}{l}\text { Extracted from } \\
\text { concrete beams }\end{array}$} & \multirow{2}{*}{$\# 4$} & Yes & 2 & - & - & - \\
\hline & & No & 3 & - & - & - \\
\hline & \multirow{2}{*}{ \#6 } & Yes* & 1 & - & - & - \\
\hline & & No* & 1 & - & - & - \\
\hline \multirow{2}{*}{ Water/RT } & \multirow{7}{*}{ \#4 } & Yes & - & 3 & 3 & 3 \\
\hline & & No & - & 2 & 2 & 2 \\
\hline Water at $110^{\circ} \mathrm{F}$ & & Yes & - & 3 & 3 & 3 \\
\hline \multirow{2}{*}{ Water at $140^{\circ} \mathrm{F}$} & & Yes & - & 3 & 3 & 3 \\
\hline & & No & - & 2 & 2 & 2 \\
\hline \multirow{2}{*}{$\begin{array}{c}\text { Alkaline } \\
\text { solution/RT }\end{array}$} & & Yes & - & 3 & 3 & 3 \\
\hline & & No & - & 2 & 2 & 2 \\
\hline \multicolumn{3}{|c|}{$\begin{array}{r}\text { Total } \\
\end{array}$} & 17 & 18 & 18 & 18 \\
\hline \multicolumn{3}{|c|}{ Grand total } & \multicolumn{4}{|c|}{71} \\
\hline
\end{tabular}

*\#6 GFRP bars manufactured with 56 yield glass fiber rovings. Rest of the bars were manufactured with 113 Yield glass fiber rovings. 
Table 1-2 Number and aging schemes of GFRP bars tested in shear

\begin{tabular}{|c|c|c|c|c|c|c|}
\hline \multirow[b]{2}{*}{ Aging schemes } & \multirow{2}{*}{$\begin{array}{l}\text { Bar } \\
\text { size }\end{array}$} & \multirow[b]{2}{*}{ Nanoclay } & \multicolumn{4}{|c|}{ Number of specimens } \\
\hline & & & $\begin{array}{c}\text { Without } \\
\text { aging }\end{array}$ & $\begin{array}{c}3 \text { months } \\
\text { aging }\end{array}$ & $\begin{array}{l}6 \text { months } \\
\text { aging }\end{array}$ & $\begin{array}{c}9 \text { months } \\
\text { aging }\end{array}$ \\
\hline \multirow{5}{*}{ Non-aged } & \multirow{2}{*}{$\# 4$} & Yes & 7 & - & - & - \\
\hline & & No & 3 & - & - & - \\
\hline & \multirow{3}{*}{ \#6 } & Yes* & 9 & - & - & - \\
\hline & & Yes & 9 & - & - & - \\
\hline & & $\mathrm{No}^{*}$ & 4 & - & - & - \\
\hline \multirow{4}{*}{$\begin{array}{l}\text { Extracted from } \\
\text { concrete beams }\end{array}$} & \multirow{2}{*}{ \#4 } & Yes & 10 & - & - & - \\
\hline & & No & 9 & - & - & - \\
\hline & \multirow{2}{*}{ \#6 } & Yes* & 4 & - & - & - \\
\hline & & No* & 4 & - & - & - \\
\hline \multirow{2}{*}{ Water/RT } & \multirow{7}{*}{$\# 4$} & Yes & - & 6 & 6 & 6 \\
\hline & & No & - & 3 & 3 & 3 \\
\hline Water at $110^{\circ} \mathrm{F}$ & & Yes & - & 6 & 6 & 6 \\
\hline \multirow{2}{*}{ Water at $140^{\circ} \mathrm{F}$} & & Yes & - & 6 & 6 & 6 \\
\hline & & No & - & 3 & 3 & 3 \\
\hline \multirow{2}{*}{$\begin{array}{c}\text { Alkaline } \\
\text { solution/RT }\end{array}$} & & Yes & - & 6 & 6 & 6 \\
\hline & & No & - & 3 & 3 & 3 \\
\hline \multicolumn{3}{|c|}{$\begin{array}{c}\text { Total } \\
\end{array}$} & 59 & 33 & 33 & 33 \\
\hline \multicolumn{3}{|c|}{ Grand total } & \multicolumn{4}{|c|}{158} \\
\hline
\end{tabular}

* \#6 GFRP bars manufactured with 56 yield glass fiber rovings. Rest of the bars were manufactured with 113 Yield glass fiber rovings.

Table 1-3 Number and aging schemes of GFRP bars tested in bond

\begin{tabular}{|c|c|c|c|c|c|c|}
\hline \multirow[b]{2}{*}{ Aging schemes } & \multirow{2}{*}{$\begin{array}{l}\text { Bar } \\
\text { size }\end{array}$} & \multirow[b]{2}{*}{ Nanoclay } & \multicolumn{4}{|c|}{ Number of specimens } \\
\hline & & & $\begin{array}{c}\text { Without } \\
\text { aging }\end{array}$ & $\begin{array}{c}3 \text { months } \\
\text { aging }\end{array}$ & $\begin{array}{c}6 \text { months } \\
\text { aging }\end{array}$ & $\begin{array}{l}9 \text { months } \\
\text { aging }\end{array}$ \\
\hline \multirow{3}{*}{ Non-aged } & \multirow{2}{*}{ \#4 } & Yes & 3 & - & - & - \\
\hline & & No & 2 & - & - & - \\
\hline & \#6 & Yes & 3 & - & - & - \\
\hline Water/RT & \multirow{4}{*}{ \#4 } & Yes & - & 2 & 2 & 2 \\
\hline Water at $110^{\circ} \mathrm{F}$ & & Yes & - & 2 & 2 & 2 \\
\hline Water at $140^{\circ} \mathrm{F}$ & & Yes & - & 2 & 2 & 2 \\
\hline $\begin{array}{c}\text { Alkaline } \\
\text { solution/RT }\end{array}$ & & Yes & - & 2 & 2 & 2 \\
\hline \multicolumn{3}{|c|}{$\begin{array}{r}\text { Total } \\
\end{array}$} & 8 & 8 & 8 & 8 \\
\hline \multicolumn{3}{|c|}{ Grand total } & \multicolumn{4}{|c|}{32} \\
\hline
\end{tabular}


Table 1-4 Number and aging schemes of GFRP bars tested in SEM

\begin{tabular}{|c|c|c|c|c|c|c|}
\hline \multirow[b]{2}{*}{ Aging schemes } & \multirow{2}{*}{$\begin{array}{l}\text { Bar } \\
\text { size }\end{array}$} & \multirow[b]{2}{*}{ Nanoclay } & \multicolumn{4}{|c|}{ Number of specimens } \\
\hline & & & $\begin{array}{c}\text { Without } \\
\text { aging }\end{array}$ & $\begin{array}{c}3 \text { months } \\
\text { aging }\end{array}$ & $\begin{array}{c}6 \text { months } \\
\text { aging }\end{array}$ & $\begin{array}{c}9 \text { months } \\
\text { aging }\end{array}$ \\
\hline \multirow{2}{*}{ Non-aged } & \multirow{2}{*}{$\# 4$} & Yes & 1 & - & - & - \\
\hline & & No & 1 & - & - & - \\
\hline \multirow{2}{*}{$\begin{array}{l}\text { Extracted from } \\
\text { concrete beams }\end{array}$} & \multirow{2}{*}{$\# 4$} & Yes & 1 & - & - & - \\
\hline & & No & 1 & - & - & - \\
\hline \multirow{2}{*}{ Water/RT } & \multirow{7}{*}{$\# 4$} & Yes & - & 1 & 1 & 1 \\
\hline & & No & - & 1 & 1 & 1 \\
\hline Water at $110^{\circ} \mathrm{F}$ & & Yes & - & 1 & 1 & 1 \\
\hline \multirow{2}{*}{ Water at $140^{\circ} \mathrm{F}$} & & Yes & - & 1 & 1 & 1 \\
\hline & & No & - & 1 & 1 & 1 \\
\hline \multirow{2}{*}{$\begin{array}{l}\text { Alkaline } \\
\text { solution/RT }\end{array}$} & & Yes & - & 1 & 1 & 1 \\
\hline & & No & - & 1 & 1 & 1 \\
\hline \multicolumn{3}{|c|}{ Total } & 4 & 7 & 7 & 7 \\
\hline \multicolumn{3}{|c|}{ Grand total } & \multicolumn{4}{|c|}{25} \\
\hline
\end{tabular}

Table 1-5 Number of moisture absorption specimens

\begin{tabular}{|l|c|}
\hline \multicolumn{1}{|c|}{ Specimen type } & \# of specimens \\
\hline Bar without nanoclay & 10 \\
\hline Bar with nanoclay & 10 \\
\hline Neat resin without nanoclay & 10 \\
\hline Neat resin with nanoclay & 10 \\
\hline Total & $\mathbf{4 0}$ \\
\hline
\end{tabular}

Table 1-6 Number of concrete beams cast with GFRP bars

\begin{tabular}{|c|c|c|c|}
\hline Bar size & Nanoclay & $\begin{array}{c}\mathbf{f}_{\mathrm{c}}{ }^{\prime} \\
(\mathbf{k s i})\end{array}$ & $\begin{array}{c}\text { Beam } \\
\text { dimension }\end{array}$ \\
\hline \multirow{4}{*}{$2-\# 4$} & Yes & \multirow{2}{*}{3.5} & \multirow{2}{*}{$5 " x 8 " x 60 "$} \\
\hline & No & & \\
\hline & Yes & \multirow{4}{*}{5} & \multirow{4}{*}{$8 " x 16 " x 120 "$} \\
\hline & No & & \\
\hline \multirow{2}{*}{$1-\# 6$} & Yes & & \\
\hline & No & & \\
\hline Total & & & 6 \\
\hline
\end{tabular}




\subsection{OVERVIEW}

In addition to the introductory Chapter 1, this report is organized into several Chapters.

Chapter 2 contains review of research findings, performance data, and current practices on FRP bars. The technical data on FRP bars are reviewed from the viewpoint of mechanical properties, durability, and beam flexure. Mechanical properties of FRP bars have been reviewed with emphasis on tension, bond, and shear. Durability of FRP bars has been reviewed with emphasis on moisture absorption and aging. Beam flexure has been reviewed with emphasis on crack width, deflection, and moment capacity of beams reinforced with FRP bars.

Chapter 3 gives an introduction to the type of tests and specimens used during the course of this research. It also gives information on aging schemes used in this study.

Chapter 4 describes the materials used for manufacturing GFRP bars and concrete beams, equipments and accessories used for manufacturing and testing of FRP bars. Pultrusion process used for manufacturing FRP bars is described as well.

Chapters 5 through 10 contain the test and specimen description, analytical procedure, test data, and discussion of test data for different tests. Different types of tests focused in this research are: tension tests (Chapter 5), shear tests (Chapter 6), bond tests (Chapter 7), moisture absorption (Chapter 8), SEM (Chapter 9), and beam flexure (Chapter 10). These chapters also contain appropriate test details, schematic diagrams of test apparatus, and representation of data obtained from those test.

Chapter 11 provides the summary and conclusions of this research. Appendix A contains detailed test results and stress vs. strain plots of tension tests. Appendix B contains detailed test results of shear and bond tests. Appendix C contains the theoretical calculations for the beams tested in this research. 


\section{LITERATURE REVIEW}

\subsection{INTRODUCTION}

This chapter contains review of published research findings, performance data, and current practices on FRP composites. Mechanical properties of Fiber Reinforced Polymers (FRP) bars have been reviewed with emphasis on tension, shear, and bond tests. Durability of FRP bars has been reviewed with emphasis on moisture absorption at room and elevated temperature and alkaline solution aging. Glass FRP reinforced beam flexure has been reviewed with emphasis on crack width, deflection, and moment capacity. In addition, effects of resins with nanoclay and their benefits and limitations are reviewed.

FRP bars used as reinforcement in concrete structures are exposed to varying environments during their service life. Moisture ingress in concrete under alkaline environment is detrimental to mechanical properties of FRP reinforcement due to chemical reaction between silica in glass and alkaline ions. Chemical aging of FRP can be prevented by following three methods:

The first method is by adopting alkali resistant glass fibers. Owens Corning Inc. developed a glass fiber under a trade name of Adventex ${ }^{\circledR}$ which is resistant to alkali solution. It has been shown that GFRP manufactured with this alkali-resistant GFRP is much more durable than that manufactured with traditional E-glass fiber (Benmokrane et al, 2002).

The second method is to modify polymer matrix with organic polymers and inorganic fillers. It has been proven that modifying vinyl ester polymer matrix with urethane would improve durability of non-modified E-glass / vinyl ester GFRP rebar in alkaline solution. Urethane-modified vinyl ester GFRP rebars showed a tensile strength loss of $84.7 \%$ after 4 months of alkaline exposure with $40 \%$ tensile strength sustained loading, while vinyl ester GFRP rebars manufactured without urethane modification failed within one month with only $25 \%$ tensile strength sustained loading in alkaline solution (Vijay, 1999). 
Urethane-modified vinyl ester resin used for manufacturing GFRP bar was developed by Reichhold Chemicals Inc.

The third method is to disperse montmorillonite nanoclay powders into the polymer matrix of GFRP during the manufacturing process. This approach is used in this research. Nanoclay provides tortuous path for moisture ingress into the FRP bar and acts as a barrier against moisture movement from surface to the core (Yano et al, 1993). Thus, the diffusion coefficient of moisture through the matrix decreases. A previous study showed that when $1 \mathrm{wt} \%$ Cloisite ${ }^{\circledR} 10 \AA ̊$ nanoclay was dispersed to vinyl ester resin in forming nanocomposites, water diffusion coefficient decreased by $60 \%$ (Shah et al, 2002). Addition of nanoclay is also known to improve flammability resistance and resin stiffness (Christopher and Meier, 2004).

\subsection{MECHANICAL PROPERTIES AND DURABILITY TESTS ON FRP BARS}

Since water is almost present in every environment, it is important to evaluate FRP materials under moisture exposure for aging effect. In concrete applications, FRP bars get exposed to different conditions such as i) concrete pore solution which is alkaline in nature, ii) salt used to melt the snow on pavements during the winter season, and iii) chemicals in waste water plants and others. Such environmental exposure adversely affects the properties of FRP bars during their service life. This research review focuses on durability and mechanical properties of GFRP bars. Mechanical properties considered in this research are: 1) tension 2) shear and 3) bond strength of bars aged in different conditioning schemes and also those embedded in concrete. In addition, moisture absorption effects under different temperatures and alkalinity are considered in this research. Since the available data correspond to the GFRP bars without nanoclay, the same have been discussed in the following sections.

\subsubsection{TENSION PROPERTIES OF GFRP}

Several types of FRP bars have been commercially produced, and each has distinct strength and durability. The properties and durability of GFRP bars vary significantly based on the type of fibers and resins, fiber volume fraction, additives and modifiers, 
sizings, fiber orientation, manufacturing process, and quality control during manufacturing.

Tension, compression, bending, and torsion tests were conducted on GFRP bars at the Constructed Facilities Center (CFC), West Virginia University, to characterize the strength and stiffness properties (Wu, 1990). Different failure modes were observed for bars in tension depending on the type of bars. Smooth bars had fiber breakage, while wrapped or ribbed bars exhibited initial matrix breakage followed by the failure and peeling of outer fibers leading to final bar rupture.

FRP bars also exhibit shear lag phenomenon, which is due to higher stress carried by outer fibers as compared to core fibers. As the bar size increases, ultimate failure stress decreases. For example, it has been reported (Wu, 1990) that \#8 GFRP bars have about $70 \mathrm{ksi}$ mean tensile strength as compared to $130 \mathrm{ksi}$ mean tensile strength of \#3 bars with fiber volume fraction, $\left(V_{f}\right)$ of 0.7 .

Benmorkrane and Masmoudi (1996) tested glass fiber reinforced bars of $1 / 2$ in. diameter with a fiber volume fraction of $55 \%$ and reported tensile strength of $112 \mathrm{ksi}$ with a failure strain of $2.05 \%$. Young's modulus was measured to be $5.46 \mathrm{msi}$, which was based on strain gage readings.

Malvar (1995) conducted five tensile tests on four types of \#6 bars following ASTM D3916-84. Elongation measurements were taken using two LVDT's on either side of each bar, attached via two clamps spacing an average of 13 in. The ultimate stress varied from 65 to $103 \mathrm{ksi}$ and Young's modulus was noted to be between 4.1 to $6.9 \mathrm{msi}$.

Kocaoz et al. (2005) tested four types of \#4 GFRP bars. Bars had higher mean strengths ranging from $142 \mathrm{ksi}$ to $147 \mathrm{ksi}$. Kocaoz et al. (2005) also found coating might have a beneficial effect on the tensile strength of FRP bars. A coating using wollastonite fillers seems to increase the tensile strength slightly. 


\subsubsection{SHEAR STRESS OF GFRP}

Shear tests were conducted by Tripathi (2003) on GFRP bars without nanoclay that showed increase in shear stress with increase in cutting tool width, which is because of increased bending effects. Single shear test gave lower shear value compared to double shear test, because of increased bending effect. \#4 GFRP bars with ribbed surface finish tested under double shear with 1 in. and $1 / 2$ in. width cutting tool showed $23.47 \mathrm{ksi}$ and $27.25 \mathrm{ksi}$, respectively. From the tests conducted, it was observed that double shear test was comparatively more consistent and accurate than single shear test due to elimination and/or minimization of bending effect.

\subsubsection{BOND STRENGTH OF GFRP WITH CONCRETE}

Research findings indicate that (Achillides et al, 2004) bond behavior of FRP bars is influenced by fiber type, embedded length, concrete strength, bar diameter, bar crosssection, bar location, and surface deformation. Direct pullout method consists of embedding GFRP rebar up to a specific distance in a concrete cylinder. Cylinders are usually 6 in. diameter and $12 \mathrm{in}$. high or concrete cubes. Although this is a common practice for determining bond behavior, it is widely believed that this method will yield unconservative bond stress values (Tripathi, 2003).

Larralde et al. (1993) studied bond behavior of \#3 and \#5 FRP bars and compared their results with steel bars. A total of 6 - \#3 bars and 6 - \#5 bars were tested at two different embedment lengths of $3 \mathrm{in}$. and $6 \mathrm{in}$. They found that the larger embedment lengths yielded an overall smaller maximum bond stress. Bars of \#3 diameter at 3 in. and 6 in. embedment lengths, showed a maximum average bond stress of $1.44 \mathrm{ksi}$ and $1.35 \mathrm{ksi}$, respectively. Bars of \#5 diameter at 3 in. and 6 in. embedment lengths, showed a maximum average bond stress of $0.97 \mathrm{ksi}$ and $0.86 \mathrm{ksi}$, respectively. They determined that the reduction in bond stress due to an increased embedment length was due a nonlinear bond stress distribution.

Cosenza, et al (1999) tested 69 FRP bar specimens of different diameters under different embedded length, temperature, and confinement pressure. They observed that FRP 
smooth rods are inadequate for use as reinforcements in concrete structures and also found that it had very low bond strength. Deformation of smooth bars with spiral glued fibers did not show any improvement. Sand-covered bars showed a good bond resistance except it had a brittle bond failure due to detachment of sand grains and poor bar interface with concrete. Twisted strands showed a higher strength as compared to the smooth bars. Deformed bars with ribs and indents showed similar bond stress as that of steel bars. Free slip value at the same bond stress value was larger than that of steel bars for both types of FRP bars with deformed surface.

Achillides et al. (2004) conducted pullout tests on more than 100 bars. They observed that bond strength of bars was controlled by inter-laminar shear strength just below the resin rich surface layer of the bar and not concrete strength. Free end slip was noted around $80 \%$ of the bond strength, which was much higher, than the conventional steel reinforcement.

Larralde et al. (1994) conducted pullout tests on \#4 bars embedded in 6 in. x 12 in. cylinders with embedment lengths of 5 in., 7 in., 9 in., and 11 in. They found that failure for the $5 \mathrm{in}$. and $7 \mathrm{in}$. embedment lengths occurred through longitudinal and radial cracks formed in the cylinder allowing the bar to be pulled out. Failure for the $11 \mathrm{in}$. embedment length occurred by splitting of the concrete cylinder. Cylinders with 7 in. and 9 in. embedment lengths failed either of the previously mentioned modes.

Katz (1999) performed a study comparing five different types of FRP bars and mild steel bar, using the direct pullout method. Rods were embedded in a 5.9 in. x 5.9 in. x 4.7 in. concrete block. Katz (1999) found that the FRP bars with mechanical deformations performed the best with an average bond stress of $2.12 \mathrm{ksi}$. The next best performance was by the FRP bars with helical wrapping and sand impregnation (small particles). They had an average bond stress at $2 \mathrm{ksi}$, followed by plain helical wrapped bars at $1.77 \mathrm{ksi}$. The steel bar performed just below the three well performing FRP bars at $1.76 \mathrm{ksi}$. 


\subsubsection{MOISTURE ABSORPTION}

The mechanical, thermal, and chemical properties of fiber reinforced polymer composites change under environmental exposure. These changes in properties must be evaluated by tests, which may last months or years. Unfortunately, under most circumstances such tests are impractical and testing time must be reduced. Therefore, accelerated testing techniques are utilized to reduce the time required to perform environmental tests. In this research, moisture absorption test at different temperatures and effects of alkaline conditioning were evaluated.

\subsubsection{MOISTURE ABSORPTION AT ROOM TEMPERATURE}

Water penetrates FRP through two processes: diffusion through the resin and flow through cracks or other material flaws. During diffusion, absorbed water is not in the liquid form, but consists of molecules or groups of molecules that are linked together by hydrogen bonds to the polymer. They are dissolved in the surface layer of the polymer and migrate into the bulk of the material under a concentration gradient. Water penetration into cracks or other flaws occurs by capillary flow. Water also penetrates at the interface of fiber-matrix. Water penetration at resin-glass interfaces of E-glass epoxy composites are reportedly 450 times faster than the penetration through resin alone. It is reported that the primary mechanism of moisture pickup is diffusion through resin and transfer of moisture through the cracks is an after effect (Springer, 1981, Vijay and Gangarao, 1999).

Vijay (1999) investigated moisture absorption of GFRP bars under tap water, salt water, and alkaline water considering temperature variations including freeze-thaw cycles. Moisture absorption tests were conducted to determine diffusivity rates under different moisture conditioning schemes. Moisture absorption tests were conducted on \#4 FRP bar specimens measuring $2 \mathrm{in}$. long and their ends were sealed using durable resin to allow moisture penetration along radial direction only. The degradation rate and magnitude of the strength and stiffness of GFRP bars in alkaline environment were significantly higher than the effects of plain and salt water. 
Vijay (1999) studied the effects of moisture at different temperature and alkaline conditioning of GFRP bars. They observed that moisture absorption was found to increase with temperature. Alkaline conditioning resulted in maximum moisture absorption as compared to other solutions. Maximum moisture content less than $0.6 \%$ was observed after 543 days of conditioning under room and freeze-thaw temperatures for tap water, salt water, and alkaline solution immersions. On an average, alkaline conditioning produced about twice, and in some cases three times the moisture content as compared to tap and salt-water conditioning. The authors concluded that the higher absorption of alkaline solution in relation to other solutions is an indication of the relative degradation in tensile strength of GFRP bars, as anticipated in accelerated aging tests.

\subsubsection{MOISTURE ABSORPTION AT ELEVATED TEMPERATURE}

Pantuso et al. (1998) conducted a study on \#4, \#5, and \#6 GFRP bars manufactured with polyester resin. The bars were cyclically exposed to water, one full day of immersion and the other day air dried at a temperature of $23.2^{\circ} \mathrm{C}$. After 2 months of exposure, they observed that there was small reduction in tensile strength and modulus of elasticity in the order of 1 to $7 \%$ and 1 to $10 \%$, respectively.

Phifer et al. (2001) studied the moisture absorption and strength reduction curves of pultruded E-glass/ vinyl ester laminates as a function of water immersion temperature ranging from room temperature to $80^{\circ} \mathrm{C}$. The authors showed that the moisture diffusion process and strength reduction with respect to time required a double exponential solution, thus indicating that there are two mechanisms that drive degradation. The mechanisms may be fiber degradation and resin/fiber interface degradation. Arrhenius (temperature dependent) equation is used to represent diffusion and strength reduction with respect to temperature.

\subsubsection{ALKALINITY}

Studies by Prian, (1999) showed that leaching of alkaline components from the fibers and the consequent increase in $\mathrm{pH}$ surrounding the fibers causes enhanced degradation of the fiber/matrix interface, which involved both accelerated fiber dissolution and loss of acidic 
components of the matrix. The deterioration and opening up of the interface allowed further water penetration, which promoted hydrolytic depolymerization of the matrix. Eventually the degradation concentrated around the interface, led to the formation of microscopic cracks and voids that further facilitated aqueous attack.

Micelli and Nanni (2001) did a study on the effects of alkaline environment and other factors on GFRP rods. The rods were made up of E glass fibers and polyester resin and exposed to alkaline solution having a $\mathrm{pH}$ of 12.6 and maintained at a temperature of $60^{\circ} \mathrm{C}$. The rods were tested after 21 days and 42 days showed strength retention of $70 \%$ and 59\%, respectively. Also tests were performed on specimens exposed to combined environmental conditioning: freeze thaw, high temperature, high relative humidity, and UV indirect exposure in a controlled chamber, the strength retention observed for $1 / 4$ in. sand coated GFRP rods was $93 \%$.

Tannous et al. (1998) examined strength loss of GFRP bars in alkaline solution with $\mathrm{pH}$ of 12 and in acidic solution and observed that the loss of strength in alkaline solution was more when GFRP bars were exposed to acidic solution at room temperature. In the case of \#3 diameter bars exposed to $25^{\circ} \mathrm{C}$ and $60^{\circ} \mathrm{C}$, strength reduction was $25 \%$ and $28.6 \%$, respectively for bars coated with polyester resin. For the bars coated with vinyl ester resin exposed to same conditioning strength, reduction was $13 \%$ and $20.3 \%$, respectively.

Vijay (1999) conducted accelerated tests on \#4 and \#6 bars (E-glass fiber) manufactured with different thermoset polymer resins to evaluate environmental effects. Of the five resins, two were vinyl ester resins of which one was isocyanurate vinyl ester and the other was urethane vinyl ester. The bars were placed in an unstressed condition in an alkaline solution of $\mathrm{pH} 13$. After 203 days of immersion, the isocyanurate vinyl ester resin bars suffered strength and stiffness losses in a range of $25.4 \%$ to $64.3 \%$ and $0.4 \%$ to $9.3 \%$, respectively while the loss in strength and stiffness for urethane vinyl ester resin was in the range of $8.4 \%$ to $16.9 \%$ and $5.3 \%$ to $7.7 \%$, respectively. They also conducted sustained stress on alkaline solution immersed \#4 bars (with resulting sustained stress approximately $25 \%$ to $30 \%$ of ultimate stress). The loss in strength and stiffness observed 
for isocyanurate vinyl ester resin bars was $37.1 \%$ to $76.5 \%$ and $6.1 \%$ to $31.6 \%$, respectively. However, about $0.8 \%$ loss in strength and $15.2 \%$ loss in stiffness was noted in bars made of urethane vinyl ester, after 203 days.

Katsuki and Uomoto (1995) studied the penetration of alkali in FRP rods by performing accelerated tests on AFRP, GFRP, and CFRP rods with vinyl ester resin. GFRP rods were exposed to $1.0 \mathrm{~mol} / \mathrm{liter} \mathrm{NaOH}$ solution at $40^{\circ} \mathrm{C}$ while the AFRP and CFRP rods to 2.0 mol/liter $\mathrm{NaOH}$ solution. After 120 days of exposure the strength loss for GFRP and AFRP rods was $72 \%$ and $5 \%$, respectively, while there was strength gain of $1 \%$ for CFRP rods. They also checked the alkali penetration on sections of FRP rods using Electron Prove Microscope Analyzer (EPMA), and the alkali penetration could be clearly seen in GFRP rods. Figure 2-1 shows a diagram showing how the section of GFRP will be seen when observed through an EPMA and a rough estimate of the alkali penetration in a GFRP rod after 7, 30, and 120 days.

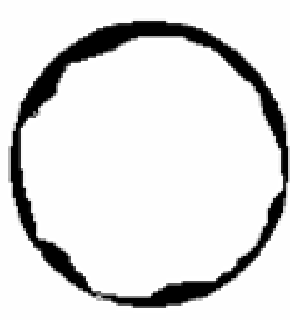

7 days

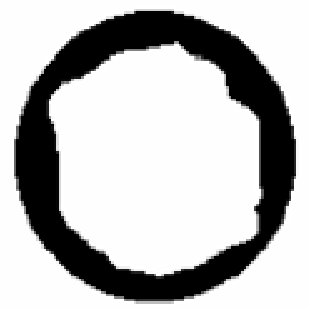

30 days

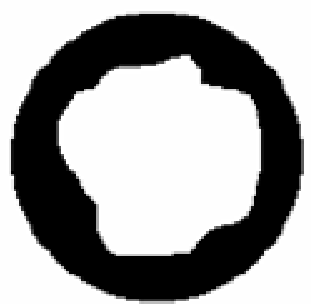

120 days

Figure 2-1 Rough estimate of alkali penetration in GFRP rods [Katsuki and Uomoto (1995)]

Sen et al. (2002) performed an experimental study on durability of E-glass/ vinyl ester bars. The bars were exposed to simulated concrete pore solution with a $\mathrm{pH}$ ranging from 13.35 to 13.5 for periods of $1,3,6$, and 9 months under unstressed and stressed conditions. They observed that specimens under unstressed conditions lost $63 \%$ of their strength while the specimen stressed to $10 \%$ of their ultimate short-term tensile strength lost $70 \%$ of their strength. The specimens exposed to more than $10 \%$ of ultimate strength failed by 180 days. 


\subsection{BEAM FLEXURE}

Alsayed (1998) studied load-deflection relationships for 12 concrete beams reinforced either by steel or GFRP bars. The resulting model provided an accurate prediction of the measured deflections for beams reinforced with steel. The errors in prediction of service load deflection and ultimate flexural strength for beams with steel reinforcement were less than $10 \%$ and $1 \%$, respectively. In the case of GFRP reinforced beams, the service load deflection predicted by the ACI model had $70 \%$ error, while that predicted by the modified model was within $15 \%$ of the measured value.

Theriault et al. (1998) studied the reinforcement ratio and concrete strength effect on 12 concrete beams reinforced with GFRP rods. Theoretical models were proposed for the prediction of crack width, crack spacing, load deflection response, ultimate capacity, and modes of failure. Three concrete strengths and two reinforcement ratios were used in the study for a total of six different specimens with 2 replications. The beam sizes were $5 \mathrm{in}$. $\mathrm{x} 7 \mathrm{in.} \mathrm{x} 70 \mathrm{in}$. with a $1 \mathrm{in}$. concrete cover. They found that: i) effect of concrete strength and reinforcement ratio on crack spacing was negligible; ii) Stiffness of the test specimens remained about the same whether the beams were loaded monotonically or cyclically; and iii) experimental strain distribution, crack network, stiffness, and regain in deflection even after partial failure of the beam clearly indicated a good bond between GFRP rebars and surrounding concrete, when tests were conducted at room temperature.

Benmokrane et al. (1995) studied typical crack patterns of 12 GFRP reinforced and 6 steel reinforced beams at moderate $\left(50 \% \mathrm{M}_{\mathrm{u}}\right)$, and high load $\left(90 \% \mathrm{M}_{\mathrm{u}}\right)$. Cracking in the flexural span consisted predominantly of vertical cracks perpendicular to the direction of maximum principal stress. Cracking outside the pure bending zone started similarly to flexural cracking; but as the load was increased, shear stresses became predominant and induced inclined cracks. Crack formation was sudden and initiated at moment $\mathrm{M}_{\mathrm{u}}$ approaching that predicted by $\mathrm{AC} 1$ code provisions. All the test beams experienced significant flexural cracking before inclined cracks joined flexural cracks. Additional load was carried in all beams as the diagonal tension cracks opened and propagated. It was observed that cracks are deeper and larger in concrete beams reinforced with GFRP 
rebars than in those reinforced with conventional steel. This is attributed to the low modulus of elasticity of GFRP rebars compared to steel rebars. Crack width, at service load $\left(50 \% \mathrm{M}_{\mathrm{u}}\right)$ for GFRP and steel reinforced beams was 0.061 in. and 0.007 in., respectively.

Toutanji et al. (2003) studied flexure behavior of three types of GFRP reinforced concrete beams ( 2 replications) with different reinforcement ratios. The beam dimensions were 7 in. x 12 in. x 120 in. Initially, the beams were not cracked where they exhibited linear moment-deflection behavior. This is attributed to the linear elastic characteristics of GFRP bars and concrete. With additional loading, cracking occurred at the constant moment zone, when the applied moment exceeded the cracking moment causing a reduction in stiffness. This is due to wider crack openings in FRP reinforced concrete beams, which is attributed to the low modulus of elasticity of GFRP.

Faza and GangaRao (1992) studied flexure behavior of 25 concrete beams of size 6 in. $\mathrm{x}$ 12 in. $x 120$ in. under four point bending. It was found that ultimate moment capacity of high strength concrete beams was increased by $90 \%$ when FRP rebars of ultimate tensile strength of $130 \mathrm{ksi}$ were used in lieu of mild steel rods (60 ksi). The ultimate moment capacity of concrete beams reinforced with sand coated rebars is about $70 \%$ higher than beams reinforced with steel rebars for same area and concrete strength. The use of sand coated FRP rebars in addition to high strength concrete is found to increase the cracking moment of the beams and reduce the crack widths. A $50 \%$ increase in ultimate moment was obtained without bond failure when deformed FRP stirrups were used in lieu of smooth FRP bars. Increase in the area of rebars, i.e, 5-\#3 vs. 3-\#4, has lead to an increase in the ultimate moment capacity by about $50 \%$.

\subsection{EFFECTS OF NANOCLAY}

Timmerman et al. (2002) studied matrices of carbon fiber/epoxy composites modified with layered inorganic clays and traditional filler to determine the effects of particle reinforcement; both at micro and nano scale, on the response of these materials to cryogenic cycling. The incorporation of nanoclay based FRP reinforcement (in proper 
concentration) resulted in laminates with micro-crack densities lower than those seen in the unmodified materials as a response to cryogenic cycling. Lower nanoclay concentrations resulted in a relatively insignificant reduction in micro-cracking and higher concentrations displayed a traditional filler effect. The concentration of the particles and their distribution in the matrix was observed to be very important in maximizing the benefits of nanoparticle reinforcement. Exfoliated and disordered intercalated structures provided the best reinforcement, with more ordered intercalated structures offering little benefit. The mechanical properties and processing characteristics of the laminates studied were not adversely influenced by the presence of the nanoparticles and the thermal expansion characteristics were improved. Overall this work showed that nanoclay could be easily used to modify traditional fiber-reinforced composite materials and enhance their resistance to thermal cycling induced stresses.

Subramaniyan et al. (2003) studied the effects of adding nanoclay to the resin, which was known to increase the elastic modulus of the resin. An increase of 50 to $80 \%$ in elastic modulus was observed for fully exfoliated clay in Nylon 6 systems. However, no significant increase in strength has been reported. In fact, reductions in tensile strength have been observed for most clay loadings. This behavior is based on the fact that failure in a material is controlled by the weakest link. The addition of nanoclay platelets, if not well exfoliated, can create weak spots, which are prone to failure initiations. There is an increase of $19 \%$ and $20 \%$ in the elastic modulus of the resin for clay loading of $5 \%$ and $8 \%$ by weight, respectively. The increase in the modulus from $5 \%$ to $8 \%$ loading is not significant. It is usually attributed to the fact that higher percentage of nanoclay in the form of nano-platelets are not fully exfoliated in the polymer matrix.

Christopher (2004) studied phenolic nanocomposites with clay content ranging from $1 \%$ to $10 \%$. The samples were prepared using the RTM machine along with a homemade mold. B-staged phenolic was used as the binder in all of the specimens and fiberglass was the reinforcement. Clay particles of $1 \%, 3 \%, 6 \%$, and $10 \%$ by weight were mixed with the phenolic and fiberglass to produce the nanocomposite. The pure B-staged phenolic had the worst flame resistance with an extinguishing time of 25 seconds. With the 
nanocomposties, the $1 \%$ clay content had the slowest flame extinguishing time of 18 seconds, even though it was 7 seconds faster than the pure phenolic. Addition of $10 \%$ clay proved to have the best flame resistance with a flame extinguishing time of only 3 seconds. When performing the burn test, as the clay \% increased, the amount of smoke decreased with increasing clay content. The mechanical testing of these nanocomposites showed decreases in strength as the clay $\%$ increased. The $1 \%$ clay content had the yield strength of $50 \mathrm{ksi}$ and $10 \%$ clay samples had the yield strength of $4 \mathrm{ksi}$.

Shah (2001) studied moisture diffusion through vinyl ester/clay nanocomposites prepared by adding nanoclay in DERAKANETM 411-350 epoxy vinyl ester resin. It was found that diffusivity of water through the resin decreased with increase in clay content. However, equilibrium moisture uptake increases with increasing amount of clay in polymer. It was also reported in the study that diffusion through polymer clay nanocomposites showed considerable amount of deviation from Fickian behavior, especially at high clay loadings. Higher equilibrium moisture content and non-Fickian behavior were explained by saying that the clay was much more hydrophilic than hydrogen bonded interactions of water with $-\mathrm{OH}$ groups present in polymer chain. Moreover, diffusion coefficient of mobile molecules, remained unchanged for a given polymer-clay system. This was an implication that the reduction in diffusion coefficient is mostly due to the immobilization of water on the clay surface. Author also reported a $50 \%$ drop in water vapor permeability and $85 \%$ drop in the diffusion coefficient of DERAKANE 411-350 vinyl ester resin containing 5 wt \% nanoclay. However, equilibrium moisture content, glass transition temperature, and elastic modulus increased with increase in amount of clay.

\subsection{SUMMARY}

Studies using small amount of nanoclay $(<5 \mathrm{wt} \%)$ indicated that of nanoparticle fillers will increase the modulus, strength, toughness, resistance to chemical attack, gas impermeability, resistance to thermal degradation, and dimensional stability of polymeric materials. It has also been reported that strength decreases with increase in nanoclay percentage. Nanoclay increases the tensile modulus of resins by $19 \%$ - $20 \%$ for a clay loading of $5 \%$ to $8 \%$, respectively (Subramaniyan et al, 2003). Literature review also 
indicates that data on manufacturing and characterization of GFRP bars with nanoclay are not available. This research will focus on manufacturing of GFRP bars with nanoclay and evaluating their mechanical properties and durability. 


\section{TEST PROCEDURES}

\subsection{INTRODUCTION}

Short and long-term tests were performed on GFRP bars with and without nanoclay prior to and after aging them in different conditioning schemes. Types of tests included tension, shear, bond, and SEM. Short-term tests refer to those on bars without aging and long-term tests refer to those on specimens subjected to aging in water at room temperature, water at $110^{\circ} \mathrm{F}$, water at $140^{\circ} \mathrm{F}$, and alkaline solution at room temperature. Tests on specimens with and without aging were conducted to determine their property retention over long-term, which are elaborated in Chapters 5 through 9. In addition to testing of GFRP bars, concrete beams reinforced with GFRP bars (with and without nanoclay) were tested in bending, which is described in Chapter 10.

\subsection{SPECIMENS AND TESTS}

The specimens tested in this research are grouped as follows, based on laboratory aging conditions:

1. Non-aged specimens: Specimens without any exposure to aging solution and stored at room temperature prior to testing.

2. Aged specimens: GFRP bar specimens with and without nanoclay were immersed in water at room temperature, water at $110^{\circ} \mathrm{F}$, water at $140^{\circ} \mathrm{F}$, and alkaline solution at room temperature. They were tested at $0,3,6$, and 9 months of aging.

\subsection{SPECIMENS}

In this research, GFRP bars with and without nanoclay manufactured at WVU laboratories were subjected to short and long-term tests.

(a). Bars without nanoclay: Bars were manufactured without nanoclay having a fiber volume fraction of $44.7 \%$. Hetron 922L-25 vinyl ester resin manufactured by Ashland Chemicals was used to saturate thirty two 113 yield E-glass rovings (for $1 / 2$ in. diameter bars) or fifty 56 yield rovings (for $3 / 4$ in. diameter bars). All the bars manufactured had ribbed surface finish. 
(b). Bars with nanoclay: Manufacturing of bars with nanoclay was similar to those without it. However, prior to fiber saturation Hetron 922L-25 resin was exfoliated with $4 \%$ nanoclay manufactured by Nanocor Inc. Details of exfoliation procedure are provided in Chapter 4 (Section 4.3.3).

\subsection{TESTS}

Brief description of short and long-term tests conducted on GFRP bars is as follows:

Table 3-1 Bar type, size and number

\begin{tabular}{|c|c|c|}
\hline \multirow{2}{*}{ Bar type } & \multicolumn{2}{|c|}{ Bar size } \\
\cline { 2 - 3 } & $\mathbf{4}$ & $\mathbf{\# ~ 6}$ \\
\hline With nanoclay & 174 & 12 \\
\hline Without nanoclay & 52 & 5 \\
\hline
\end{tabular}

\subsubsection{TENSION TEST}

Axial tension tests performed on GFRP bars were described in Chapter 5. Schedule 80 steel pipes split along the center were used as grips at each end of the test specimen. These split pipes were bonded to the specimens using Pliogrip ${ }^{\mathrm{TM}}$, a commercially available resin. A minimum curing time of 24 hours was allowed for the resin to set. Theses grips were simple to work with and were extremely effective. This was noticed from failure modes of the specimen that consists of fiber/bar breaking at the middle portion. Length of the grips were decided based on diameter of the bar specimen to be tested as described in Chapter 5 (Section 5.2.3). Strain gage was attached at the center of each specimen to measure strains at different load levels.

\subsubsection{SHEAR TEST}

Shear test performed on FRP bars is described in Chapter 6. Load was applied on the cutting tool to shear the specimen in two cross-sections, which is known as double shear test. Double shear test was conducted by using shear testing apparatus. Double shear test was performed using $1 / 2$ in. wide cutting tool. Specimens were anchored at both the ends and subjected to shear at two parallel cross sections as described in Chapter 6 (Section $6.2 .5)$. 


\subsubsection{BOND TEST}

Shear test performed on FRP bars is described in Chapter 7. Pullout tests were performed on FRP bars to evaluate their bond strength with concrete. The FRP bars were embedded in a concrete cylinder measuring 6 in. diameter and 12 in. height. Contact length of the GFRP bar within concrete cylinder was 3 in., while remaining length of the bar was debonded from concrete using foam tubes around the bar. Bars were cast in concrete cylinders at one end and attached with split steel grips at the other end. Slip at the unloading end of the bar was measured using an LVDT.

\subsubsection{MOISTURE ABSORPTION}

Three-inch long specimens were cut and sealed at the ends with a suitable resin to avoid moisture penetration at the cut ends. The specimens were then immersed in water. The initial weight of each specimen was noted before immersion. Moisture gain of the specimens was regularly monitored. Similar to GFRP bars specimens, moisture absorption was monitored in neat resin specimens with and without nanoclay. The test specimens dimensions are $1 / 2$ in. diameter and $1 / 2$ in. height.

\subsubsection{SEM}

Scanning Electron Microscope (SEM) imaging was carried out on $1 / 2$ in. long specimens cut from GFRP bar which was surface polished using suspended alumina solution. The polished samples were coated with a thin layer of gold prior to SEM imaging. From each type of conditioning schemes, one specimen was considered for conducting SEM imaging. SEM images were investigated for moisture absorption path, intergrity of fibers, extent of clay exfoliation, and fiber-resin interface defects due to the presence of nanoclay.

\subsubsection{FLEXURE TEST}

Beams were tested under three and four point bending until the specimen failure, i.e., rebar rupture in tension or concrete crushing in compression. Longer strain gages were used for concrete which are attached to the surface prepared using AE 10. LVDT were attached to the concrete beam at the mid-span to obtain the deflection. Load cell, strain 
gage, and LVDT data were automatically recorded using a data acquisition system during loading and unloading. Crack widths were measured by using a micrometer and crack patterns in all the beams were traced onto a tracing sheet. Tests consisted of several cycles of loading and unloading to evaluate the ductility behavior and energy absorption of each beam.

\subsection{TYPES OF AGING}

GFRP bars were subjected to the following types of aging. Following aging duration of 3 , 6, and 9 months, bars were tested in tension, shear, bond, and SEM. GFRP bars for bond test consisted of nanoclay only.

(a). Water at room temperature: Bars with and without nanoclay were immersed in water at room temperature.

(b). Water at $110^{\circ} \mathbf{F}$ : Bars with and without nanoclay were immersed in a water tank at an elevated temperature of $110^{\circ} \mathrm{F}$. The tank was heated using thermostats and the temperature was maintained by covering the tank with a heat resistance cover.

(c). Water at $140^{\circ} \mathbf{F}$ : Bars with nanoclay were immersed in a water tank at an elevated temperature of $140^{\circ} \mathrm{F}$. The tank was heated using thermostats and the temperature was maintained by covering the tank with a heat resistance cover.

(d). Alkaline solution at room temperature: Bars with and without nanoclay were immersed in alkaline solution $(\mathrm{pH} 12.5$ to13) at room temperature. Alkaline solution consisted of $0.2 \%$ calcium hydroxide, $1.4 \%$ potassium hydroxide, $1 \%$ sodium hydroxide, and $97.4 \%$ water. 


\section{MATERIALS, MANUFACTURING, AND EQUIPMENTS}

\subsection{INTRODUCTION}

In this research, significant emphasis was placed on manufacturing aspects of FRP bars with nanoclay with emphasis on exfoliation of nanoclay. At present, FRP bar manufacturers are not utilizing nanoclay in their mass production process. Utilization of nanoclay in FRP bar manufacturing requires an in-depth understanding of exfoliation procedures, optimum level of nanoclay, resin-clay chemistry, including their interfacial properties, and resin viscosity. Manufacturing of FRP bars with nanoclay became a necessity due to complexity and cost considerations in low-scale manufacturing of these bars. FRP bars were manufactured at room temperature with nanoclay at CFC-WVU laboratories. Significant amount of planning, revisions, and refinements were made to manufacture GFRP bars with superior properties and performance using durable vinyl ester resins and nanoclay at room temperature. Trial runs were conducted to select optimum resin chemistry, proper fiber volume fraction, fiber placement, fiber wetting, shape of lugs, reduction in void content, mold details, and bar dimensions. Materials used in this study, mold, and bar manufacturing details are provided in this chapter.

Nanoclay is hydrophilic in nature with one of its dimensions being smaller than 100 nanometers (Southern Clay products Inc.). Though nanoclays exhibit an initial moisture pickup they provide a tortuous path for moisture ingress into the FRP bar and act as a barrier against moisture movement from the bar surface to the core. Addition of nanoclay is also known to improve flammability resistance and resin stiffness (Hay and Shaw 2000). In this research, GFRP bars were manufactured by exfoliating nanoclay in vinyl ester resin. Tension, bond, shear, SEM, and moisture absorption tests were conducted on GFRP bars with and without nanoclay.

\subsection{MATERIALS FOR MANUFACTURING GFRP REBAR}

GFRP bars were manufactured by using vinyl ester resin (Hetron 922L-25), E-glass fibers, nanoclay, and Methyl Ethyl Ketone Peroxide (MEKP) as catalyst through which curing was achieved at room temperature. Properties of each material are as follows. 


\subsubsection{RESIN}

Vinyl ester resin used in this research to manufacture FRP bars is similar to polyester resins in that it is composed of an unsaturated oligomer dissolved in styrene and cured via a free radical reaction. Typical chemical structure of vinyl ester resin is shown in Figure 4-1. The main backbone of vinyl ester is the bisphenol ' $A$ ' epoxy structure, which does not have chemical links that are easily susceptible to chemical attack or corrosion. Also, unsaturation points are found only at the ends of the molecule and not as part of the repeating unit, which gives the resin a better failure strain and resistance against impact damage.

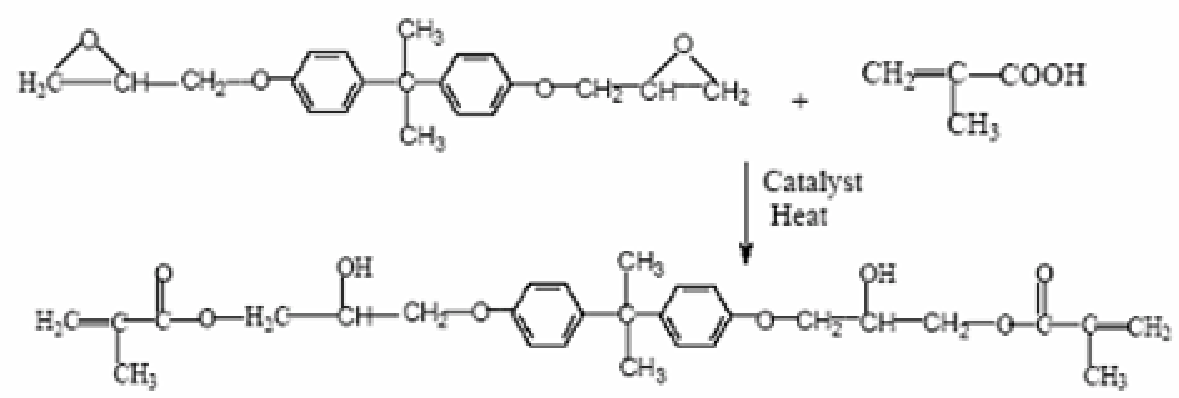

\section{Figure 4-1 Synthesis of vinyl ester by the reaction of a bisphenol-A glycidylether with methacrylic acid.}

In this study, vinyl ester polymer resin (Hetron 922L-25) manufactured by Ashland chemicals was used with Methyl Ethyl Ketone Peroxide (MEKP) as catalyst. Properties of vinyl ester resin are listed in Table 4-1. 
Table 4-1 Properties of vinyl ester resin

\begin{tabular}{|c|c|}
\hline Boiling point & $293.4^{\circ} \mathrm{F} @ 760 \mathrm{mmHg}$ \\
\hline Vapor pressure & $4.500 \mathrm{mmHg} @ 68.00^{\circ} \mathrm{F}$ \\
\hline Specific vapor density & 3.500 @ Air $=1$ \\
\hline Specific gravity & 1.033 @ $77.00^{\circ} \mathrm{F}$ \\
\hline Liquid density & $8.600 \mathrm{lbs} /$ gal @ $77.00^{\circ} \mathrm{F}$ \\
\hline Percent volatile & $47.0-49.0 \%$ \\
\hline Evaporation rate & Slower than ethyl ether \\
\hline Appearance & Clear \\
\hline State & Liquid \\
\hline Physical form & Homogeneous solution \\
\hline Color & Amber \\
\hline Odor & Pungent \\
\hline pH & Not applicable \\
\hline Viscosity & $250.0-300.0 \mathrm{cps} @ \mathrm{spdl} \mathrm{\# 2} @ 30 \mathrm{rpm}$ \\
\hline Thermal expansion & $56.8 \times 10^{-6} \mathrm{~m} / \mathrm{m} /{ }^{\circ} \mathrm{C}$ \\
\hline Solubility in water & Negligible \\
\hline
\end{tabular}

Vinyl esters are cured at room temperature with initiator/promoter systems. However, these resins are not fully cured under ambient conditions. The degree of cure increases with time, but if maximum properties are required, then a post-curing step is necessary. The most common initiator is MEKP. It should be noted that MEKP is not a true catalyst because it is consumed in the reaction.

\subsubsection{CATALYST}

Methyl Ethyl Ketone peroxide (MEKP) is a colorless solution of methyl ethyl ketone peroxide in dimethyl phthalate, with 9\% active oxygen. Some properties of MEKP are listed in Table 4-2.

Table 4-2 Properties of MEKP catalyst

\begin{tabular}{|l|l|}
\hline Molecular weight & 176.22 \\
\hline Boiling point & $244^{\circ} \mathrm{F}$ \\
\hline Specific density & 1.12 at $15^{\circ} \mathrm{C}$ \\
\hline Vapor density & 6.1 Air $=1$ \\
\hline
\end{tabular}


Curing time of vinyl ester resin mainly depends on the amount of MEKP added by weight percentage. Recommended amount of MEKP for various applications are shown in Table 4-3.

Table 4-3 Guidelines for use of MEKP with vinyl ester resin

\begin{tabular}{|l|l|}
\hline Minimum for a slow cure, or for very thick sections, or for high temperatures & $0.75 \%$ \\
\hline Normal for boat layups at moderate temperatures $\left(20^{\circ}\right.$ to $\left.25^{\circ} \mathrm{C}\right)$ & $1.5-2.0 \%$ \\
\hline Hot batch for single layers or small patches or for low-temperature use & $3.0-4.0 \%$ \\
\hline
\end{tabular}

\subsubsection{FIBERS}

Glass fiber is the most widely used reinforcement for composites because of its cost efficiency. It is mainly used in following three types for applications requiring strength and durability.

1. E-Glass is the standard form and is also known as electrical grade. It has very low alkali content and good electrical, mechanical, and chemical properties.

2. C-Glass is a chemical resistant grade and is often used where protection from corrosive environments is required.

3. S-Glass also referred to as R-Glass, has enhanced mechanical properties and is mainly used for aerospace applications.

E-glass fibers are popularly used for reinforcing composites due to the following advantages:

1. Low cost

2. High strength

3. High stiffness

4. Relatively low density

5. Non-flammable

6. Resistance to heat, chemicals, and electricity and

7. Magnetic transparency

E-glass has the following properties as shown in Table 4-4. 
Table 4-4 Properties of E-glass fibers

\begin{tabular}{|l|l|}
\hline Specific gravity & $2.6-2.7 \mathrm{gm} / \mathrm{cc}$ \\
\hline Freezing/ melting point & $>\sim 1400^{\circ} \mathrm{F}\left(800^{\circ} \mathrm{C}\right)$ \\
\hline Solubility & Insoluble \\
\hline Physical state & Solid \\
\hline Odor & Odorless \\
\hline Color & Yellow-White to White \\
\hline Thermal expansion & $5.3 \times 10^{-6} \mathrm{~m} / \mathrm{m} /{ }^{\circ} \mathrm{C}$ \\
\hline Type of sizing & Silane \\
\hline
\end{tabular}

Continuous filament glass fibers are most commonly produced by direct melt process. Molten glass is drawn through a large number of accurately dimensioned platinum bushings. The diameter of the bushing holes is 1 to $2 \mathrm{~mm}$ but the winding operation reduces the diameter of the glass down to 10-15 $\mu \mathrm{m}$. All the fibers are sized (surface treated) when they are produced and then gathered as strand and wound on a drum. This sizing is critical to the performance of the composite as it dictates the adhesion between reinforcing fiber and polymer matrix.

GFRP bars in this research were manufactured using 32 E-glass fiber rovings of 113 Yield with silane sizing. Fibers were cut to a required length from continuous rovings (spool) and passed through Teflon plates (Figure 4-6). Properties of E-glass are as follows.

1. Tensile stress $-500 \mathrm{ksi}$,

2. Modulus of elasticity $-10.5 \mathrm{msi}$ and

3. Strain to failure $-4.8 \%$

E-Glass is a low alkali glass with a typical nominal composition of $\mathrm{SiO}_{2}(54.5 \mathrm{wt} \%)$, $\mathrm{Al}_{2} \mathrm{O}_{3}$ (14.5 wt \%), $\mathrm{CaO}$ (17 wt \%), $\mathrm{MgO}$ (4.5 wt \%), $\mathrm{B}_{2} \mathrm{O}_{3}$ (8.5 wt \%), $\mathrm{Na}_{2} \mathrm{O}(0.5$ wt \%), and some other materials may also be present at impurity levels. 


\subsubsection{NANOCLAY}

Nanoclay material used in this research consisted of montmorillonite which is unique among minerals. It exists as nanoscale particles, which are agglomerated due to surface attraction of one particle to another. When the attractive force is minimized using surface treatment, each particle can disperse to its naturally occurring nanoscale size. Montmorillonite is a 2-to-1 layered smectite clay mineral with a platey structure (Figure 4-2). Individual platelet thicknesses are just one nanometer $\left(10^{-9} \mathrm{~m}\right)$, but surface dimensions are generally 300 - 600 nanometers or more, resulting in high aspect ratio. Structure of montmorillonite is given as:

$\mathrm{M}_{\mathrm{y}}^{+}\left(\mathrm{Al}_{2-\mathrm{y}} \mathrm{Mg}_{\mathrm{y}}\right)\left(\mathrm{Si}_{4}\right) \mathrm{O}_{10}(\mathrm{OH})_{2 *} \mathrm{nH}_{2} \mathrm{O}$

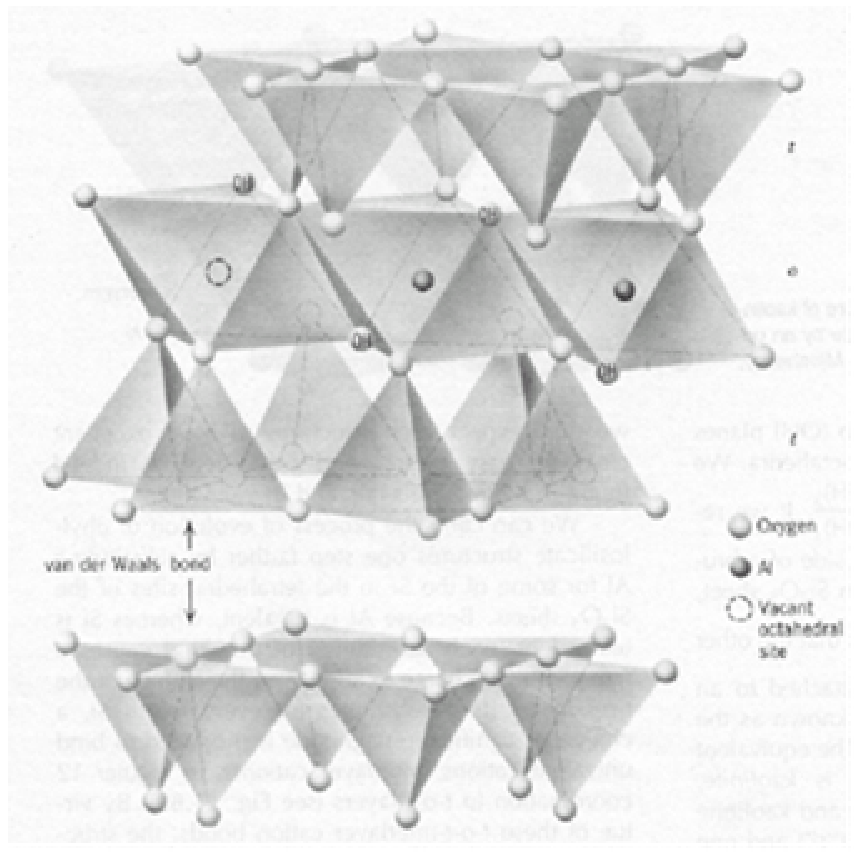

Figure 4-2 Montmorillonite's unique platey particle structure (Nanocor Inc.)

Naturally occurring montmorillonite is hydrophilic. Since polymers are generally organophilic, unmodified nanoclay disperses in polymers with great difficulty. Through clay surface modification techniques, montmorillonite is made organophilic and therefore, compatible with conventional organic polymers. Surface compatibilization which is also known as intercalation is carried out for facilitating easy dispersion of nanoclays in polymers. Complete dispersion of nanoclays is called as "exfoliation". 
Nanoclay was designated as nanomer by Nanocor Inc. When nanomers are exfoliated in a resin matrix, they form a near-molecular blend called a nanocomposite (Nanocor Inc.).

In exfoliated form, nanomer particles have a flexible sheet-type structure where length and breadth of the particles range from 1.5 to a few tenths of a micron. However, the thickness is extremely small, measuring only about a nanometer. These dimensions result in an extremely high average aspect ratio of (200 - 500). A single gram of nanoclay contains over a million individual particles. Nanomer contains $65 \sim 75$ wt $\%$ of Montmorillonite and 25 35 wt \% of Alkyl Dimethyl Benzyl Ammonium.
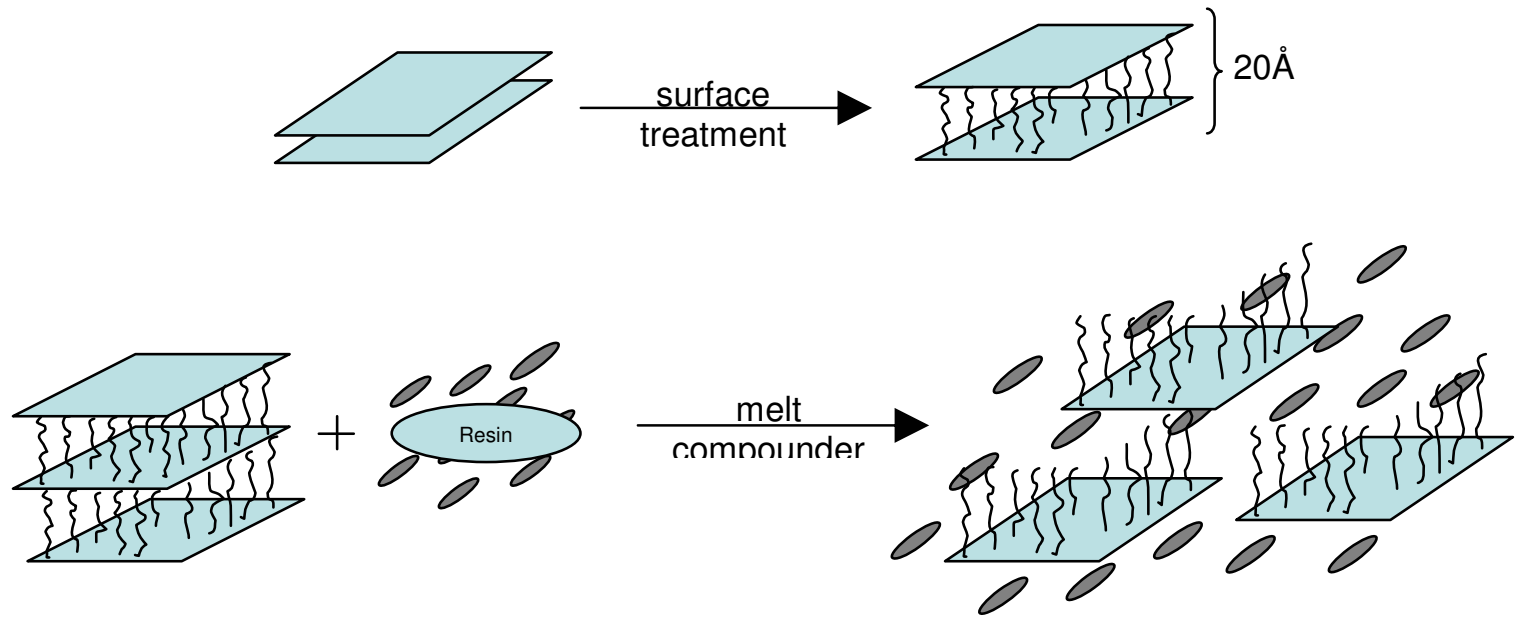

Figure 4-3 Nanoclay-resin interaction before and after exfoliation

For this study, nanoclay designated as Nanomer I.33M (Nanocore Inc.) was used which is compatible with vinyl ester resin (Figure 4-3). About 4\% of Nanomer was added to the resin and mixed for an extended duration using shear mixer. Mixing container was cooled using ice cubes during mixing. Care was taken to remove air bubbles formed during mixing by applying vacuum to the resin. Properties of nanomer are listed in Table 4-5.

Table 4-5 Properties of Nanoclay

\begin{tabular}{|c|c|}
\hline Solubility in water & Negligible \\
\hline Appearance & Soft, off white powder \\
\hline Odor & Odorless \\
\hline Specific gravity & $1.7 \mathrm{gm} / \mathrm{cc}$ \\
\hline Stability & Stable \\
\hline
\end{tabular}




\subsection{EQUIPMENTS FOR MANUFACTURING GFRP REBAR}

\subsubsection{MOLD}

Aluminum molds were manufactured at CFC-WVU laboratory to produce FRP bars (Figures 4-4 \& 4-5). The first mold was manufactured to make bars of $4 \mathrm{ft}$. length and $1 / 2$ in. diameter with crescent shaped lugs. One end of the mold was fitted with a pulley to facilitate pulling of fibers in a slow, yet uniform manner. Holes of $1 / 4$ in. were drilled at a center-to-center distance of 4 in. on top surface of the mold to inject additional resin into rib locations of the mold.

After successfully manufacturing $4 \mathrm{ft}$. long bars, longer mold was manufactured to make bars of $12 \mathrm{ft}$. length and $1 / 2$ in. diameter with ribs of uniform radius as compared to the non-uniform ribs of the old mold. Holes of 3/16 in. were drilled at a center-to-center distance of $3 \mathrm{in}$. on top surface of the mold to inject additional resin into the mold. Procedure for manufacturing the GFRP bar remained same as the old mold except a cone of $1 \frac{1}{2}$ in. outer diameter, $1 / 2$ in. inner diameter, and 2 in. length was attached to the mold to guide the fibers into the mold. Use of guiding cone helped reduce abrasion at fiber entry location.

Another mold of $12 \mathrm{ft}$. length and 3/4 in. diameter was manufactured with ribs of uniform radius. Procedure for manufacturing GFRP bars remained the same.

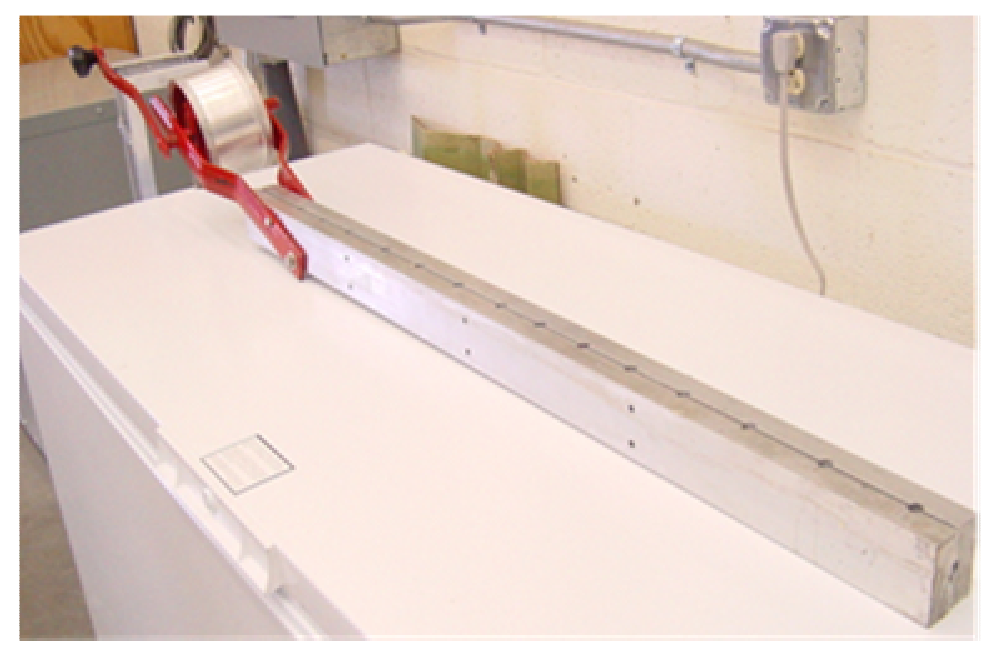

Figure 4-4 FRP bar mold (4 ft.) with drum type pulley 


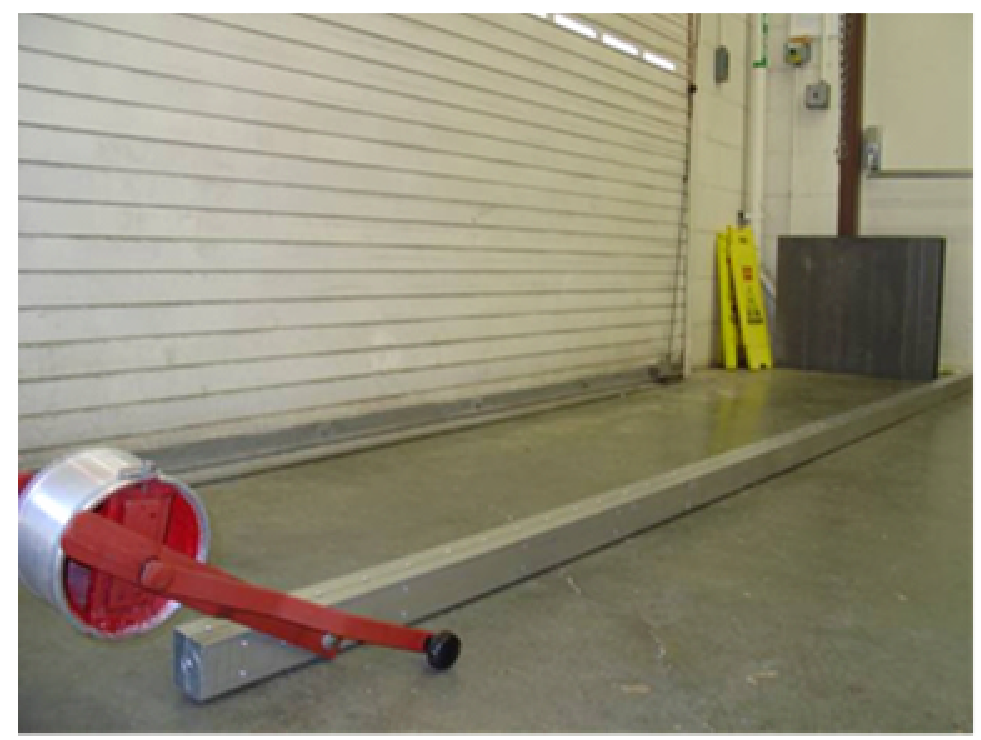

Figure 4-5 FRP bar mold (12 ft.) with drum type pulley

\subsubsection{RESIN BATH}

Teflon plates of $1 / 2$ in. thickness with circular drilled holes were used for guiding glass fibers into and out of the resin bath (Figures 4-6 \& 4-7). Teflon plates decreased the cling between glass rovings as each roving passed through a separate hole in the Teflon plate and minimized friction between plate holes and glass fibers. Holes were drilled such that the Teflon plates allowed fibers to enter resin bath at an angle and stay horizontal during wetting for some distance, and finally exit out an angle and into the mold inlet.

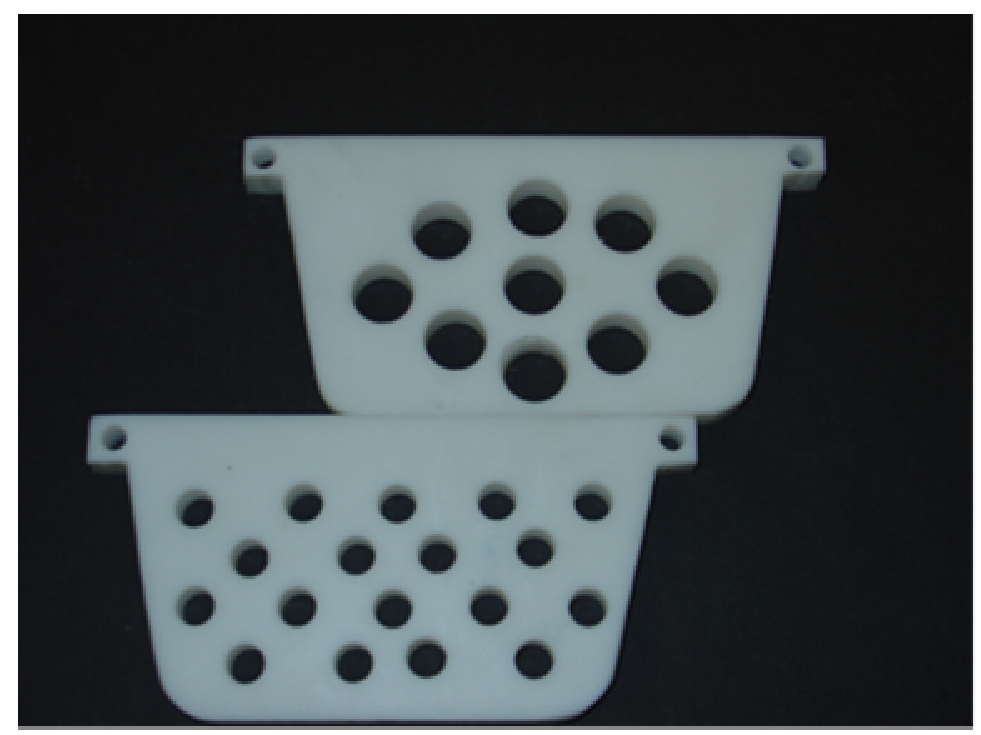

Figure 4-6 Teflon plates drilled with holes 


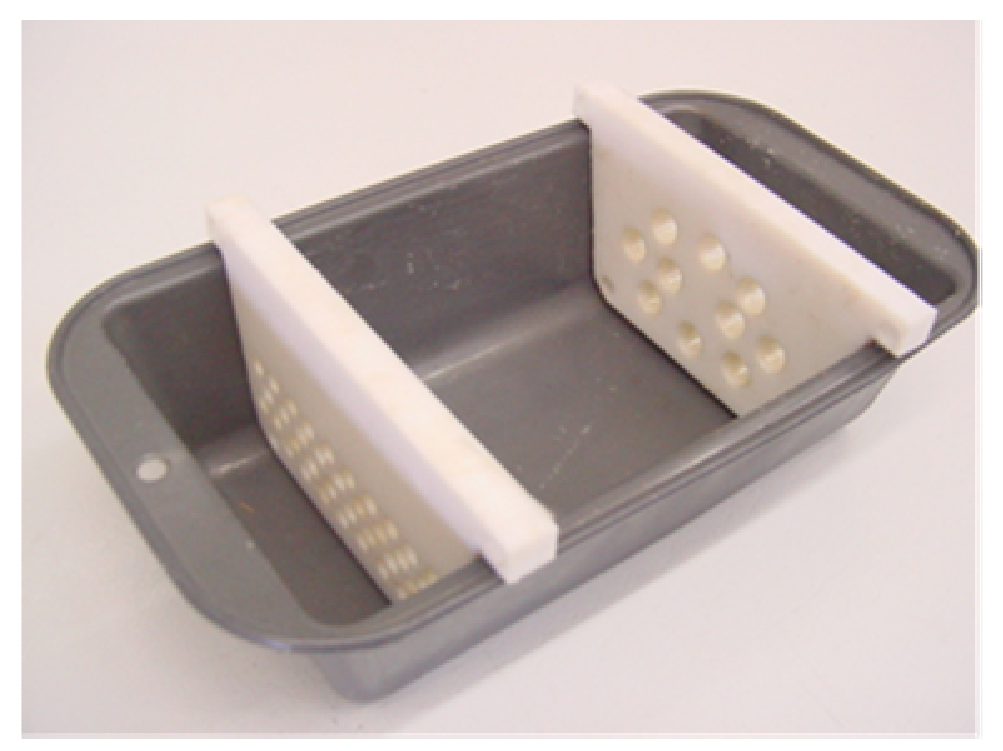

Figure 4-7 Teflon plates drilled with holes in resin bath tray

\subsubsection{SHEAR MIXER}

Shear mixer was manufactured in CFC-WVU laboratory to mix the resin with nanoclay (Figure 4-8). Good nanoclay exfoliation was obtained by mixing through the shear mixer. The shear mixer consisted of a $1 \mathrm{hp}$ motor with 10 speed controller. Details of the Shear mixer operation used in this research are as follows.

1. The high-speed rotation of the rotor blades within the work-head exerts a powerful suction, drawing resin upward from the bottom of the vessel and into the center of the work-head.

2. Centrifugal force drives resin with nanoclay towards the periphery of the workhead where they (resin and clay) are subjected to a milling action between the ends of the rotor blades and the inner wall of the stator.

3. This is followed by intense hydraulic shear as the resin and nanoclay are forced, at high velocity, out through the perforations in the stator and circulated into the main body of the mix.

4. The materials ejected from the head are projected radially at high speed towards the sides of the mixing vessel. At the same time fresh material is continually drawn into the work-head maintaining the mixing cycle. The effect of the horizontal (radial) ejection and suction into the head is to set up a circulatory 
pattern of mixing, which is carried out below the surface without any turbulence at the surface.

5. The impeller fixed few inches above the rotor blade pushes the material down which is ejected from the head.

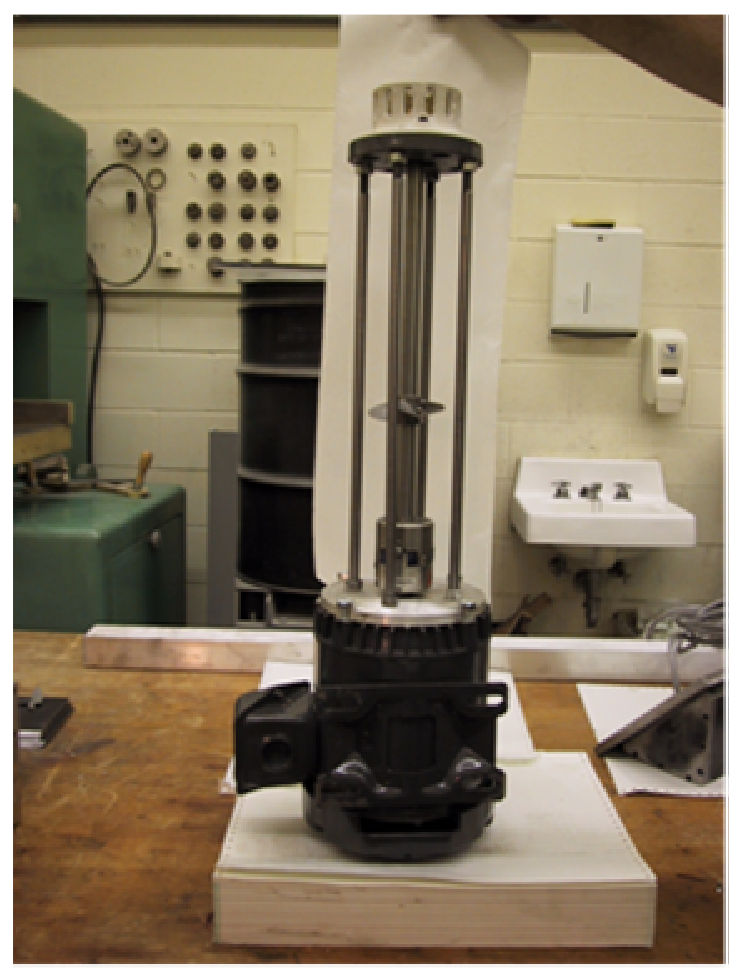

Figure 4-8 Shear mixer built at CFC-WVU laboratory

\subsection{MANUFACTURING PROCESS}

Vinyl ester polymer was exfoliated with about $4 \%$ of nanoclay for an extended duration of 2 hour using a shear mixer. After mixing, Methyl Ethyl Ketone Peroxide catalyst was used to obtain initial setting time of $1 / 2 \mathrm{hr}$.

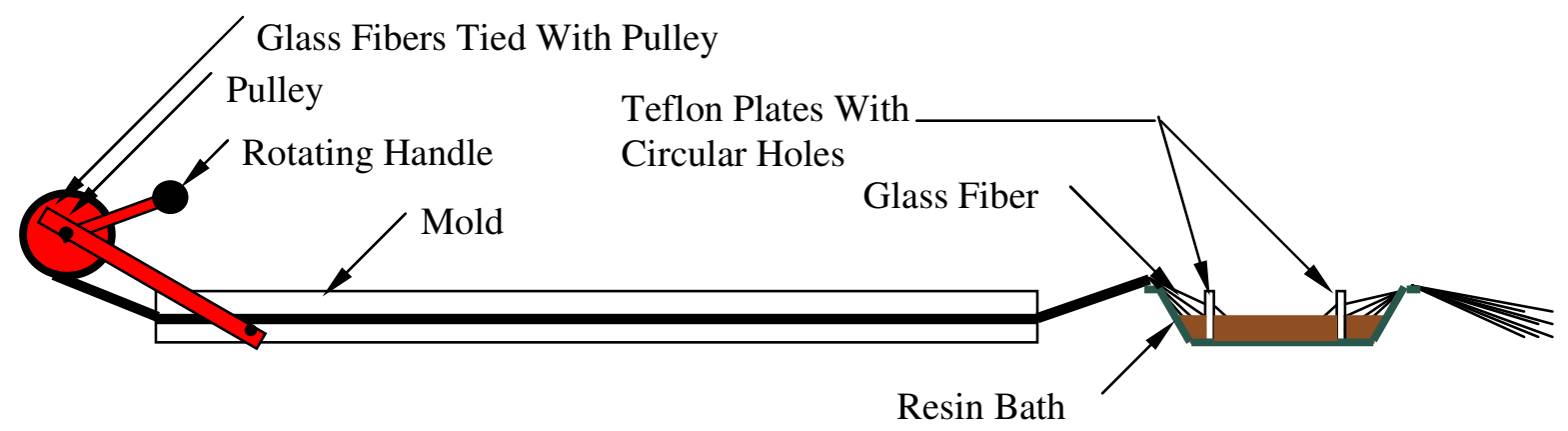

Figure 4-9 Schematic diagram showing pultrusion of GFRP bar 
GFRP bar manufacturing mold was coated with mold-releasing agents. Glass fibers (rovings) were passed through Teflon plates and then through the mold. After passing through the mold, the fiber rovings were tied to an attachment in the pulley drum (Figure 4-9). Teflon plate assembly with fibers was placed inside a tray to allow fiber wetting (Figure 4-10). Vinyl ester resin with catalyst was transferred to the tray and glass fibers were dipped in the resin prior to pulling (Figure 4-11). Slow pulley rotation (rate of pulling is $\approx 1 / 2$ feet/minute) provided adequate wetting of fibers with resin. Pulling was continued until wet fibers were pulled out at other end of the mold. After pulling, resin was poured through vertical holes on top of the mold such that bars with good rib finish were obtained. The vertical top holes in the mold reached rib channel of the mold facilitating excellent resin filling in the mold. Demolding was carried out after 24 hours of room temperature curing. Bar and the ribs were well formed with proper resin wetting during this manufacturing process.

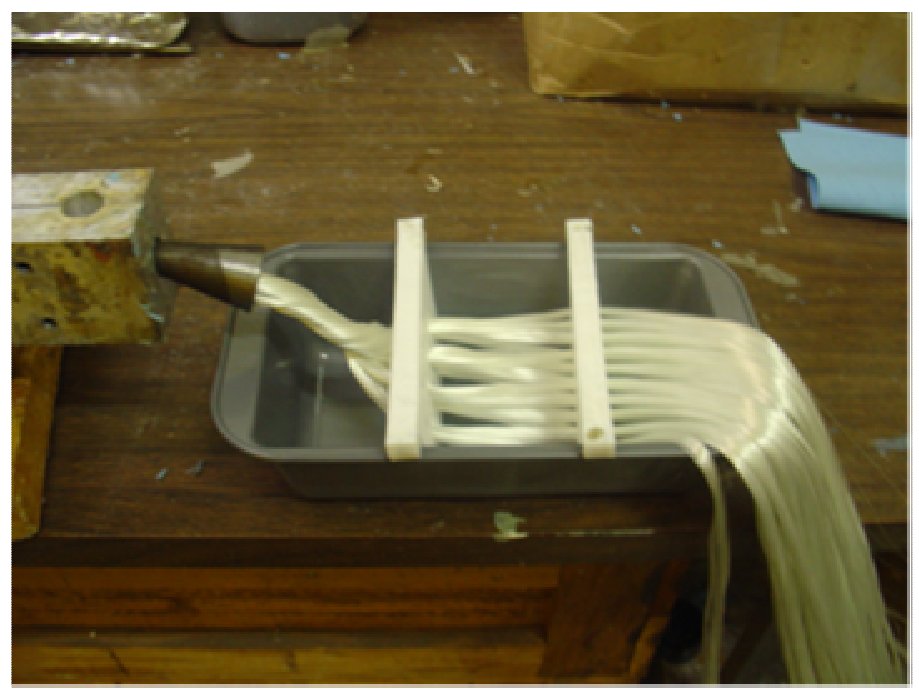

Figure 4-10 Fibers passing through Teflon plate 


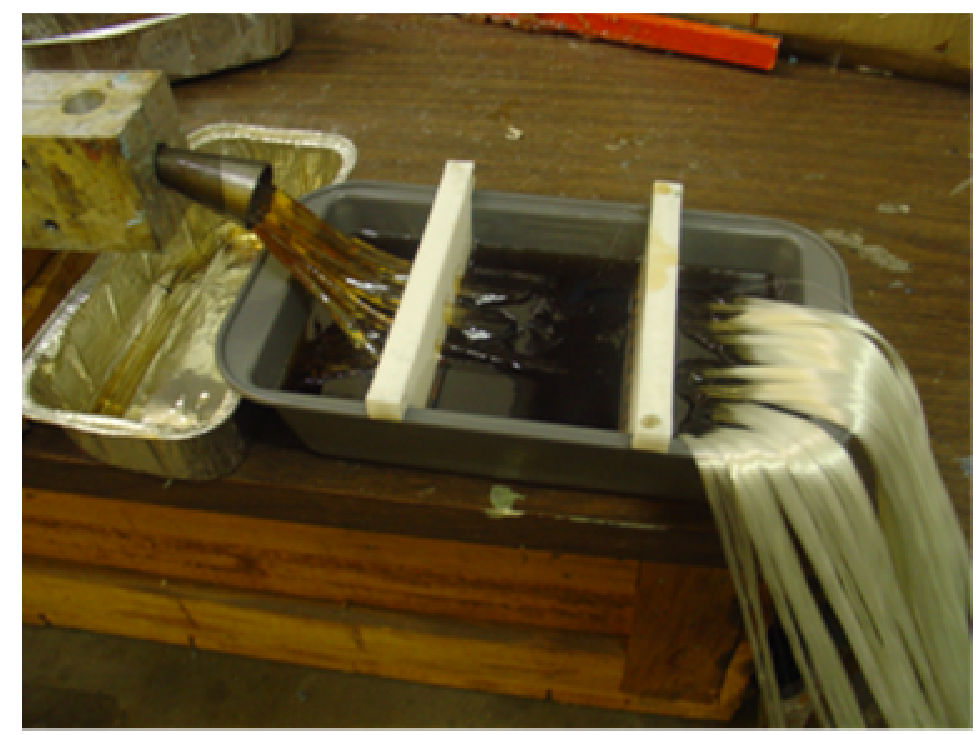

Figure 4-11 Fibers passing through resin bath into the mold

\subsection{EQUIPMENTS AND ACCESSORIES FOR TESTING AND AGING}

\subsubsection{UNIVERSAL TESTING MACHINE}

Testing of specimens were carried out with the help of Universal Testing Machine (UTM), also called as Baldwin machine, having a maximum load capacity of 200 kips. Tension, pullout, and shear tests were conducted with the help of UTM by using suitable fixtures.

The UTM consisted of three loading scales and the lower scale of capacity 10 kips was used for shear and bond test and medium scale of capacity 50 kips was used for tension tests. The Baldwin machine provided direct electrical signal outlet to automatically record load from the machine through data acquisition system. Using a manual-loading wheel, speed of loading was controlled.

\subsubsection{DATA ACQUISITION, STRAIN GAGE, AND LVDT}

System 5000-scanner 5100 data acquisition manufactured by Vishay Micromeasurements was used for tension, bond, and flexure test to record the values from UTM, strain from strain gage, and deflection from LVDT (Linear Variable Displacement Transducers). 
To facilitate the placement of strain gage GFRP bar was minimally grinded at the center of the bar. Grinding was carried out carefully to prevent damage to glass fibers. Strain gage of $350 \Omega$ resistance was attached to the bar surface using M-bond to determine Young's Modulus of the bars. Soldering was carried out and strain gage was attached to data acquisition system. Strain gage was used for tension test to record the strain value and to plot the stress-strain curve.

Calibrated LVDTs were used during bond tests to measure the slip in the bar and to plot load-slip curve. LVDTs were used to record global displacements in beams by attaching them to high level card of the data acquisition system.

\section{Data Acquisition System}

The data acquisition system had strain gage cards and high-level cards. Depending on the data to be collected, appropriate cards were used. The data was interpreted using the STRIANSMART software. The recorded readings could be exported into Excel files by the software. The data acquisition system is capable of being connected to 20 channels. Usually 3 strain gage cards and 1 high-level card were used during testing. The channels detected strain gages, load cells and LVDT's during testing. Some of the features of the data acquisition systems are:

- Inputs accepted from strain gages, strain gage based transducers, LVDT's, thermocouples, and sensors with high-level outputs

- Stable, accurate, low-noise signal conditioning

- Scanning and recording intervals as short as 0.1 second for up to 1,200 inputs

- Built-in bridge completion for 120,350, and 1,000 Ohm strain gages

- Availability of ISA (Windows 3.1 or 95) and/or PCMCIA (Windows 95) hardware interfaces

\subsubsection{GRIPS}

Schedule 80 steel pipes were used as grips for tension test and bond test (Figure 4-12 \& 4-13). Split pipes of 8 in. ( $1 / 2$ in. diameter) and 10 in. ( $3 / 4$ in. diameter) length were used as grips and attached to $1 / 2$ in. and $3 / 4$ in. bars, respectively using Pliogrip ${ }^{\mathrm{TM}}$. Grips were 
fastened to test specimens (GFRP bars) using C-clamps and cured for 24 hrs. GFRP bar after bonding the grips at one of the ends shown in Figure 4-14.

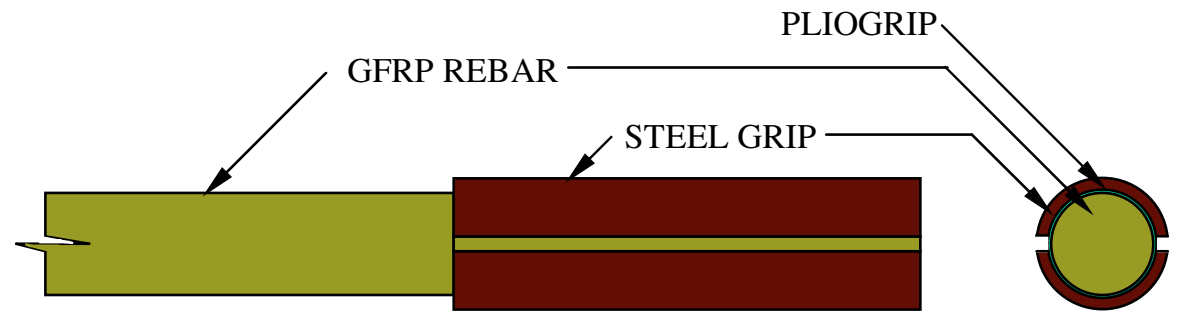

Figure 4-12 Schematic diagram showing bar attached with grips

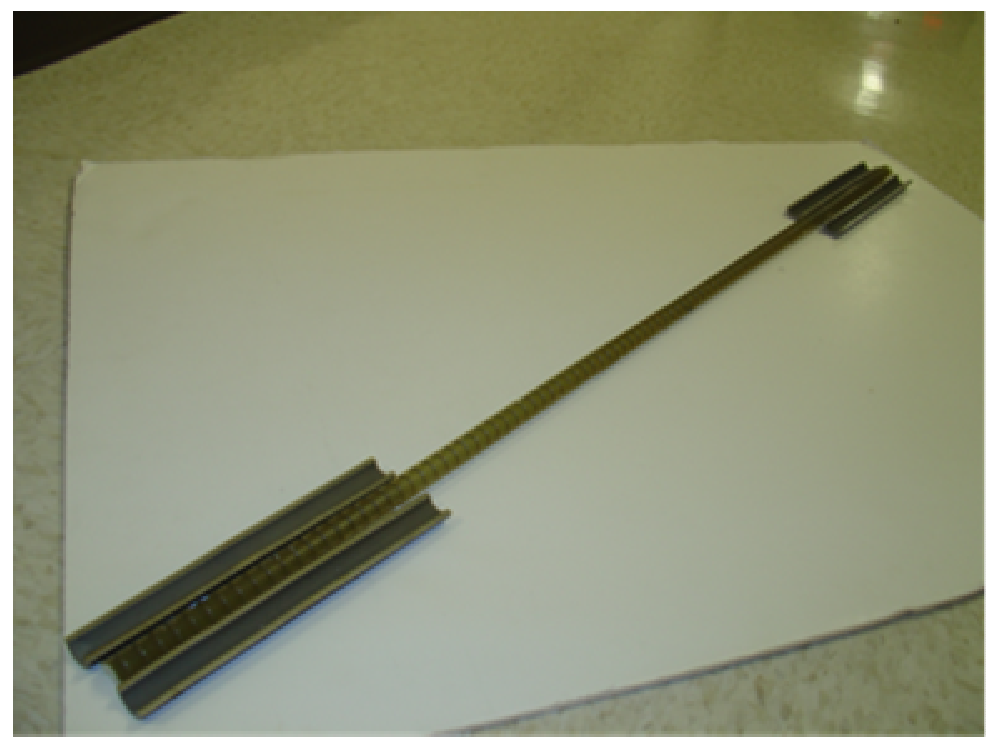

Figure 4-13 GFRP bar and grips

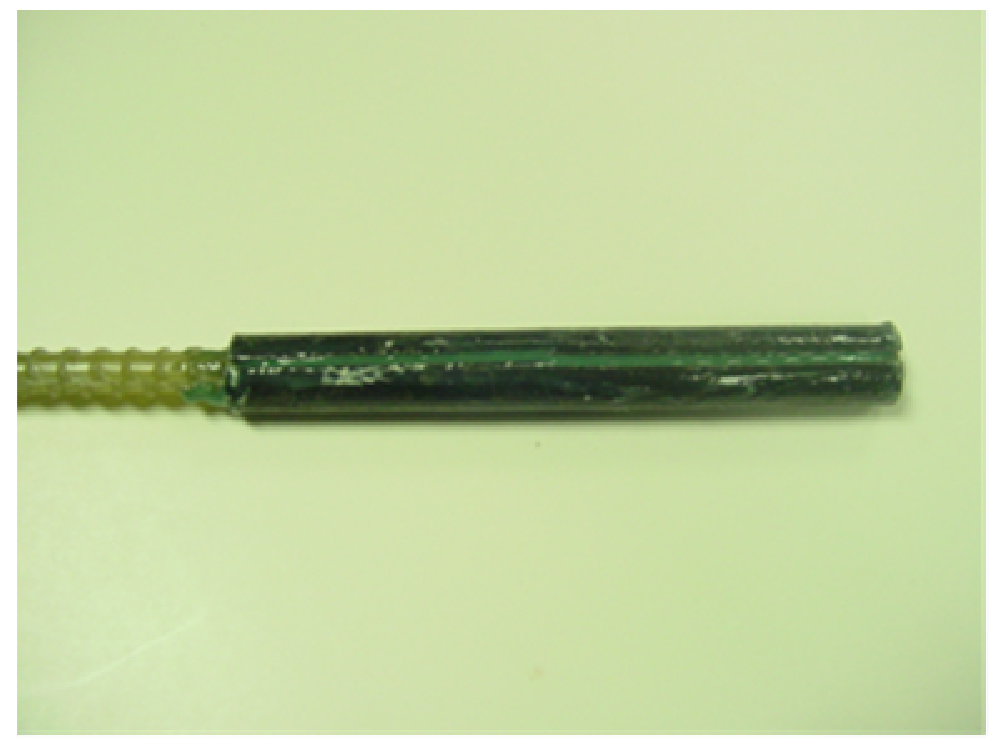

Figure 4-14 GFRP bar attached with steel grips 


\subsubsection{ELEVATED TEMPERATURE BATH}

Accelerated aging of specimens at elevated temperature was achieved by immersing the specimens in an epoxy paint coated steel tanks filled with water which was maintained at temperatures of $110^{\circ} \mathrm{F}$ and $140^{\circ} \mathrm{F}$ (Figure 4-15). The tanks were heated using thermostats and the temperature was maintained by covering the tanks with heat resistance covers.

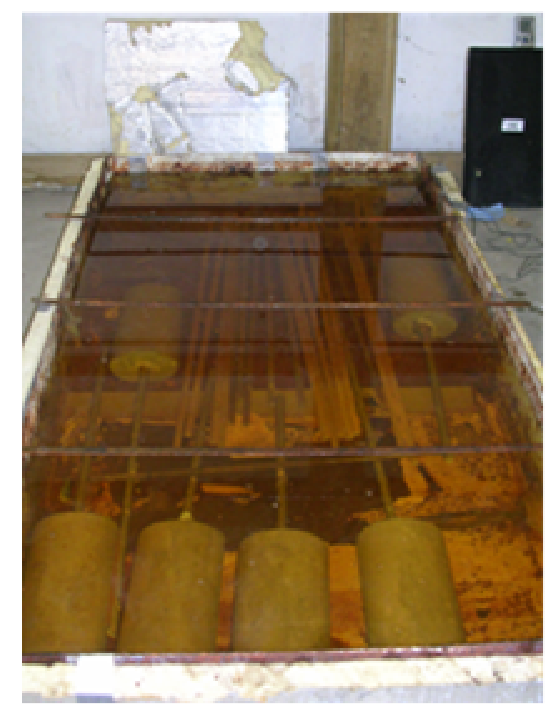

Figure 4-15 GFRP bars aging in elevated temperature $\left(140^{\circ} \mathrm{F}\right)$

\subsubsection{ALKALINE SOLUTION AGING}

Alkaline solution ( $\mathrm{pH} 12.5$ to 13 ) was used for aging the specimens in a plastic water tank. Alkaline solution consisted of $0.2 \%$ calcium hydroxide, $1.4 \%$ potassium hydroxide, $1 \%$ sodium hydroxide, and $97.4 \%$ water (Figure 4-16). Aged bars were subjected to tension, shear, and bond (not without nanoclay) tests. SEM images of the aged bars were taken and evaluated for any reduction in the glass fiber diameter due to alkaline reaction. 


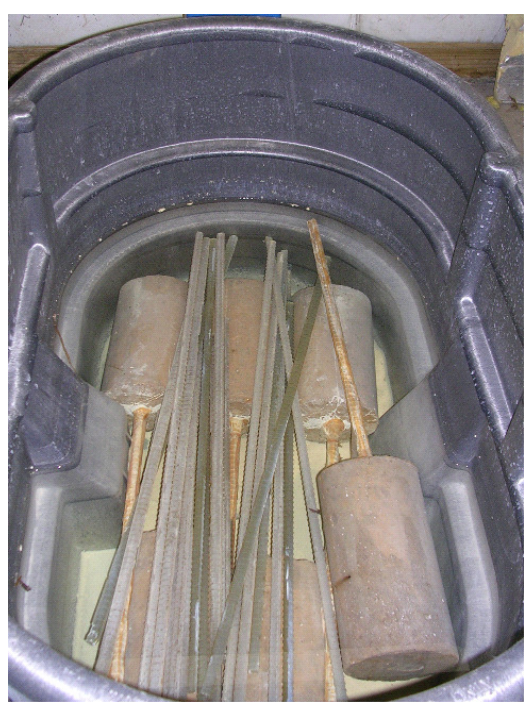

Figure 4-16 GFRP bars aging in Alkaline solution

\subsection{MATERIALS FOR CASTING CONCRETE BEAM}

Beams were cast with Class K concrete conforming to the WVDOT-DOH specification, GFRP bars with and without nanoclay were used as tension reinforcement and \#3 steel bars were used as compression and shear reinforcement. Plain concrete cylinders were simultaneously cast to obtain concrete compressive strength $\left(f_{c}{ }^{\prime}\right)$.

\subsubsection{CONCRETE}

Class K ready-mixed concrete was used for casting beams, which was supplied by Hoy REDI-MIX Company, Morgantown, WV. Compressive strength of concrete was 5000 psi and 3500 psi for $10 \mathrm{ft}$. and $5 \mathrm{ft}$. long beams, respectively. Curing of beams and cylinders was carried out using wet burlaps for 28 days.

\subsubsection{STEEL BARS}

Deformed rebars of \#3 size were used as compression and shear reinforcements for the beams. Stirrups were manufactured at CFC-WVU by bending \#3 bars in a bar bending assembly. Uniform stirrups spacing of 6 in. was maintained in all the beams. Two \#3 rebars were used at the top (compression zone) to support the stirrups. GFRP bars and stirrups were tied together using steel binding wires. 


\subsubsection{FORMWORK}

Figures 4-17 and 4-18 show wood formworks built at CFC-WVU for casting concrete beams of size 5 in. $x 8$ in. $x 60$ in. and 8 in. $x 16$ in. $x 120$ in., respectively. All the sides of the forms were sealed with silicon gel to prevent water loss from the concrete. Inside walls of wood formworks were oiled to facilitate easy demolding of concrete beams. GFRP rebars were positioned in the formwork by using rebar chair to obtain proper rebar cover and placement.

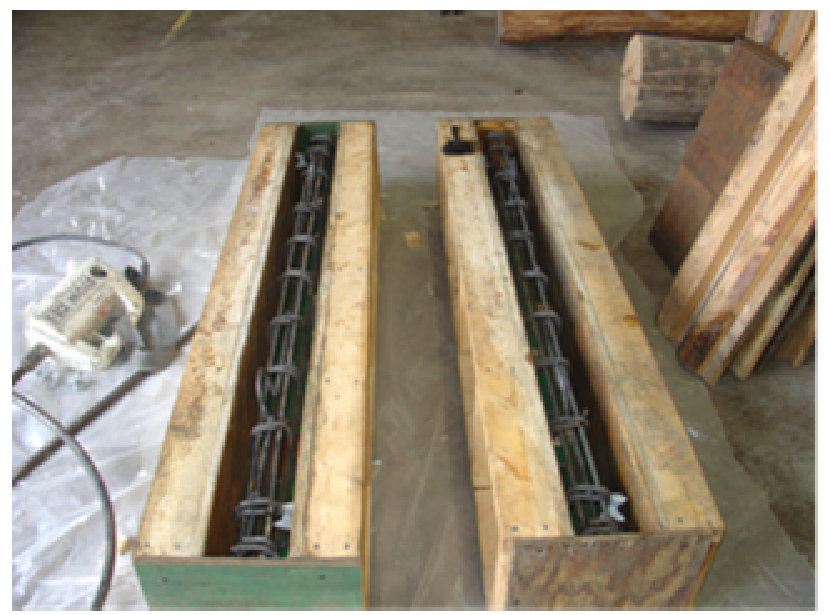

Figure 4-17 Formwork and reinforcement for 5 in. $x 8$ in. $x 60$ in. beam

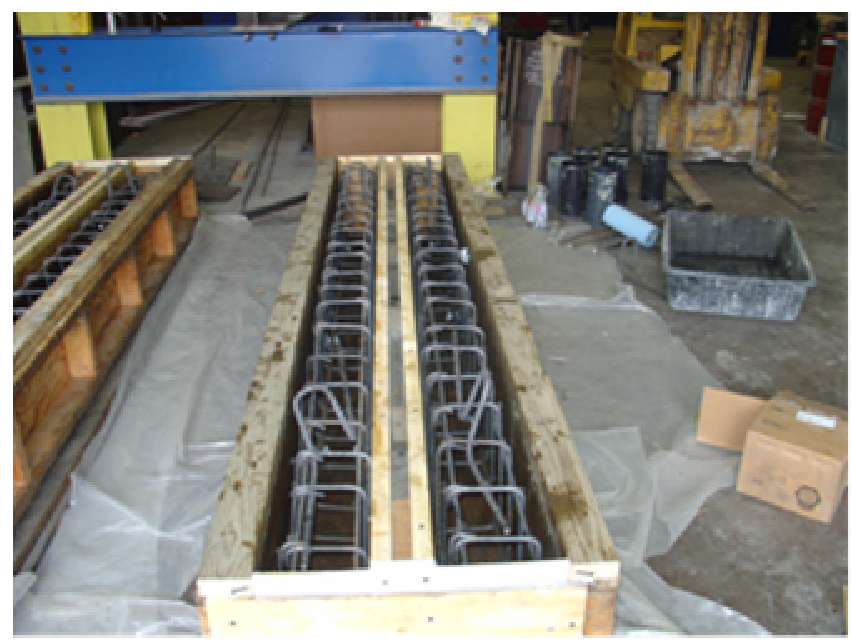

Figure 4-18 Formwork and reinforcement for 8 in. $x 16$ in. $x 120$ in. beam 


\section{TENSION TESTS}

\subsection{INTRODUCTION}

Axial tension tests were conducted on GFRP bars with and without nanoclay subjected to different aging schemes. Tension test procedure and analytical calculations used in this study are described in Section 5.2. Schematic diagram of a tension test specimen is shown in Figure 5-1. GFRP bars were bonded with steel grips on both ends using a commercially available resin called Pliogrip ${ }^{\mathrm{TM}}$. Grips consisted of schedule 80 steel pipes that were split along the length in half. Internal diameter of the grips was same as the external diameter of the bar to be tested. A minimum of 24 hours curing time was allowed for the Pliogrip resin to cure before the specimens were tested with the help of a Universal Testing Machine (UTM). Length of the grips was based on the diameter of the bars tested as shown in Table 5-2. GFRP tension test specimens were subjected to 3 months, 6 months, and 9 months aging in water at room temperature, water at $110^{\circ} \mathrm{F}$, water at $140^{\circ} \mathrm{F}$, and alkaline solution at room temperature (Table 5-1).
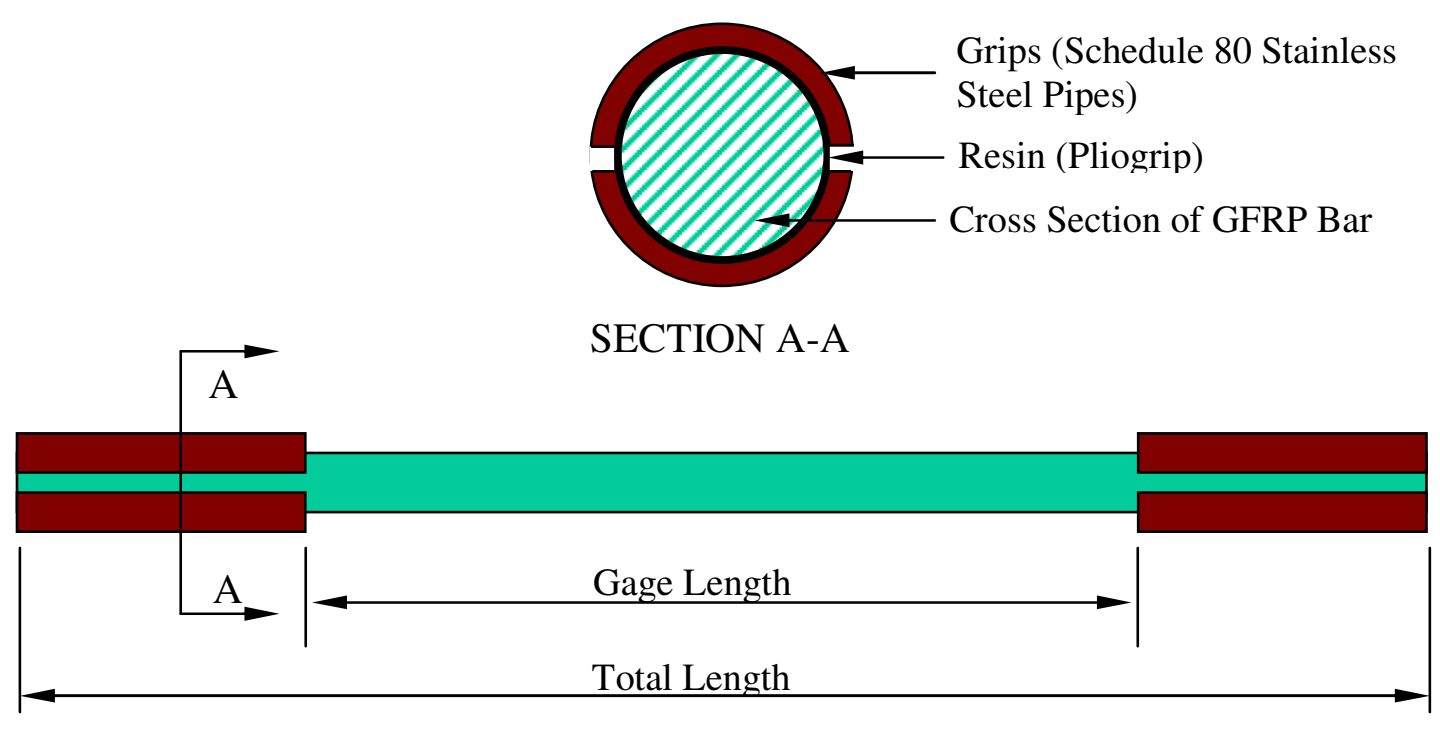

Figure 5-1 Schematic Diagram of a Tension Test Specimen 
Table 5-1 Number and aging schemes of GFRP bars tested in tension

\begin{tabular}{|c|c|c|c|c|c|c|}
\hline \multirow[b]{2}{*}{ Aging schemes } & \multirow{2}{*}{$\begin{array}{l}\text { Bar } \\
\text { size }\end{array}$} & \multirow[b]{2}{*}{ Nanoclay } & \multicolumn{4}{|c|}{ Number of specimens } \\
\hline & & & $\begin{array}{c}\text { Without } \\
\text { aging }\end{array}$ & $\begin{array}{c}3 \text { months } \\
\text { aging }\end{array}$ & $\begin{array}{c}6 \text { months } \\
\text { aging }\end{array}$ & $\begin{array}{c}9 \text { months } \\
\text { aging } \\
\end{array}$ \\
\hline \multirow{4}{*}{ Non-aged } & \multirow{2}{*}{$\# 4$} & Yes & 3 & - & - & - \\
\hline & & No & 3 & - & - & - \\
\hline & \multirow{2}{*}{ \#6 } & Yes* & 2 & - & - & - \\
\hline & & Yes & 2 & - & - & - \\
\hline \multirow{4}{*}{$\begin{array}{l}\text { Extracted from } \\
\text { concrete beams }\end{array}$} & \multirow{2}{*}{$\# 4$} & Yes & 2 & - & - & - \\
\hline & & No & 3 & - & - & - \\
\hline & \multirow{2}{*}{$\# 6$} & Yes* & 1 & - & - & - \\
\hline & & $\mathrm{No}^{*}$ & 1 & - & - & - \\
\hline \multirow{2}{*}{ Water/RT } & \multirow{7}{*}{$\# 4$} & Yes & - & 3 & 3 & 3 \\
\hline & & No & - & 2 & 2 & 2 \\
\hline Water at $110^{\circ} \mathrm{F}$ & & Yes & - & 3 & 3 & 3 \\
\hline \multirow{2}{*}{ Water at $140^{\circ} \mathrm{F}$} & & Yes & - & 3 & 3 & 3 \\
\hline & & No & - & 2 & 2 & 2 \\
\hline \multirow{2}{*}{$\begin{array}{c}\text { Alkaline } \\
\text { solution/RT }\end{array}$} & & Yes & - & 3 & 3 & 3 \\
\hline & & No & - & 2 & 2 & 2 \\
\hline
\end{tabular}

*GFRP bars manufactured with 56 yield glass fiber rovings. Rest of the bars were manufactured with 113 Yield glass fiber rovings.

\subsection{DEVELOPMENT OF THE TEST}

This test method was used from the previous research carried out by the CFC-WVU. Additional details can be obtained from the reference Vijay et al, 2003.

\subsubsection{REFERENCE DOCUMENTS}

(a).Japan Society of Civil Engineers (JSCE) 1997. Recommendation for design and construction of concrete structures using continuous fiber reinforced materials, concrete engineering series 23, Ed. A. Machida, Research committee on continuous fiber reinforced materials, Tokyo, Japan, PP.

(b).ASTM D 3916-02: Standard Test Method for Tensile Properties of Pultruded Glass Fiber Reinforced Plastic Rod. 


\subsubsection{TERMINOLOGY}

1. Test section: The portion of a specimen to be tested between the anchoring sections of the test specimen.

2. Grip length (anchoring section): The end part of the test specimen where an anchorage is fitted to transmit the load from the testing machine to the test section.

3. Gage length: The distance between two gage points on the test section providing a reference length to the specimen.

4. Anchorage: Device fitted to the anchoring section of a test specimen to transmit loads from the testing machine to the test specimen.

5. Tensile capacity: The tensile load at the failure of the test specimen.

\subsubsection{SPECIMEN PREPARATION}

\section{(a). Preparation:}

i. Non-aged: Care was taken so that the specimen was not subjected to any processing. During the sampling and preparation of test specimens, all deformation, heating, outdoor exposure to ultraviolet light etc., causing changes to the material properties of the test specimen was avoided.

ii. Aged: Specimens were aged in water at room temperature, water at $110^{\circ} \mathrm{F}$, water at $140^{\circ} \mathrm{F}$, and alkaline solution at room temperature for 3,6 , and 9 months.

(b).Test section length and Grip length: A test section length of 40 times the diameter was used with a grip length of 8 in. for \# 4 bars and 10 in. for \# 6 bars on each side (Table 5-2).

Table 5-2 Length of steel grips used for tension test

\begin{tabular}{|c|c|c|}
\hline $\begin{array}{c}\text { Diameter of the } \\
\text { test specimen (in) }\end{array}$ & $\begin{array}{c}\text { Test section } \\
\text { length (in) }\end{array}$ & $\begin{array}{c}\text { Length of steel } \\
\text { grip } \\
\text { (in) }\end{array}$ \\
\hline $0.50(\# 4)$ & 20 & 8 \\
\hline $0.75(\# 6)$ & 30 & 10 \\
\hline
\end{tabular}


(c). Anchorages (Grips): Steel pipes of appropriate diameter and length (as mentioned above) were split and bonded to each end of the FRP rebar using Pliogrip ${ }^{\mathrm{TM}}$, a commercially available resin. The resin was allowed to cure for a minimum of 24 hours, before the specimens were tested.

(d). Number of specimens: Number of specimens tested depends upon the availability of the specimens.

\subsubsection{TEST EQUIPMENT}

The tension specimens were tested on Universal Testing Machine (UTM) with a maximum load capacity of 200 kips. A computerized data acquisition was used to record the load and strain data.

\subsubsection{TEST METHOD}

(a). Strain gage: In order to determine the Young's modulus of the test specimen, a strain gage was mounted in the center of the test section in the direction of tension (Figure $5-2)$.

(b).Mounting: When mounting the test specimen on the testing machine, care was taken to ensure that the longer axis of the test specimen coincides with imaginary line joining the two end anchors fitted to the testing machine (Figures 5-3 \& 5-4).

(c). Loading rate: The applied rate of loading for the tension test specimen was between 15-70 ksi per minute.

(d). Testing temperature: The test temperature was generally with the range of $40-100^{\circ} \mathrm{F}$.

(e).Loading: The load was applied and recorded until failure and strain gage measurements were recorded until the strain gage was intact.

\subsubsection{CALCULATION}

The material properties of GFRP bar were assessed only on the basis of the test specimen undergoing failure in the test section. In cases where there was tensile failure or slippage in anchoring section, the data was disregarded and/or additional tests were performed. (a). Tensile stress, $\sigma$ : The tensile stress was calculated according to Eq. (5.1) 


$$
\sigma=\frac{F}{A}
$$

Where,

$\sigma=$ Tensile stress (ksi)

$\mathrm{F}=$ Load at which the stress is being calculated (kips)

$A=$ Cross sectional area of test specimen (in. ${ }^{2}$ ) - based on the die diameter

(b). Strain, $\varepsilon$ : The load and the corresponding strain were automatically recorded from the strain gage to a data acquisition system.

(c). Stiffness, E (Young's Modulus): The stresses calculated from Eq. 5.1 and the corresponding strains were then plotted to get the stress-strain curve. A typical stressstrain plot is shown in Figure 5-5, with stress on the y-axis and strain on the x-axis. Stress-strain curves were linear for GFRP bars with and without nanoclay. The slope of this curve gives the stiffness of the test specimen. The data points used for the calculation of the stiffness were between $20 \%$ to $60 \%$ of the tensile capacity of the specimen.

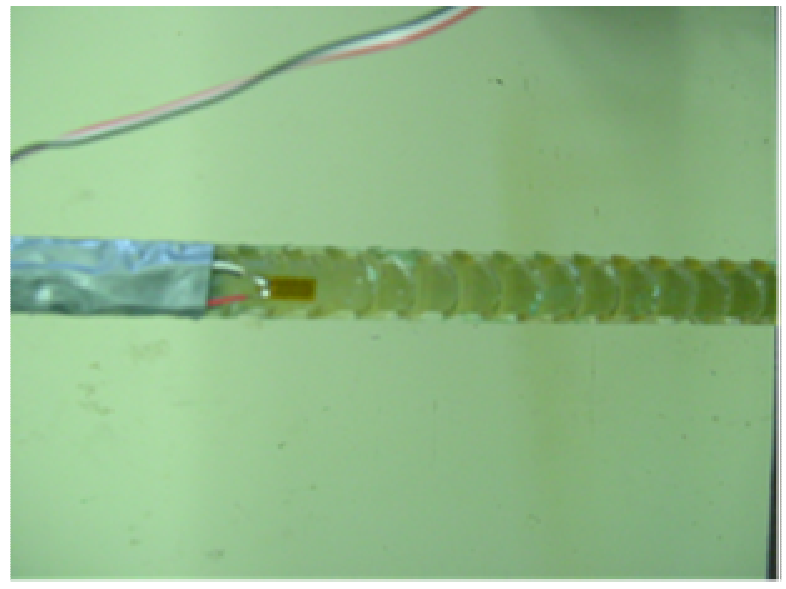

Figure 5-2 GFRP bar fixed with strain gage 


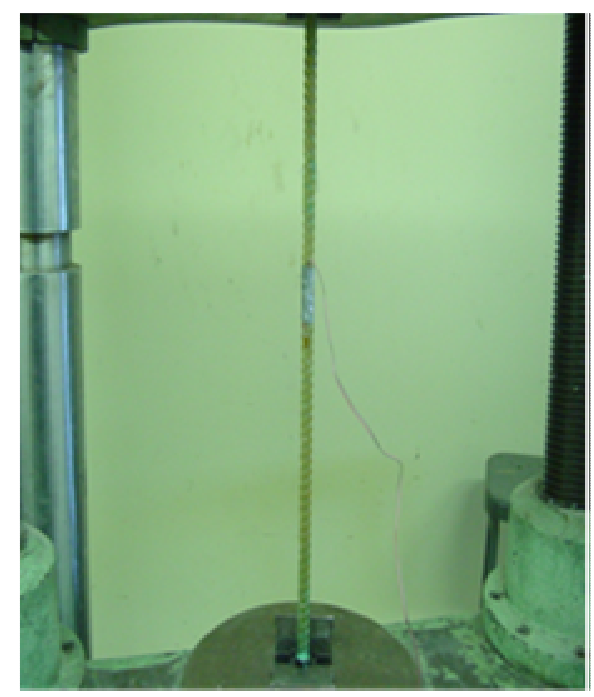

Figure 5-3 Tension test setup using UTM

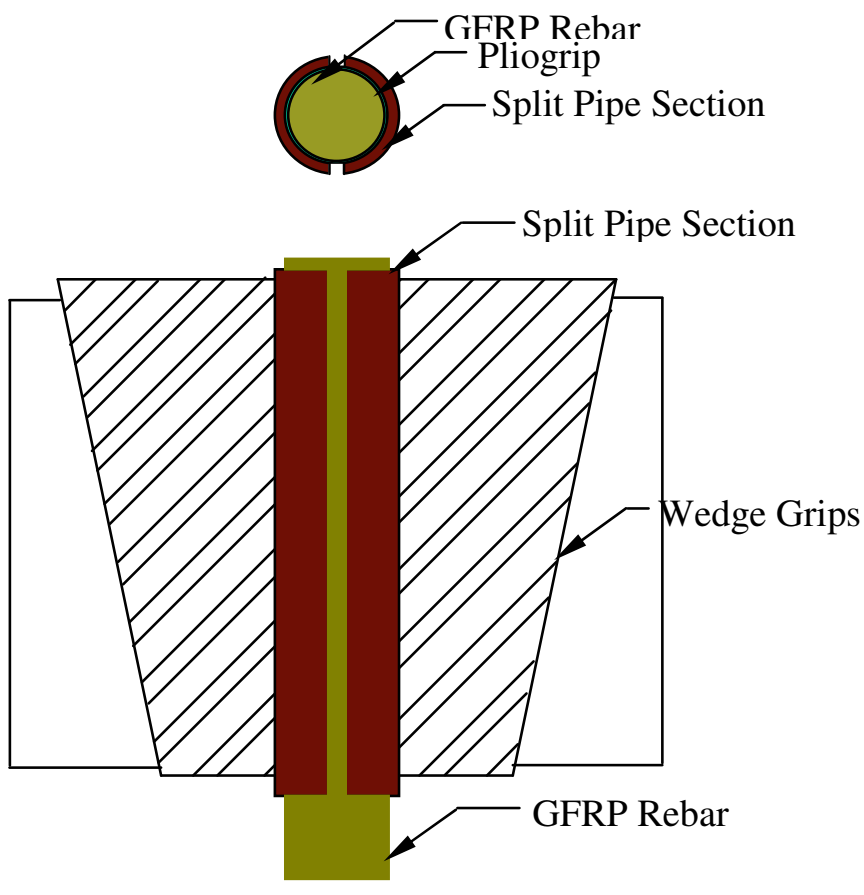

Figure 5-4 Diagram showing GFRP bar held between wedge grips of UTM 


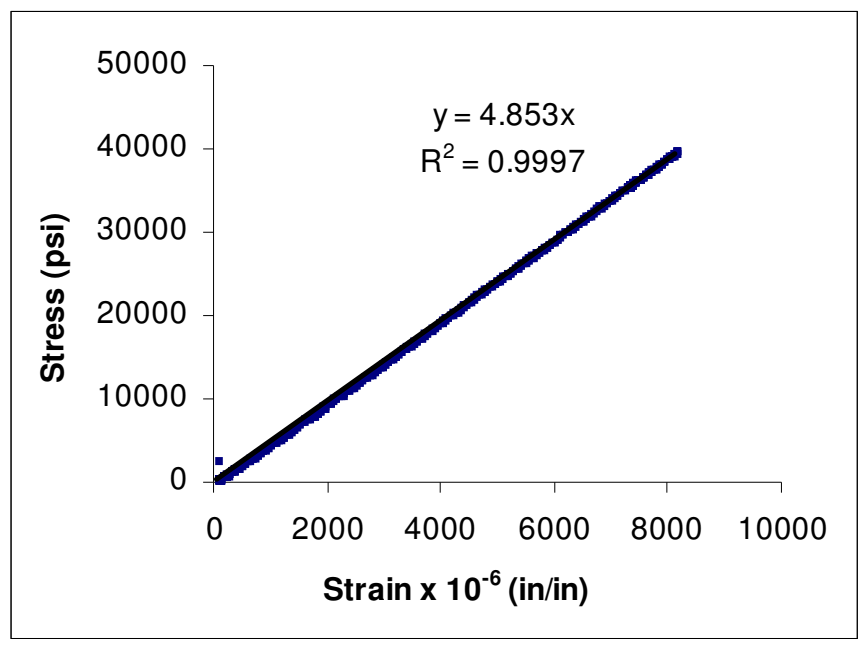

Figure 5-5 Typical stress-strain plot from a tension test of GFRP bar

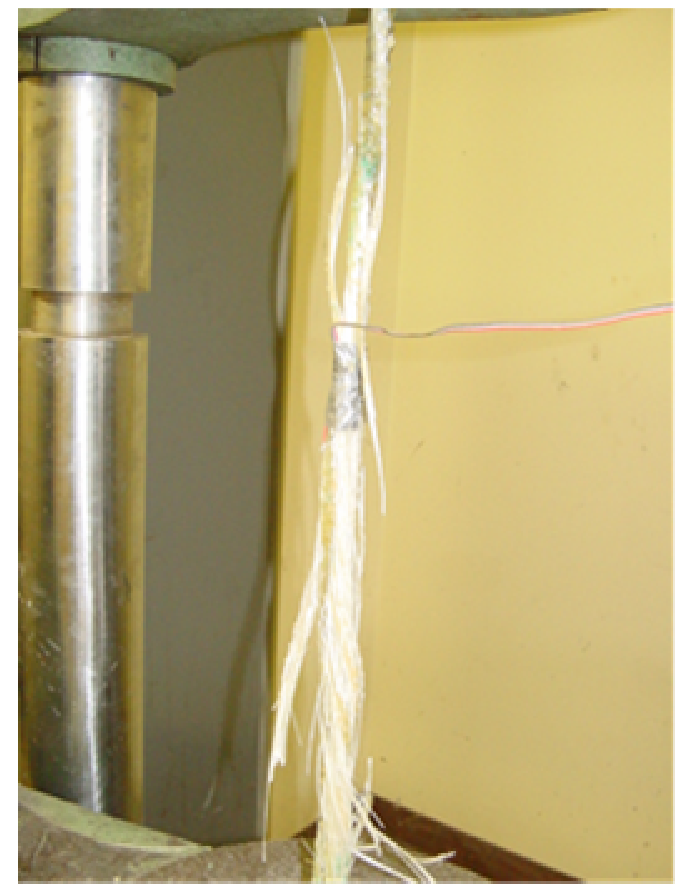

Figure 5-6 GFRP bar after testing 


\subsection{TEST RESULTS}

\subsubsection{TENSION- NO AGING}

\section{Test and Specimen Details}

- Aging - No aging

- Diameter of the bars tested - 0.5 in. (\#4) \& 0.75 in. (\#6)

- Length of the specimens - 36 in. (\#4) \& 50 in. (\#6)

- Grip length on each end - 8 in. (\#4) \& $10 \mathrm{in.} \mathrm{( \# 6)}$

- Number of specimens tested - 8

- Strains were measured at the center of the specimen using a strain gage

- Stiffness values were calculated using stress-strain plots

\section{Test Results}

Table 5-3 Summary of test results of \#4 and \#6 bars with and without nanoclay subjected to no aging

\begin{tabular}{|c|c|c|c|c|c|}
\hline \multirow{2}{*}{$\begin{array}{c}\text { No of } \\
\text { months } \\
\text { in } \\
\text { aging }\end{array}$} & \multirow{2}{*}{ Bar size } & \multicolumn{2}{|c|}{$\begin{array}{l}\text { Average maximum stress } \\
\qquad(\mathrm{ksi})\end{array}$} & \multicolumn{2}{|c|}{$\begin{array}{l}\text { Average stiffness } \\
\qquad(\mathrm{msi})\end{array}$} \\
\hline & & $\begin{array}{l}\text { Without } \\
\text { nanoclay }\end{array}$ & $\begin{array}{c}\text { With } \\
\text { nanoclay }\end{array}$ & $\begin{array}{l}\text { Without } \\
\text { nanoclay }\end{array}$ & $\begin{array}{c}\text { With } \\
\text { nanoclay }\end{array}$ \\
\hline \multirow{3}{*}{0} & $\# 4$ & $\begin{array}{c}130.76 \pm 2.55 \\
(1.95 \%)\end{array}$ & $\begin{array}{c}91.48 \pm 4.17 \\
(4.55 \%)\end{array}$ & $\begin{array}{c}4.49 \pm 0.15 \\
(3.43 \%)\end{array}$ & $\begin{array}{c}4.68 \pm 0.25 \\
(5.37 \%)\end{array}$ \\
\hline & $\# 6^{*}$ & - & $\begin{array}{c}81.42 \pm 10.55 \\
(12.96 \%)\end{array}$ & - & $\begin{array}{c}4.84 \pm 0.42 \\
(8.63 \%)\end{array}$ \\
\hline & \#6 & - & $\begin{array}{c}81.83 \pm 10.80 \\
(13.20 \%)\end{array}$ & - & $\begin{array}{c}4.80 \pm 0.50 \\
(10.31 \%)\end{array}$ \\
\hline
\end{tabular}

*\#6 GFRP bars manufactured with 56 yield glass fiber rovings. Rest of the bars were manufactured with 113 Yield glass fiber rovings.

(Values in parenthesis indicate standard deviations as a percentage of the average value)

\section{Discussion of Test Results}

\section{\#4 Bars With and Without Nanoclay}

Average Tensile Stress

- Without nanoclay $=130.76 \pm 2.55 \mathrm{ksi}$ (Std. dev. was $1.95 \%$ of avg. value $)$

- With nanoclay $=91.48 \pm 4.17 \mathrm{ksi}$ (Std. dev. was $4.55 \%$ of avg. value) 


\section{Average Stiffness}

- Without nanoclay $=4.49 \pm 0.15 \mathrm{msi}$ (Std. dev. was $3.43 \%$ of avg. value)

- With nanoclay $=4.68 \pm 0.25 \mathrm{msi}$ (Std. dev. was $5.37 \%$ of avg. value)

Failure mode - All specimens failed at the center. The failure was initiated with the splitting of fibers in the outer layer. At the end of the test, the fibers split at the center (Figure 5-6).

$>$ Comparison of Stress - \#4 bars with nanoclay showed 30.04\% lower average stress as compared to \#4 bars without nanoclay (91.48 ksi vs. $130.76 \mathrm{ksi}$ ), which suggested that addition of nanoclay decreased the stress distribution, in turn reducing the stress. Strength reduction is also attributed to an increase in resins viscosity by nanoclay exfoliation, possibility of micro voids, and possible damage to glass fiber surface during manual pulling of fibers. In addition, nanoclay may have resulted in reduction of bond strength between fibers and resin due to additional interface.

Comparison of Stiffness - \#4 bars with nanoclay showed 5.12\% higher average stiffness as compared to \#4 bars without nanoclay (4.68 msi vs. $4.49 \mathrm{msi}$ ), which suggested that addition of nanoclay provided a small increase in stiffness.

\section{\#6 Bars with Nanoclay}

\section{Average Tensile Stress}

- With nanoclay $(56$ Yield $)=81.42 \pm 10.55 \mathrm{ksi}$ (Std. dev. was $12.96 \%$ of avg. value $)$

- With nanoclay $(113$ Yield $)=81.83 \pm 10.80 \mathrm{ksi}$ (Std. dev. was $13.20 \%$ of avg. value $)$

\section{Average Stiffness}

- With nanoclay $(56$ Yield $)=4.84 \pm 0.42 \mathrm{msi}$ (Std. dev. was $8.63 \%$ of avg. value $)$

- With nanoclay $(113$ Yield $)=4.80 \pm 0.50 \mathrm{msi}$ (Std. dev. was $10.31 \%$ of avg. value)

\section{Comparison of Stress}

- \#6 bars with nanoclay showed 11\% lower average stress as compared to \#4 bars with nanoclay (81.42 ksi vs. $91.48 \mathrm{ksi}$ ). This was due to shear lag phenomenon in larger diameter bars as compared to smaller bars, where outer core fibers carry higher stress compared to inner fibers.

- \#6 GFRP bars with nanoclay manufactured with 113 Yields showed $0.5 \%$ higher strength than in case of \#6 bars with nanoclay manufactured with 56 Yield 
rovings ( $81.83 \mathrm{ksi}$ vs. $81.42 \mathrm{ksi}$ ). From the results obtained, no strength difference in bars manufactured with 56 and 113 Yield glass fiber rovings was observed.

Comparison of Stiffness - \#6 bars with nanoclay showed 3.42\% higher average stiffness as compared to \#4 bars with nanoclay (4.84 msi vs. $4.68 \mathrm{msi}$ ).

$>$ Higher standard deviation (12.96\% vs. $4.55 \%)$ was noted in larger diameter bars, which is attributed to manual pultrusion process employed in pulling the fibers and difficulty in maintaining the fiber alignment during pulling.

\subsubsection{TENSION- WATER AT RT, $110^{\circ} \mathrm{F}$, AND $140^{\circ} \mathrm{F}$ AGING}

\section{Test and Specimen Details}

- Aging - Water at room temperature (RT), water at $110^{\circ} \mathrm{F}$, and water at $140^{\circ} \mathrm{F}$ for 3,6 , and 9 months

- Diameter of the bars tested - 0.5 in. (\#4)

- Length of the specimens - $36 \mathrm{in}$.

- Grip length on each end - 8 in.

- Number of specimens tested-39

- Strains were measured at the center of the specimen using a strain gage

- Stiffness values were calculated using stress-strain plots 


\section{Test Results}

Table 5-4 Summary of test results of \#4 bars with and without nanoclay aged in water at RT for 3, 6, and 9 months

\begin{tabular}{|c|c|c|c|c|}
\hline \multirow{2}{*}{$\begin{array}{c}\text { No of } \\
\text { months }\end{array}$} & \multicolumn{2}{|c|}{$\begin{array}{c}\text { Average maximum stress } \\
\text { (ksi) }\end{array}$} & \multicolumn{2}{c|}{ Average maximum stiffness } \\
in aging & Without & With & Without & With \\
& nanoclay & nanoclay & nanoclay & nanoclay \\
\hline \multirow{2}{*}{0} & $130.76 \pm 2.55$ & $91.48 \pm 4.17$ & $4.49 \pm 0.15$ & $4.68 \pm 0.25$ \\
& $(1.95 \%)$ & $(4.55 \%)$ & $(3.43 \%)$ & $(5.37 \%)$ \\
\hline 3 & $114.24 \pm 0.28$ & $89.24 \pm 11.69$ & $4.76 \pm 0.12$ & $4.85 \pm 0.11$ \\
& $(0.25 \%)$ & $(13.09 \%)$ & $(2.52 \%)$ & $(2.23 \%)$ \\
\hline \multirow{2}{*}{6} & $111.46 \pm 7.32$ & $87.06 \pm 11.25$ & $4.95 \pm 0.01$ & $4.71 \pm 0.05$ \\
& $(6.57 \%)$ & $(12.92 \%)$ & $(0.14 \%)$ & $(0.98 \%)$ \\
\hline 9 & $115.35 \pm 0.17$ & $90.70 \pm 12.78$ & $4.91 \pm 0.13$ & $4.87 \pm 0.18$ \\
& $(0.15 \%)$ & $(13.43 \%)$ & $(2.59 \%)$ & $(3.74 \%)$ \\
\hline
\end{tabular}

(Values in parenthesis indicate standard deviations as a percentage of the average value)

Table 5-5 Summary of test results of \#4 bars with and without nanoclay aged in water at $110^{\circ} \mathrm{F}$ for 3,6 , and 9 months

\begin{tabular}{|c|c|c|c|c|}
\hline \multirow{2}{*}{$\begin{array}{c}\text { No of } \\
\text { months } \\
\text { in aging }\end{array}$} & \multicolumn{2}{|c|}{$\begin{array}{c}\text { Average maximum stress } \\
\qquad(\mathbf{k s i})\end{array}$} & \multicolumn{2}{|c|}{$\begin{array}{l}\text { Average maximum stiffness } \\
\text { (msi) }\end{array}$} \\
\hline & $\begin{array}{l}\text { Without } \\
\text { nanoclay }\end{array}$ & $\begin{array}{c}\text { With } \\
\text { nanoclay }\end{array}$ & $\begin{array}{l}\text { Without } \\
\text { nanoclay }\end{array}$ & $\begin{array}{c}\text { With } \\
\text { nanoclay }\end{array}$ \\
\hline 0 & $\begin{array}{c}130.76 \pm 2.55 \\
(1.95 \%)\end{array}$ & $\begin{array}{c}91.48 \pm 4.17 \\
(4.55 \%)\end{array}$ & $\begin{array}{c}4.49 \pm 0.15 \\
(3.43 \%)\end{array}$ & $\begin{array}{c}4.68 \pm 0.25 \\
(5.37 \%)\end{array}$ \\
\hline 3 & - & $\begin{array}{c}76.34 \pm 8.93 \\
(11.70 \%)\end{array}$ & - & $\begin{array}{c}4.67 \pm 0.40 \\
(8.54 \%)\end{array}$ \\
\hline 6 & - & $\begin{array}{c}74.96 \pm 6.71 \\
(8.95 \%)\end{array}$ & - & $\begin{array}{c}4.96 \pm 0.19 \\
(3.81 \%)\end{array}$ \\
\hline 9 & - & $\begin{array}{c}76.33 \pm 20.27 \\
(26.55 \%)\end{array}$ & - & $\begin{array}{c}4.91 \pm 0.06 \\
(1.13 \%)\end{array}$ \\
\hline
\end{tabular}

(Values in parenthesis indicate standard deviations as a percentage of the average value) 
Table 5-6 Summary of test results of \#4 bars with and without nanoclay aged in water at $140^{\circ} \mathrm{F}$ for 3,6 , and 9 months

\begin{tabular}{|c|c|c|c|c|}
\hline \multirow{2}{*}{$\begin{array}{c}\text { No of } \\
\text { months }\end{array}$} & \multicolumn{2}{|c|}{$\begin{array}{c}\text { Average maximum stress } \\
\text { (ksi) }\end{array}$} & \multicolumn{2}{c|}{ Average maximum stiffness } \\
in aging & Without & With & Without & With \\
& nanoclay & nanoclay & nanoclay & nanoclay \\
\hline \multirow{2}{*}{0} & $130.76 \pm 2.55$ & $91.48 \pm 4.17$ & $4.49 \pm 0.15$ & $4.68 \pm 0.25$ \\
& $(1.95 \%)$ & $(4.55 \%)$ & $(3.43 \%)$ & $(5.37 \%)$ \\
\hline 3 & $98.09 \pm 4.05$ & $74.34 \pm 2.98$ & $4.83 \pm 0.23$ & $4.65 \pm 0.18$ \\
& $(4.13 \%)$ & $(4.01 \%)$ & $(4.68 \%)$ & $(3.85 \%)$ \\
\hline 6 & $91.27 \pm 4.72$ & $74.54 \pm 1.16$ & $4.80 \pm 0.23$ & $4.75 \pm 0.40$ \\
& $(5.17 \%)$ & $(1.55 \%)$ & $(4.87 \%)$ & $(8.44 \%)$ \\
\hline 9 & $83.02 \pm 1.78$ & $77.39 \pm 7.97$ & $4.84 \pm 0.11$ & $4.71 \pm 0.04$ \\
& $(2.15 \%)$ & $(10.30 \%)$ & $(2.34 \%)$ & $(0.77 \%)$ \\
\hline
\end{tabular}

(Values in parenthesis indicate standard deviations as a percentage of the average value)

\section{Discussion of Test Results}

\section{Average Tensile Stress for Non-Aged Bar}

- Without nanoclay $=130.76 \pm 2.55 \mathrm{ksi}$ (Std. dev. was $1.95 \%$ of avg. value $)$

- With nanoclay $=91.48 \pm 4.17 \mathrm{ksi}$ (Std. dev. was $4.55 \%$ of avg. value $)$

\section{Average Stiffness for Non-Aged Bar}

- Without nanoclay $=4.49 \pm 0.15$ msi (Std. dev. was $3.43 \%$ of avg. value)

- With nanoclay $=4.68 \pm 0.25 \mathrm{msi}$ (Std. dev. was $5.37 \%$ of avg. value)

Failure mode - All specimens with and without nanoclay after aging failed at the center. The failure was initiated with the splitting of fibers in the outer layer. At the end of the test, the fibers split at the center. 


\section{$\underline{\text { Bars with and without Nanoclay Aged in Water at RT up to } 9 \text { Months }}$}

\section{Average Tensile Stress}

- Without nanoclay $=115.35 \pm 0.17 \mathrm{ksi}$ (Std. dev. was $0.15 \%$ of avg. value)

- With nanoclay $=90.70 \pm 12.78 \mathrm{ksi}$ (Std. dev. was $13.43 \%$ of avg. value)

\section{$>$ Average Stiffness}

- Without nanoclay $=4.91 \pm 0.13 \mathrm{msi}$ (Std. dev. was $2.59 \%$ of avg. value)

- With nanoclay $=4.87 \pm 0.18 \mathrm{msi}$ (Std. dev. was $3.74 \%$ of avg. value)

$>$ Comparison of Stress - \#4 bars without nanoclay aged in water at RT up to 9 months showed $11.78 \%$ lower average stress as compared to \#4 bars without nanoclay subjected to no aging (115.35 ksi vs. $130.76 \mathrm{ksi})$. \#4 bars with nanoclay under same conditioning showed $0.85 \%$ lower average stress as compared to \#4 bars with nanoclay subjected to no aging (90.70 ksi vs. $91.48 \mathrm{ksi})$.

Comparison of Stiffness - \#4 bars without nanoclay aged in water at RT up to 9 months showed $9.35 \%$ higher average stiffness as compared to \#4 bars without nanoclay subjected to no aging (4.91 msi vs. $4.49 \mathrm{msi}$ ). \#4 bars with nanoclay under same conditioning showed $4.06 \%$ higher average stiffness as compared to \#4 bars with nanoclay subjected to no aging (4.87 msi vs. $4.68 \mathrm{msi}$ ).

$>$ GFRP bar with and without nanoclay showed a decrease of $0.85 \%$ and $11.78 \%$, respectively. Therefore bars without nanoclay showed $10.93 \%(11.77 \%-0.85 \%=$ $10.93 \%$ ) more strength reduction than the bars with nanoclay.

\section{$\underline{\text { Bars with Nanoclay Aged in Water at } 110^{\circ} \mathrm{F} \text { up to } 9 \text { Months }}$}

Average Tensile Stress $=76.33 \pm 20.27 \mathrm{ksi}$ (Std. dev. was $26.55 \%$ of avg. value $)$

$>$ Average Stiffness $=4.91 \pm 0.06 \mathrm{msi}$ (Std. dev. was $1.13 \%$ of avg. value)

$>$ Comparison of Stress - \#4 bars with nanoclay aged in water at $110^{\circ} \mathrm{F}$ up to 9 months showed $16.56 \%$ lower average stress as compared to \#4 bars with nanoclay subjected to no aging (76.33 ksi vs. $91.48 \mathrm{ksi})$.

Comparison of Stiffness - \#4 bars with nanoclay aged in water at $110^{\circ} \mathrm{F}$ up to 9 months showed $4.91 \%$ higher average stiffness as compared to \#4 bars with nanoclay subjected to no aging (4.91 msi vs. $4.68 \mathrm{msi}$ ). 


\section{Bars with and without Nanoclay Aged in Water at $140^{\circ} \mathrm{F}$ up to 9 Months}

\section{Average Tensile Stress}

- Without nanoclay $=83.02 \pm 1.78 \mathrm{ksi}$ (Std. dev. was $2.15 \%$ of avg. value)

- With nanoclay $=77.39 \pm 7.97 \mathrm{ksi}$ (Std. dev. was $10.30 \%$ of avg. value $)$

\section{$>$ Average Stiffness}

- Without nanoclay $=4.84 \pm 0.11 \mathrm{msi}$ (Std. dev. was $2.34 \%$ of avg. value)

- With nanoclay $=4.71 \pm 0.04$ msi (Std. dev. was $0.77 \%$ of avg. value)

$>$ Comparison of Stress - \#4 bars without nanoclay aged in water at $140^{\circ} \mathrm{F}$ up to 9 months showed $36.51 \%$ lower average stress as compared to \#4 bars without nanoclay subjected to no aging (83.02 ksi vs. $130.76 \mathrm{ksi})$. \#4 bars with nanoclay under same conditioning showed $15.40 \%$ lower average stress as compared to \#4 bars with nanoclay subjected to no aging (77.39 ksi vs. $91.48 \mathrm{ksi})$.

$>$ Comparison of Stiffness - \#4 bars without nanoclay aged in water at $140^{\circ} \mathrm{F}$ up to 9 months showed $7.79 \%$ higher average stiffness as compared to \#4 bars without nanoclay subjected to no aging (4.84 msi vs. $4.49 \mathrm{msi}$ ). \#4 bars with under same conditioning showed $0.64 \%$ higher average stiffness as compared to \#4 bars with nanoclay subjected to no aging (4.71 msi vs. $4.68 \mathrm{msi})$.

GFRP bar with and without nanoclay showed a decrease of $15.40 \%$ and $36.51 \%$, respectively. Therefore bars without nanoclay showed $21.11 \%(36.51 \%-15.40 \%=$ $21.11 \%$ ) more strength reduction than the bars with nanoclay.

\subsubsection{TENSION- ALKALINE SOLUTION AT RT AGING}

\section{Test and Specimen Details}

- Aging - Alkaline solution at room temperature for 3, 6, and 9 months

- Diameter of the bars tested-0.5 in. (\#4)

- Length of the specimens - 36 in.

- Grip length on each end - 8 in.

- Number of specimens tested - 15

- Strains were measured at the center of the specimen using a strain gage

- Stiffness values were calculated using stress-strain plots 


\section{Test Results}

Table 5-7 Summary of test results of \#4 bars with and without nanoclay aged in alkaline solution at RT for 3, 6, and 9 months

\begin{tabular}{|c|c|c|c|c|}
\hline \multirow{2}{*}{$\begin{array}{c}\text { No of } \\
\text { months }\end{array}$} & \multicolumn{2}{|c|}{$\begin{array}{c}\text { Average maximum stress } \\
\text { (ksi) }\end{array}$} & \multicolumn{2}{c|}{ Average maximum stiffness } \\
in aging & Without & With & Without & With \\
& nanoclay & nanoclay & nanoclay & nanoclay \\
\cline { 2 - 5 } & $130.76 \pm 2.55$ & $91.48 \pm 4.17$ & $4.49 \pm 0.15$ & $4.68 \pm 0.25$ \\
0 & $(1.95 \%)$ & $(4.55 \%)$ & $(3.43 \%)$ & $(5.37 \%)$ \\
\hline 3 & $112.87 \pm 1.22$ & $89.55 \pm 10.13$ & $4.79 \pm 0.23$ & $4.73 \pm 0.28$ \\
& $(1.08 \%)$ & $(11.31 \%)$ & $(4.72 \%)$ & $(5.98 \%)$ \\
\hline \multirow{2}{*}{6} & $109.38 \pm 1.72$ & $79.06 \pm 11.83$ & $4.86 \pm 0.25$ & $4.84 \pm 0.15$ \\
& $(1.57 \%)$ & $(14.97 \%)$ & $(5.24 \%)$ & $(3.09 \%)$ \\
\hline 9 & $110.74 \pm 0.86$ & $81.63 \pm 12.78$ & $4.72 \pm 0.08$ & $4.87 \pm 0.17$ \\
& $(0.77 \%)$ & $(15.66 \%)$ & $(1.80 \%)$ & $(3.42 \%)$ \\
\hline
\end{tabular}

(Values in parenthesis indicate standard deviations as a percentage of the average value)

\section{Discussion of Test Results}

\section{Bars with and without Nanoclay Aged in Alkaline Solution at RT up to 9 Months}

Average Tensile Stress

- Without nanoclay $=110.74 \pm 0.86 \mathrm{ksi}$ (Std. dev. $0.77 \%$ of avg. value)

- With nanoclay $=81.63 \pm 12.78 \mathrm{ksi}$ (Std. dev. was $15.66 \%$ of avg. value)

$>$ Average Stiffness

- Without nanoclay $=4.72 \pm 0.08$ msi (Std. dev. was $1.80 \%$ of avg. value)

- With nanoclay $=4.87 \pm 0.17$ msi (Std. dev .was $3.42 \%$ of avg. value)

Comparison of Stress - \#4 bars without nanoclay aged in alkaline solution at RT for 9 months showed $15.31 \%$ lower average stress as compared to \#4 bars without nanoclay subjected to no aging (110.74 ksi vs. $130.76 \mathrm{ksi})$. \#4 bars with nanoclay under same conditioning showed $10.77 \%$ lower average stress as compared to \#4 bars with nanoclay subjected to no aging (81.63 ksi vs. $91.48 \mathrm{ksi})$. 
Comparison of Stiffness - \#4 bars without nanoclay aged in alkaline solution at RT for 9 months showed $5.12 \%$ higher average stiffness as compared to \#4 bars without nanoclay subjected to no aging (4.72 msi vs. $4.49 \mathrm{msi}$ ). \#4 bars with nanoclay under same conditioning showed $4.06 \%$ higher average stiffness as compared to \#4 bars with nanoclay subjected to no aging (4.87 msi vs. $4.68 \mathrm{msi}$ ).

$>$ GFRP bar with and without nanoclay showed a decrease of $10.77 \%$ and $15.31 \%$, respectively. Therefore bars without nanoclay showed $4.54 \%(15.31 \%-10.77 \%=$ $4.54 \%$ ) more strength reduction than the bars with nanoclay.

\subsubsection{TENSION- BARS EXTRACTED FROM THE BEAMS}

\section{Test and Specimen Details}

- Aging - Bars extracted from concrete beams

- Diameter of the bars tested - 0.5 in. (\#4) \& 0.75 in. (\#6)

- Length of the specimens - 36 in. - \#4 \& 50 in. - \#6

- Grip length on each end - 8 in. - \#4 \& 10 in. - \#6

- Number of specimens tested - 7

- Strains were measured at the center of the specimen using a strain gage

- Stiffness values were calculated using stress-strain plots 


\section{Test Results}

Table 5-8 Summary of test results of bars extracted from the concrete beam

\begin{tabular}{|c|c|c|c|c|c|}
\hline \multirow{2}{*}{$\begin{array}{l}\text { No of } \\
\text { months } \\
\text { in aging }\end{array}$} & \multirow[t]{2}{*}{ Bar size } & \multicolumn{2}{|c|}{$\begin{array}{c}\text { Average maximum stress } \\
\qquad(\mathrm{ksi})\end{array}$} & \multicolumn{2}{|c|}{$\begin{array}{l}\text { Average maximum stiffness } \\
\qquad(\mathrm{msi})\end{array}$} \\
\hline & & $\begin{array}{l}\text { Without } \\
\text { nanoclay }\end{array}$ & $\begin{array}{c}\text { With } \\
\text { nanoclay }\end{array}$ & $\begin{array}{l}\text { Without } \\
\text { nanoclay }\end{array}$ & $\begin{array}{c}\text { With } \\
\text { nanoclay }\end{array}$ \\
\hline \multirow{2}{*}{ U } & \#4 & $\begin{array}{c}130.76 \pm 2.55 \\
(1.95 \%)\end{array}$ & $\begin{array}{c}91.48 \pm 4.17 \\
(4.55 \%)\end{array}$ & $\begin{array}{c}4.49 \pm 0.15 \\
(3.43 \%)\end{array}$ & $\begin{array}{c}4.68 \pm 0.25 \\
(5.37 \%)\end{array}$ \\
\hline & $\# 6 *$ & - & $\begin{array}{c}81.42 \pm 10.55 \\
(12.96 \%)\end{array}$ & - & $\begin{array}{c}4.84 \pm 0.42 \\
(8.63 \%)\end{array}$ \\
\hline \multirow[t]{2}{*}{2} & \#4 & $\begin{array}{c}110.33 \pm 2.12 \\
(1.92 \%)\end{array}$ & $\begin{array}{c}78.05 \pm 7.77 \\
(9.96 \%)\end{array}$ & $\begin{array}{c}4.85 \pm 0.15 \\
(3.11 \%)\end{array}$ & $\begin{array}{c}4.58 \pm 0.08 \\
(1.70 \%)\end{array}$ \\
\hline & $\# 6^{*}$ & 96.59 & 75.65 & 5.36 & 4.76 \\
\hline
\end{tabular}

*\#6 GFRP bars manufactured with 56 yield glass fiber rovings

(Values in parenthesis indicate standard deviations as a percentage of the average value)

\section{Discussion of Tests Results}

\section{\#4 Bars with and without Nanoclay Extracted From the Beams}

\section{Average Tensile Stress}

- Without nanoclay $=110.33 \pm 2.12 \mathrm{ksi}$ (Std. dev. was $1.92 \%$ of avg. value $)$

- With nanoclay $=78.05 \pm 7.77 \mathrm{ksi}$ (Std. dev. was $9.96 \%$ of avg. value)

\section{Average Stiffness}

- Without nanoclay $=4.85 \pm 0.15$ msi (Std. dev. was $3.11 \%$ of avg. value)

- With nanoclay $=4.58 \pm 0.08 \mathrm{msi}$ (Std. dev. was $1.70 \%$ of avg. value)

Comparison of Stress - \#4 bars without nanoclay extracted from the beams after 2 months showed $15.62 \%$ lower average stress as compared to \#4 bars without nanoclay subjected to no aging (110.33 ksi vs. $130.76 \mathrm{ksi})$. \#4 bars with nanoclay under same conditioning showed $14.68 \%$ lower average stress as compared to \#4 bars with nanoclay subjected to no aging (78.05 ksi vs. $91.48 \mathrm{ksi}$ ).

Comparison of Stiffness - \#4 bars without nanoclay extracted from the beams after 2 months showed $8.02 \%$ higher average stiffness as compared to \#4 bars without 
nanoclay subjected to no aging (4.85 msi vs. $4.49 \mathrm{msi}$ ). \#4 bars with nanoclay under same conditioning showed $2.13 \%$ lower average stiffness as compared to \#4 bars with nanoclay subjected to no aging (4.58 msi vs. $4.68 \mathrm{msi})$.

$>$ GFRP bars with and without nanoclay extracted from concrete beams (2 months) showed almost similar decrease of $14.68 \%$ and $15.62 \%$, respectively.

$>$ Strength reduction of the bars is attributed to possible fiber damage to the glass fiber at the surface during extraction from the beams.

\section{\#6 Bars with and without Nanoclay Extracted From the Beams}

$>$ Tensile Stress

- Without nanoclay $=96.59 \mathrm{ksi}$

- With nanoclay $=75.65 \mathrm{ksi}$

\section{Stiffness}

- Without nanoclay $=5.36 \mathrm{msi}$

- With nanoclay $=4.76 \mathrm{msi}$

Comparison of Stress - \#6 bars with nanoclay extracted from the beams after 2 months showed $7.09 \%$ lower average stress as compared to \#6 bars with nanoclay subjected to no aging (75.65 ksi vs. $81.42 \mathrm{ksi})$.

Comparison of Stiffness - \#6 bars with nanoclay extracted from the beams after 2 months showed $1.65 \%$ lower average stiffness as compared to \#6 bars with nanoclay under no aging (4.76 msi vs. $4.84 \mathrm{msi}$ ). 


\subsection{SUMMARY AND CONCLUSION}

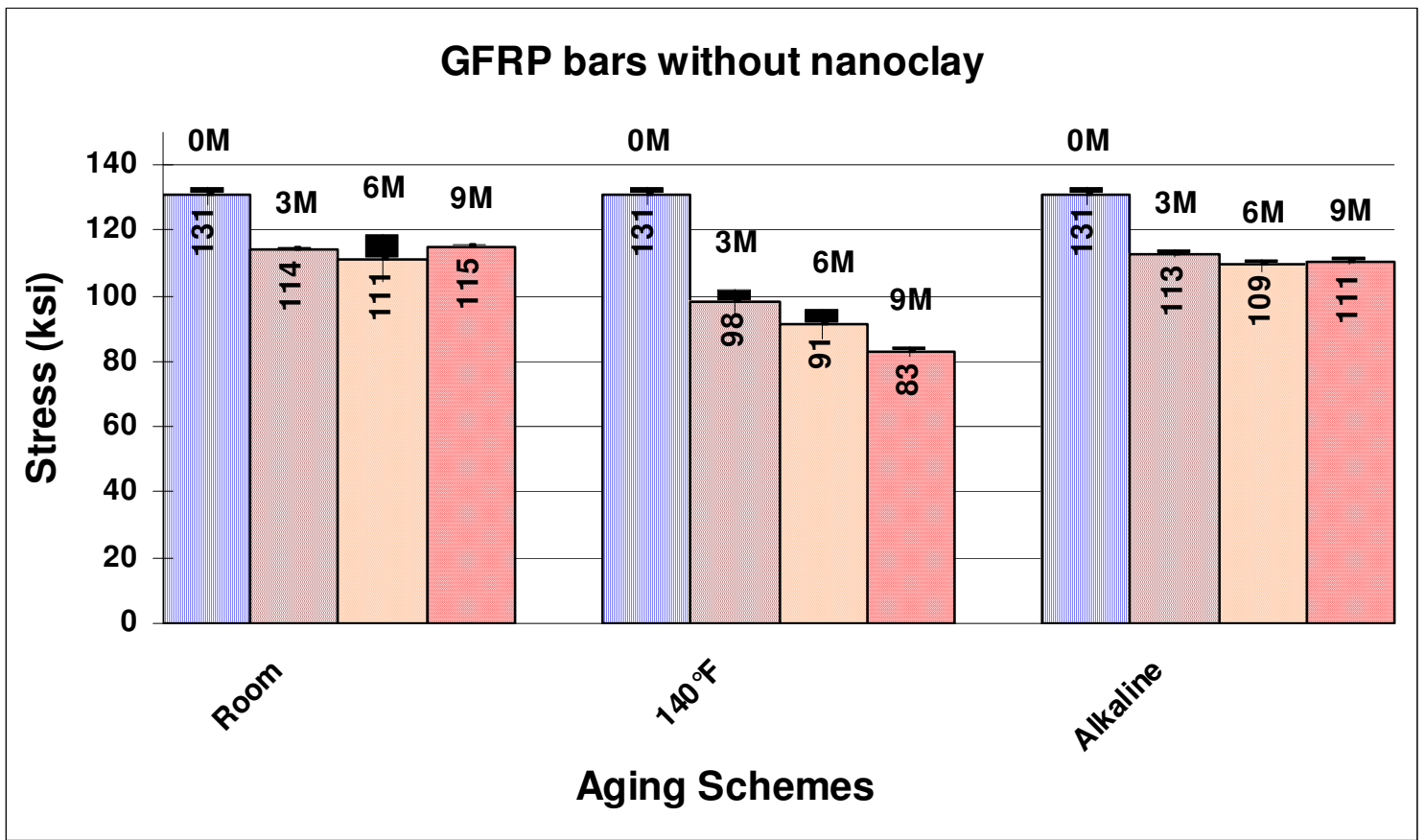

Figure 5-7 Comparison of tensile stress of GFRP bars without nanoclay aged in different aging schemes to non-aged bars (Note: M-Months; Std. dev. is also shown at the top of the bars in the graph as a shaded rectangle)

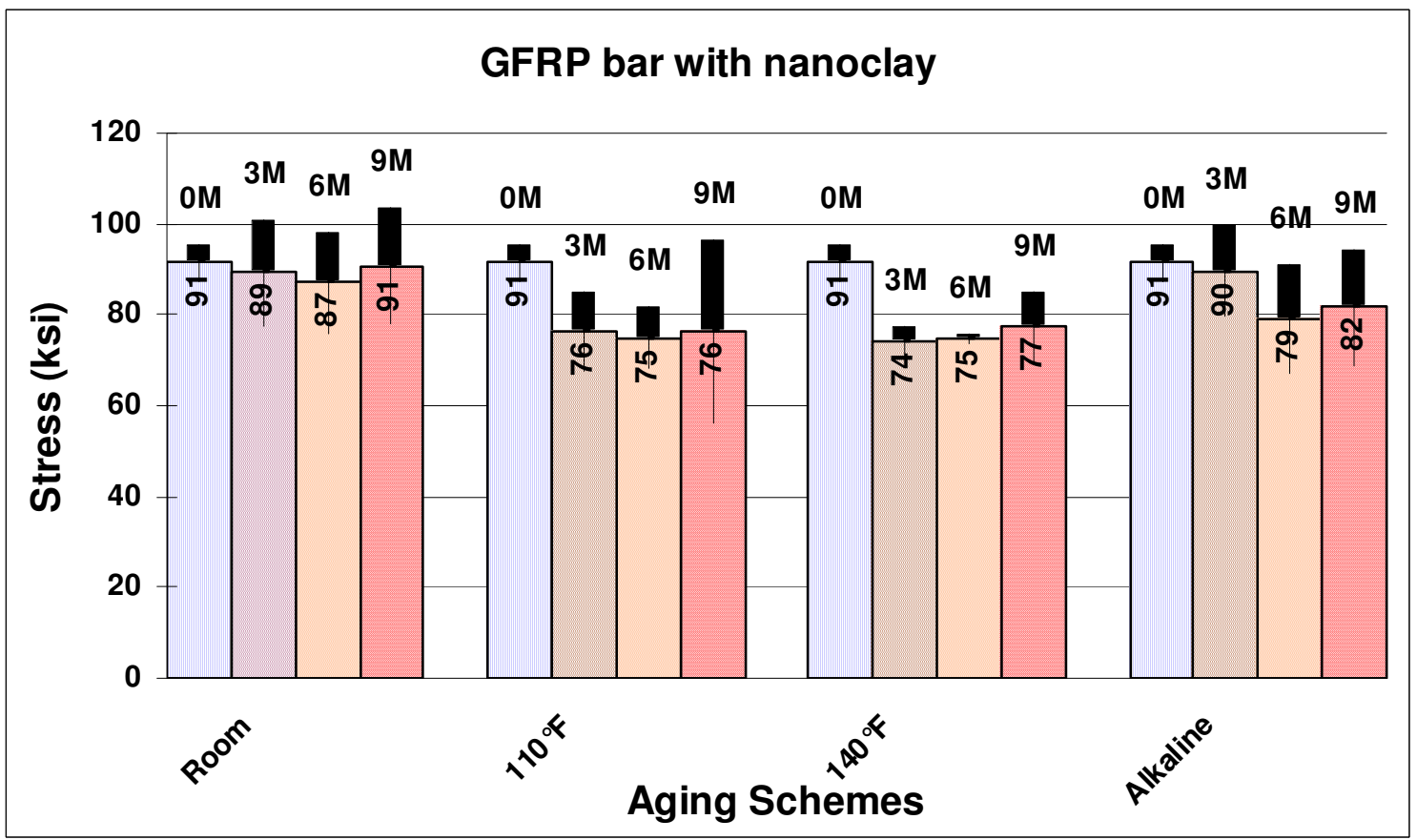

Figure 5-8 Comparison of tensile stress of GFRP bars with nanoclay aged in different aging schemes to non-aged bars (Note: M-Months; Std. dev. is also shown at the top of the bars in the graph as a shaded rectangle) 


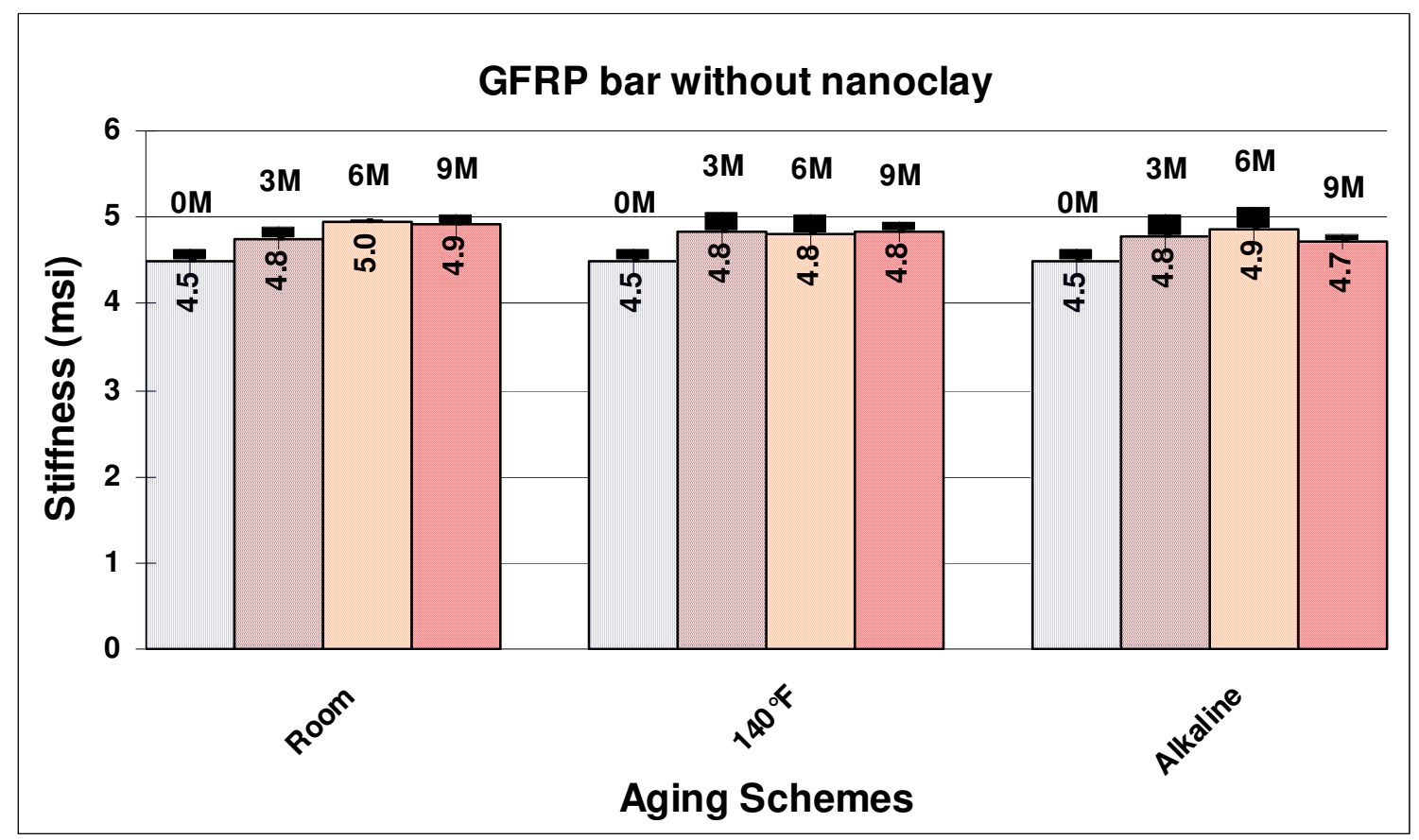

Figure 5-9 Comparison of stiffness of GFRP bars without nanoclay aged in different aging schemes to non-aged bars (Note: M-Months; Std. dev. is also shown at the top of the bars in the graph as a shaded rectangle)

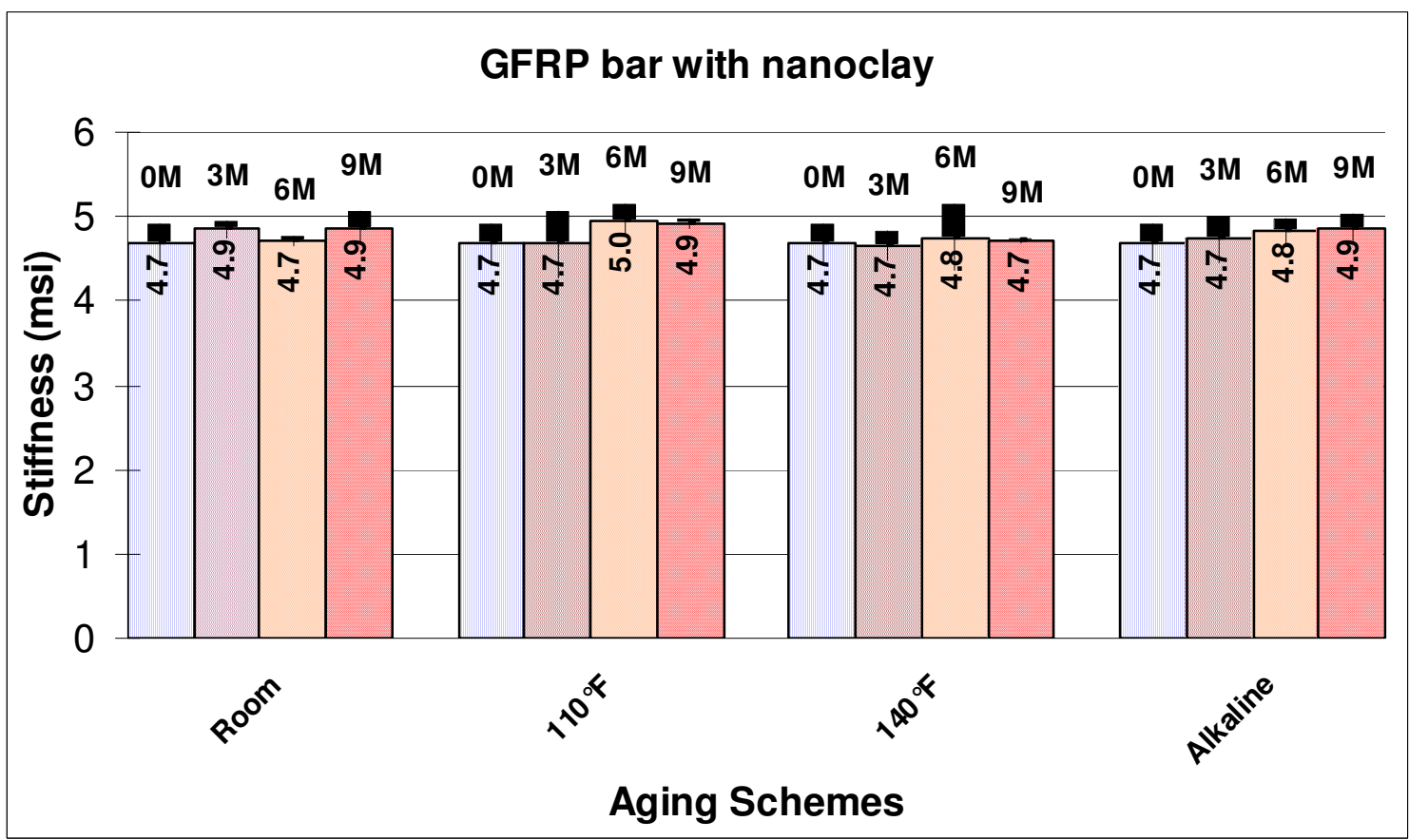

Figure 5-10 Comparison of stiffness of GFRP bars with nanoclay aged in different aging schemes to non-aged bars (Note: M-Months; Std. dev. is also shown at the top of the bars in the graph as a shaded rectangle) 


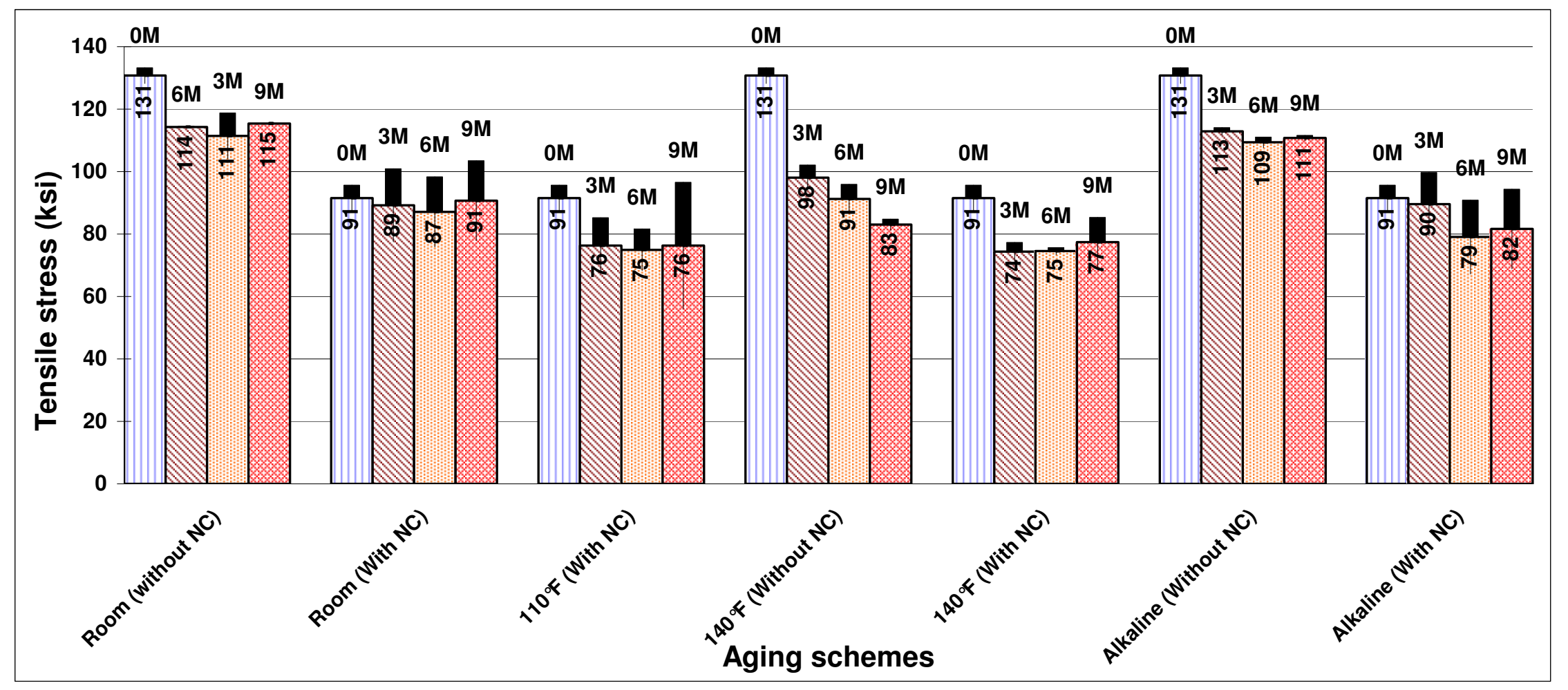

Figure 5-11 Comparison of tensile stress of GFRP bars with and without nanoclay aged in different aging schemes to non-aged bars (Note: N.C-Nanoclay and M-Months; Std. dev. is also shown at the top of the bars in the graph as a shaded rectangle) 


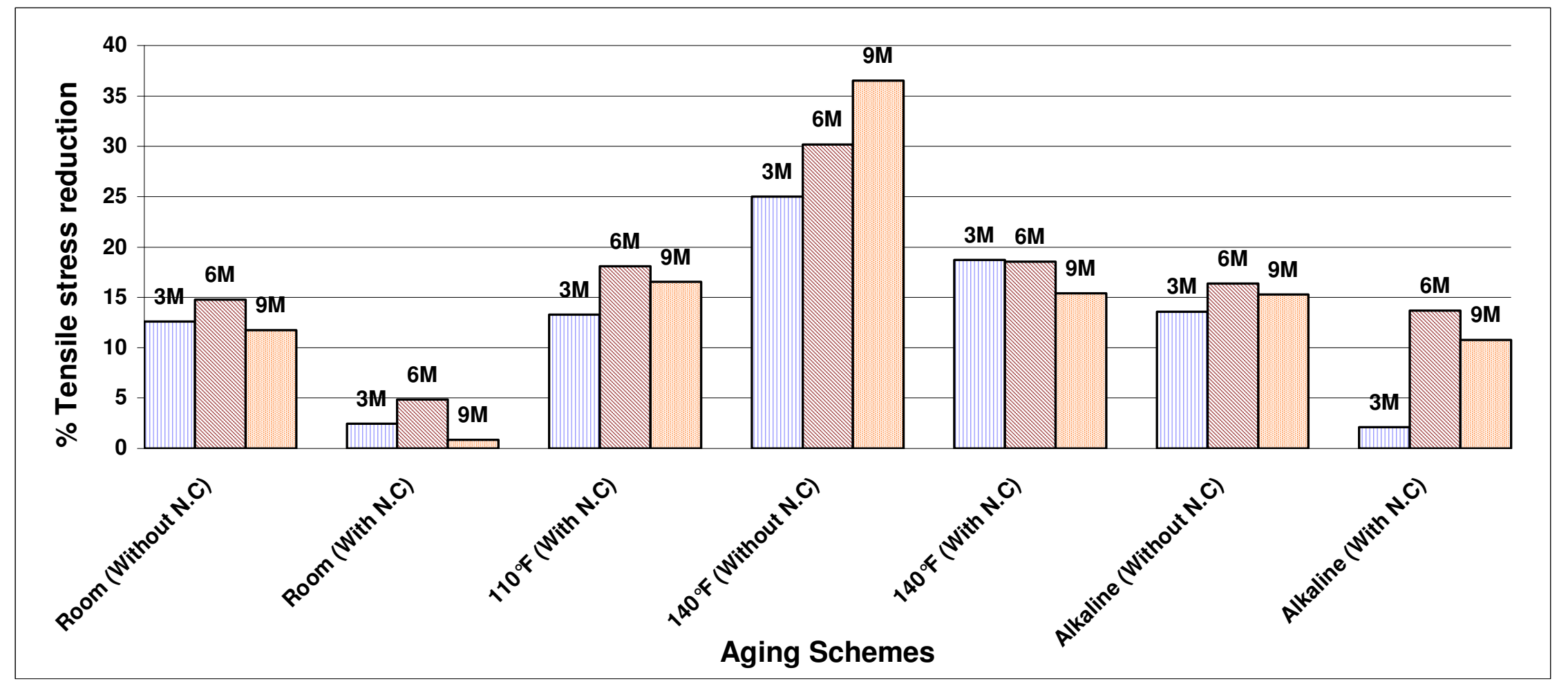

Figure 5-12 Comparison of percentage tensile stress reduction of GFRP bars with and without nanoclay aged in different aging schemes to non-aged bars (Note: N.C-Nanoclay and M-Months) 


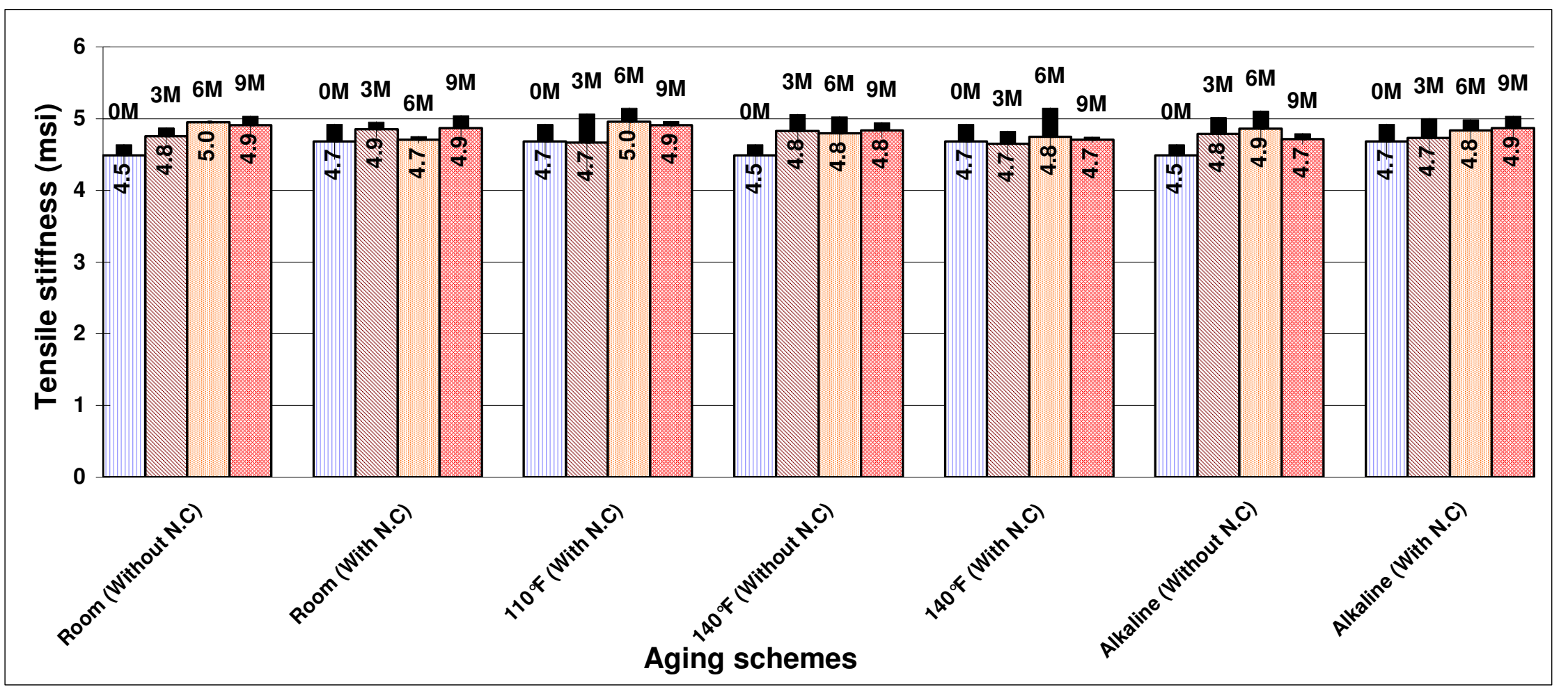

Figure 5-13 Comparison of stiffness of GFRP bars with and without nanoclay aged in different aging schemes to nonaged bars (Note: N.C-Nanoclay and M-Months; Std. dev. is also shown at the top of the bars in the graph as a shaded rectangle) 


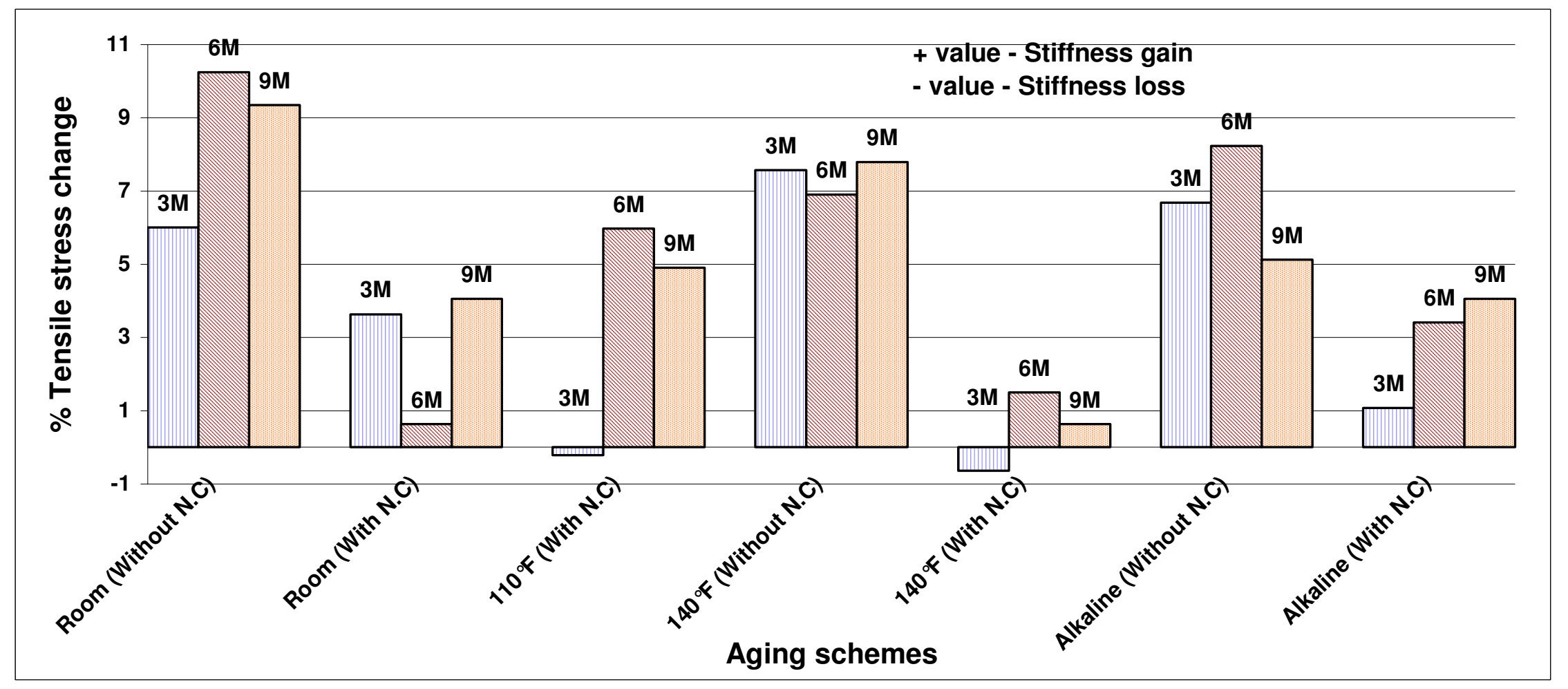

Figure 5-14 Comparison of percentage tensile stiffness change of GFRP bars with and without nanoclay aged in different aging schemes to non-aged bars (Note: N.C-Nanoclay and M-Months) 
- \#4 bars with nanoclay showed $30.04 \%$ lower average stress as compared to \#4 bars without nanoclay (91.48 ksi vs. $130.76 \mathrm{ksi}$ ), which suggested that addition of nanoclay decreased the ultimate failure stress. Intercalation of clays with the precursor of a thermosetting polymer can change the functionality of the polymer. The change in functionality affects the extent of cross-linking and glass transition temperature $T_{g}$ (Fengge, 2004).

- Strength reduction in GFRP bars due to addition of nanoclay is attributed to:

$>$ Increase in resin viscosity, leading to increased micro voids.

$>$ Reduction in bond strength between fibers and resin due to the presence of nanoclay that may locally affect the stress distribution.

$>$ Possible abrasion between fibers and nanoclay particles in the resin during pulling process that may create glass fiber surface imperfections under increased resin viscosity.

Increased resin viscosity leading to fiber twisting during pulling process, which was visually observed. This problem can be eliminated by using automatic pultrusion with sufficient fiber tension.

- GFRP bars with nanoclay exhibited better durability than those without nanoclay in all types of conditioning schemes (Table 5-9) considered in this research.

$>$ Maximum stress reduction after 9 months of water conditioning at room temperature without and with nanoclay were $11.77 \%$ and $0.85 \%$, respectively.

$>$ Maximum stress reduction after 9 months of water conditioning at $110^{\circ} \mathrm{F}$ with nanoclay was $16.56 \%$. Bars without nanoclay were not used for $110^{\circ} \mathrm{F}$ conditioning.

$>$ Maximum stress reduction after 9 months of water conditioning at $140^{\circ} \mathrm{F}$ without and with nanoclay were $36.51 \%$ and $15.40 \%$, respectively.

Maximum stress reduction after 9 months of alkaline conditioning at room temperature without and with nanoclay were $15.31 \%$ and $10.77 \%$, respectively. 
- Among different aging schemes, (water at room temperature, water at $110^{\circ} \mathrm{F}$, water at $140^{\circ} \mathrm{F}$, and alkaline solution at room temperature) water at elevated temperature of $140^{\circ} \mathrm{F}$ was found to be more severe on strength reduction followed by alkaline aging $\left(36.51 \%\right.$ without nanoclay vs. $15.40 \%$ with nanoclay at $140^{\circ} \mathrm{F}$ aging as compared to $15.31 \%$ without nanoclay and $10.77 \%$ with nanoclay at alkaline solution). Increase in temperature is known to accelerate both the glass fiber and matrix degradation.

> Nanoclay was found to provide better durability with increasing temperature, which is attributed to bridging the difference in thermal compatibility between glass fiber $\left(5.3 \times 10^{-6} \mathrm{~m} / \mathrm{m} /{ }^{\circ} \mathrm{C}\right)$ and matrix $(56.8 \mathrm{x}$ $\left.10^{-6} \mathrm{~m} / \mathrm{m} /{ }^{\circ} \mathrm{C}\right)$.

$>$ Neat resin exfoliated with $4 \%$ nanoclay was found to have lower moisture absorption than neat resin without nanoclay (refer to Chapter 8). This needs to be verified for an extended duration.

- Flexure tests were conducted on GFRP bars with nanoclay subjected to no aging to verify the results obtained from the tension test (Appendix A). The maximum stress of GFRP bars from flexure test was $5.47 \%$ higher than the stress obtained from tension test (96.77 ksi vs. $91.48 \mathrm{ksi})$.

- Addition of nanoclay resulted in a reduction of ultimate failure stress in non-aged bars. However, better durability was noted in bars with nanoclay under different aging schemes.

- Effect of temperature on stress and stiffness - \#4 GFRP bar with $2 \%$ nanoclay subjected to $170^{\circ} \mathrm{F}$ for 5 days showed a strength reduction of $4.79 \%$ as compared to a identical bar (103.06 ksi vs. $108.24 \mathrm{ksi}$ ) and a stiffness reduction of $4.57 \%$ (4.81 ksi vs. $5.03 \mathrm{ksi})$.

- Effect of yield of glass fibers - \#6 GFRP bars with nanoclay manufactured with 113 Yields showed $0.5 \%$ higher strength than \#6 bars with nanoclay manufactured with 56 Yield rovings (81.83 ksi vs. $81.42 \mathrm{ksi})$. Therefore no discernable strength difference in bars manufactured with 56 and 113 Yield glass fiber rovings can be found from our test data. 
- Bars without and with nanoclay extracted from concrete beams after flexure tests indicated $15.62 \%$ and $14.68 \%$ stress reduction, respectively as compared to nonaged specimens (Table 5-9). However, no definite conclusions are drawn because extraction of bars from the beams possibly resulted in fiber damage.

- \#6 bars with nanoclay showed 11\% lower average stress as compared to \#4 bars with nanoclay (81.42 ksi vs. $91.48 \mathrm{ksi}$ ). This was due to shear lag phenomenon in larger diameter bars as compared to smaller bars, where outer core fibers carry higher stress compared to inner fibers. 
Table 5-9 Summary of Tension Tests

\begin{tabular}{|c|c|c|c|c|c|c|}
\hline $\begin{array}{c}\text { No. of } \\
\text { Months } \\
\text { in aging }\end{array}$ & $\begin{array}{c}\text { Aging } \\
\text { condition }\end{array}$ & $\begin{array}{l}\text { Bar } \\
\text { size }\end{array}$ & Nanoclay & $\begin{array}{c}\text { Average } \\
\text { Maximum } \\
\text { stress (ksi) }\end{array}$ & $\begin{array}{c}\text { Average } \\
\text { Stiffness } \\
\text { (msi) }\end{array}$ & $\begin{array}{c}\% \\
\text { strength } \\
\text { reduction }\end{array}$ \\
\hline \multirow{4}{*}{0} & \multirow{4}{*}{ No aging } & \multirow{2}{*}{$\# 4$} & Yes & $91.48 \pm 4.17$ & $4.68 \pm 0.25$ & \multirow{4}{*}{ N/A } \\
\hline & & & No & $130.76 \pm 2.55$ & $4.49 \pm 0.15$ & \\
\hline & & \multirow{2}{*}{ \#6 } & Yes $^{\dagger}$ & $81.42 \pm 10.55$ & $4.84 \pm 0.42$ & \\
\hline & & & Yes & $81.83 \pm 10.80$ & $4.80 \pm 0.50$ & \\
\hline \multirow{4}{*}{2} & \multirow{4}{*}{$\begin{array}{l}\text { Bars } \\
\text { extracted } \\
\text { from } \\
\text { concrete } \\
\text { beams }\end{array}$} & \multirow{2}{*}{ \#4 } & Yes & $78.05 \pm 7.77$ & $4.58 \pm 0.08$ & $14.68 \%$ \\
\hline & & & No & $110.33 \pm 2.12$ & $4.85 \pm 0.15$ & $15.62 \%$ \\
\hline & & \multirow{2}{*}{$\# 6$} & Yes $^{\dagger}$ & $75.65 \pm 0.00$ & $4.76 \pm 0.00$ & $7.09 \%$ \\
\hline & & & $\mathrm{No}^{\dagger}$ & $96.59 \pm 0.00$ & $5.36 \pm 0.00$ & - \\
\hline \multirow{7}{*}{3} & \multirow{2}{*}{ Water/RT } & \multirow{7}{*}{$\# 4$} & Yes & $89.24 \pm 11.69$ & $4.85 \pm 0.11$ & $2.45 \%$ \\
\hline & & & No & $114.24 \pm 0.28$ & $4.76 \pm 0.12$ & $12.63 \%$ \\
\hline & Water $/ 110^{\circ} \mathrm{F}$ & & Yes & $76.34 \pm 8.93$ & $4.67 \pm 0.40$ & $13.27 \%$ \\
\hline & \multirow{2}{*}{ Water $/ 140^{\circ} \mathrm{F}$} & & Yes & $74.34 \pm 2.98$ & $4.65 \pm 0.18$ & $18.74 \%$ \\
\hline & & & No & $98.09 \pm 4.05$ & $4.83 \pm 0.23$ & $24.98 \%$ \\
\hline & \multirow{2}{*}{ Alkaline/RT } & & Yes & $89.55 \pm 10.13$ & $4.73 \pm 0.28$ & $2.11 \%$ \\
\hline & & & No & $112.87 \pm 1.22$ & $4.79 \pm 0.23$ & $13.68 \%$ \\
\hline \multirow{7}{*}{6} & \multirow{2}{*}{ Water/RT } & \multirow{7}{*}{$\# 4$} & Yes & $87.06 \pm 11.25$ & $4.71 \pm 0.05$ & $4.83 \%$ \\
\hline & & & No & $111.46 \pm 7.32$ & $4.95 \pm 0.01$ & $14.76 \%$ \\
\hline & Water $/ 110^{\circ} \mathrm{F}$ & & Yes & $74.96 \pm 6.71$ & $4.96 \pm 0.19$ & $18.06 \%$ \\
\hline & \multirow{2}{*}{ Water $/ 140^{\circ} \mathrm{F}$} & & Yes & $74.54 \pm 1.16$ & $4.75 \pm 0.40$ & $18.52 \%$ \\
\hline & & & No & $91.27 \pm 4.72$ & $4.80 \pm 0.23$ & $30.20 \%$ \\
\hline & \multirow{2}{*}{ Alkaline/RT } & & Yes & $79.06 \pm 11.83$ & $4.84 \pm 0.15$ & $13.58 \%$ \\
\hline & & & No & $109.38 \pm 1.72$ & $4.86 \pm 0.25$ & $16.35 \%$ \\
\hline \multirow{7}{*}{9} & \multirow{2}{*}{ Water/RT } & \multirow{7}{*}{ \#4 } & Yes & $90.70 \pm 12.78$ & $4.87 \pm 0.18$ & $0.85 \%$ \\
\hline & & & No & $115.35 \pm 0.17$ & $4.91 \pm 0.13$ & $11.77 \%$ \\
\hline & Water $/ 110^{\circ} \mathrm{F}$ & & Yes & $76.33 \pm 20.27$ & $4.91 \pm 0.06$ & $16.56 \%$ \\
\hline & \multirow{2}{*}{ Water $/ 140^{\circ} \mathrm{F}$} & & Yes & $77.39 \pm 7.97$ & $4.71 \pm 0.04$ & $15.40 \%$ \\
\hline & & & No & $83.02 \pm 1.78$ & $4.84 \pm 0.11$ & $36.51 \%$ \\
\hline & \multirow{2}{*}{ Alkaline/RT } & & Yes & $81.63 \pm 12.78$ & $4.87 \pm 0.17$ & $10.77 \%$ \\
\hline & & & No & $110.74 \pm 0.86$ & $4.72 \pm 0.08$ & $15.31 \%$ \\
\hline
\end{tabular}

RT- Room temperature ${ }^{\dagger}$ \#6 GFRP bars manufactured with 56 Yield glass fiber rovings. Rest of the bars were manufactured with 113 Yield glass fiber rovings. 


\section{SHEAR TESTS}

\subsection{INTRODUCTION}

Shear tests were performed on \#4 and \#6 GFRP bars with and without nanoclay that were subjected to aging. Table 6-1 shows the type and number of bars tested in shear. Shear test procedure and analytical calculations are given in Section 6.2. Figure 6-1 shows a photograph and schematic diagram of the shear test apparatus and the cutting tool used. Double shear test was performed on GFPR bars using $1 / 2$ in. wide cutting tool.
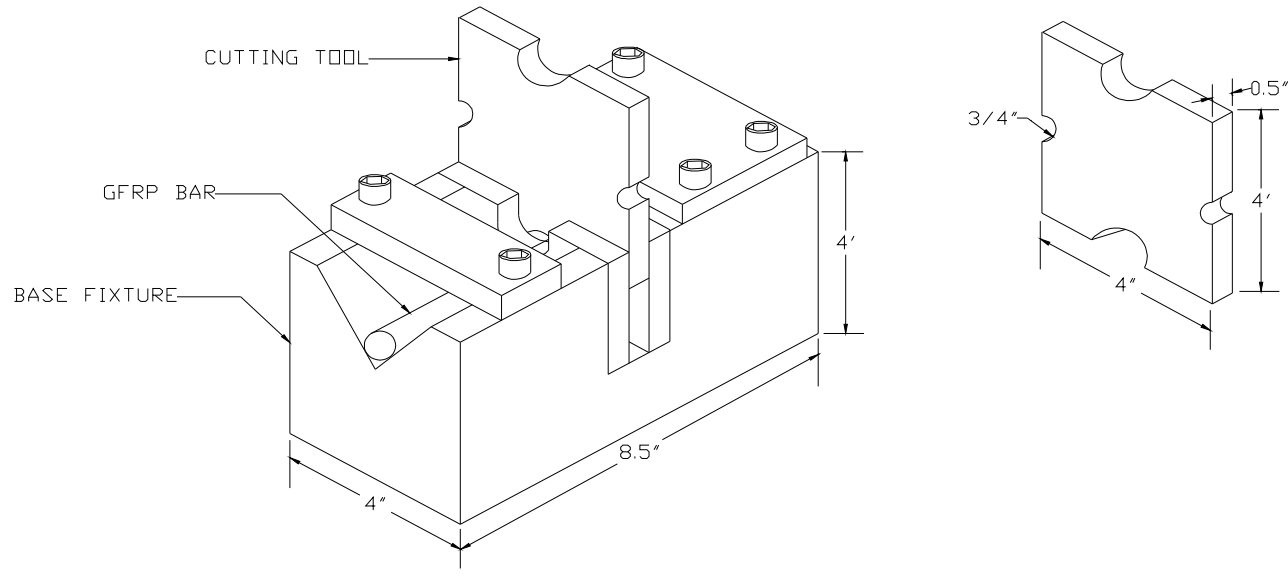

(a)

(b)

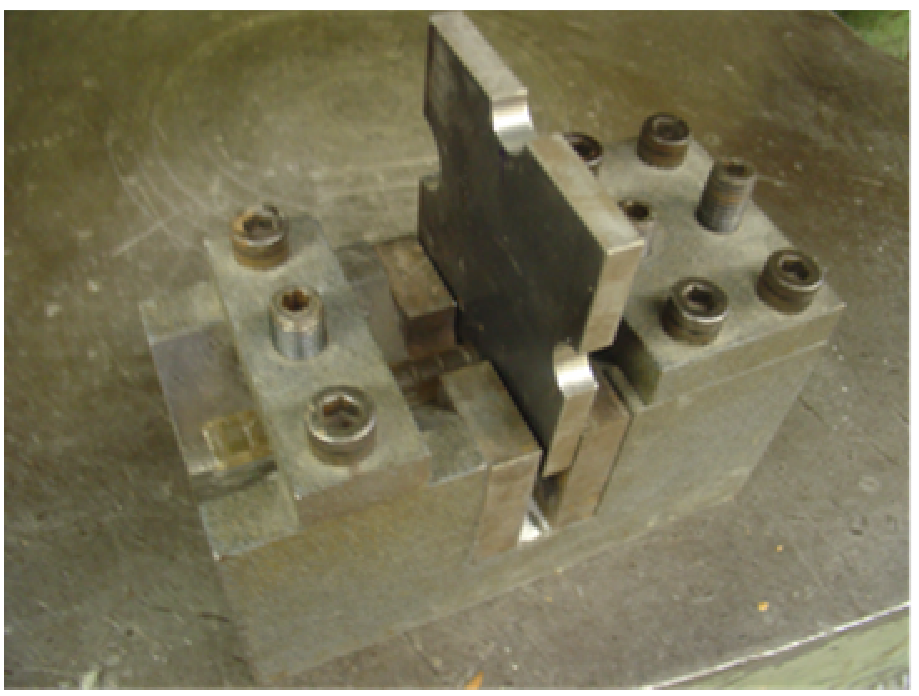

(c)

Figure 6-1 Shear Testing Apparatus 
Table 6-1 Number and aging schemes of GFRP bars tested in shear

\begin{tabular}{|c|c|c|c|c|c|c|}
\hline \multirow[b]{2}{*}{ Aging schemes } & \multirow{2}{*}{$\begin{array}{l}\text { Bar } \\
\text { size }\end{array}$} & \multirow[b]{2}{*}{ Nanoclay } & \multicolumn{4}{|c|}{ Number of specimens } \\
\hline & & & $\begin{array}{c}\text { Without } \\
\text { aging }\end{array}$ & $\begin{array}{l}3 \text { months } \\
\text { aging }\end{array}$ & $\begin{array}{l}6 \text { months } \\
\text { aging }\end{array}$ & $\begin{array}{c}9 \text { months } \\
\text { aging }\end{array}$ \\
\hline \multirow{5}{*}{ Non-aged } & \multirow{2}{*}{ \#4 } & Yes & 7 & - & - & - \\
\hline & & No & 3 & - & - & - \\
\hline & \multirow{3}{*}{ \#6 } & Yes* & 9 & - & - & - \\
\hline & & Yes & 9 & - & - & - \\
\hline & & $\mathrm{No}^{*}$ & 4 & - & - & - \\
\hline \multirow{4}{*}{$\begin{array}{l}\text { Extracted from } \\
\text { concrete beams }\end{array}$} & \multirow{2}{*}{ \#4 } & Yes & 10 & - & - & - \\
\hline & & No & 9 & - & - & - \\
\hline & \multirow{2}{*}{ \#6 } & Yes* & 4 & - & - & - \\
\hline & & No* & 4 & - & - & - \\
\hline \multirow{2}{*}{ Water/RT } & \multirow{7}{*}{ \#4 } & Yes & - & 6 & 6 & 6 \\
\hline & & No & - & 3 & 3 & 3 \\
\hline Water at $110^{\circ} \mathrm{F}$ & & Yes & - & 6 & 6 & 6 \\
\hline \multirow{2}{*}{ Water at $140^{\circ} \mathrm{F}$} & & Yes & - & 6 & 6 & 6 \\
\hline & & No & - & 3 & 3 & 3 \\
\hline \multirow{2}{*}{$\begin{array}{c}\text { Alkaline } \\
\text { solution/RT }\end{array}$} & & Yes & - & 6 & 6 & 6 \\
\hline & & No & - & 3 & 3 & 3 \\
\hline
\end{tabular}

*\#6 GFRP bars manufactured with 56 yield glass fiber rovings. Rest of the bars were manufactured with 113 Yield glass fiber rovings.

\subsection{DEVELOPMENT OF THE TEST}

This test method was used in previous research efforts by the CFC-WVU. Additional details can be obtained from the reference Vijay et al, 2003.

\subsubsection{REFERENCE DOCUMENTS}

Japan Society of Civil Engineers (JSCE) 1997. Recommendation for design and construction of concrete structures using continuous fiber reinforced materials, concrete engineering series 23, Ed. A. Machida, Research committee on continuous fiber reinforced materials, Tokyo, Japan, PP.

\subsubsection{TERMINOLOGY}

1. Test section: The portion of a specimen to be tested between the anchoring sections of the test specimen. 
2. Anchoring section: The end parts of the test specimen where the test specimen is anchored to the shear apparatus.

3. Shear apparatus: Apparatus used to conduct the shear test as shown in Figure 6-1.

4. Anchor length: The length of the FRP bar anchored to the shear fixture on each end of the bar.

5. Cutting tool: The device, which is used to transfer the load from the testing machine to the test specimen.

6. Double shear test: Two cross-sections of the bar were tested in shear.

7. Shear capacity: Maximum shear at the failure of test specimen.

\subsubsection{SPECIMEN PREPARATION}

\section{a. Preparation:}

i. Non-aged: Care was taken so that the specimen was not subjected to any processing. During the sampling and preparation of test specimens, all deformation, heating, outdoor exposure to ultraviolet light etc., causing changes to the material properties of the test specimen was avoided.

ii. Aged: Specimens were aged in water at room temperature, water at $110^{\circ} \mathrm{F}$, water at $140^{\circ} \mathrm{F}$, and alkaline solution at room temperature for 3, 6, and 9 months.

b. Test section length and anchorage length: The shear tests were performed with $1 / 2$ in. wide cutting tool. Hence the test section length was $1 / 2$ in. The remaining length of the bar was anchored on both the ends. The total length of the specimen including the anchor length for shear test was 6 in.

c. Anchorages: Bolts were used to anchor the specimen to the shear fixture to minimize bending effects.

d. Number of specimens: Number of specimens tested depends upon the availability of the specimens.

\subsubsection{TEST EQUIPMENT}

The shear specimens were tested on Universal Testing Machine (UTM) with a maximum load capacity of 200 kips. A computerized data acquisition was used to record the load. 


\subsubsection{TEST METHOD}

(a). Shear apparatus: The shear testing apparatus was constructed so that a rod-shaped test specimen is sheared on two planes more or less simultaneously by two blades (edges) converging along the faces perpendicular to the axis direction of the test specimen. The discrepancy in the axis direction between the upper and lower blades was kept as small as possible.

(b).Mounting: The test specimen was mounted in the center of the shear apparatus, touching the cutting tool such that no gap was visible between the contact surface of the cutting tool and the test specimen.

(c). Loading rate: The applied rate of loading for the tension test specimen was between 5 -15 ksi per minute.

(d).Testing temperature: The test temperature was generally with in the range of 40$100^{\circ} \mathrm{F}$.

(e). Loading: The load was applied until failure occurred and the measurements were recorded until the test specimen fails.

\subsubsection{CALCULATION}

Shear stress of the specimens was calculated using Eq. (6.1),

$$
\tau=\frac{P}{n \cdot A}
$$

Where,

$\tau=$ Shear stress $(\mathrm{ksi})$

$\mathrm{P}=$ Shear failure load (kips)

$\mathrm{A}=$ Cross-sectional area of test specimen (in. ${ }^{2}$ ) based on the die diameter

$\mathrm{n}=2$ for double shear test

\subsection{TEST RESULTS}

\subsubsection{SHEAR- NO AGING}

\section{Test and Specimen Details}

- Aging - None

- Diameter of the bars tested-0.5 in. (\#4) \& 0.75in. (\#6)

- Length of the specimens -6 in.

- Cutting tool width $-1 / 2$ in.

- Number of specimens tested-23 


\section{Test Results}

Table 6-2 Summary of test results of \#4 and \#6 bar with and without nanoclay subjected to no aging

\begin{tabular}{|c|c|c|c|c|}
\hline \multirow{2}{*}{$\begin{array}{c}\text { No of } \\
\text { months }\end{array}$} & \multirow{2}{*}{ Bar size } & Without & \multicolumn{3}{|c|}{ Whear stress } \\
\cline { 3 - 5 } in aging & & nanoclay & 56 Yield & 113 Yield \\
\cline { 3 - 5 } & & $26.27 \pm 0.62$ & $24.77 \pm 1.19$ & - \\
\hline \multirow{2}{*}{0} & $\# 4$ & $(2.39 \%)$ & $(4.82 \%)$ & $22.00 \pm$ \\
\cline { 3 - 5 } & \multirow{2}{*}{$\# 6$} & $22.95 \pm 2.05$ & $20.02 \pm 1.81$ & $1.86(8.45)$ \\
\hline
\end{tabular}

(Values in parenthesis indicate standard deviations as a percentage of the average value)

\section{Discussion of Tests Results}

\section{\#4 and \#6 Bars with and without Nanoclay}

\section{Average Double Shear Stress of \#4 bars}

- Without nanoclay $=26.27 \pm 0.62 \mathrm{ksi}$ (Std. dev. was $2.39 \%$ of avg. value)

- With nanoclay $=24.77 \pm 1.19 \mathrm{ksi}$ (Std. dev. was $4.82 \%$ of avg. value)

\section{Average Double Shear Stress of \#6 bars}

- Without nanoclay $=22.95 \pm 2.05 \mathrm{ksi}$ (Std. dev. was $8.94 \%$ of avg. value)

- With nanoclay $=20.02 \pm 1.81 \mathrm{ksi}$ (Std. dev. was $9.05 \%$ of avg. value $)$

\#4 bars with nanoclay showed a 5.71\% lower (average) shear stress as compared to \#4 bars without nanoclay (24.77 ksi vs. $26.27 \mathrm{ksi}$ ) and \#6 bars with nanoclay showed $12.77 \%$ lower (average) shear stress as compared to \#6 bars without nanoclay (20.02 ksi vs. $22.95 \mathrm{ksi}$ ), which suggested that addition of nanoclay will decrease the stress distribution, in turn reducing the stress. Shear stress reduction is also attributed to an increase in resins viscosity by nanoclay exfoliation, which may have increased micro voids. In addition, nanoclay appears to reduce bond strength between fibers and resin.

\#4 bars without nanoclay sho0wed $12.64 \%$ higher average shear stress than \#6 bars without nanoclay (26.27 ksi vs. 22.95 ksi). Similarly \#4 bars with nanoclay showed 19.18\% higher average shear stress than \#6 bars with nanoclay (24.77 ksi vs. 20.02 ksi). 


\subsubsection{SHEAR- WATER AT RT, $110^{\circ} \mathrm{F}$, AND $140^{\circ} \mathrm{F}$ AGING}

Test and Specimen Details

- Aging - Water at room temperature $(R T)$, water at $110^{\circ} \mathrm{F}$, and water at $140^{\circ} \mathrm{F}$ for 3, 6, and 9 months

- Diameter of the bars tested-0.5 in. (\#4)

- Length of the specimens -6 in.

- Cutting tool width $-1 / 2$ in.

- Number of specimens tested- 72

\section{Test Results}

Table 6-3 Summary of test results of bar with and without nanoclay aged in water at $\mathrm{RT}, 110^{\circ} \mathrm{F}$, and $140^{\circ} \mathrm{F}$ for 3,6 , and 9 months

\begin{tabular}{|c|c|c|c|c|c|}
\hline \multirow{2}{*}{$\begin{array}{c}\text { No of } \\
\text { months } \\
\text { in } \\
\text { aging }\end{array}$} & \multicolumn{2}{|c|}{$\begin{array}{c}\text { Bar in water @ room } \\
\text { temp (ksi) }\end{array}$} & \multirow{2}{*}{$\begin{array}{c}\text { Bars with } \\
\text { nanoclay in } \\
\text { water @ } \\
1^{\circ} 0^{\circ} \text { temp } \\
\text { (ksi) }\end{array}$} & \multicolumn{2}{|c|}{$\begin{array}{c}\text { Bar in water @ } 140^{\circ} \mathrm{F} \\
\text { temp }(\mathrm{ksi})\end{array}$} \\
\hline & $\begin{array}{l}\text { Without } \\
\text { nanoclay }\end{array}$ & $\begin{array}{c}\text { With } \\
\text { nanoclay }\end{array}$ & & $\begin{array}{l}\text { Without } \\
\text { nanoclay }\end{array}$ & $\begin{array}{c}\text { With } \\
\text { nanoclay }\end{array}$ \\
\hline 0 & $\begin{array}{c}26.27 \pm 0.62 \\
(2.39 \%)\end{array}$ & $\begin{array}{c}24.77 \pm 1.19 \\
(4.82 \%)\end{array}$ & $\begin{array}{c}24.77 \pm 1.19 \\
(4.82 \%)\end{array}$ & $\begin{array}{c}26.27 \pm 0.62 \\
(2.39 \%)\end{array}$ & $\begin{array}{c}24.77 \pm 1.19 \\
(4.82 \%)\end{array}$ \\
\hline 3 & $\begin{array}{c}25.13 \pm 0.89 \\
(3.56 \%)\end{array}$ & $\begin{array}{c}24.20 \pm 1.57 \\
(6.48 \%)\end{array}$ & $\begin{array}{c}22.19 \pm 1.61 \\
(7.24 \%)\end{array}$ & $\begin{array}{c}21.77 \pm 0.71 \\
(3.26 \%)\end{array}$ & $\begin{array}{c}20.63 \pm 1.38 \\
(6.73 \%)\end{array}$ \\
\hline 6 & $\begin{array}{c}24.79 \pm 1.40 \\
(5.64 \%)\end{array}$ & $\begin{array}{c}23.63 \pm 0.75 \\
(3.18 \%)\end{array}$ & $\begin{array}{c}22.12 \pm 1.12 \\
(5.04 \%)\end{array}$ & $\begin{array}{c}21.13 \pm 0.27 \\
(1.26 \%)\end{array}$ & $\begin{array}{c}20.06 \pm 0.68 \\
(3.38 \%)\end{array}$ \\
\hline 9 & $\begin{array}{c}22.76 \pm 0.53 \\
(2.33 \%)\end{array}$ & $\begin{array}{c}22.72 \pm 1.23 \\
(5.42 \%)\end{array}$ & $\begin{array}{c}21.86 \pm 1.85 \\
(8.07 \%)\end{array}$ & $\begin{array}{c}20.98 \pm 0.39 \\
(1.86 \%)\end{array}$ & $\begin{array}{c}19.83 \pm 0.49 \\
(2.49 \%)\end{array}$ \\
\hline
\end{tabular}

(Values in parenthesis indicate standard deviations as a percentage of the average value)

\section{Discussion of Tests Results}

$>$ Average Double Shear Stress For Non-Aged Bar

- Without nanoclay $=26.27 \pm 0.62 \mathrm{ksi}$ (Std. dev. was $2.39 \%$ of avg. value)

- With nanoclay $=24.77 \pm 1.19 \mathrm{ksi}$ (Std. dev. was $4.82 \%$ of avg. value)

Failure mode - All of the test specimens failed at the shear edge of the cutting tool. 


\section{$\underline{\text { Bars with and without Nanoclay Aged in Water at RT up to } 9 \text { Months }}$}

$>$ Average Double Shear Stress

- Without nanoclay $=22.76 \pm 0.53 \mathrm{ksi}$ (Std. dev. was $2.33 \%$ of avg. value)

- With nanoclay $=22.72 \pm 1.23 \mathrm{ksi}$ (Std. dev. was $5.42 \%$ of avg. value)

> Comparison of Stress - \#4 bars without nanoclay aged in water at RT up to 9 months showed 13.36\% lower (average) stress as compared to \#4 bars without nanoclay subjected to no aging (22.76 ksi vs. $26.27 \mathrm{ksi})$. \#4 bars with nanoclay under same conditioning 8.28\% lower (average) stress as compared to \#4 bars with nanoclay subjected to no aging (22.72 ksi vs. $24.77 \mathrm{ksi})$.

GFRP bars with and without nanoclay aged in water at RT up to 9 months showed a decrease of $8.28 \%$ and $13.36 \%$, respectively, compared to the non-aged specimens.

\section{Bars with Nanoclay Aged in Water at $110^{\circ} \mathrm{F}$ up to 9 Months}

$>$ Average Double Shear Stress $=21.86 \pm 1.85 \mathrm{ksi}($ Std. dev. was $8.07 \%$ of avg. value $)$

Comparison of Stress - \#4 bars with nanoclay aged in water at $110^{\circ} \mathrm{F}$ up to 9 months showed 11.75\% lower (average) stress as compared to \#4 bars with nanoclay subjected to no aging (21.86 ksi vs. $24.77 \mathrm{ksi})$.

\section{Bars with and without Nanoclay Aged in Water at $140^{\circ} \mathrm{F}$ up to 9 Months}

\section{Average Double Shear Stress}

- Without nanoclay $=20.98 \pm 0.39 \mathrm{ksi}$ (Std. dev. was $1.86 \%$ of avg. value)

- With clay $=19.83 \pm 0.49 \mathrm{ksi}$ (Std. dev. was $2.49 \%$ of avg. value)

Comparison of Stress - \#4 bars without nanoclay aged in water at $140^{\circ} \mathrm{F}$ up to 9 months showed 20.14\% lower (average) stress as compared to \#4 bars without nanoclay subjected to no aging (20.98 ksi vs. $26.27 \mathrm{ksi}$ ). \#4 bars with nanoclay under same conditioning showed $19.94 \%$ lower (average) stress as compared to \#4 bars with nanoclay subjected to no aging (19.83 ksi vs. $24.77 \mathrm{ksi})$.

$>$ GFRP bars with and without nanoclay aged in water at $140^{\circ} \mathrm{F}$ up to 9 months showed a decrease of $19.94 \%$ and $20.14 \%$, respectively compared to the non-aged specimens. 


\subsubsection{SHEAR- ALKALINE SOLUTION AT RT AGING}

\section{Test and Specimen Details}

- Aging - Alkaline solution at room temperature aging for 3, 6, and 9 months

- Diameter of the bars tested - 0.5 in. (\#4)

- Length of the specimens -6 in.

- Cutting tool width $-1 / 2$ in.

- Number of specimens tested - 27

\section{Test Results}

Table 6-4 Summary of test results of bar with and without nanoclay aged in alkaline solution at RT for 3, 6, and 9 months

\begin{tabular}{|c|c|c|}
\hline \multirow{2}{*}{$\begin{array}{c}\text { No of } \\
\text { months } \\
\text { in aging }\end{array}$} & \multicolumn{2}{|c|}{ Shear stress } \\
\cline { 2 - 3 } & $\begin{array}{c}\text { Without } \\
\text { nanoclay }\end{array}$ & $\begin{array}{c}\text { With } \\
\text { nanoclay }\end{array}$ \\
\hline 0 & $\begin{array}{c}26.27 \pm 0.62 \\
(2.39 \%)\end{array}$ & $\begin{array}{c}24.77 \pm 1.19 \\
(4.82 \%)\end{array}$ \\
\hline 3 & $\begin{array}{c}23.51 \pm 1.62 \\
(6.90 \%)\end{array}$ & $\begin{array}{c}22.46 \pm 1.54 \\
(6.84 \%)\end{array}$ \\
\hline 6 & $\begin{array}{c}22.24 \pm 2.65 \\
(11.90 \%)\end{array}$ & $\begin{array}{c}23.12 \pm 1.18 \\
(5.10 \%)\end{array}$ \\
\hline 9 & $\begin{array}{c}22.25 \pm 0.39 \\
(1.75 \%)\end{array}$ & $\begin{array}{c}23.40 \pm 1.16 \\
(4.95 \%)\end{array}$ \\
\hline
\end{tabular}

(Values in parenthesis indicate standard deviations as a percentage of the average value)

\section{Discussion of Test Results}

Bars with and without Nanoclay Aged in Alkaline Solution at RT up to 9 Months

\section{Average Double Shear Stress}

- Without nanoclay $=22.25 \pm 0.39 \mathrm{ksi}$ (Std. dev. was $1.75 \%$ of avg. value)

- With nanoclay $=23.40 \pm 1.168 \mathrm{ksi}$ (Std. dev. was $4.95 \%$ of avg. value)

$>$ Comparison of Stress - \#4 bars without nanoclay aged in alkaline solution at RT up to 9 months showed $15.30 \%$ lower (average) stress as compared to \#4 bars without nanoclay subjected to no aging (22.25 ksi vs. $26.27 \mathrm{ksi}$ ). \#4 bars with nanoclay under 
same conditioning showed 5.53\% lower (average) stress as compared to \#4 bars with nanoclay subjected to no aging (23.40 ksi vs. $24.77 \mathrm{ksi})$.

GFRP bars with and without nanoclay aged in alkaline solution at RT up to 9 months showed a decrease of $5.53 \%$ and $15.30 \%$, respectively compared to the non-aged specimens.

\subsubsection{SHEAR- BARS EXTRACTED FROM THE BEAMS}

\section{Test and Specimen Details}

- Aging - Bars extracted from the beams

- Diameter of the bars tested - 0.5 in. (\#4) \& 0.75 in. (\#6)

- Length of the specimens -6 in.

- Cutting tool width $-1 / 2$ in.

- Number of specimens tested - 27

\section{Test Results}

Table 6-5 Summary of test results of \#4 and \#6 bar with and without nanoclay extracted from the concrete beams

\begin{tabular}{|c|c|c|c|}
\hline \multirow{2}{*}{$\begin{array}{c}\text { No of } \\
\text { months }\end{array}$} & \multirow{2}{*}{ Bar size } & \multicolumn{2}{|c|}{ Shear stress } \\
\cline { 3 - 4 } in aging & & Without & With \\
nanoclay & nanoclay \\
\hline \multirow{2}{*}{0} & \multirow{2}{*}{ \#4 } & $\begin{array}{c}26.27 \pm 0.62 \\
(2.39 \%)\end{array}$ & $\begin{array}{c}24.77 \pm 1.19 \\
(4.82 \%)\end{array}$ \\
\cline { 2 - 4 } & \multirow{2}{*}{2} & $22.95 \pm 2.05$ & $20.02 \pm 1.81$ \\
& & $(8.94 \%)$ & $(9.05 \%)$ \\
\cline { 2 - 4 } & $\# 4$ & $24.71 \pm 1.69$ & $23.41 \pm 1.72$ \\
& & $(6.83 \%)$ & $(7.35 \%)$ \\
& \multirow{2}{*}{2} & $22.31 \pm 1.58$ & $19.54 \pm 1.42$ \\
& & $(7.10 \%)$ & $(7.26 \%)$ \\
\hline
\end{tabular}

(Values in parenthesis indicate standard deviations as a percentage of the average value) 


\section{Discussion of Tests Results}

\section{\#4 and \#6 Bars with and without Nanoclay Extracted From the Beams}

\section{Average Double Shear Stress of \#4 bars}

- Without nanoclay $=24.71 \pm 1.69 \mathrm{ksi}$ (Std. dev. was $6.83 \%$ of avg. value)

- With nanoclay $=23.41 \pm 1.72 \mathrm{ksi}($ Std. dev. was $7.35 \%$ of avg. value $)$

\section{Average Double Shear Stress of \#6 bars}

- Without nanoclay $=22.31 \pm 1.58 \mathrm{ksi}$ (Std. dev. was $7.10 \%$ of avg. value)

- With nanoclay $=19.54 \pm 1.42 \mathrm{ksi}($ Std. dev. was $7.26 \%$ of avg. value $)$

\section{$>$ Comparison of Stress}

- \#4 bars without nanoclay extracted from the concrete beams showed 5.94\% lower (average) stress as compared to \#4 bars without nanoclay subjected to no aging (24.71 ksi vs. $26.27 \mathrm{ksi}$ ). \#4 bars with nanoclay under same conditioning showed $5.49 \%$ lower (average) stress as compared to \#4 bars with nanoclay subjected to no aging (23.41 ksi vs. $24.77 \mathrm{ksi}$ ).

- \#6 bars without nanoclay extracted from the concrete beams showed $2.79 \%$ lower (average) stress as compared to \#6 bars without nanoclay subjected to no aging (22.31 ksi vs. $22.95 \mathrm{ksi}$ ). \#6 bars with nanoclay under same conditioning showed $2.40 \%$ lower (average) stress as compared to \#6 bars with nanoclay subjected to no aging (19.54 ksi vs. $20.02 \mathrm{ksi}$ ). 


\subsection{SUMMARY AND CONCLUSION}

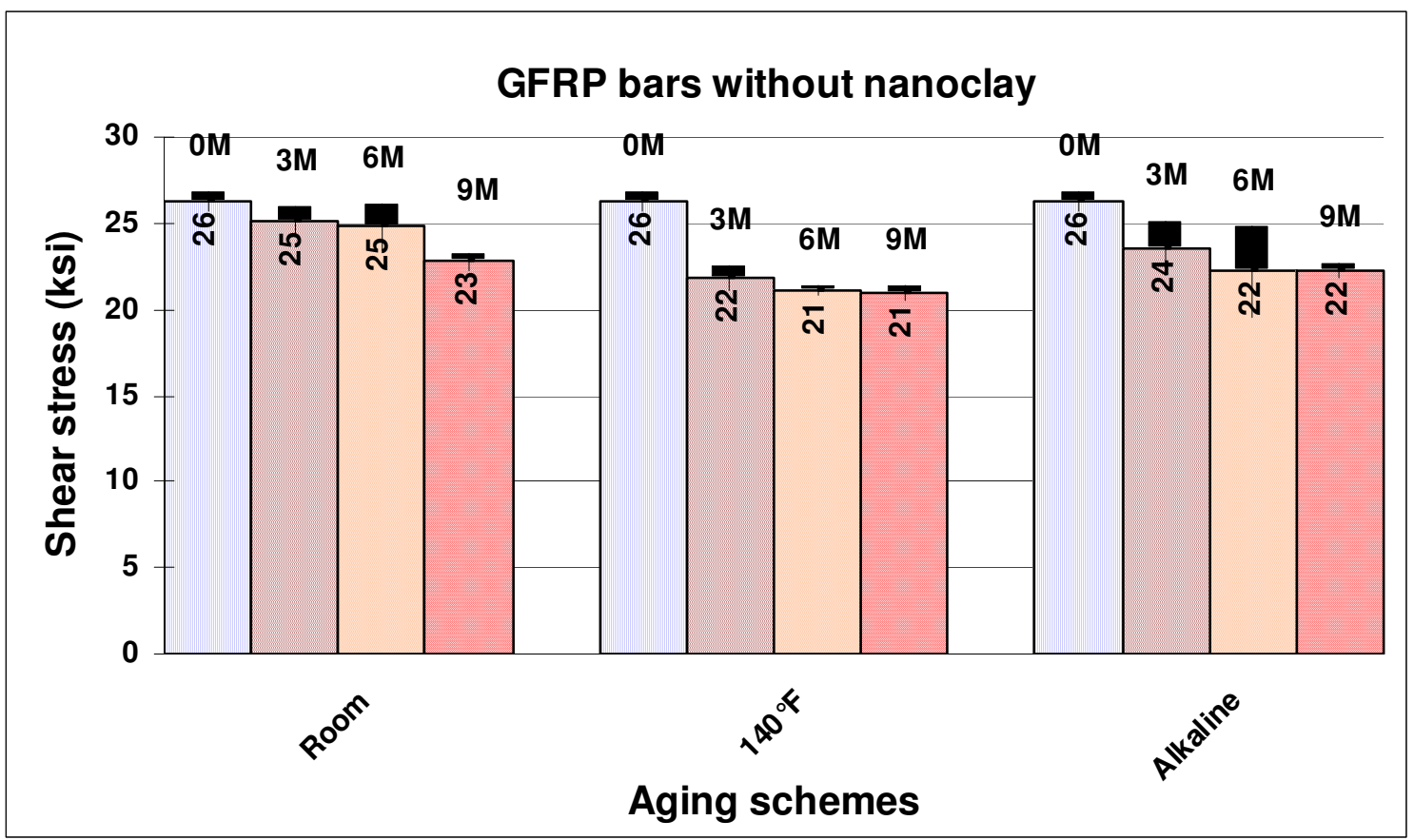

Figure 6-2 Comparison of shear stress of GFRP bars without nanoclay aged in different aging schemes non-aged bars (Note: M-Months; Std. dev. is also shown at the top of the bars in the graph as a shaded rectangle)

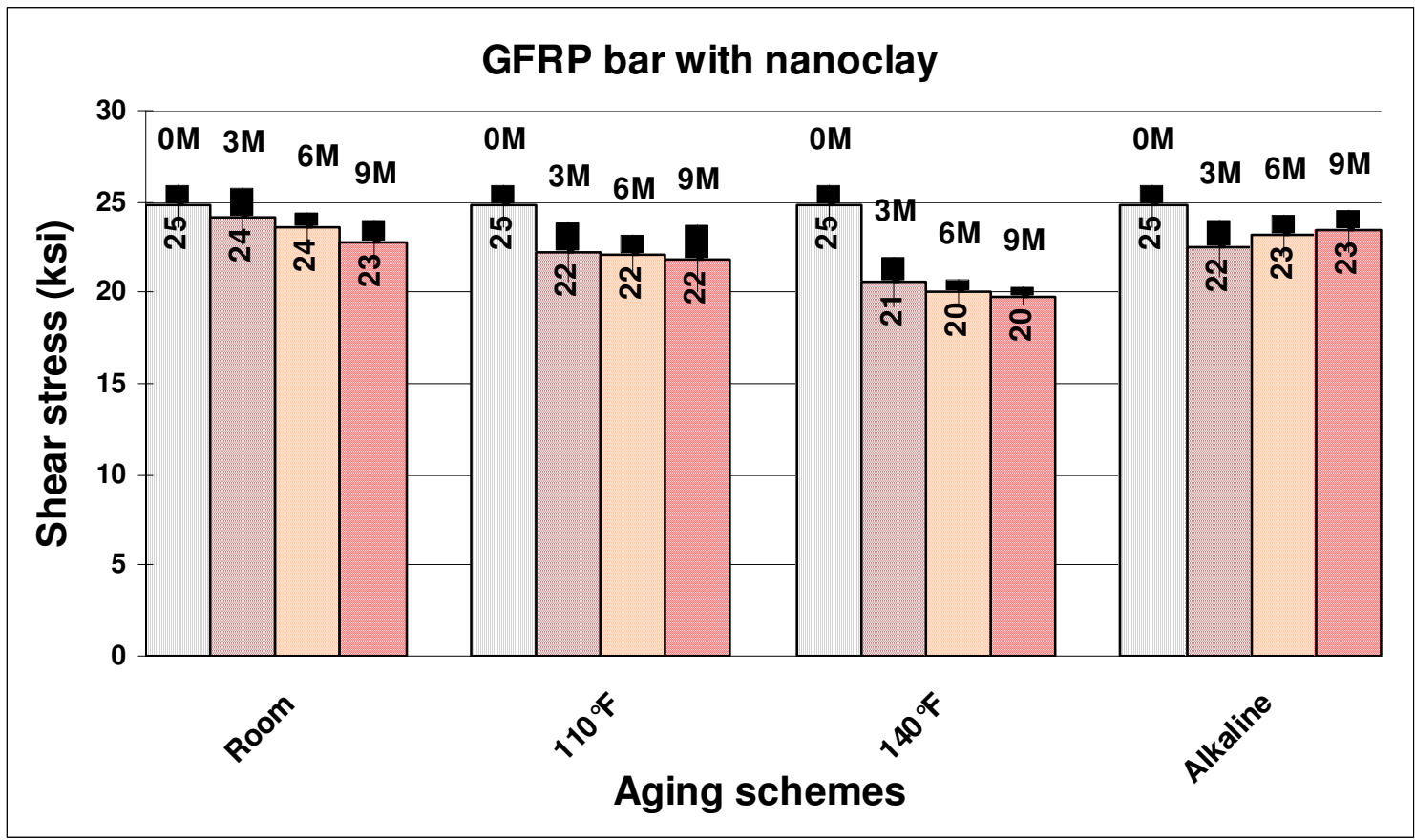

Figure 6-3 Comparison of shear stress of GFRP bars with nanoclay aged in different aging schemes to bars without aging (Note: M-Months; Std. dev. is also shown at the top of the bars in the graph as a shaded rectangle) 


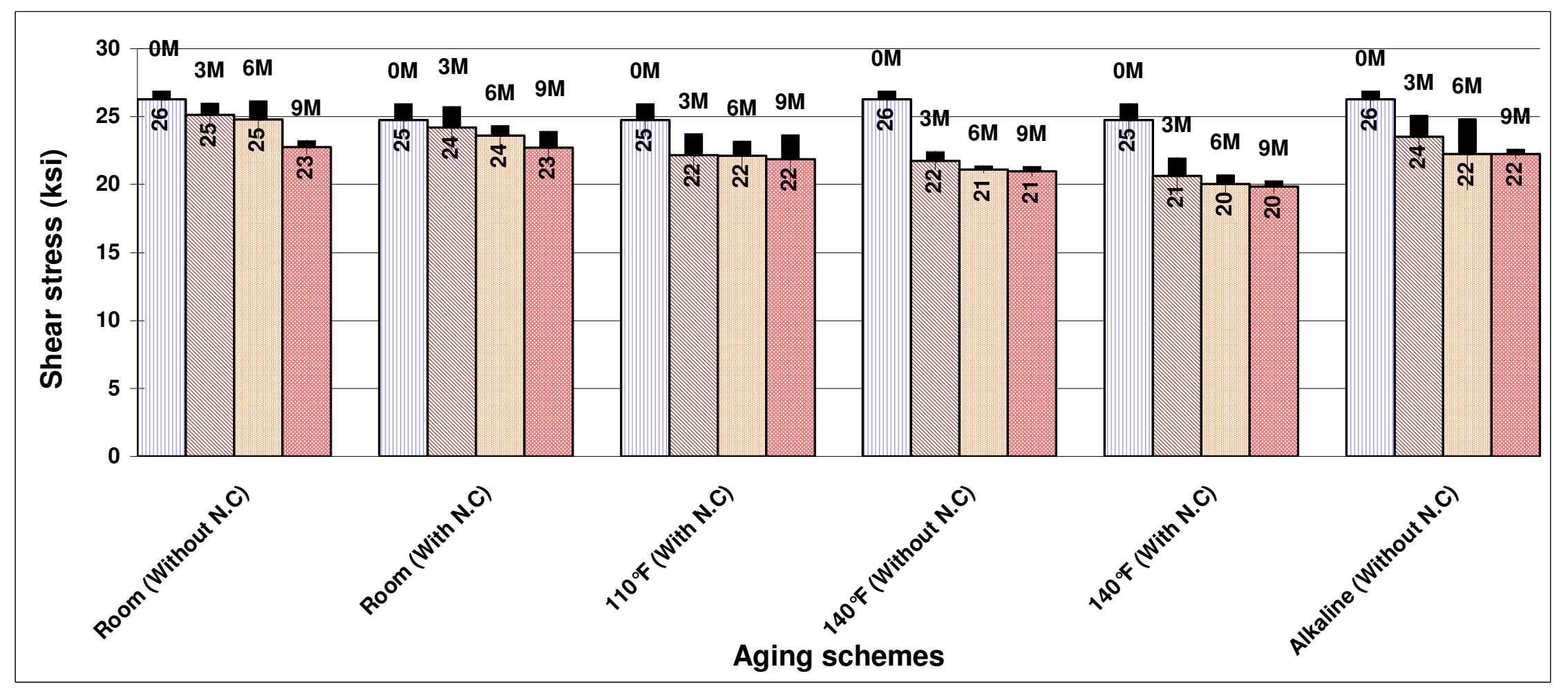

Figure 6-4 Comparison of shear stress of GFRP bars with and without nanoclay aged in different aging schemes to nonaged bars (Note: N.C-Nanoclay and M-Months; Std. dev. is also shown at the top of the bars in the graph as a shaded rectangle) 


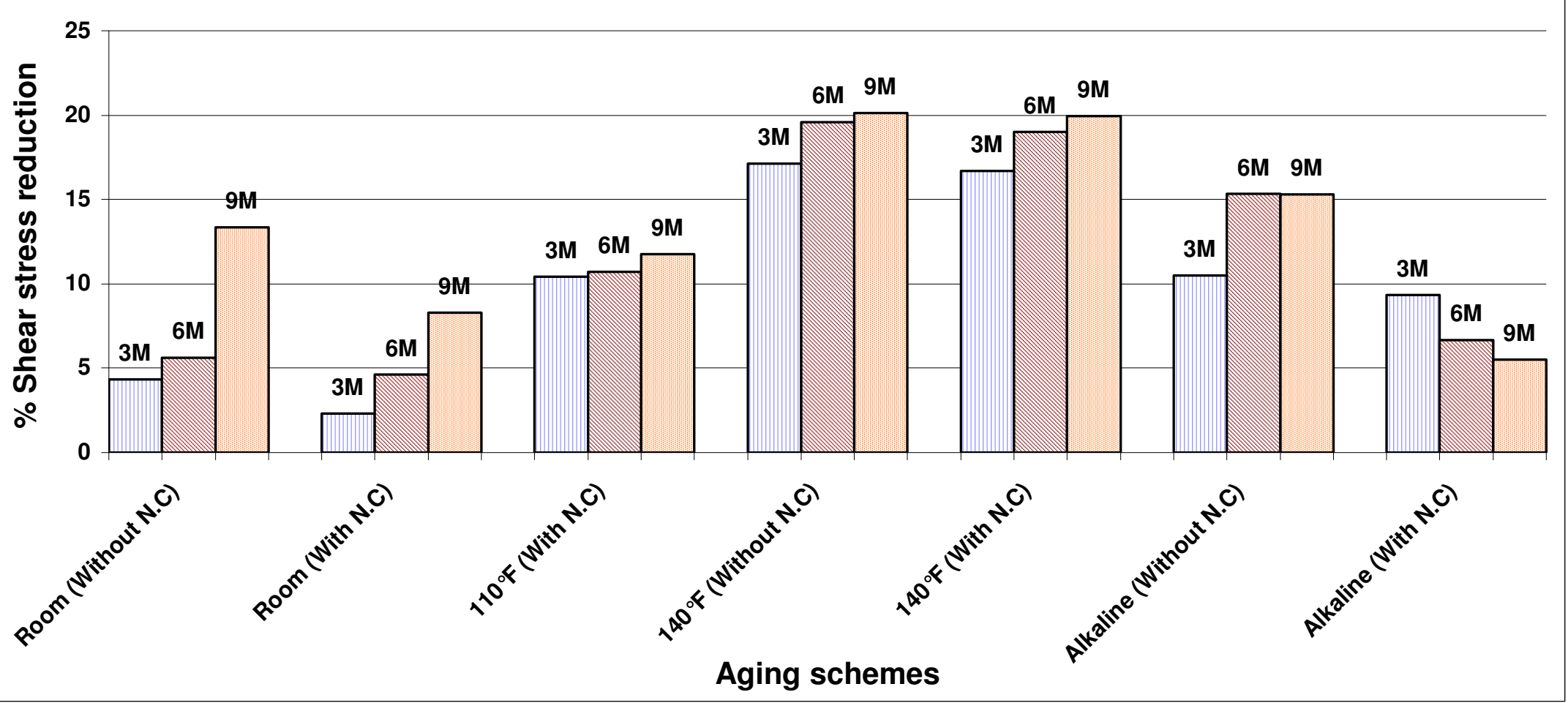

Figure 6-5 Comparison of percentage shear stress reduction of GFRP bars with and without nanoclay aged in different aging schemes to non-aged bars (Note: N.C-Nanoclay and M-Months) 
- \#4 bars with nanoclay showed 5.71\% lower (average) shear stress as compared to \#4 bars without nanoclay (24.77 ksi vs. $26.27 \mathrm{ksi}$ ) and \#6 bars with nanoclay showed $12.77 \%$ lower (average) stress as compared to \#6 bars without nanoclay (20.02 ksi vs. $22.95 \mathrm{ksi}$ ), which suggested that addition of nanoclay decreased the shear stress. Reduction in shear strength is attributed to reduction in interlaminar shear reduction in interfacial bond stress between fibers and resin.

- Shear stress reduction in GFRP bars due to addition of nanoclay is attributed to:

$>$ Increase in resin viscosity by nanoclay exfoliation, leading to increased micro voids.

$>$ Reduction in bond strength between fibers and resin due to the presence of nanoclay that may locally affect the stress distribution.

$>$ Possible abrasion between fibers and nanoclay particles in the resin during pulling process that may create glass fiber surface imperfections under increased resin viscosity.

- GFRP bar with nanoclay exhibited better durability than those without nanoclay in all types of conditioning schemes (Table 6-8) considered in this research.

$>$ Maximum stress reduction after 9 months of water conditioning at room temperature without and with nanoclay were $13.36 \%$ and $8.28 \%$, respectively.

Maximum stress reduction after 9 months of water conditioning at $110^{\circ} \mathrm{F}$ with nanoclay was $11.75 \%$. Bars without nanoclay were not used for $110^{\circ} \mathrm{F}$ conditioning.

$>$ Maximum stress reduction after 9 months of water conditioning at $140^{\circ} \mathrm{F}$ without and with nanoclay were $20.14 \%$ and $19.94 \%$, respectively.

Maximum stress reduction after 9 months of alkaline conditioning at room temperature without and with nanoclay were $15.30 \%$ and $5.53 \%$, respectively.

- Among different aging schemes, (water at room temperature, water at $110^{\circ} \mathrm{F}$, water at $140^{\circ} \mathrm{F}$, and alkaline solution at room temperature) water at elevated temperature of $140^{\circ} \mathrm{F}$ was found to be more severe on shear stress reduction followed by alkaline aging $(20.14 \%$ without nanoclay vs. $19.94 \%$ with nanoclay 
at $140^{\circ} \mathrm{F}$ as compared to $15.30 \%$ without nanoclay and $5.53 \%$ with nanoclay at alkaline solution).

$>$ Nanoclay was found to provide better durability with increasing temperature, which is attributed to bridging the difference in thermal compatibility between glass fiber $\left(5.3 \times 10^{-6} \mathrm{~m} / \mathrm{m} /{ }^{\circ} \mathrm{C}\right)$ and matrix $(56.8 \mathrm{x}$ $\left.10^{-6} \mathrm{~m} / \mathrm{m} /{ }^{\circ} \mathrm{C}\right)$.

Neat resin exfoliated with nanoclay was found to have lower moisture absorption than neat resin without nanoclay (refer to Chapter 8).

- Addition of nanoclay resulted in a reduction of shear stress in non-aged bars. However, better durability was noted in bars with nanoclay under different aging schemes.

- Effect of Yield of glass fibers - \#6 bars manufactured with 113 Yield glass fiber rovings showed an increase in shear stress of $9.89 \%$ as compared to bars manufactured with 56 Yield glass fiber rovings (20.02 ksi vs. $22.00 \mathrm{ksi}$ ).

- \#4 Bars without and with nanoclay extracted from concrete beams after flexure tests indicated $5.94 \%$ and $5.49 \%$ stress reduction, respectively as compared to non-aged specimens (Table 6-8). \#6 Bars without and with nanoclay extracted from concrete beams after flexure tests indicated $2.79 \%$ and $2.40 \%$ stress reduction, respectively as compared to non-aged specimens (Table 6-8). However, no definite conclusions are drawn because extracted of bars from the beams possibly resulted in fiber damage.

- \#4 bars without nanoclay showed an increased shear stress of $12.64 \%$ over \#6 bars without nanoclay (26.27 ksi vs. $22.95 \mathrm{ksi}$ ). Similarly \#4 bars with nanoclay showed an increase shear stress of $19.18 \%$ over \#6 bars with nanoclay (24.77 ksi vs. $20.02 \mathrm{ksi}$ ). 
Table 6-6 Summary of Shear test

\begin{tabular}{|c|c|c|c|c|c|}
\hline $\begin{array}{c}\text { No of } \\
\text { months in } \\
\text { aging }\end{array}$ & $\begin{array}{l}\text { Aging } \\
\text { condition }\end{array}$ & $\begin{array}{l}\text { Bar } \\
\text { size }\end{array}$ & Nanoclay & $\begin{array}{c}\text { Average } \\
\text { Maximum stress } \\
(\text { ksi) } \\
\end{array}$ & $\begin{array}{c}\% \\
\text { strength } \\
\text { reduction }\end{array}$ \\
\hline \multirow{5}{*}{0} & \multirow{5}{*}{ No aging } & \multirow{2}{*}{ \#4 } & Yes & $24.77 \pm 1.19$ & \multirow{5}{*}{ N/A } \\
\hline & & & No & $26.27 \pm 2.55$ & \\
\hline & & \multirow{3}{*}{$\# 6$} & Yes $^{\dagger}$ & $20.02 \pm 1.81$ & \\
\hline & & & Yes & $22.00 \pm 1.86$ & \\
\hline & & & $\mathrm{No}^{\dagger}$ & $22.95 \pm 2.05$ & \\
\hline \multirow{4}{*}{2} & \multirow{4}{*}{$\begin{array}{c}\text { Bars } \\
\text { extracted } \\
\text { from } \\
\text { concrete } \\
\text { beams }\end{array}$} & \multirow{2}{*}{ \#4 } & Yes & $23.41 \pm 1.72$ & $5.49 \%$ \\
\hline & & & No & $24.71 \pm 1.69$ & $5.94 \%$ \\
\hline & & \multirow{2}{*}{ \#6 } & Yes $^{\dagger}$ & $19.54 \pm 1.42$ & $2.40 \%$ \\
\hline & & & $\mathrm{No}^{\dagger}$ & $22.31 \pm 1.58$ & $2.79 \%$ \\
\hline \multirow{7}{*}{3} & \multirow{2}{*}{ Water/RT } & \multirow{7}{*}{ \#4 } & Yes & $24.20 \pm 1.57$ & $2.30 \%$ \\
\hline & & & No & $25.13 \pm 0.89$ & $4.34 \%$ \\
\hline & Water $/ 110^{\circ} \mathrm{F}$ & & Yes & $22.19 \pm 1.61$ & $10.42 \%$ \\
\hline & \multirow{2}{*}{ Water $/ 140^{\circ} \mathrm{F}$} & & Yes & $20.63 \pm 1.38$ & $16.71 \%$ \\
\hline & & & No & $21.77 \pm 0.71$ & $17.13 \%$ \\
\hline & \multirow{2}{*}{ Alkaline/RT } & & Yes & $22.46 \pm 1.54$ & $9.33 \%$ \\
\hline & & & No & $23.51 \pm 1.62$ & $10.51 \%$ \\
\hline \multirow{7}{*}{6} & \multirow{2}{*}{ Water/RT } & \multirow{7}{*}{ \#4 } & Yes & $23.63 \pm 0.75$ & $4.60 \%$ \\
\hline & & & No & $24.79 \pm 1.40$ & $5.63 \%$ \\
\hline & Water $/ 110^{\circ} \mathrm{F}$ & & Yes & $22.12 \pm 1.12$ & $10.70 \%$ \\
\hline & \multirow{2}{*}{ Water $/ 140^{\circ} \mathrm{F}$} & & Yes & $20.06 \pm 0.68$ & $19.01 \%$ \\
\hline & & & No & $25.43 \pm 0.32$ & $19.58 \%$ \\
\hline & \multirow{2}{*}{ Alkaline/RT } & & Yes & $23.12 \pm 1.18$ & $6.66 \%$ \\
\hline & & & No & $22.24 \pm 2.65$ & $15.34 \%$ \\
\hline \multirow{7}{*}{9} & \multirow{2}{*}{ Water/RT } & \multirow{7}{*}{ \#4 } & Yes & $22.72 \pm 1.23$ & $8.28 \%$ \\
\hline & & & No & $22.76 \pm 0.53$ & $13.36 \%$ \\
\hline & Water $/ 110^{\circ} \mathrm{F}$ & & Yes & $21.86 \pm 1.85$ & $11.75 \%$ \\
\hline & \multirow{2}{*}{ Water $/ 140^{\circ} \mathrm{F}$} & & Yes & $19.83 \pm 0.49$ & $19.94 \%$ \\
\hline & & & No & $20.98 \pm 0.39$ & $20.14 \%$ \\
\hline & \multirow{2}{*}{ Alkaline/RT } & & Yes & $23.40 \pm 1.16$ & $5.53 \%$ \\
\hline & & & No & $22.25 \pm 0.39$ & $15.30 \%$ \\
\hline
\end{tabular}

RT- Room temperature *\#6 GFRP bars manufactured with 56 yield glass fiber rovings. Rest of the bars were manufactured with 113 Yield glass fiber rovings. 


\section{BOND TESTS}

\subsection{INTRODUCTION}

Bond tests were performed on aged and non-aged bars of \#4 and \#6 size. Bond test procedure and analytical calculation procedure used in this study are given in section 7.2. Type and number of bars tested in bond are shown in Table 7-1. Figure 7-1 shows test setup for bond tests. A schematic diagram of the test specimen and the cross section of the GFRP bar with the concrete cylinder are shown in Figure 7-2. The FRP bars were embedded in a concrete cylinder for a length of 3 in. A foam tube was used (12 in. -3 in. $=9$ in.; 9/2 in. = 4.5 in.) on either side (both at top and bottom) of the length of FRP bar in contact with the concrete. A thin coat of oil was applied on the surface of the foam tube to make sure no bond was developed between concrete and the foam. An LVDT was used to record the slip at the unloading end of the bar while load was applied at the other end of the bar. The loading end was bonded with schedule 80 steel pipes ( 8 in. long) using a commercially available resin, called Pliogrip ${ }^{\mathrm{TM}}$, similar to the tension test specimen as described in section 5.2.3. The total length of the FRP bar including the length inside the cylinder was 36 in. - 40 in.

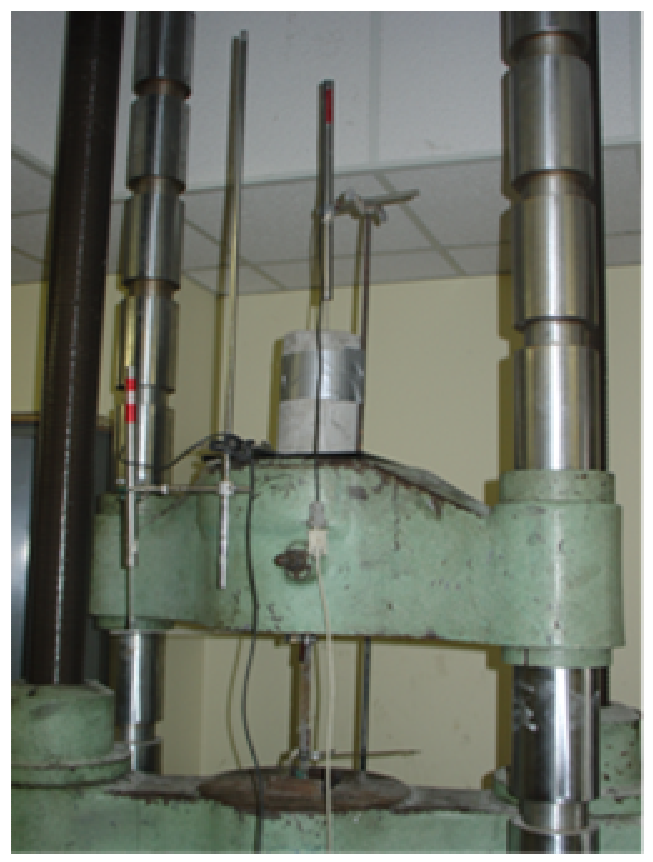

Figure 7-1 Bond Test Apparatus 
Table 7-1 Number and aging schemes of GFRP bars tested in bond

\begin{tabular}{|c|c|c|c|c|c|c|}
\hline \multirow[b]{2}{*}{ Aging schemes } & \multirow{2}{*}{$\begin{array}{l}\text { Bar } \\
\text { size }\end{array}$} & \multirow[b]{2}{*}{ Nanoclay } & \multicolumn{4}{|c|}{ Number of specimens } \\
\hline & & & $\begin{array}{c}\text { Without } \\
\text { aging }\end{array}$ & $\begin{array}{c}3 \text { months } \\
\text { aging }\end{array}$ & $\begin{array}{c}6 \text { months } \\
\text { aging }\end{array}$ & $\begin{array}{c}9 \text { months } \\
\text { aging }\end{array}$ \\
\hline \multirow{3}{*}{ Non-aged } & \multirow{2}{*}{ \#4 } & Yes & 3 & - & - & - \\
\hline & & No & 2 & - & - & - \\
\hline & $\# 6$ & Yes & 3 & - & - & - \\
\hline Water/RT & \multirow{4}{*}{ \#4 } & Yes & - & 2 & 2 & 2 \\
\hline Water at $110^{\circ} \mathrm{F}$ & & Yes & - & 2 & 2 & 2 \\
\hline Water at $140^{\circ} \mathrm{F}$ & & Yes & - & 2 & 2 & 2 \\
\hline $\begin{array}{c}\text { Alkaline } \\
\text { solution/RT }\end{array}$ & & Yes & - & 2 & 2 & 2 \\
\hline
\end{tabular}

\subsection{DEVELOPMENT OF THE TEST}

This test method was used from the previous research carried out by the CFC-WVU. Additional details can be obtained from the reference Vijay et al, 2003.

\subsubsection{REFERENCE DOCUMENTS}

(a).Japan Society of Civil Engineers (JSCE) 1997. Recommendation for design and construction of concrete structures using continuous fiber reinforced materials, concrete engineering series 23, Ed. A. Machida, Research committee on continuous fiber reinforced materials, Tokyo, Japan, PP.

(b). ASTM C234-91a, Standard Test Method for Comparing Concretes on the Basis of the Bond Developed with Reinforcing Steel.

(c). ASTM C617-98, Standard Practice for Capping Cylindrical Concrete Specimens. 


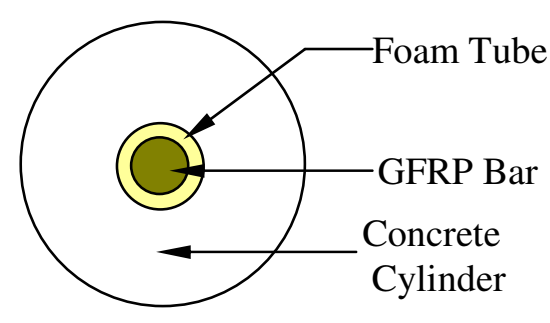

SECTION B-B

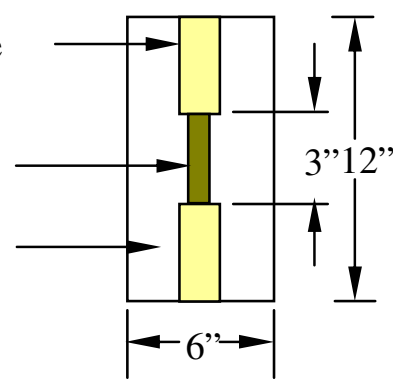

SECTION A-A

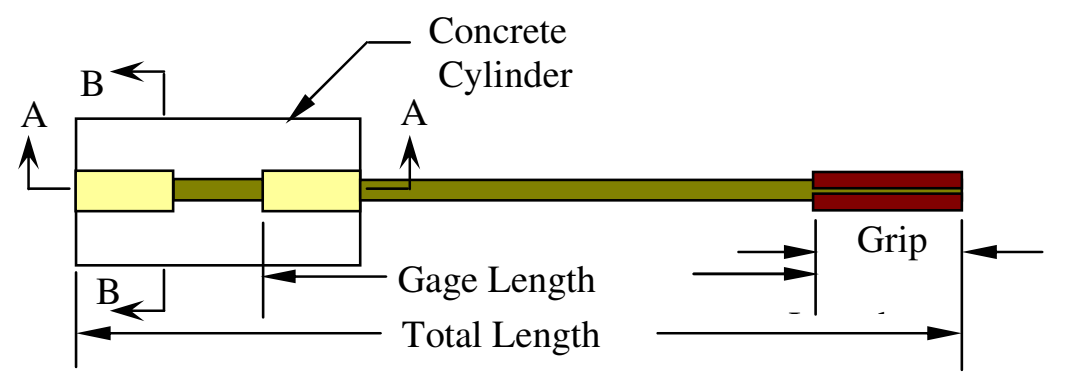

Figure 7-2 Schematic Diagram of the Bond Test Setup

\subsubsection{TERMINOLOGY}

Test section: The portion of a specimen to be tested between the anchoring section on one side and the concrete cylinder on the other side.

Grip length (anchoring section): The end part of the test specimen where an anchorage is fitted to transmit the load from the testing machine to the test section.

Anchorage: Device fitted to the anchoring section of a test specimen to transmit loads from the testing machine to the test specimen.

Embedded length: The length of the GFRP bar in contact with the concrete.

Embedment cylinder: The concrete cylinder in which the FRP bar is embedded.

\subsubsection{SPECIMEN PREPARATION}

\section{a. Preparation:}

i. Non-aged: Care was taken so that the specimen was not subjected to any processing. During the sampling and preparation of test specimens, all parameters that cause changes (deformation, heating, outdoor exposure to 
ultraviolet light etc.,) to the material properties of the test specimen were avoided.

ii. Aged: Specimens were aged in water at room temperature, water at $110^{\circ} \mathrm{F}$, water at $140^{\circ} \mathrm{F}$, and alkaline solution at room temperature for 3,6 , and 9 months.

b. Test section length and grip length: A test section length of 22 in. was used with a grip length of 8 in. on the loading end of the bar. The total length of the specimen including the grip length was $40 \mathrm{in}$.

c. Anchorages (Grips): Steel pipes of appropriate diameter and length were split and bonded to end of the FRP rebar using Pliogrip ${ }^{\mathrm{TM}}$, a commercially available resin. The resin was allowed to cure for a minimum of 24 hours before the specimens were tested.

d. Embedment cylinder: FRP bar was embedded in a concrete cylinder of 12 in. length and 6 in. diameter.

e. Embedment length and debonding element: An embedment length of 3 in. was adopted. The remaining length of FRP bar was debonded from the concrete using foam tubes between the bar and the concrete.

f. Number of specimens: Number of specimens tested was two in each group.

\subsubsection{TEST EQUIPMENT}

The bond specimens were tested on Universal Testing Machine (UTM) with a maximum load capacity of 200 kips. A computerized data acquisition was used to record the load and slip data.

\subsubsection{TEST METHOD}

(a).Mounting: When mounting the test specimen on the testing machine, care was taken to ensure that the longer axis of the test specimen coincides with the imaginary line joining the two end anchors fitted to the testing machine.

(b).Loading rate: The applied rate of loading for the tension test specimen was between 250-750 psi per minute.

(c). Testing temperature: The test temperature was generally with the range of $40-100^{\circ} \mathrm{F}$.

(d). Loading: The load was applied until bar slip. 


\subsubsection{CALCULATION}

The material properties of FRP bar were assessed only on the basis of the test specimen undergoing failure in the test section. In cases where there was tensile failure or slippage in anchoring section, the data was disregarded. A typical stress-slip plot is shown in Figure 7-3, with stress on the y-axis and slip on the $\mathrm{x}$-axis.

(a). Average bond stress, $\tau$ : The bond stress was calculated using Eq. (7.1)

$$
\tau=\frac{F}{S}
$$

Where,

$\tau=$ Average bond stress (ksi)

$\mathrm{F}=\mathrm{Load}$ at which bond failure occurs (kips)

$\mathrm{S}=$ Surface area of the GFRP bar in contact with the concrete was calculated from Eq. (7.2) (in. $\left.{ }^{2}\right)$

(b). Contact surface area, $S$ : The contact surface area was calculated as below,

$$
\mathrm{S}=\pi \mathrm{d}_{\mathrm{x}} 1_{\mathrm{x}}
$$

Where,

$$
\begin{aligned}
& \mathrm{S}=\text { Contact surface area (in. }{ }^{2} \text { ) } \\
& \mathrm{d}_{\mathrm{x}}=\text { Diameter of GFRP bar (in.) } \\
& \mathrm{l}_{\mathrm{x}}=\text { Length embedment (in.) }
\end{aligned}
$$

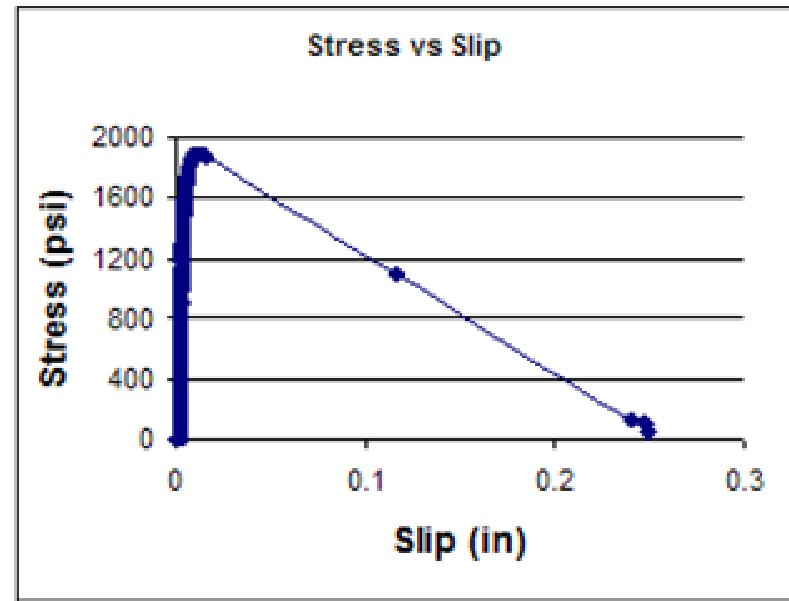

Figure 7-3 Typical stress vs. slip (unloading end) plot for GFRP bars without nanoclay in bond test 


\subsection{TEST RESULTS}

\subsubsection{BOND- NO AGING}

\section{Test and Specimen Details}

- Aging - No aging

- Diameter of the bars tested - 0.5 in. (\#4) \& 0.75 in. (\#6)

- Length of the specimens $-40 \mathrm{in}$.

- Concrete cylinder strength and dimension - 4 ksi, $12 \mathrm{in}$. long and $6 \mathrm{in}$. diameter

- Number of specimens tested - 8

- Slip at the unloading end of the bar was recorded using LVDT

\section{Test Results}

Table 7-2 Summary of test results of \#4 and \#6 bars with and without nanoclay subjected to no aging

\begin{tabular}{|c|c|c|c|}
\hline \multirow{2}{*}{$\begin{array}{c}\text { No of } \\
\text { months } \\
\text { in aging }\end{array}$} & \multirow{2}{*}{$\begin{array}{c}\text { Bar } \\
\text { diameter }\end{array}$} & \multicolumn{2}{|c|}{ Maximum bond stress (psi) } \\
\hline & & $\begin{array}{l}\text { Without } \\
\text { nanoclay }\end{array}$ & With nanoclay \\
\hline & \#4 & $\begin{array}{c}1706.34 \pm 33.86 \\
(1.98 \%)\end{array}$ & $\begin{array}{c}1734.08 \pm 36.10 \\
(2.08 \%)\end{array}$ \\
\hline & \#6 & - & $\begin{array}{c}1793.06 \pm 62.53 \\
(3.49 \%)\end{array}$ \\
\hline
\end{tabular}

\section{Discussion of Tests Results}

\section{Average bond stress of \#4 bars}

- Without nanoclay $=1706.34 \pm 33.86$ psi (Std. dev. was $1.98 \%$ of avg. value). Maximum slip measured was 0.026 in. before slip.

- With nanoclay $=1734.08 \pm 36.10$ psi (Std. dev. was $2.08 \%$ of avg. value). Maximum slip measured was 0.020 in. before slip.

$>$ Average bond stress of \#6 bars with nanoclay = $1793.06 \pm 62.53$ psi (Std. dev. was $3.49 \%$ of avg. value). Maximum slip measured was 0.028 in. before slip.

Failure mode - All the specimens failed due to bar slip inside concrete. The ribs on the surface served as resistance to slip. 
Comparison of Stress - \#4 bars with nanoclay showed a small 1.56\% higher average stress as compared to \#4 bars without nanoclay (1734.08 psi vs. 1706.34 psi).

\subsubsection{BOND- WATER AT RT, $110^{\circ} \mathrm{F}, 140^{\circ} \mathrm{F}$, AND ALKAINE SOLUTION AT RT}

\section{Test and Specimen Details}

- Aging - Water at room temperature (RT), water at $110^{\circ} \mathrm{F}$, water at $140^{\circ} \mathrm{F}$, and alkaline solution at room temperature for 3, 6, and 9 months

- Diameter of the bars tested-0.5 in. (\#4)

- Length of the specimens $-40 \mathrm{in}$.

- Concrete cylinder strength and dimension - $4 \mathrm{ksi}, 12 \mathrm{in.}$ long and $6 \mathrm{in}$. diameter

- Number of specimens tested - 24

- Slip at the unloading end of the bar was recorded using LVDT

- Failure mode - All the specimens failed due to bar slip inside concrete. The ribs on the surface served as resistance to slip.

\section{Test Results}

Table 7-3 Summary of test results of bars with nanoclay aged in Water at RT, $110^{\circ} \mathrm{F}, 140^{\circ} \mathrm{F}$, and alkaline solution at $\mathrm{RT}$ for 3,6 , and 9 months

\begin{tabular}{|c|c|c|c|c|}
\hline \multirow{2}{*}{$\begin{array}{c}\text { No of } \\
\text { months } \\
\text { in }\end{array}$} & \multicolumn{4}{|c|}{ Maximum bond stress (psi) } \\
\cline { 2 - 5 } aging & Water @ room & Water @ & Water @ 140 & F \\
temp & $\mathbf{1 1 0}^{\circ} \mathbf{F}$ temp & Alkaline @ \\
romp & $1734.08 \pm 36.10$ & $1734.08 \pm 36.10$ \\
\hline 0 & $1734.08 \pm 36.10$ & $1734.08 \pm 36.10$ & $(2.08 \%)$ & $(2.08 \%)$ \\
\hline 3 & $(2.08 \%)$ & $(2.08 \%)$ & $1706.0 \pm 213.22$ & $1814.82 \pm 81.10$ \\
\hline 6 & $1816.87 \pm 28.08$ & $1855.73 \pm 41.37$ & $(12.50 \%)$ & $(2.23 \%)$ \\
\hline 9 & $(1.55 \%)$ & $(2.23 \%)$ & $1878.70 \pm 9.24$ & $1819.88 \pm 60.06$ \\
& $(4.19 \%)$ & $(0.05 \%)$ & $(0.49 \%)$ & $(3.30 \%)$ \\
\hline & $(3.62 \%)$ & $(2.19 \%)$ & $(5.34 \%)$ & $(3.96 \%)$ \\
\hline
\end{tabular}

(Values in parenthesis indicate standard deviations as a percentage of the average value) 


\section{Discussion of Tests Results}

$>$ Average bond stress for non-aged bars with nanoclay $=1734.08 \pm 36.10 \mathrm{psi}$ (Std. dev. was $2.08 \%$ of avg. value). Maximum slip measured was 0.020 in. before slip.

\section{Bars Aged in Water at RT up to 9 Months}

$>$ Average bond stress $=1818.27 \pm 65.82 \mathrm{psi}(\mathrm{Std}$. dev. was $3.62 \%$ of avg. value $)$. Maximum slip measured was 0.018 in. before slip.

$>$ \#4 bars aged in water at RT for 9 months showed $4.85 \%$ higher average stress as compared to \#4 bars subjected to no aging (1818.27 psi vs. 1734.08 psi).

\section{Bars Aged in Water at $110^{\circ} \mathrm{F}$ up to 9 Months}

Average bond stress $=1753.12 \pm 38.34$ psi (Std. dev. was 2.19\% of avg. value) Maximum slip measured was 0.016 in. before slip.

\#4 bars aged in water at $110^{\circ} \mathrm{F}$ for 9 months showed $1.10 \%$ higher average stress as compared to \#4 bars subjected to no aging (1753.12 psi vs. 1734.08 psi).

\section{Bars Aged in water at $140^{\circ} \mathrm{F}$ up to 9 Months}

Average bond stress $=1773.41 \pm 94.77$ psi (Std. dev. was $5.34 \%$ of avg. value) Maximum slip measured was 0.019 in. before slip.

\#4 bars aged in water at $140^{\circ} \mathrm{F}$ for 9 months showed $2.27 \%$ higher average stress as compared to \#4 bars subjected to no aging (1773.41 psi vs. 1734.08 psi).

\section{Bars Aged in Alkaline Solution at RT up to 9 Months}

$>$ Average bond stress $=1755.66 \pm 70.23$ psi (Std. dev. was 3.96\% of avg. value) . Maximum slip measured was 0.024 in. before slip.

$>$ \#4 bars aged in alkaline solution at RT for 9 months showed 1.24\% higher average stress as compared to \#4 bars subjected to no aging (1755.66 psi vs. 1734.08 psi). 


\subsection{SUMMARY AND CONCLUSION}

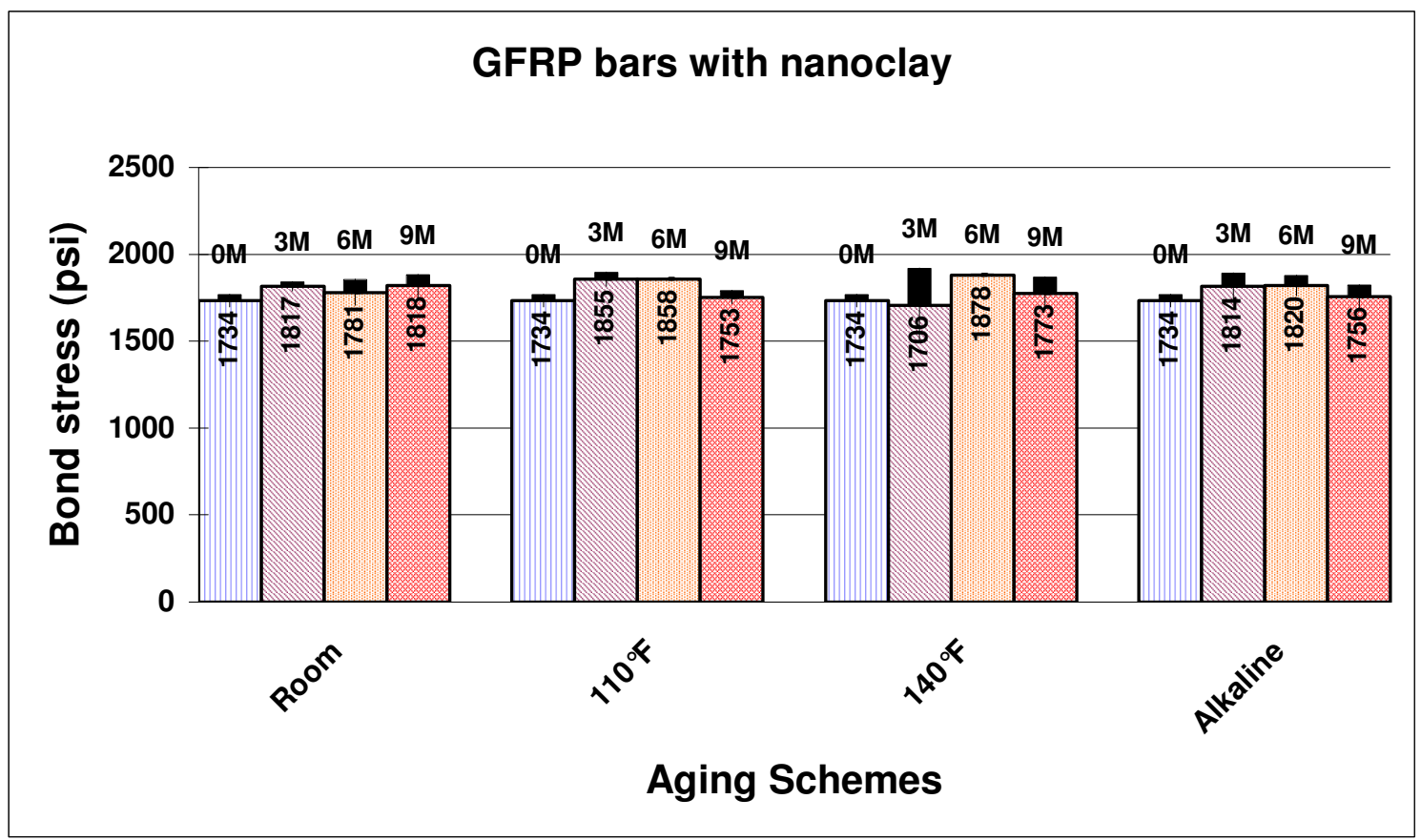

Figure 7-4 Comparison of bond stress of GFRP bars with nanoclay aged in different aging schemes to non-aged bars (Note: M-Months; Std. dev. is also shown at the top of the bars in the graph as a shaded rectangle)

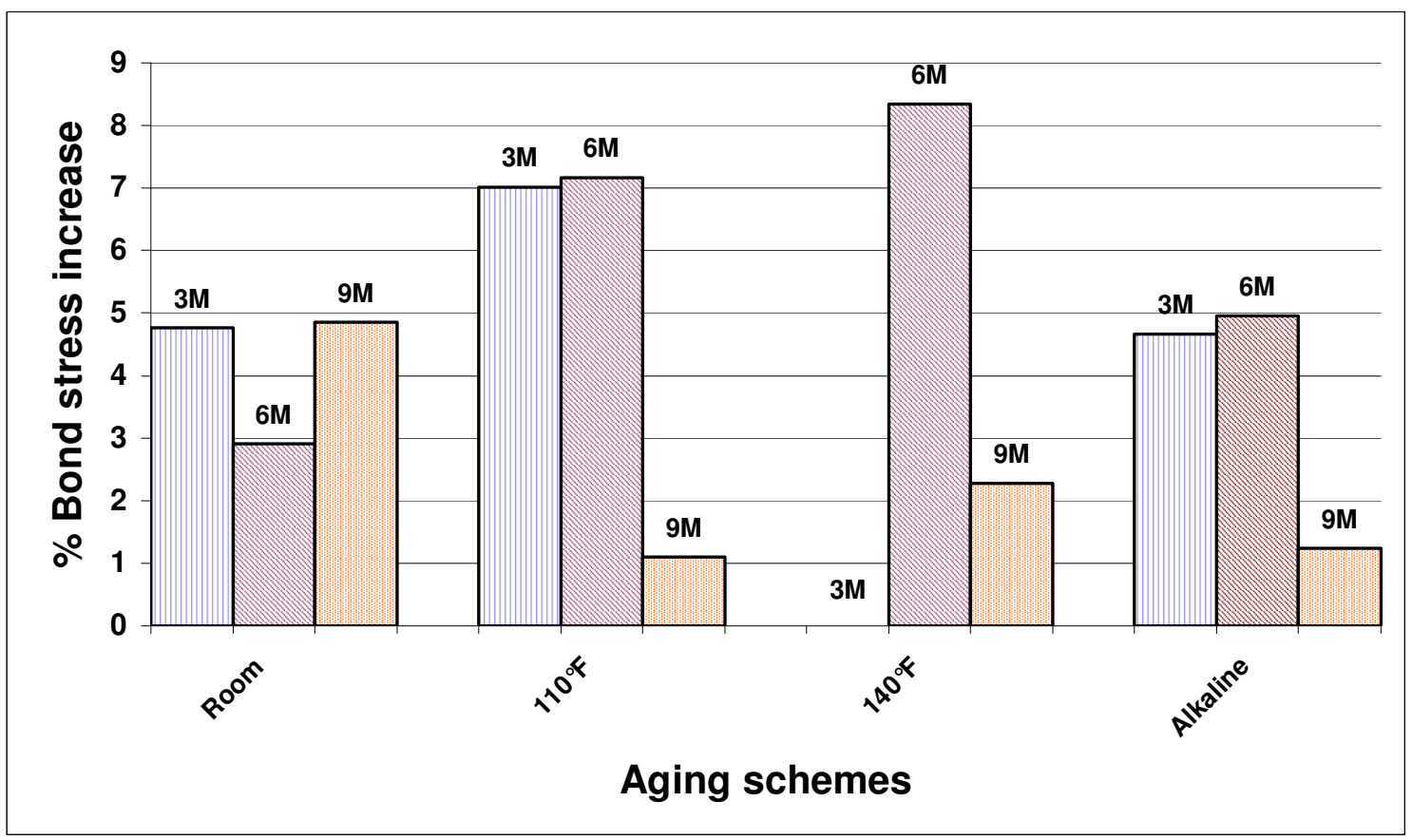

Figure 7-5 Comparison of percentage bond stress increase of GFRP bars with nanoclay aged in different aging schemes to non-aged bars (Note: M-Months) 
- GFRP bar with nanoclay conditioned at different aging schemes showed higher bond strength than the original bond strength (Figure 7-5), because increase in stress was noted due to post curing of concrete and rebars. Increase in bond stress may be due to bar swelling also.

- Bond strength increase was noted with different conditioning schemes with nanoclay.

Water at room temperature up to 9 months $-4.86 \%$ increase

$>$ Water at $110^{\circ} \mathrm{F}$ up to 9 months $-1.10 \%$ increase

$>$ Water at $140^{\circ} \mathrm{F}$ up to 9 months $-2.27 \%$ increase

Alkaline solution at room temperature up to 9 months $-1.24 \%$ increase

- Such increase in bond strength up to $14 \%$ under 15 months of water and freezethaw conditioning for bars without nanoclay has been noted in other studies as well (Vijay and GangaRao, 1999). Results indicate that the addition of nanoclay helped in controlling the bar swelling and influenced corresponding bond stress development.

- Mechanisms that influence bond strength development are:

$>$ Swelling of the rebar

$>$ Interface between concrete and FRP bar

$>$ Interface between fibers within a bar 
Table 7-4 Summary of Bond Test

\begin{tabular}{|c|c|c|c|c|c|}
\hline $\begin{array}{l}\text { Number } \\
\text { of } \\
\text { months }\end{array}$ & Aging condition & $\begin{array}{l}\text { Bar } \\
\text { size }\end{array}$ & Nanoclay & $\begin{array}{c}\text { Average bond } \\
\text { stress (ksi) }\end{array}$ & $\begin{array}{l}\text { \% strength } \\
\text { difference }\end{array}$ \\
\hline \multirow{3}{*}{0} & \multirow{3}{*}{ No aging } & & Yes & $1734.08 \pm 36.10$ & \multirow{3}{*}{ N/A } \\
\hline & & & No & $1706.34 \pm 33.86$ & \\
\hline & & $\# 6$ & Yes & $1793.06 \pm 62.53$ & \\
\hline \multirow{4}{*}{3} & Water/RT & \multirow{4}{*}{ \#4 } & \multirow{4}{*}{ Yes } & $1816.87 \pm 28.08$ & $4.77 \%$ inc \\
\hline & Water $/ 110^{\circ} \mathrm{F}$ & & & $1855.73 \pm 41.37$ & $7.01 \%$ inc \\
\hline & Water $/ 140^{\circ} \mathrm{F}$ & & & $1706.00 \pm 213.22$ & $1.62 \% \mathrm{dec}$ \\
\hline & Alkaline/RT & & & $1814.82 \pm 81.10$ & $4.66 \%$ inc \\
\hline \multirow{4}{*}{6} & Water/RT & \multirow{4}{*}{$\# 4$} & \multirow{4}{*}{ Yes } & $1781.53 \pm 74.71$ & $2.91 \%$ inc \\
\hline & Water $/ 110^{\circ} \mathrm{F}$ & & & $1858.46 \pm 0.89$ & $7.17 \%$ inc \\
\hline & Water $/ 140^{\circ} \mathrm{F}$ & & & $1878.70 \pm 9.24$ & $8.34 \%$ inc \\
\hline & Alkaline/RT & & & $1819.88 \pm 60.06$ & $4.95 \%$ inc \\
\hline \multirow{4}{*}{9} & Water/RT & \multirow{4}{*}{ \#4 } & \multirow{4}{*}{ Yes } & $1818.27 \pm 65.82$ & $4.86 \%$ inc \\
\hline & Water $/ 110^{\circ} \mathrm{F}$ & & & $1753.12 \pm 38.34$ & $1.10 \%$ inc \\
\hline & Water $/ 140^{\circ} \mathrm{F}$ & & & $1773.41 \pm 94.77$ & $2.27 \%$ inc \\
\hline & Alkaline/RT & & & $1755.66 \pm 70.23$ & $1.24 \%$ inc \\
\hline
\end{tabular}

RT- Room temperature 


\section{MOISTURE ABSORPTION}

\subsection{INTRODUCTION}

Moisture tests were conducted on GFRP bars and neat resin specimens with and without nanoclay at room temperature to determine moisture gain over a period of 400 days and above. Table 8-1 gives the type and number of specimens of different types of bars tested. The test specimen preparation is described in Section 8.2. The specimens were immersed in distilled water and their weights were monitored at regular intervals for a period of 400 days and above. Tables 8-2 and 8-3 shows the initial and final weight and the percentage gain in weight of the specimens tested.

Table 8-1 Number of specimens

\begin{tabular}{|c|c|}
\hline Specimen type & \# of specimens \\
\hline Bar without nanoclay & 10 \\
\hline Bar with nanoclay & 10 \\
\hline Near resin without nanoclay & 10 \\
\hline Neat resin with nanoclay & 10 \\
\hline
\end{tabular}

\subsection{SPECIMEN PREPARATION AND TEST METHOD}

\subsubsection{GFRP BAR SPECIMENS}

Moisture content of GFRP bars with nanoclay and without nanoclay was compared to determine the difference in moisture absorption. FRP bars were cut to 3 in. length and both ends were sealed with resin and cured to prevent water entry through sides. Bar surface and sides were examined for presence of resin flakes, which may result in incorrect calculation of moisture content. Bars were numbered (Figure 8-1) and their dry weights were noted before immersing them in the water. Samples were immersed in a container having potable water and left undisturbed till next reading was taken (Figure 82). Samples were cleaned with paper towels to absorb surface moisture and weighed regularly for an accuracy of 4 decimals. Moisture uptake data were plotted against time to compare percentage moisture absorption of FRP bar with and without nanaoclay. Weights were taken once a day for first week and time interval for measurement was considerably increased during the following weeks. 


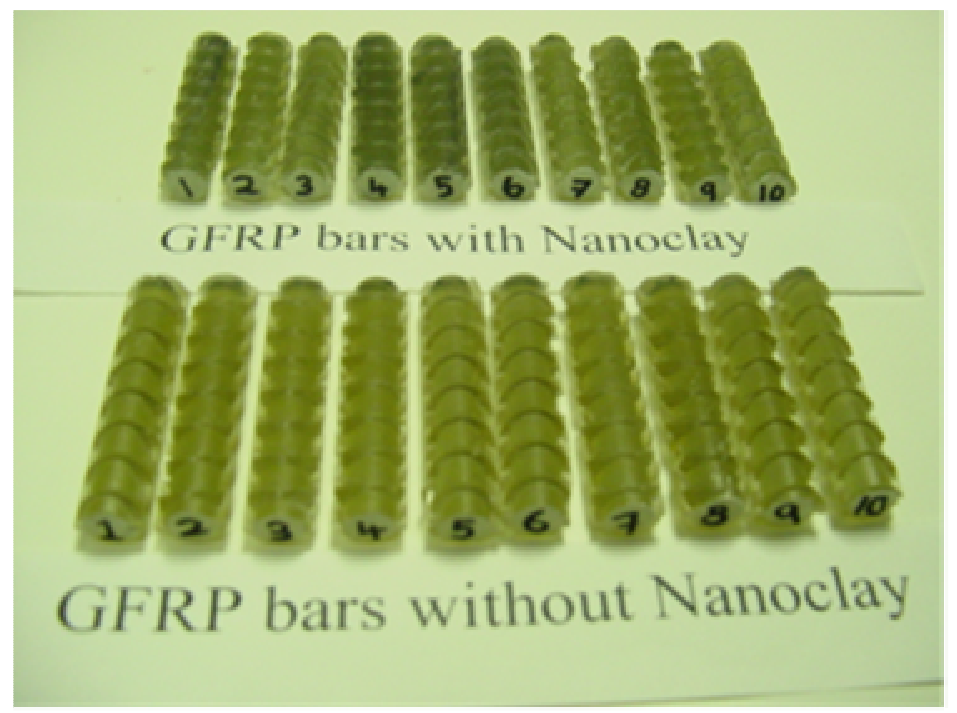

Figure 8-1 Numbering of GFRP bar

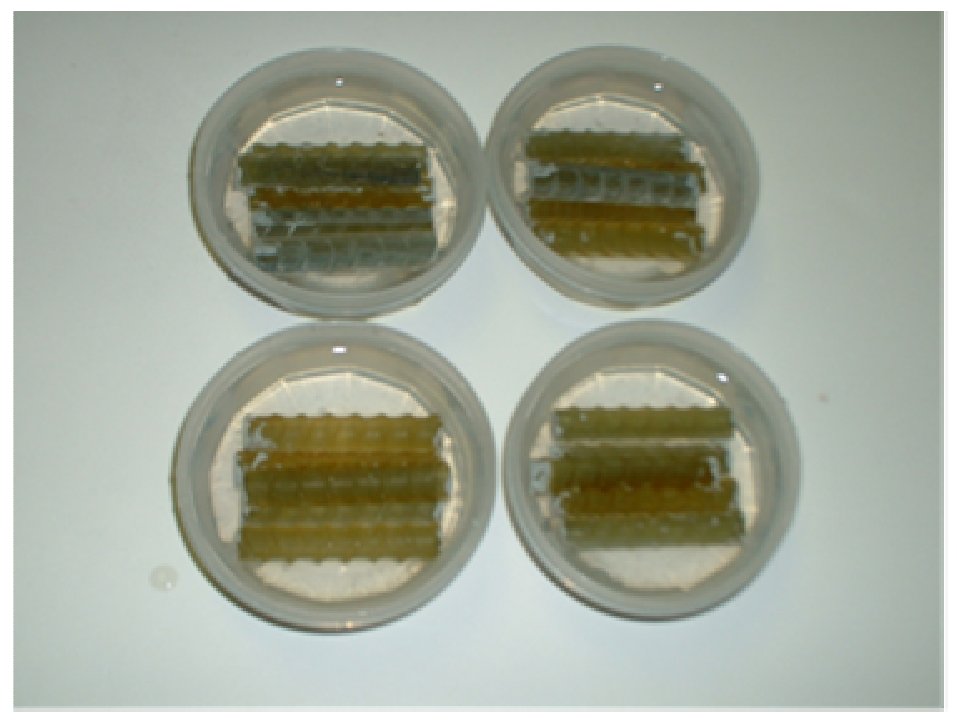

Figure 8-2 GFRP bars immersed in water

\subsubsection{NEAT RESIN SPECIMENS}

Specimens of $1 / 2$ in. diameter and $1 / 2$ in. height were made with neat resin (Hetron 922L25) exfoliated with (4\%) and without nanoclay. Specimens surface and sides were examined for presence of resin flakes, which may result in incorrect calculation of moisture content. Same conditioning and measurement procedure was used for GFRP bars (Figures 8-3 \& 8-4). 


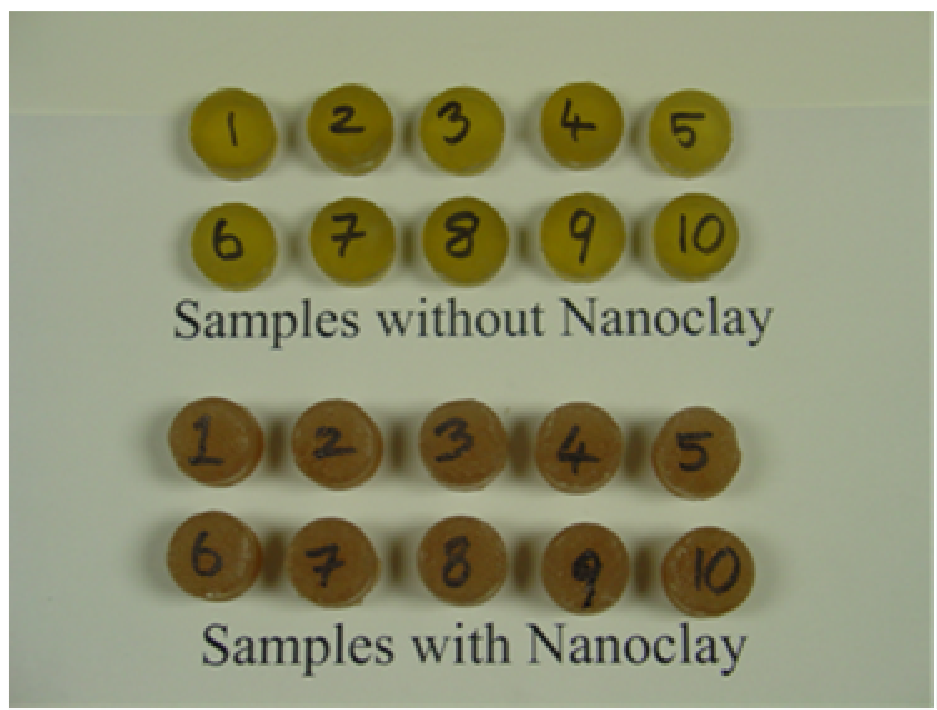

Figure 8-3 Specimens for moisture absorption test

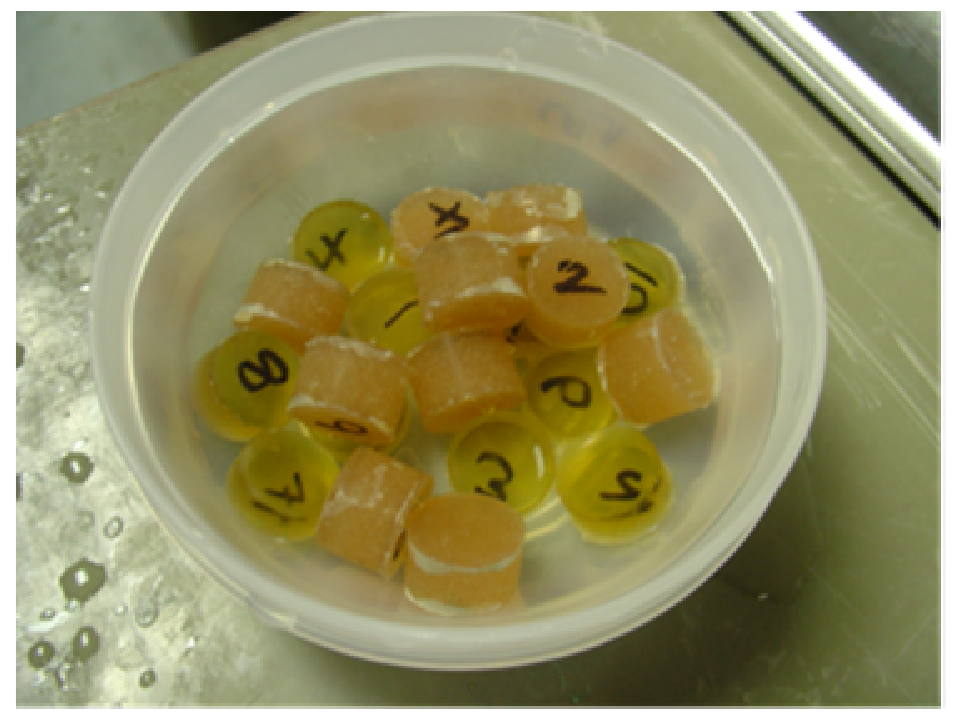

Figure 8-4 Resin specimens immersed in water

\subsubsection{CALCULATION}

The percentage weight gain in the specimens were calculated using Eq. (8.1).

$$
g=\left[\frac{W_{d}-W}{W}\right] \times 100
$$

Where,

$\mathrm{g}=$ Percentage gain in the moisture,

$\mathrm{W}_{\mathrm{d}}=$ Weight of the specimens after'd' days (gm),

$\mathrm{W}=$ Initial weight of the specimens before immersion in water $(\mathrm{gm})$. 


\subsection{TEST RESULTS}

\subsubsection{GFRP BAR WITH AND WITHOUT NANOCLAY}

\section{Test and Specimen Details}

- Diameter of the bar-0.5 in. (\#4)

- Length of the specimens -3 in.

- Fiber-E-glass

- Number of specimens tested-10

- Nanoclay-Yes $(2 \%) \& N o$

- Period-400 days

\section{Test Results}

Table 8-2 Percentage weight gain of GFRP bars with and without nanoclay

\begin{tabular}{|c|c|c|c|}
\hline Date & $\mathbf{0 2 / 0 9 / 0 4}$ & $\mathbf{0 7 / 2 1 / 0 5}$ & \multirow{2}{*}{$\begin{array}{c}\text { weight } \\
\text { gain }\end{array}$} \\
\cline { 1 - 2 } Days & $\mathbf{0}$ & $\mathbf{4 0 1}$ & 0.9010 \\
\hline $\begin{array}{c}\text { Without } \\
\text { nanoclay }\end{array}$ & 18.8614 & 19.0528 & 1.0435 \\
\hline With nanoclay & 18.2181 & 18.4081 & \\
\hline
\end{tabular}

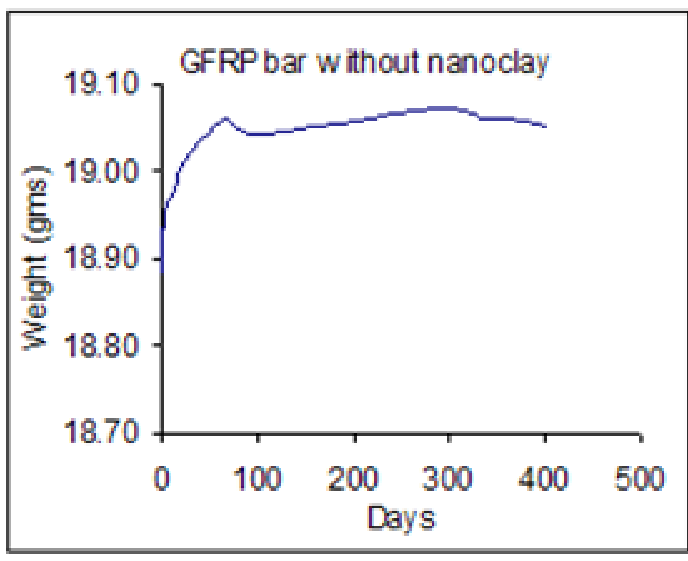

(a)

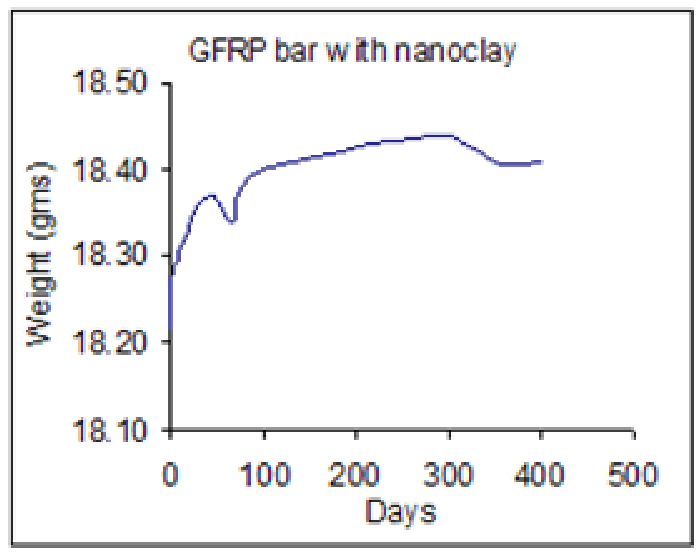

(b)

Figure 8-5 Moisture gain of GFRP bars (a) without and (b) with nanoclay 


\section{Discussion of Test Results}

- It should be noted that the nanoclay is hydrophilic in nature and absorbs moisture (Table 8-2).

- GFRP bars picked up moisture initially and rate of moisture gain decreased with time.

\subsubsection{NEAT RESIN WITH AND WITHOUT NANOCLAY}

\section{Test and Specimen Details}

- Diameter of the specimens - $0.5 \mathrm{in}$. (\#4)

- Length of the specimens - $0.5 \mathrm{in}$.

- Fiber-None

- Number of specimens tested - 10

- Nanoclay - Yes $(4 \%) \& N o$

- Period - 70 days

\section{Test Results}

Table 8-3 Percentage weight gain of neat resin with and without nanoclay

\begin{tabular}{|c|c|c|c|}
\hline Date & $\mathbf{0 4 / 1 1 / 0 5}$ & $\mathbf{0 7 / 2 1 / 0 5}$ & \multirow{2}{*}{$\begin{array}{c}\text { weight } \\
\text { gain }\end{array}$} \\
\cline { 1 - 3 } Days & $\mathbf{0}$ & $\mathbf{7 0}$ & 1.5259 \\
\hline $\begin{array}{c}\text { Without } \\
\text { nanoclay }\end{array}$ & 2.3038 & 2.3387 & 1.3467 \\
\hline With nanoclay & 4.1147 & 4.1701 & \\
\hline
\end{tabular}




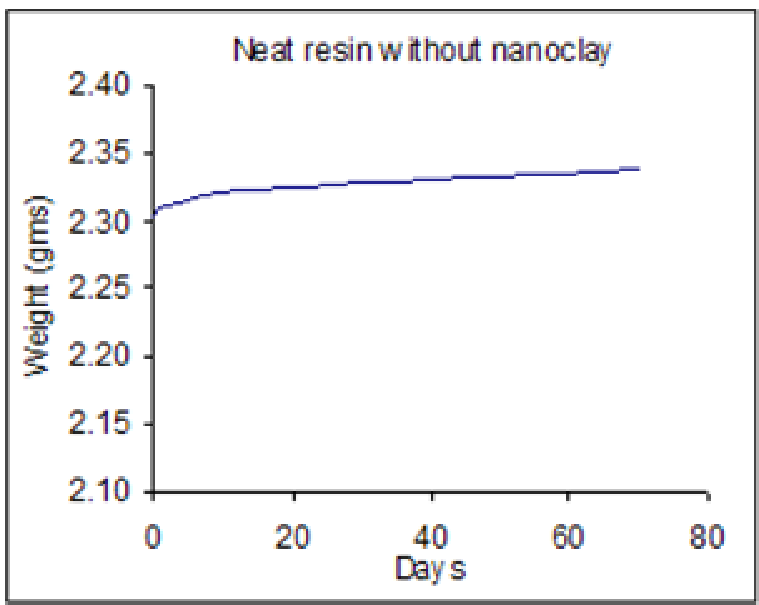

(a)

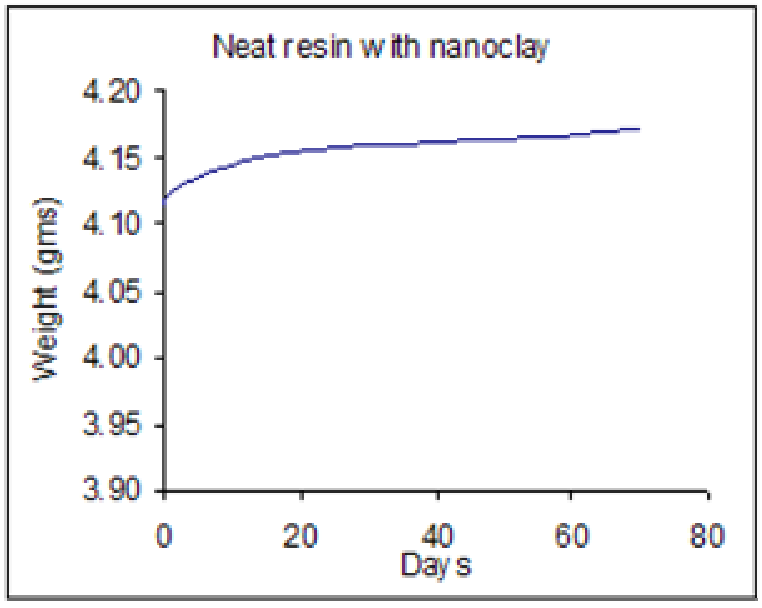

(b)

Figure 8-6 Moisture gain of neat resin (a) without and (b) with nanoclay

\section{Discussion of Test Results}

- Neat resin without nanoclay had higher moisture pick up than resin exfoliated with 4\% nanoclay. Moisture pick up higher in the initial weeks and gradually stabilized thereafter.

- Neat resin without nanoclay showed $1.5259 \%$ gain as compared to $1.3467 \%$ gain by neat resin with nanoclay.

- More specimens need to be further examined.

\subsection{SUMMARY AND CONCLUSION}

- Neat resin without nanoclay had higher moisture pick up than resin exfoliated with nanoclay.

- GFRP bar with nanoclay showed slightly higher moisture gain than bar without nanoclay.

- The results indicate possible pore and micro crack formation during fiber wetting and pulling process. 


\section{SCANNING ELECTRON MICROSCOPE (SEM)}

\subsection{INTRODUCTION}

Scanning Electron Microscope (SEM) imaging was conducted on aged GFRP bars with and without nanoclay to investigate the moisture absorption path, integrity of fibers, extent of clay exfoliation, and fiber-resin interface defects due to the presence of nanoclay. Samples were grinded and coated with metallic conductors and images were taken. SEM was also performed on resin samples exfoliated with $2 \%, 3.5 \%, 4 \%$, and $5 \%$ to find the optimum nanoclay percent to be exfoliated in the resin for manufacturing GFPR bars with nanoclay. SEM was performed on one sample of each category aging and bars extracted from the beams as shown in Table 9-1.

Table 9-1 Number and aging schemes of GFRP bars tested in SEM

\begin{tabular}{|c|c|c|c|c|c|c|}
\hline \multirow[b]{2}{*}{ Aging schemes } & \multirow{2}{*}{$\begin{array}{l}\text { Bar } \\
\text { size }\end{array}$} & \multirow[b]{2}{*}{ Nanoclay } & \multicolumn{4}{|c|}{ Number of specimens } \\
\hline & & & $\begin{array}{l}\text { Without } \\
\text { aging }\end{array}$ & $\begin{array}{c}3 \text { months } \\
\text { aging }\end{array}$ & $\begin{array}{c}6 \text { months } \\
\text { aging }\end{array}$ & $\begin{array}{c}9 \text { months } \\
\text { aging }\end{array}$ \\
\hline \multirow{2}{*}{ Non-aged } & \multirow{2}{*}{$\# 4$} & Yes & 1 & - & - & - \\
\hline & & No & 1 & - & - & - \\
\hline \multirow{2}{*}{$\begin{array}{l}\text { Extracted from } \\
\text { concrete beams }\end{array}$} & \multirow{2}{*}{$\# 4$} & Yes & 1 & - & - & - \\
\hline & & No & 1 & - & - & - \\
\hline \multirow{2}{*}{ Water/RT } & \multirow{7}{*}{ \#4 } & Yes & - & 1 & 1 & 1 \\
\hline & & No & - & 1 & 1 & 1 \\
\hline Water at $110^{\circ} \mathrm{F}$ & & Yes & - & 1 & 1 & 1 \\
\hline \multirow{2}{*}{ Water at $140^{\circ} \mathrm{F}$} & & Yes & - & 1 & 1 & 1 \\
\hline & & No & - & 1 & 1 & 1 \\
\hline \multirow{2}{*}{$\begin{array}{c}\text { Alkaline } \\
\text { solution/RT }\end{array}$} & & Yes & - & 1 & 1 & 1 \\
\hline & & No & - & 1 & 1 & 1 \\
\hline
\end{tabular}

\subsection{DEVELOPMENT OF THE TEST}

\subsubsection{SPECIMEN PREPARATION}

SEM samples were prepared as follows.

1. Samples were first grinded with $800 \mu \mathrm{m}$ sand paper and $600 \mu \mathrm{m}$ till the sample surface is smooth and flat.

2. Samples were then polished with $3 \mu \mathrm{m}, 1 \mu \mathrm{m}$, and $0.5 \mu \mathrm{m}$ alumina suspended solution till the samples were smooth and polished.

3. Samples were then coated with thin layer of gold to emit electrons. 


\subsubsection{TEST EQUIPMENTS}

The Scanning Electron Microscope creates magnified images by using electrons instead of light waves. The sample (\#4 bars $1 / 2$ in. height) was placed inside the microscope's vacuum column through an airtight door. After the air was pumped out of the column, an electron gun (at the top) emits a beam of high-energy electrons. This beam travels downward through a series of magnetic lenses designed to focus the electrons to a very fine spot. Near the bottom, a set of scanning coils move the focused beam back and forth across the specimen, row by row. As the electron beam hits each spot on the sample, secondary electrons are knocked loose from its surface. A detector counts these electrons and sends the signals to an amplifier. The final image is built up from the number of electrons emitted from each spot on the sample. Image captured at required resolution and location on the GFRP bars saved into a computer disk and further analyzed.

\subsection{SEM IMAGES}

\subsubsection{SPECIMENS - NEAT RESIN}

\section{Test and Specimen Details}

- Fiber - No

- Number of specimens tested-4

- Nanoclay-Yes (2\%, 3.5\%, $4 \%$ and $5 \%)$

- Aging-None 


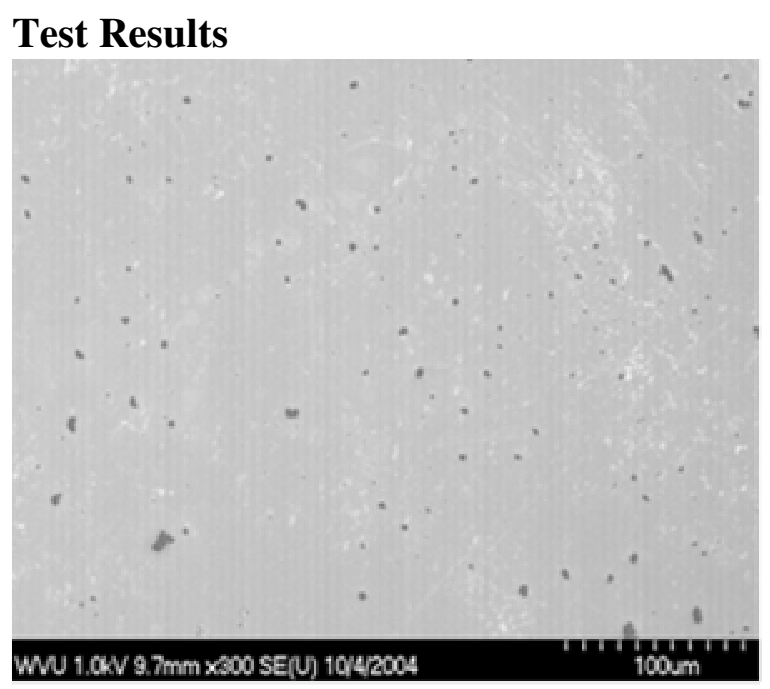

(a)

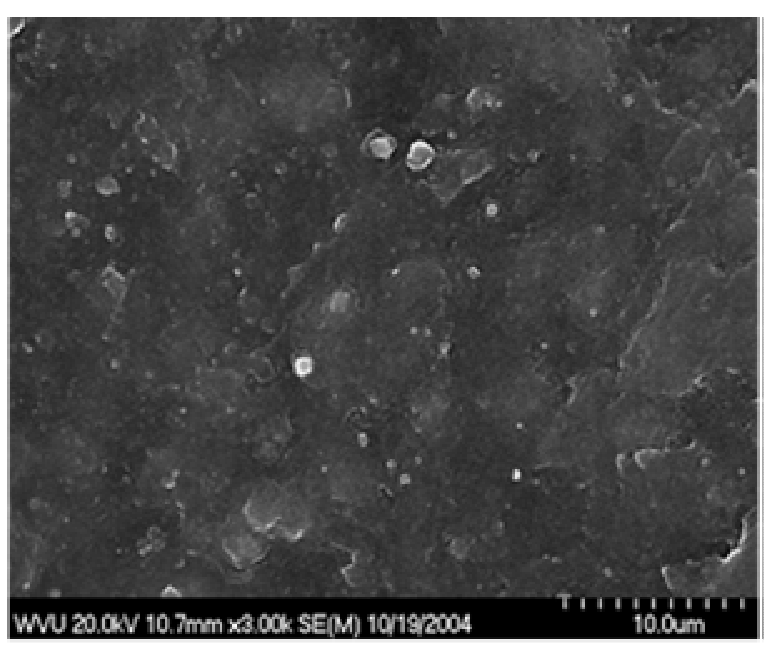

(b)

Figure 9-1 SEM image of vinyl ester resin partially exfoliated with (a) $2 \%$ nanoclay and (b) 3.5\% nanoclay showing scattered nanoclay

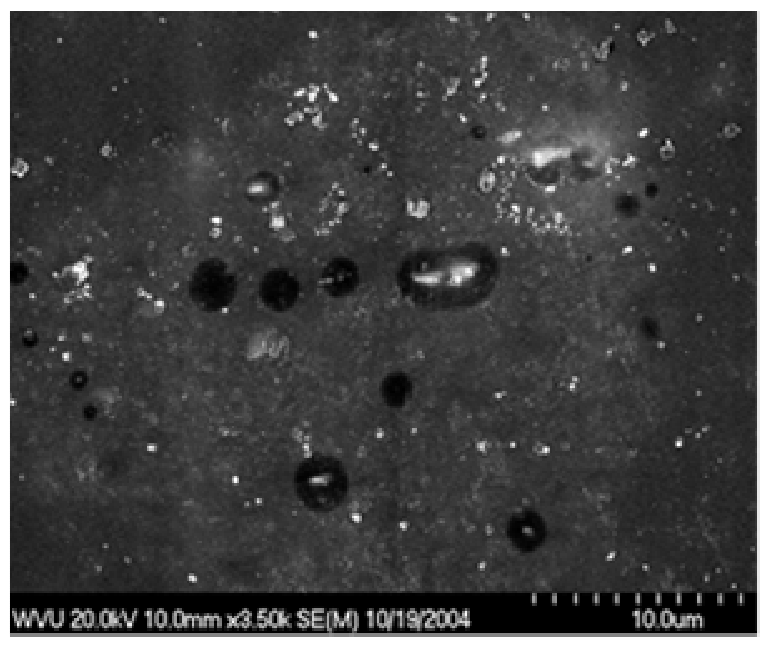

(a)

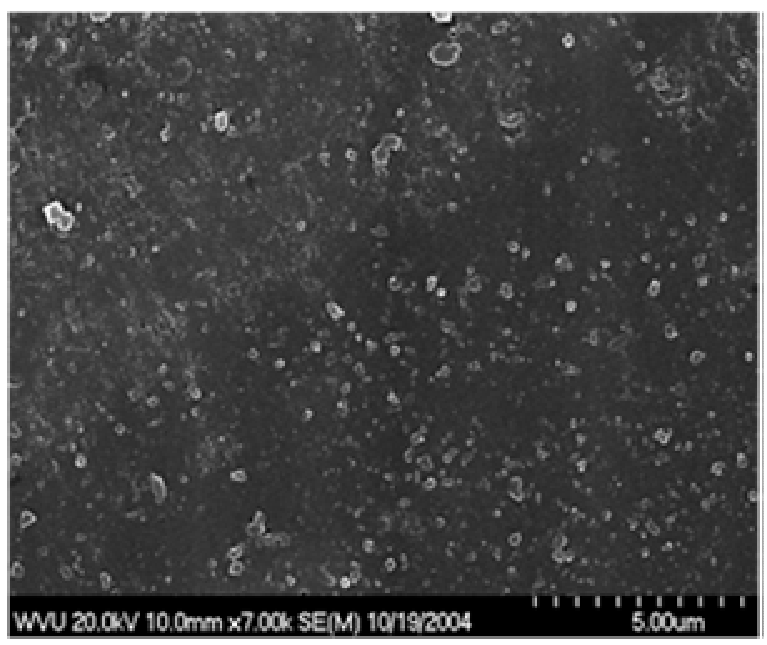

(b)

Figure 9-2 SEM image of vinyl ester resin partially exfoliated with (a) 4\% nanoclay and (b) $5 \%$ nanoclay

\section{Discussion of Tests Results}

- Neat resin exfoliated with $2 \%$ nanoclay showed scattered nanoclay particles in the SEM image.

- Neat resin exfoliated with 5\% nanoclay showed densely spaced nanoclay particles in the SEM image. However, resin viscosity increased significantly, thus limiting fiber wettability. 
- Neat resin exfoliated with $4 \%$ nanoclay was selected as optimum clay content and used for all the bars manufactured in this research.

\subsubsection{SPECIMENS - NO AGING}

\section{Test and Specimen Details}

- Aging - None

- Nanoclay - Yes $(4 \%) \& N o$

- Fiber-E-glass

- Bar size - 0.5 in.

- Number of specimens tested-2

\section{GFRP Bars without Nanoclay Subjected To No Aging}

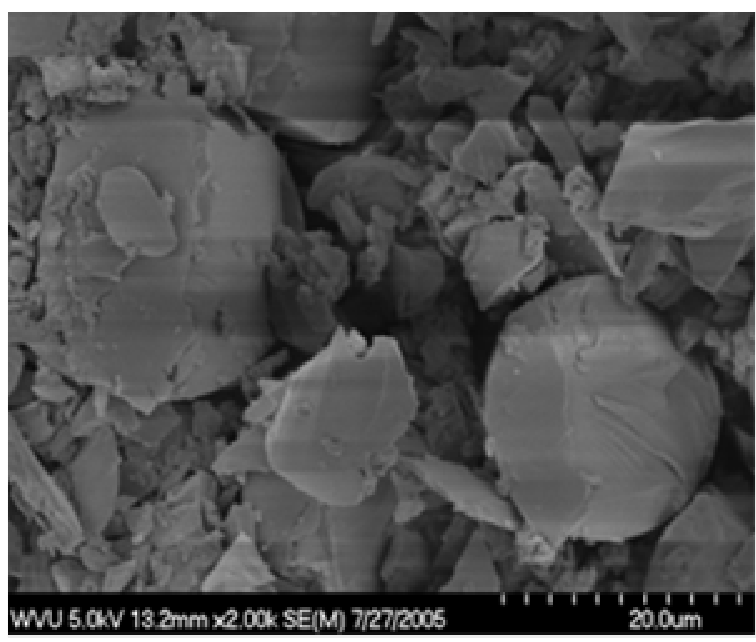

(a)

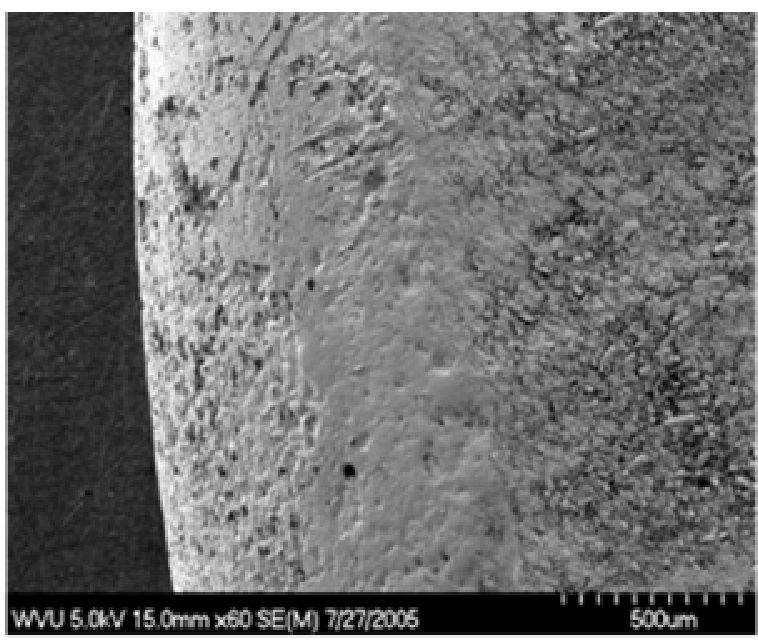

(b)

Figure 9-3 SEM image showing (a) glass fibers densely packed with the resin at the center of the bar (b) resin fiber interaction at edge 


\section{GFRP Bars with Nanoclay Subjected To No Aging}

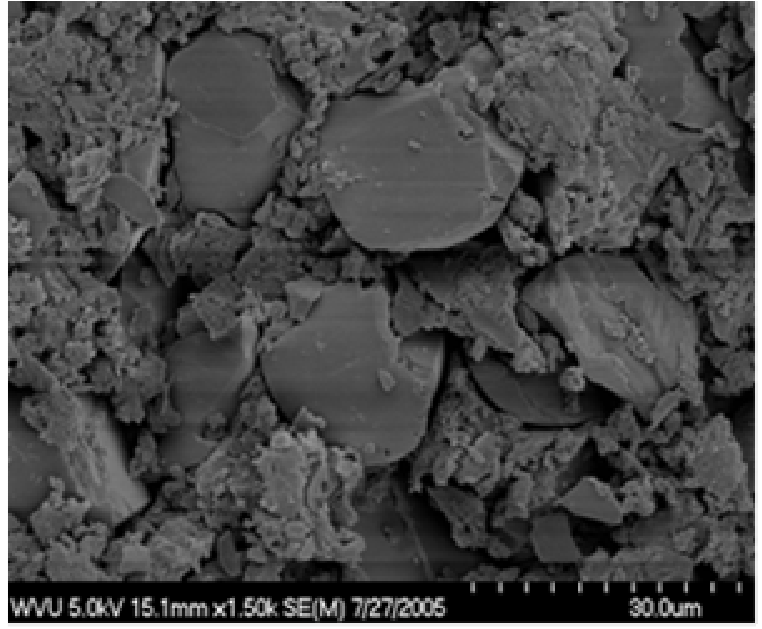

(a)

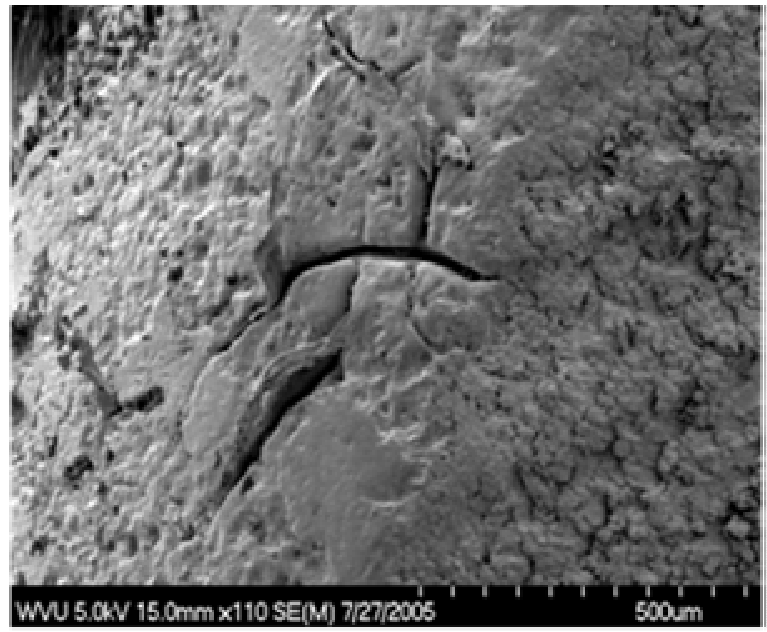

(b)

Figure 9-4 SEM image showing (a) glass fibers densely packed with the resin exfoliated with clay at the center of the bar (b) cracks formed in the rib of the bars allowing path for moisture entry

\subsubsection{SPECIMENS - WATER AT RT, $110^{\circ} \mathrm{F}$, AND $140^{\circ} \mathrm{F}$ AGING}

\section{Test and Specimen Details}

- Aging - Water at room temperature, water at $110^{\circ} \mathrm{F}$, and water at $140^{\circ} \mathrm{F}$ aging for 3, 6, and 9 months

- Nanoclay-Yes $(4 \%) \& N o$

- Fiber-E-glass

- Bar size - 0.5 in.

- Number of specimens tested - 7 


\section{GFRP Bars without Nanoclay Aged in Water at RT up to 3 Months}

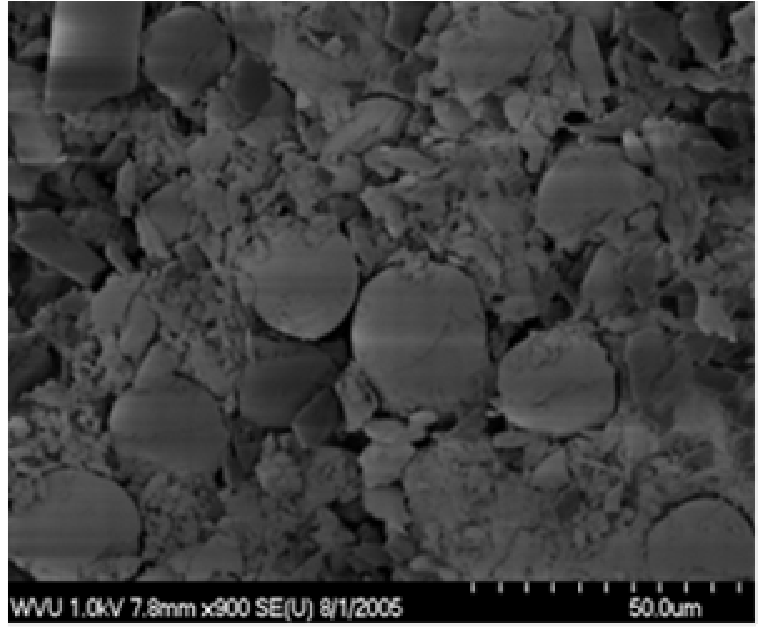

(a)

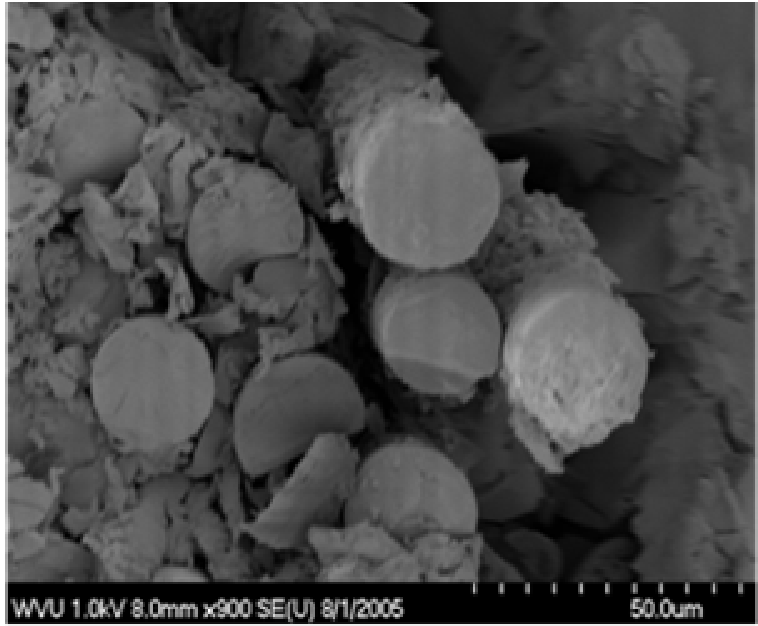

(b)

Figure 9-5 SEM images showing (a) glass fibers densely packed with the resin at the center of the bar (b) fiber-resin isolation/pullout at the edges

\section{GFRP Bars with Nanoclay Aged in Water at RT up to 3 Months}

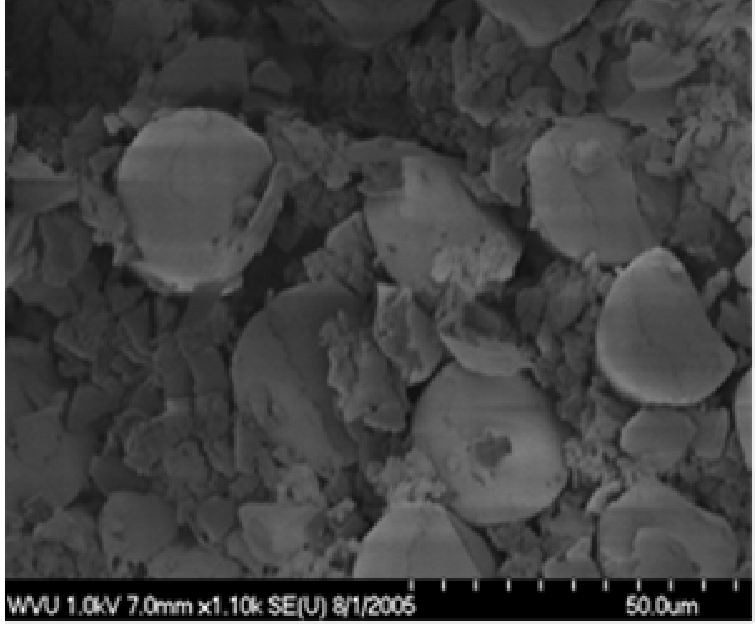

(a)

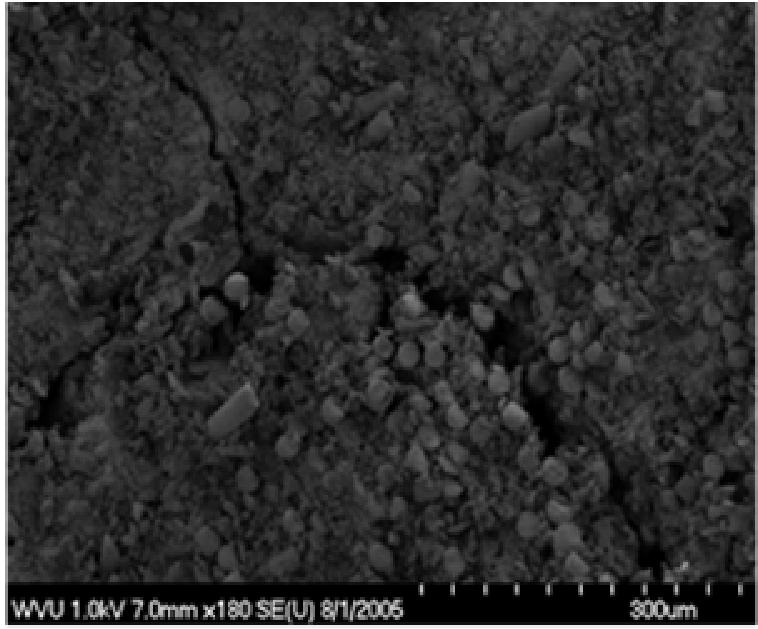

(b)

Figure 9-6 SEM image showing (a) glass fibers densely packed with the resin exfoliated with clay at the center of the bar (b) crack formed in edge of the bar leading to moisture ingression 


\section{GFRP Bars without Nanoclay Aged in Water at RT up to 6 Months}

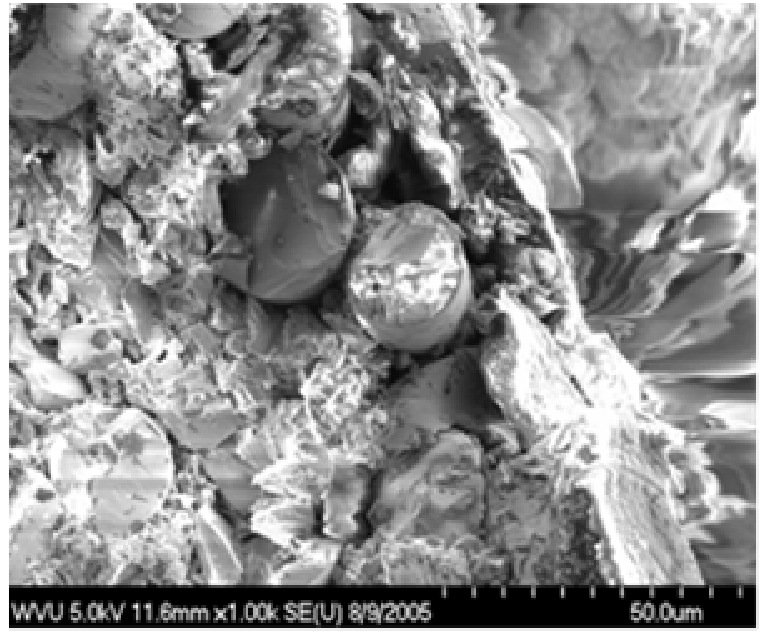

(a)

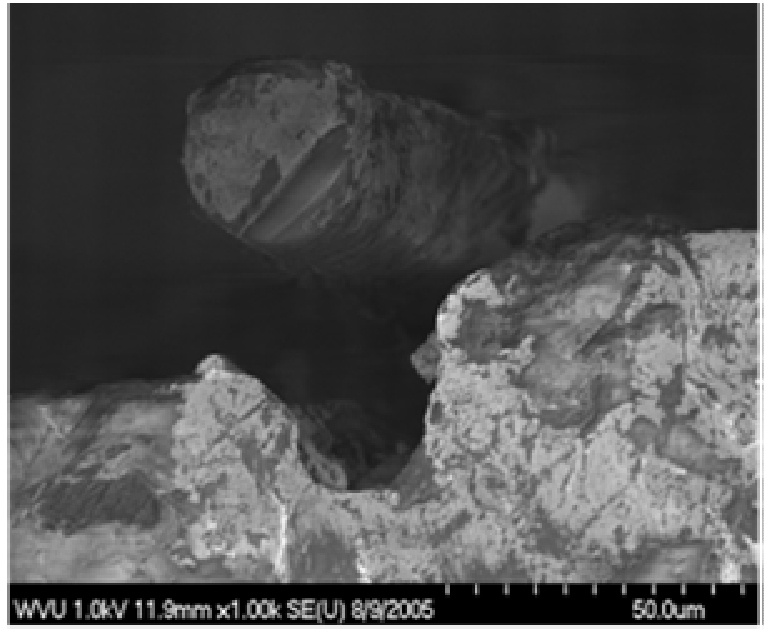

(b)

Figure 9-7 SEM image showing (a) fiber- resin interface at the edge of the bar (b) fibers and resin seperation

\section{GFRP Bars with Nanoclay Aged in Water at RT up to 6 Months}

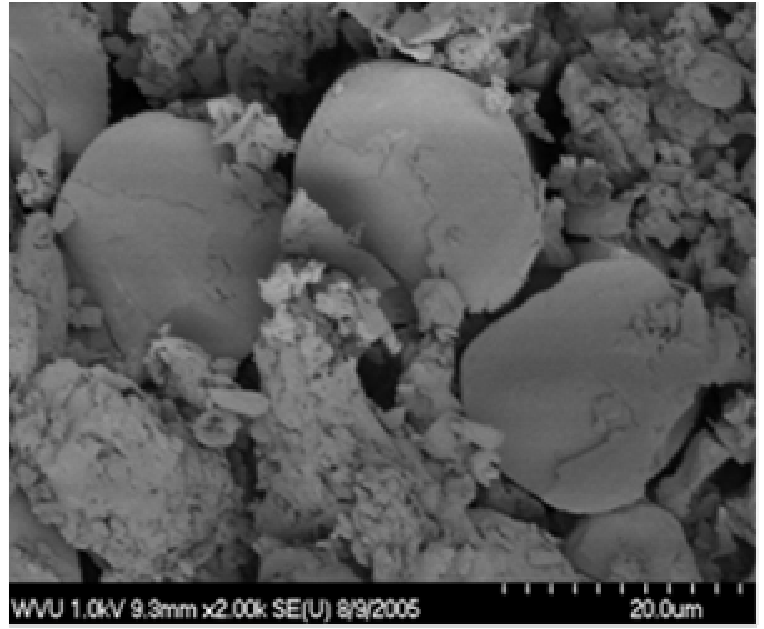

(a)

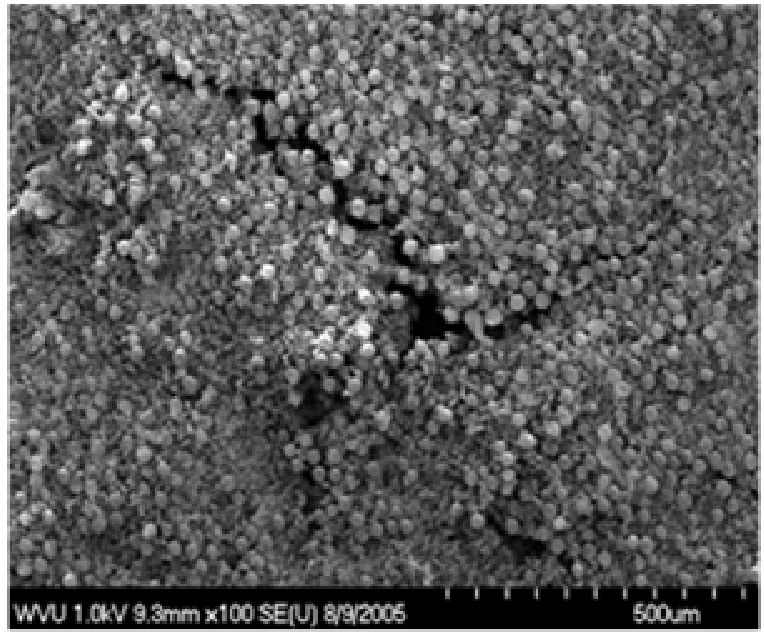

(b)

Figure 9-8 SEM image showing (a) glass fibers densely packed with the resin exfoliated with clay at the center of the bar (b) crack formation in the bars at the edge leading to moisture ingression 


\section{GFRP Bars without Nanoclay Aged in Water at RT up to 9 Months}

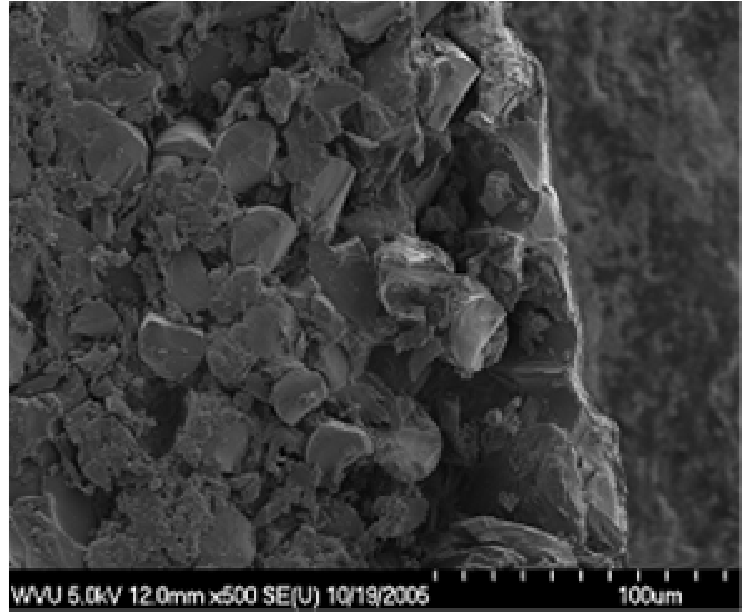

(a)

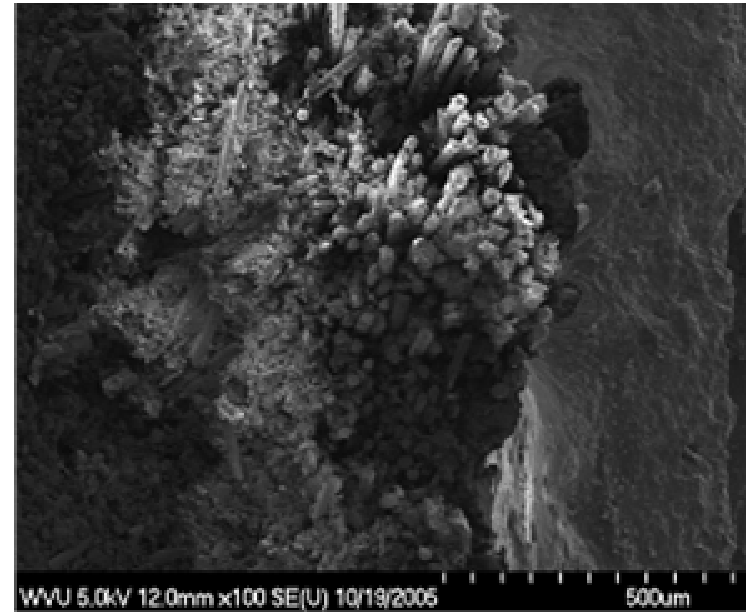

(b)

Figure 9-9 SEM image showing (a) fiber- resin interface at the edge of the bar (b) fiber-resin isolation/pullout at the edges

\section{GFRP Bars with Nanoclay Aged in Water at RT up to 9 Months}

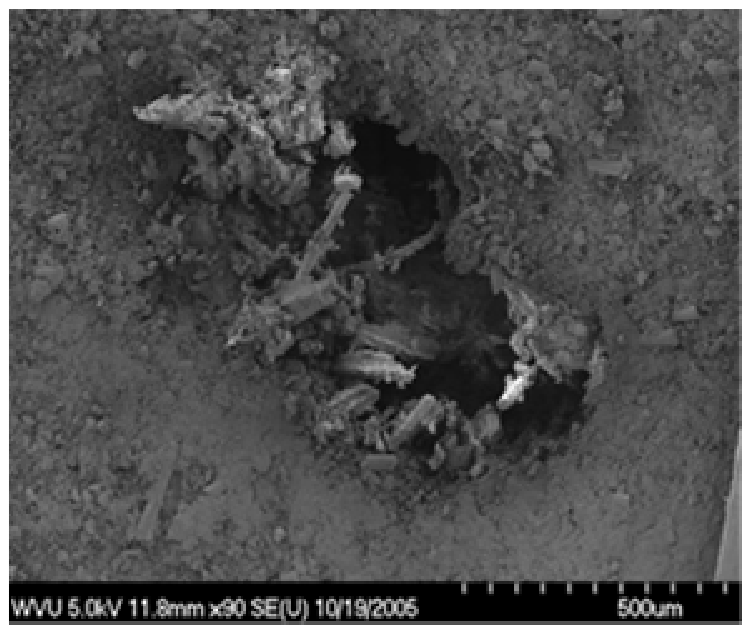

(a)

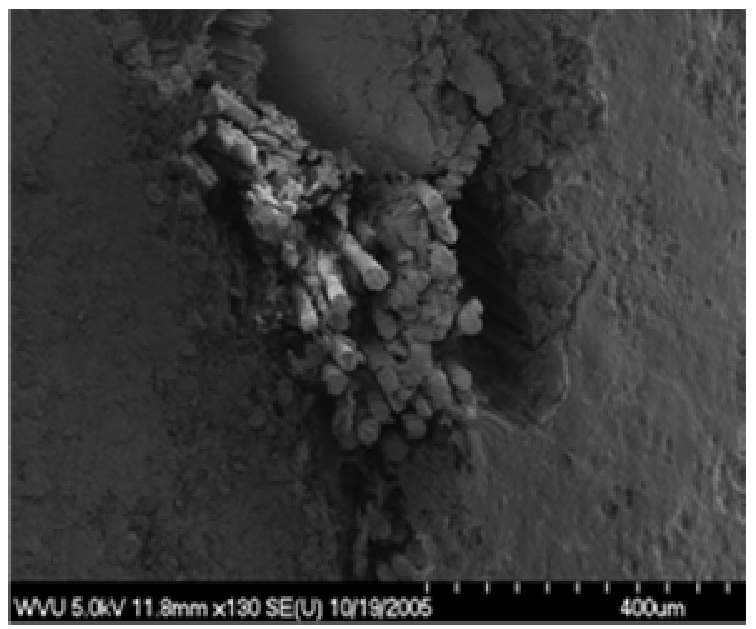

(b)

Figure 9-10 SEM image showing (a) cavity formation near the edge of bars with fiber-rein isolation (b) fiber-resin isolation/pullout at the edges 


\section{GFRP Bars with Nanoclay Aged in Water at $110^{\circ} \mathrm{F}$ up to 3 Months}

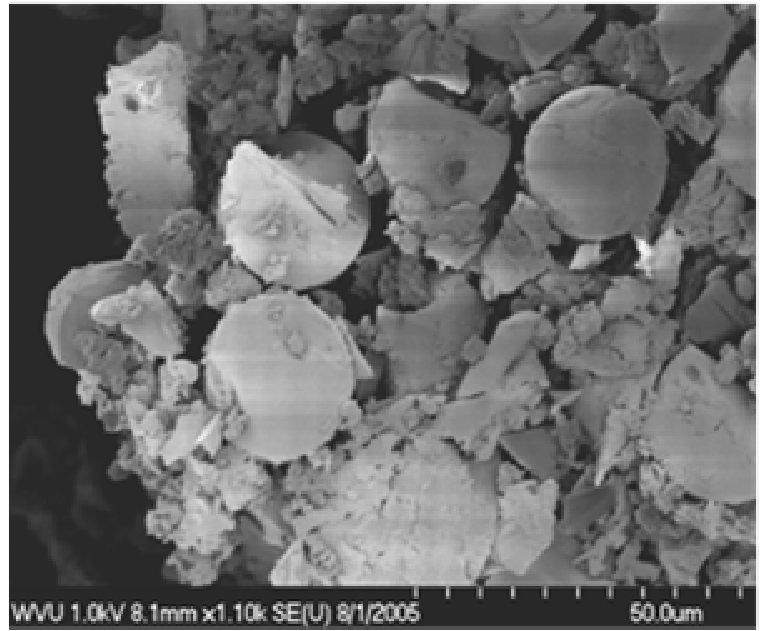

(a)

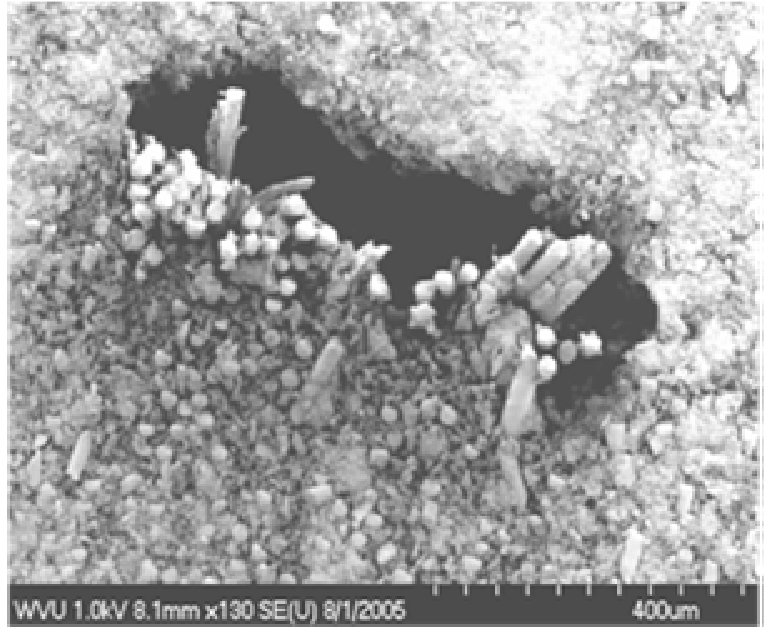

(b)

Figure 9-11 SEM image showing (a) fiber-resin isolation at the edge of bar (b) fiberresin isolation/pullout at the edges

\section{GFRP Bars with Nanoclay Aged in Water at $110^{\circ} \mathrm{F}$ up to 6 Months}

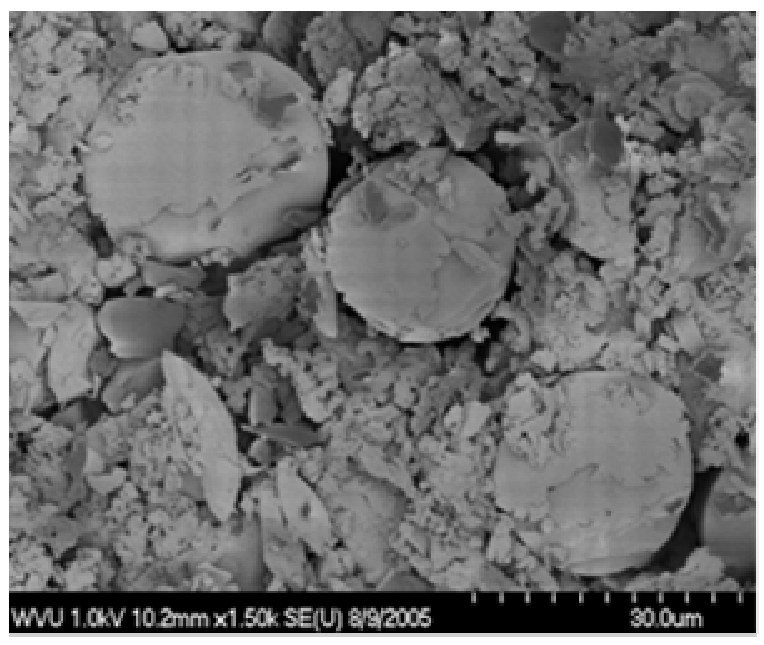

(a)

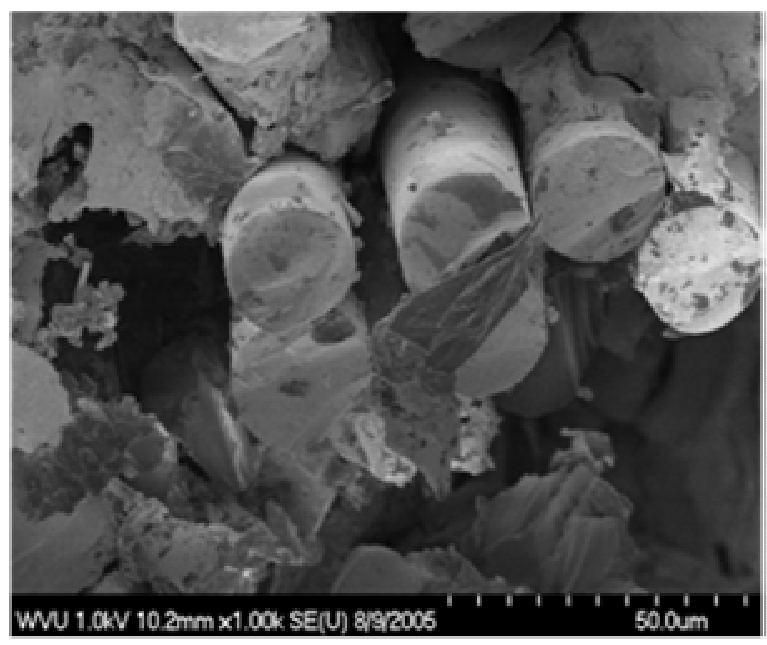

(b)

Figure 9-12 SEM image showing (a) fiber and resin interaction in the center of the bar (b) fiber-resin isolation/pullout at the edges 


\section{GFRP Bars with Nanoclay Aged in Water at $110^{\circ} \mathrm{F}$ up to 9 Months}

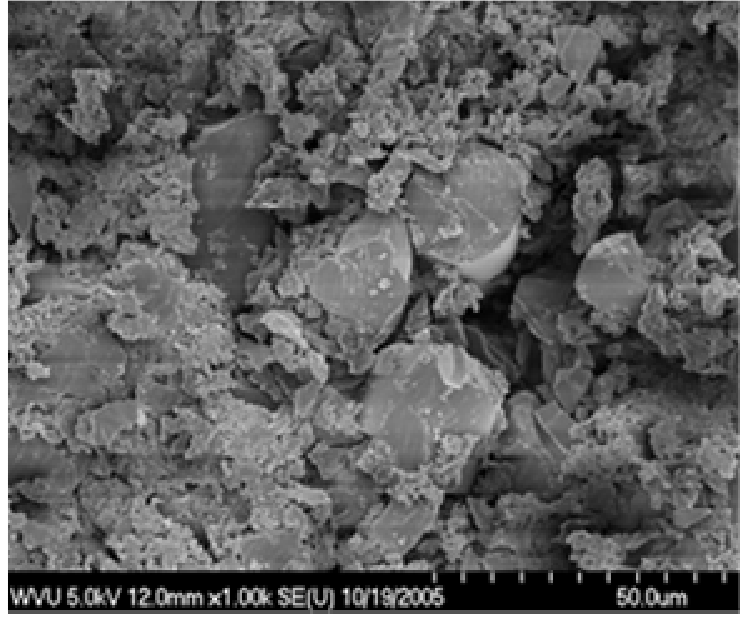

(a)

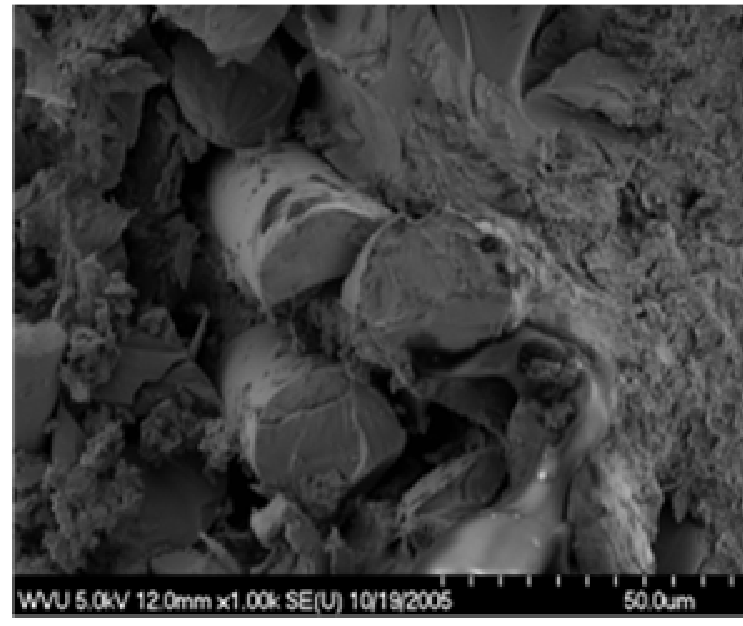

(b)

Figure 9-13 SEM image showing (a) glass fibers densely packed with the resin at the center of the bar (b) fiber-resin isolation/pullout at the edges

\section{GFRP Bars without Nanoclay Aged in Water at $140^{\circ} \mathrm{F}$ up to 3 Months}

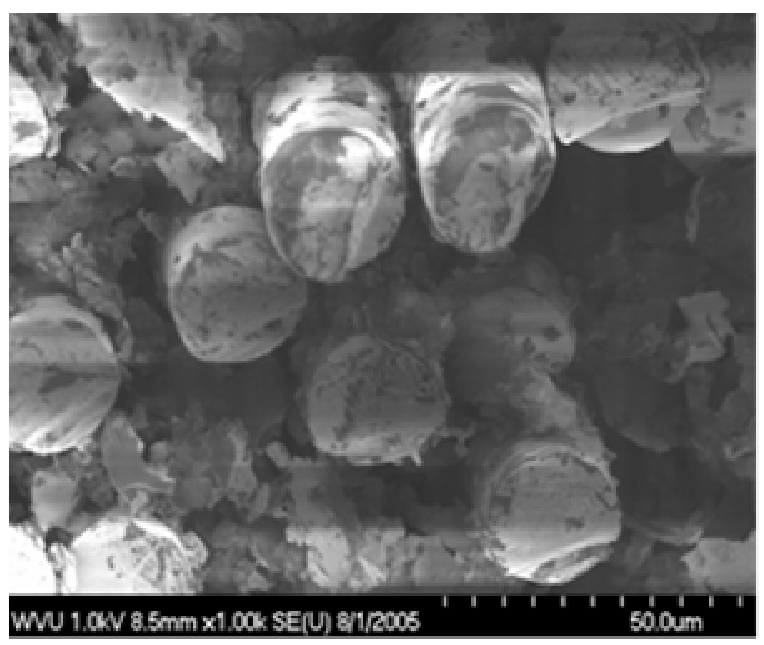

(a)

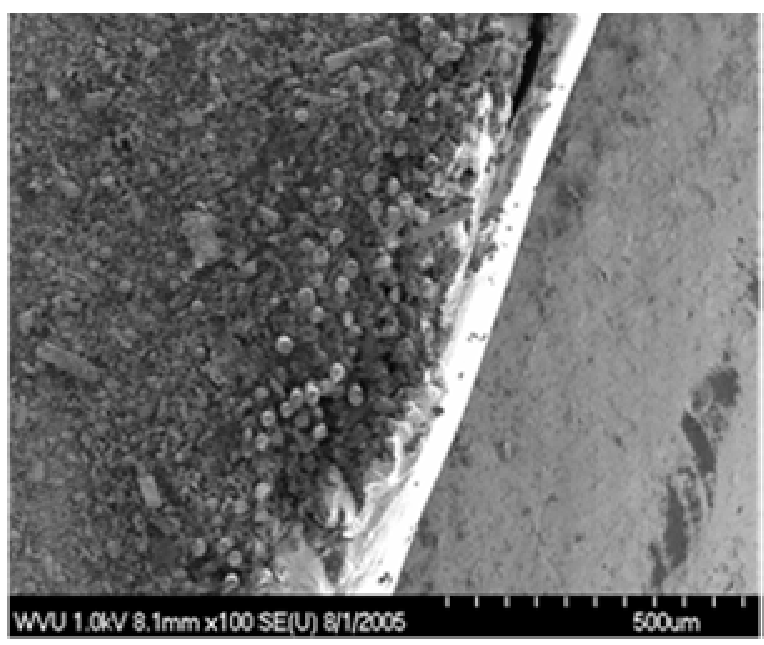

(b)

Figure 9-14 SEM image showing (a) damage/pullout at the resin and fibers interface (b) fiber-resin isolation/pullout at the edges 


\section{GFRP Bars with Nanoclay Aged in Water at $140^{\circ} \mathrm{F}$ up to 3 Months}

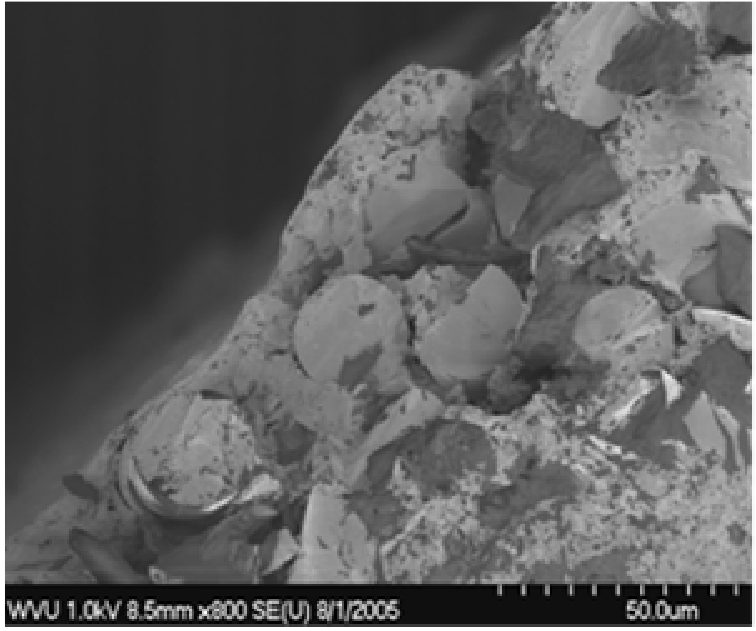

(a)

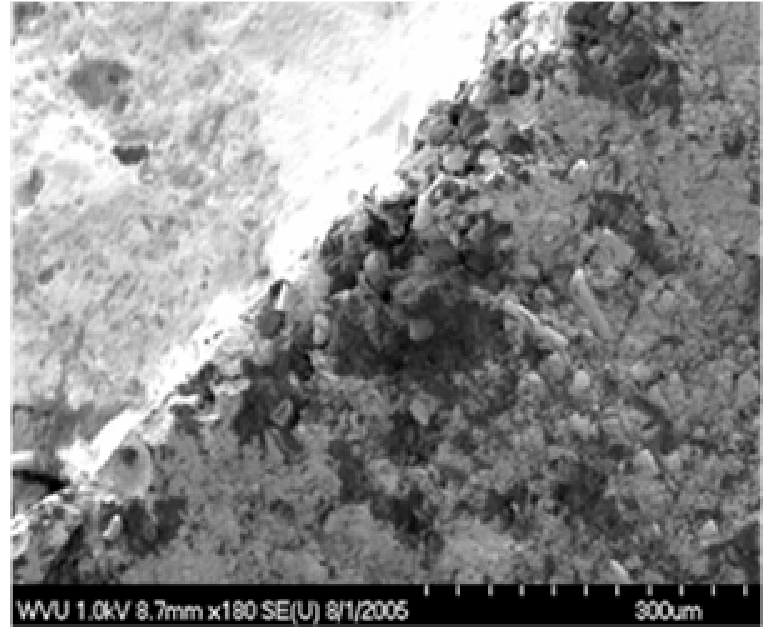

(b)

Figure 9-15 SEM image showing (a) resin damaged at the edge due to conditioning (b) cavity formation and fiber-resin damage in edge

\section{GFRP Bars without Aged in Water at $140^{\circ} \mathrm{F}$ up to 6 Months}

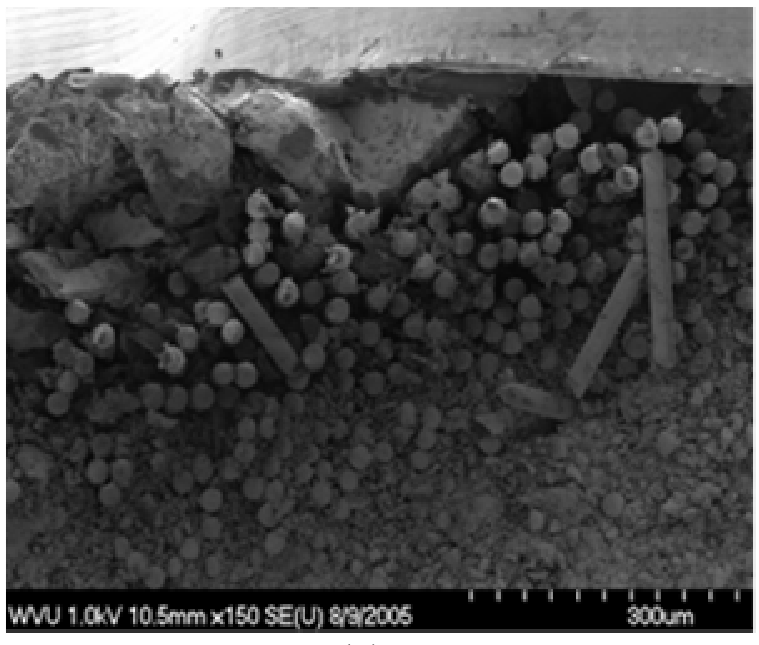

(a)

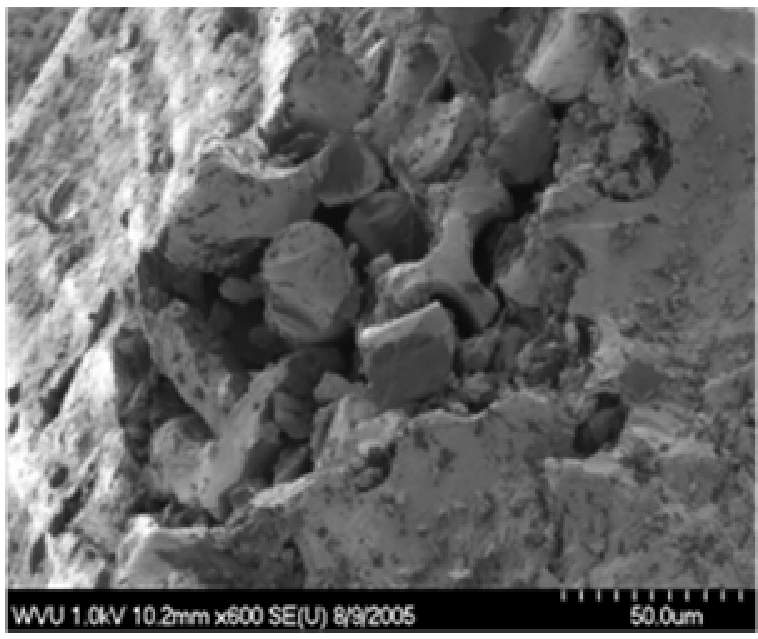

(b)

Figure 9-16 SEM image showing (a) fiber damage and resin isolation at edge of the bar (b) resin damage at the edge of the bar 


\section{GFRP Bars with Nanoclay Aged in Water at $140^{\circ} \mathrm{F}$ up to 6 Months}

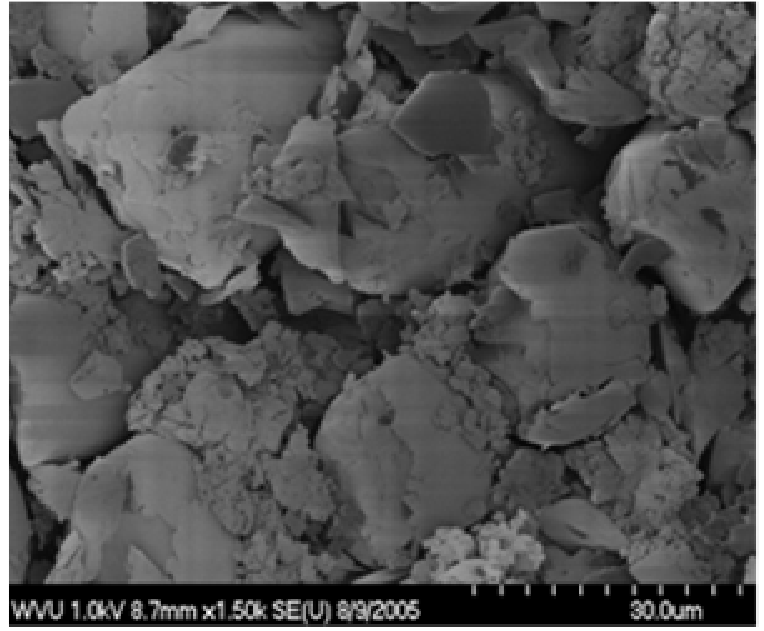

(a)

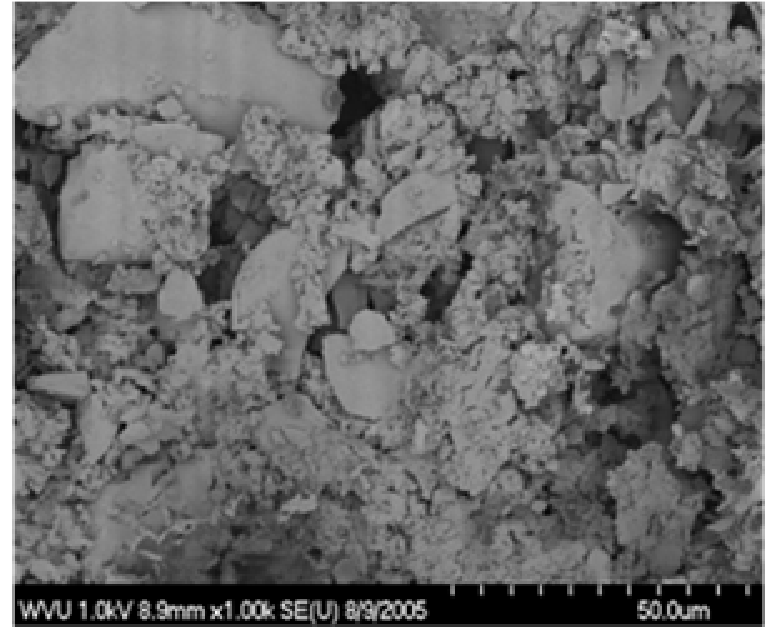

(b)

Figure 9-17 SEM imaging showing (a) fiber-resin interaction at the center of the bar (b) fiber-rein interaction at the edge of the bar

\section{GFRP Bars without Aged in Water at $140^{\circ} \mathrm{F}$ up to 9 Months}

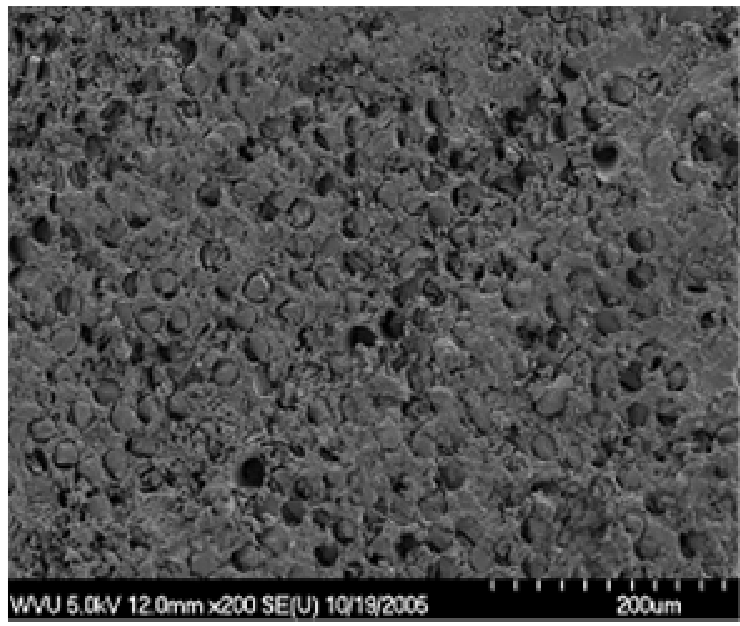

(a)

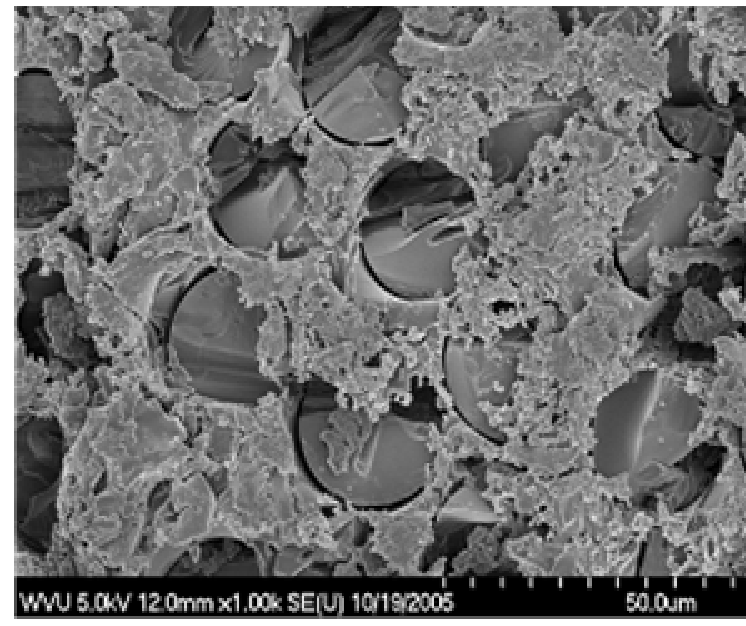

(b)

Figure 9-18 SEM imaging showing (a) fiber-resin interaction at the center of the bar (b) fiber-rein interaction at the edge of the bar 


\section{GFRP Bars with Aged in Water at $140^{\circ} \mathrm{F}$ up to 9 Months}

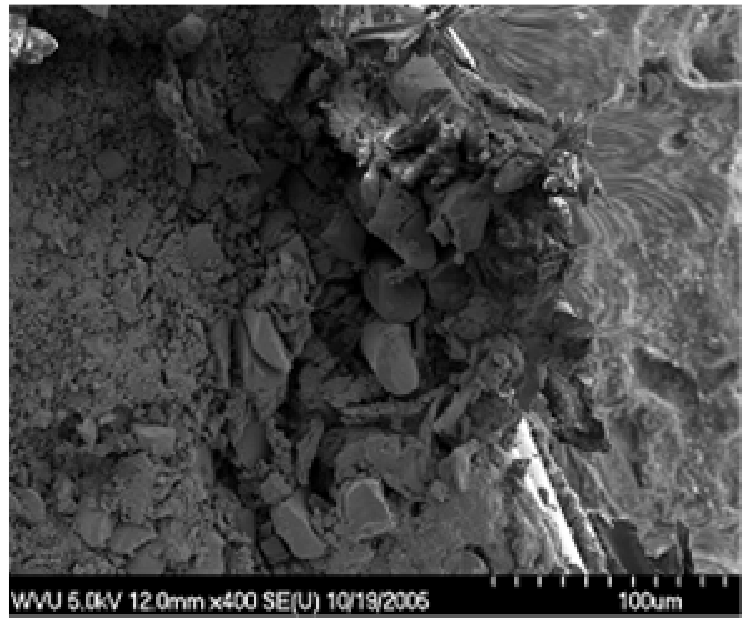

(a)

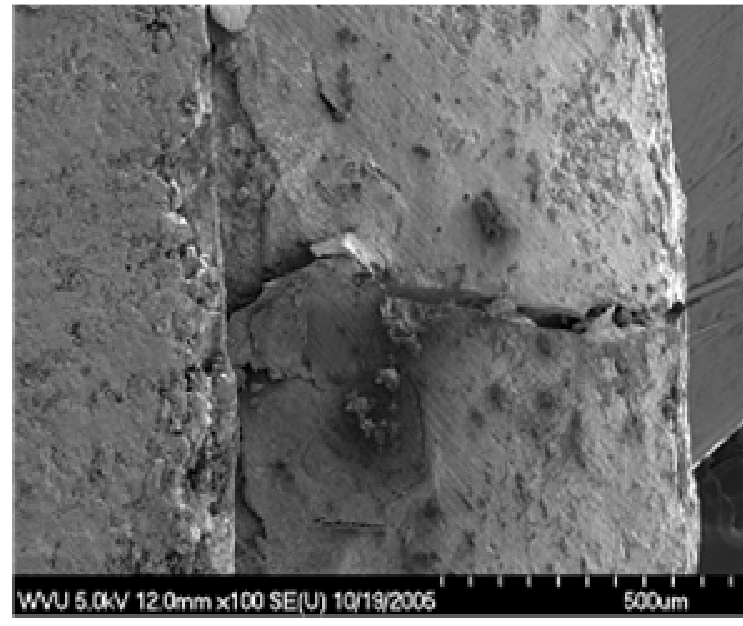

(b)

Figure 9-19 SEM imaging showing (a) fiber-resin isolation/pullout at the edges (b) crack formation in the rib of the bar

\subsubsection{SPECIMENS - ALKALINE SOLUTION AT RT AGING}

Test and Specimen Details

- Aging - Alkaline solution at room temperature for 3, 6, and 9 months

- Nanoclay - Yes $(4 \%) \& N o$

- Fiber-E-glass

- Bar size - $0.5 \mathrm{in}$.

- Number of specimens tested - 7 


\section{GFRP Bars without Nanoclay Aged in Alkaline Solution at RT up to 3 Months}

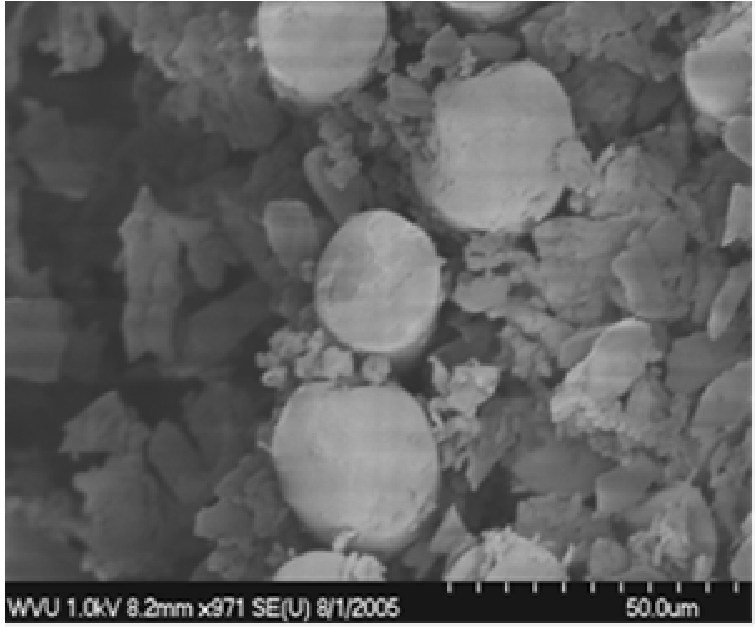

(a)

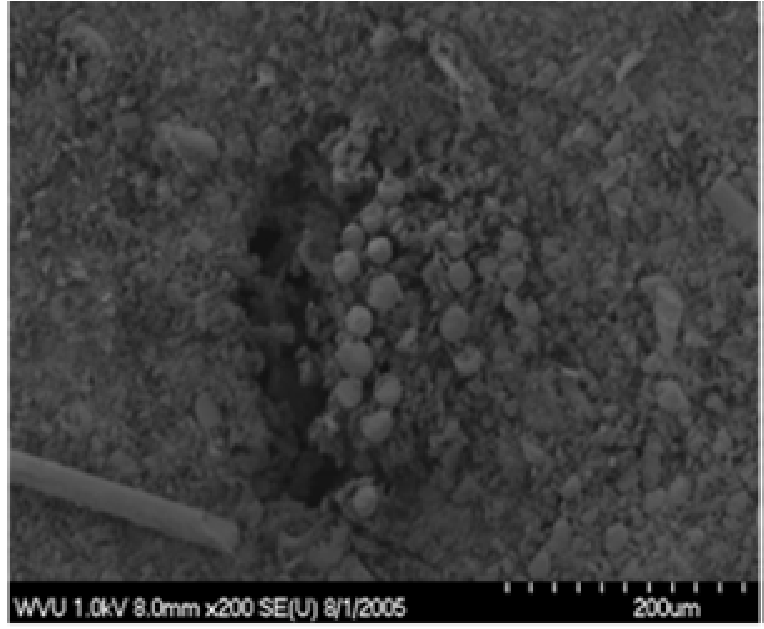

(b)

Figure 9-20 SEM image showing (a) resin damage and cavity formation over the bars edge (b) fiber isolation and cavity formation

\section{GFRP Bars with Nanoclay Aged in Alkaline Solution at RT up to 3 Months}

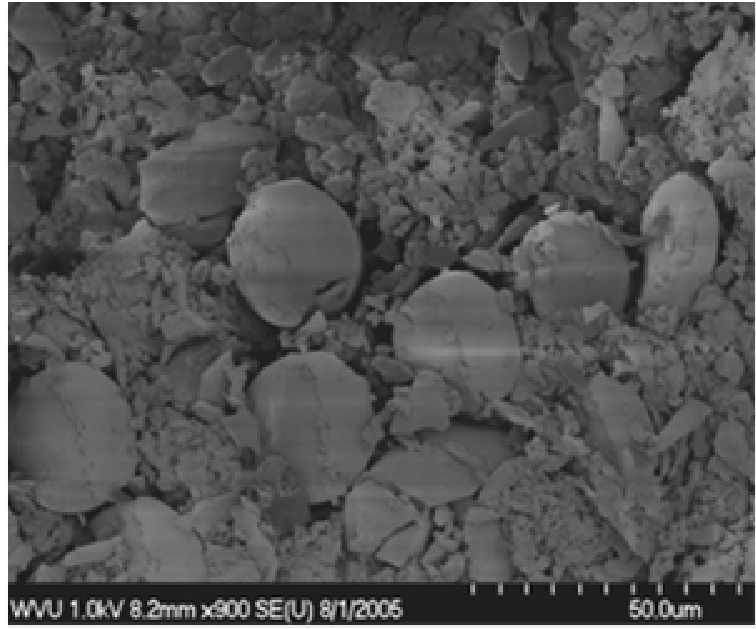

(a)

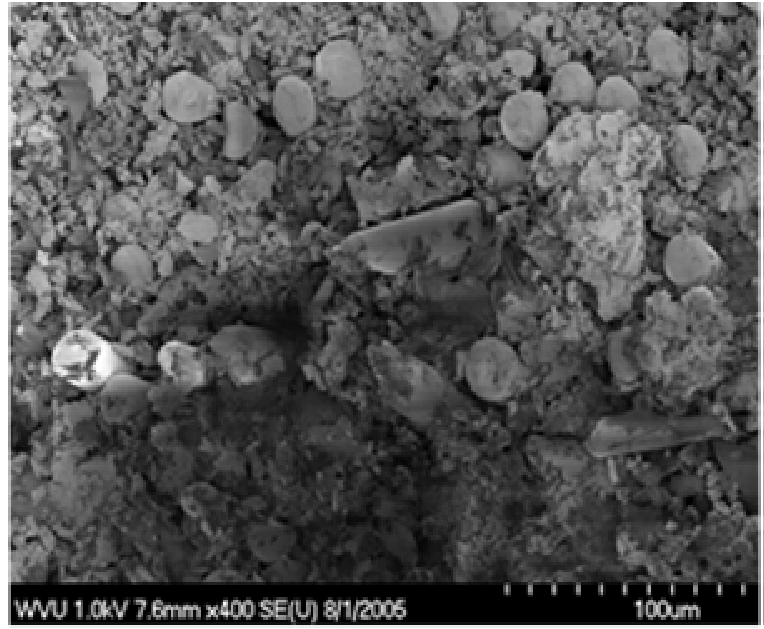

(b)

Figure 9-21 SEM image showing (a) damage resin in the edges there by reducing the fiber-resin interaction (b) cavity formation and resin damage in the edge 


\section{GFRP Bars without Nanoclay Aged in Alkaline Solution at RT up to 6 Months}

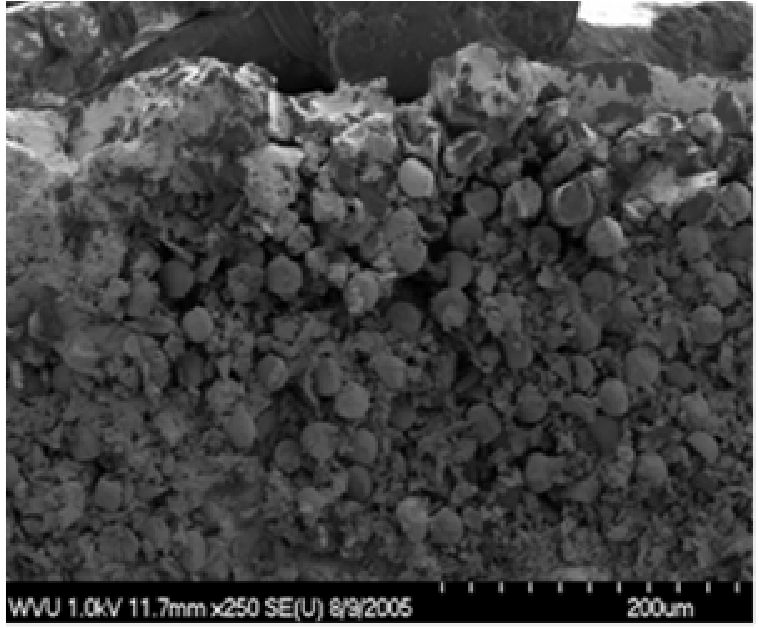

(a)

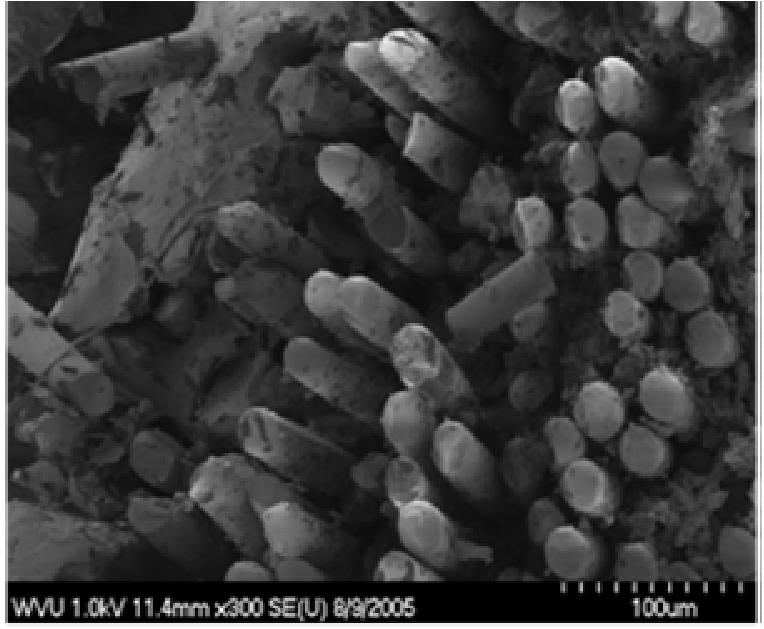

(b)

Figure 9-22 SEM image showing (a) fiber-resin isolation leading to decreased stress distribution (b) disturbance of fiber-resin isolation and fibers

\section{GFRP Bars with Nanoclay Ages in Alkaline Solution at RT up to 6 Months}

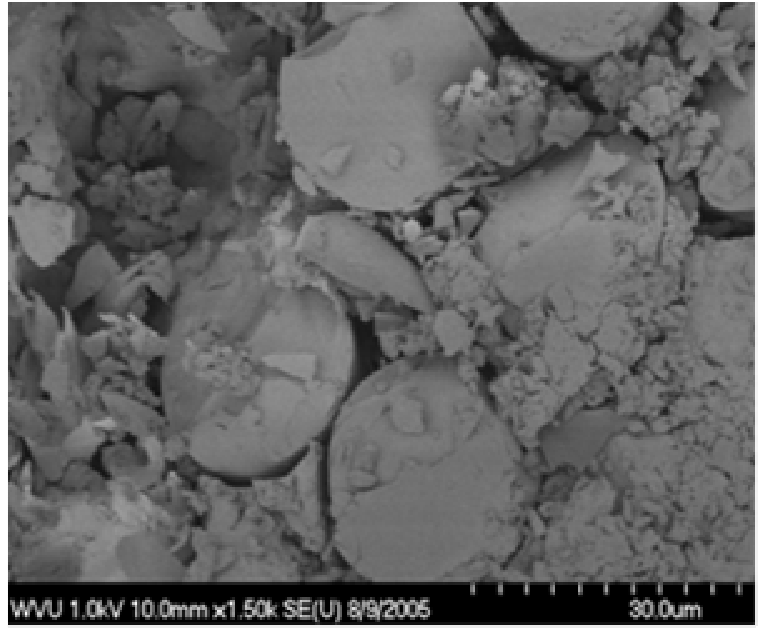

(a)

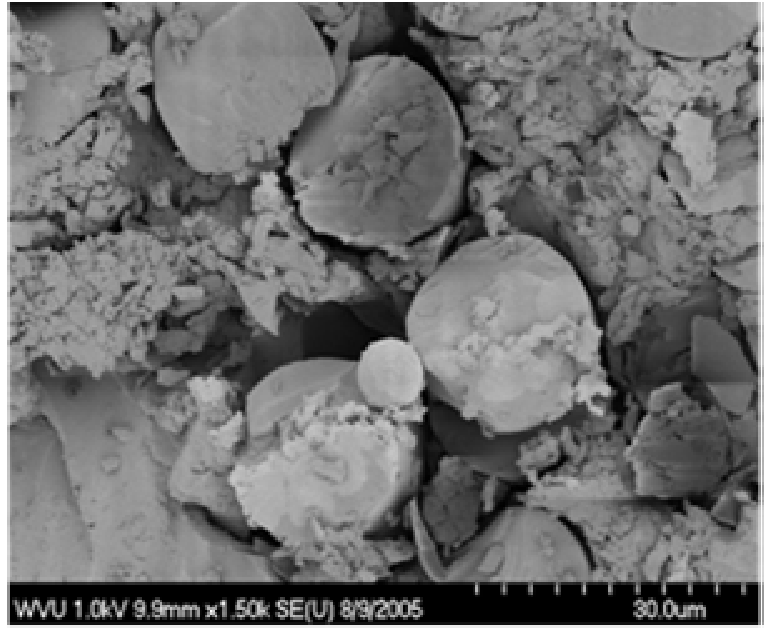

(b)

Figure 9-23 SEM image showing (a) fiber-resin interaction at the center of the bar (b) fiber-resin interaction is decreasing at the edge of the bar 


\section{GFRP Bars without Nanoclay Aged in Alkaline Solution at RT up to 9 Months}

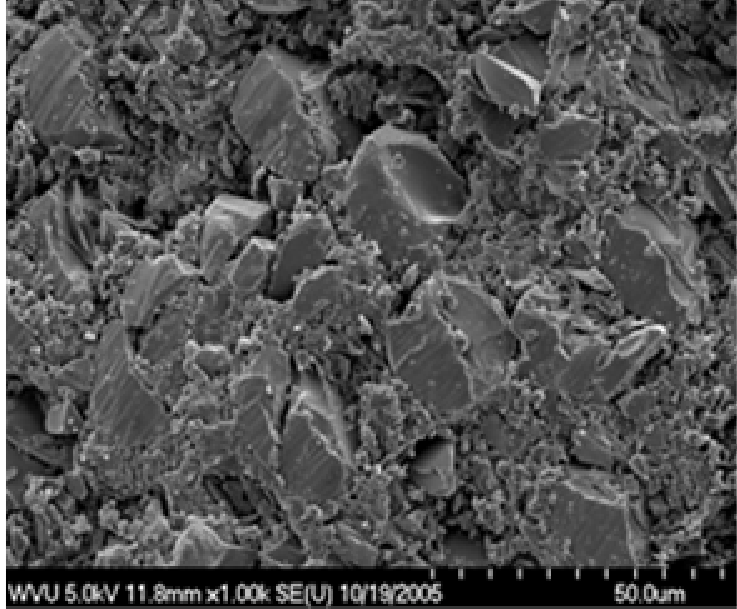

(a)

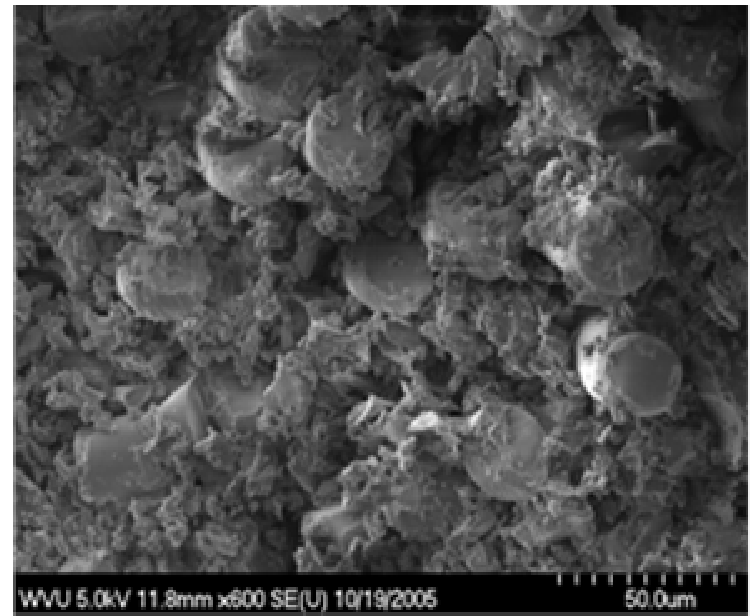

(b)

Figure 9-24 SEM image showing (a) fiber-resin interaction at the center of the bar (b) fiber-resin interaction is decreasing at the edge of the bar

\section{GFRP Bars with Nanoclay Aged in Alkaline Solution at RT up to 9 Months}

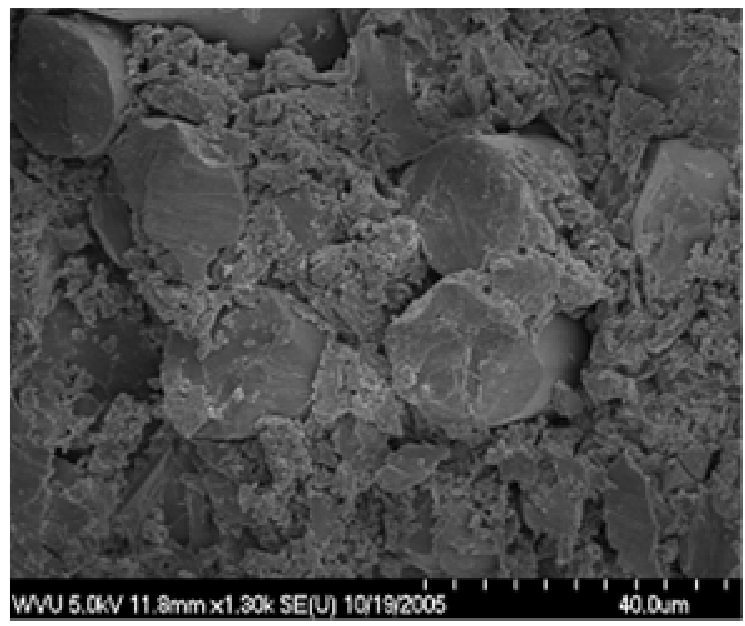

(a)

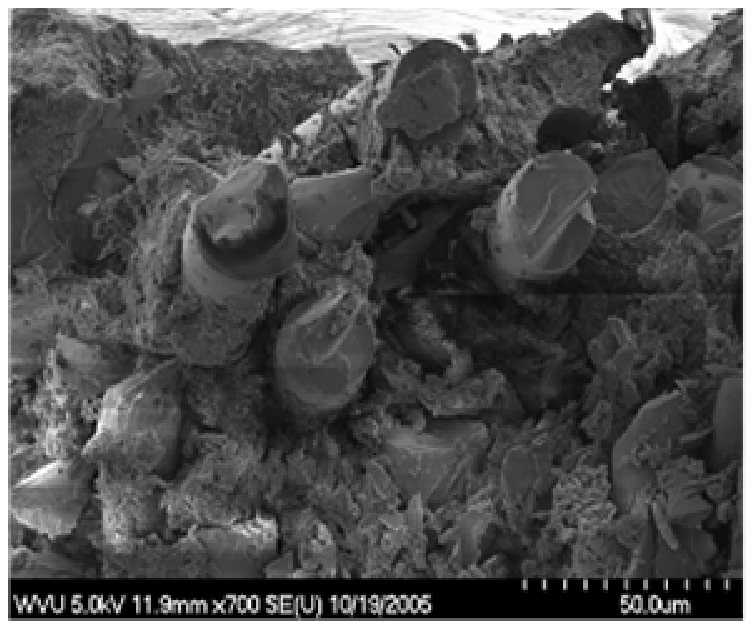

(b)

Figure 9-25 SEM image showing (a) fiber-resin interaction at the center of the bar (b) fiber-resin interaction is decreasing at the edge of the bar 


\subsubsection{SPECIMENS - EXTRACTED FROM CONCRETE BEAMS}

Test and Specimen Details

- Aging - Bars extracted from the concrete beams

- Nanoclay-Yes $(4 \%) \& N o$

- Fiber-E-glass

- Bar size - 0.5 in.

- Number of specimens tested - 2

GFRP Bars without Nanoclay Extracted From Beams after 2 Months of Aging

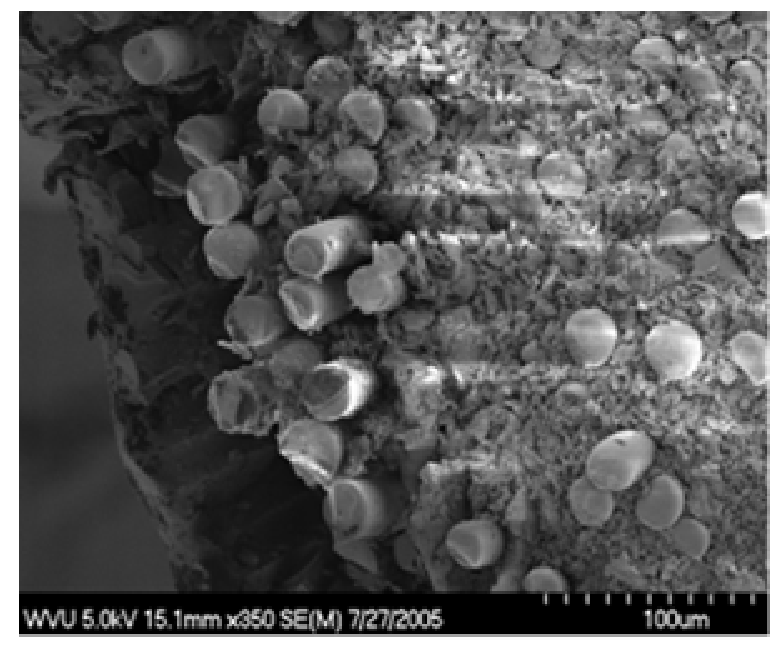

(a)

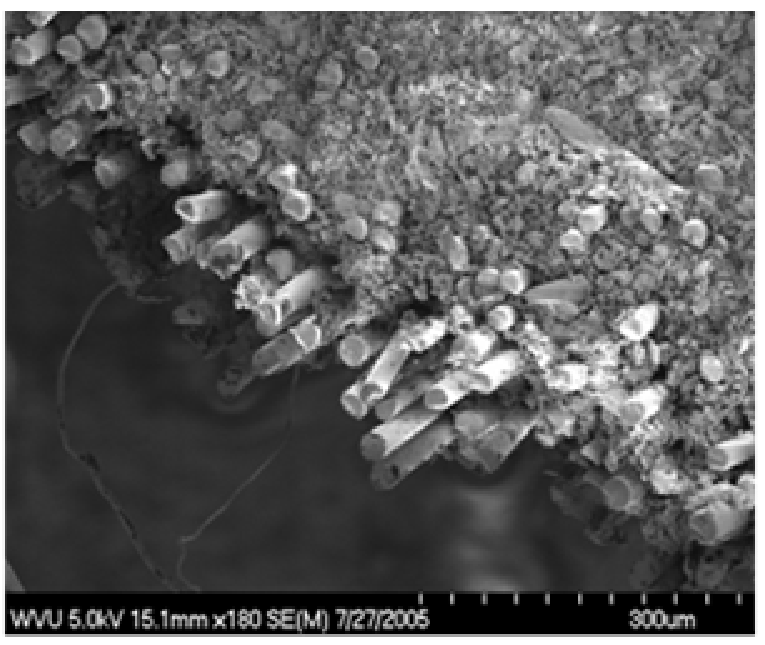

(b)

Figure 9-26 SEM image showing (a) resin damage over the edge of the bar (b) resin damage over the bars edge 


\section{GFRP Bars with Nanoclay Extracted From Beam after 2 Months of Aging}

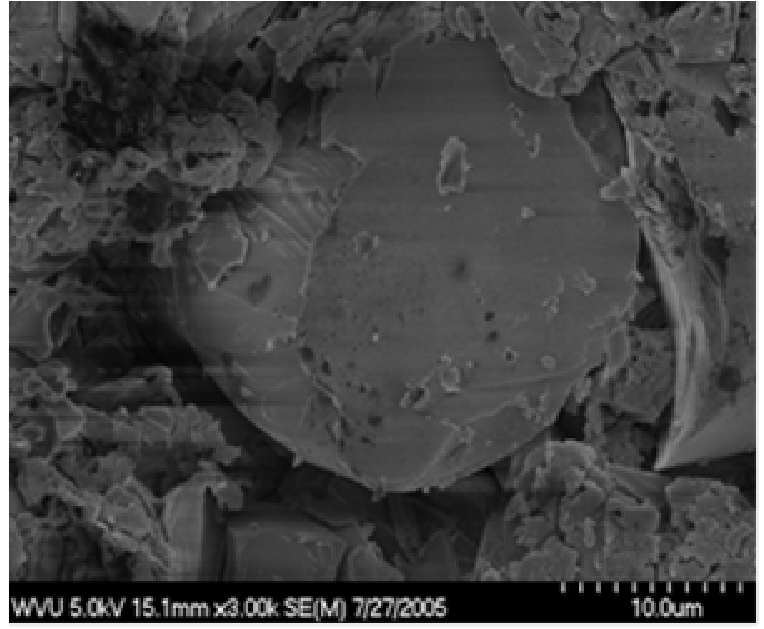

(a)

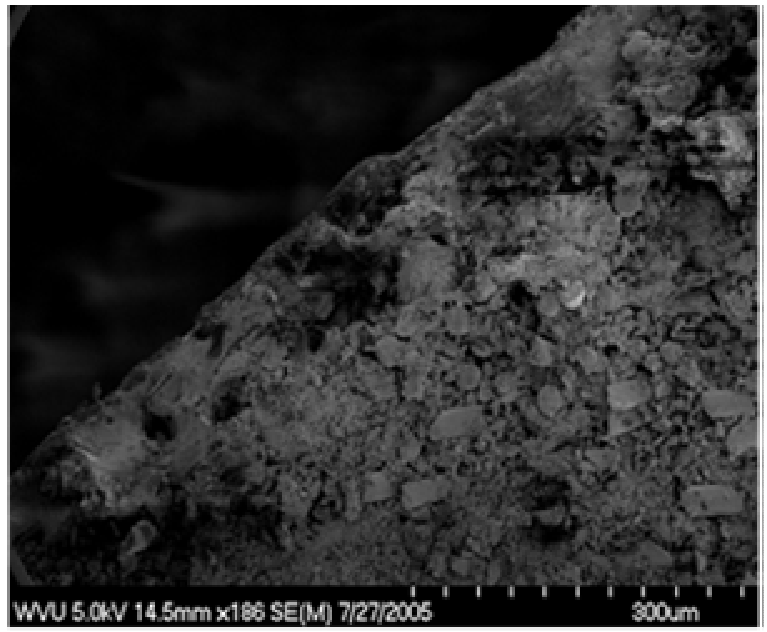

(b)

Figure 9-27 SEM image showing (a) fiber and resin interaction in the center of the bar (b) resin damage and cavity formation in the edge of the bar

\subsection{SUMMARY AND CONCLUSION}

- Neat resin exfoliated with $4 \%$ nanoclay was selected as optimum clay content and used for all the bars manufactured in this research.

- Many of the GFRP bars without nanoclay exhibited pulling out of fibers near edges as compared to those with nanoclay.

- Bars subjected to $140^{\circ} \mathrm{F}$ and alkaline conditioning showed more number of fibers being pulled out and/or damaged from the matrix along the bar edges, which causes a reduction in bar strength. 


\section{BEAM FLEXURE}

\subsection{INTRODUCTION}

Several concrete beams were cast using GFRP bars manufactured with and without nanoclay in CFC-WVU laboratory to evaluate their flexural behavior. A total of four 8 in. x 16 in. x 120 in. and two 5 in. x 8 in. x 60 in. beams were cast with 5000 psi and 3500 psi concrete, respectively. Beams of $10 \mathrm{ft}$. and $5 \mathrm{ft}$. length were designed for tensioncontrolled and compression-controlled failures, respectively. Beams of $5 \mathrm{ft}$. length were tested under three point bending and those of $10 \mathrm{ft}$. length were tested under four point bending. Steel rebars of \#3 diameter were used as compression and shear reinforcements. The parameters of interest are: ultimate moment capacities, failure modes, crack widths, strains in concrete and rebar, and pre-and post-cracking deflections. The designation and beam details are provided in Table 10-1.

Table 10-1 Beam designation and specifications

\begin{tabular}{|c|c|c|c|c|c|}
\hline $\begin{array}{c}\text { Beam } \\
\text { designation }\end{array}$ & $\begin{array}{c}\text { Beam } \\
\text { dimensions } \\
\text { (inch) }\end{array}$ & Nanoclay & $\begin{array}{c}\text { Concrete } \\
\text { strength } \\
\text { (psi) }\end{array}$ & $\begin{array}{c}\text { Tension } \\
\text { GFRP } \\
\text { Rebar }\end{array}$ & $\begin{array}{l}\text { Failure } \\
\text { modes }\end{array}$ \\
\hline B1-T & \multirow{2}{*}{$5 \times 8 \times 60$} & No & \multirow{2}{*}{3500} & \multirow{4}{*}{$2-\# 4$} & \multirow{6}{*}{ Tension } \\
\hline B1-T-NC & & Yes & & & \\
\hline B2-T & \multirow{4}{*}{$8 \times 16 \times 120$} & No & \multirow{4}{*}{5000} & & \\
\hline B2-T-NC & & Yes & & & \\
\hline B3-T & & No & & \multirow[t]{2}{*}{$1-\# 6$} & \\
\hline B3-T-NC & & Yes & & & \\
\hline
\end{tabular}

* \#3 steel rebars were used as compression and shear reinforcement

\subsection{DEVELOPMENT OF THE TEST}

This test method was used from the previous research carried out by the CFC-WVU. Additional details can be obtained from the reference Vijay et al, 1999.

\subsubsection{REFERENCE DOCUMENTS}

(a).ACI 318R-02: Building Code Requirements for Reinforced Concrete and Commentary, American Concrete Institute. 
(b).ACI 440.1R-03: Guide for the Design and Construction of Concrete Reinforced with FRP Bars, American Concrete Institute.

\subsubsection{TERMINOLOGY}

(a). Tension Failure: Failure consisted of bar rupture at mid-span followed by spalling of the concrete in the shape of a small vertical wedge surrounding the bars on tension side.

(b). Compression Failure: Failure of the beam by concrete crushing in the middle third region.

(c). Three-point bending: The beam is supported at two ends and loaded at mid span.

(d).Four-point bending: The beams is supported at two ends and loaded at two points at $1 / 3^{\text {rd }}$ of span.

(e). Effective span: The unsupported length of the beam subjected to loading.

\subsubsection{SPECIMEN PREPARATION}

a. Preparation: Care was taken so that the GFRP bar specimen was not subjected to any processing. During the sampling and preparation of test specimens, all deformation, heating, outdoor exposure to ultraviolet light etc., causing changes to the material properties of the test specimen was avoided.

b. Effective span: An effective span of $50 \mathrm{in}$. was kept for $5 \mathrm{ft}$. long beams B1-T and B1-T-NC and $108 \mathrm{in.}$ for all the other beams with $10 \mathrm{ft}$. length.

c. Number of specimens: One beam for each type was tested.

d. Strain gage: The beams surface was smoothened and suitable platform for strain gage was prepared using AE 10, which was cured for 24 hours. Long strain gages were attached with the concrete using M-bond.

\subsubsection{TEST EQUIPMENTS}

A hydraulic loading jack was used for loading the beam. Load cell, strain gage, and LVDT were used to measure load, strain, and deflection, respectively. Load cell and LVDT were calibrated before the test. Strain gages were attached on tensile GFRP rebar and on concrete surface of the beam on compression side. Crack-width and spacing was 
measured using micrometer and ruler, respectively. A computerized data acquisition was used to record the load, strain, and deflection data.

\subsubsection{TEST METHODS}

(a).Load cell: Load applied by the jack was measured using the load cell, which had a maximum capacity of 100 kips.

(b).LVDT: The deflection at mid-span of the beam was recorded using a LVDT which was connected to a computerized data acquisition.

(c). Strain gage: Concrete and rebar strains were measured using 1 in. or $1 \frac{1 / 2}{\mathrm{in}}$. and narrow strain gages which was connected to a computerized data acquisition.

(d). Micrometer: Crack-width and spacing was measured using micrometer and ruler.

(e). Loading rate: The applied rate of loading for specimen was between 2-3 kip per minute.

(f). Testing temperature: The test temperature was generally with in the range of 40$100^{\circ} \mathrm{F}$.

(g).Loading: The load was applied and the measurements were recorded until the failure of the specimen.

Beams were tested in three and four point bending until the specimen failure, i.e., rebar rupture in tension failure or concrete crushing in compression failure. Test setup for three-point bending and four-point bending is shown in Figures 10-1 and 10-2. Each test consisted of several cycles of loading and unloading to evaluate the ductility behavior and energy absorption of each beam. Residual strains and deflections were measured in each load cycle. Load cell, strain gage, and LVDT data were automatically recorded using a data acquisition system during loading and unloading. Crack widths were measured by using a micrometer and crack patterns in all the beams were traced onto a tracing sheet. Data obtained from the experiments was analyzed and corresponding discussions are provided. 


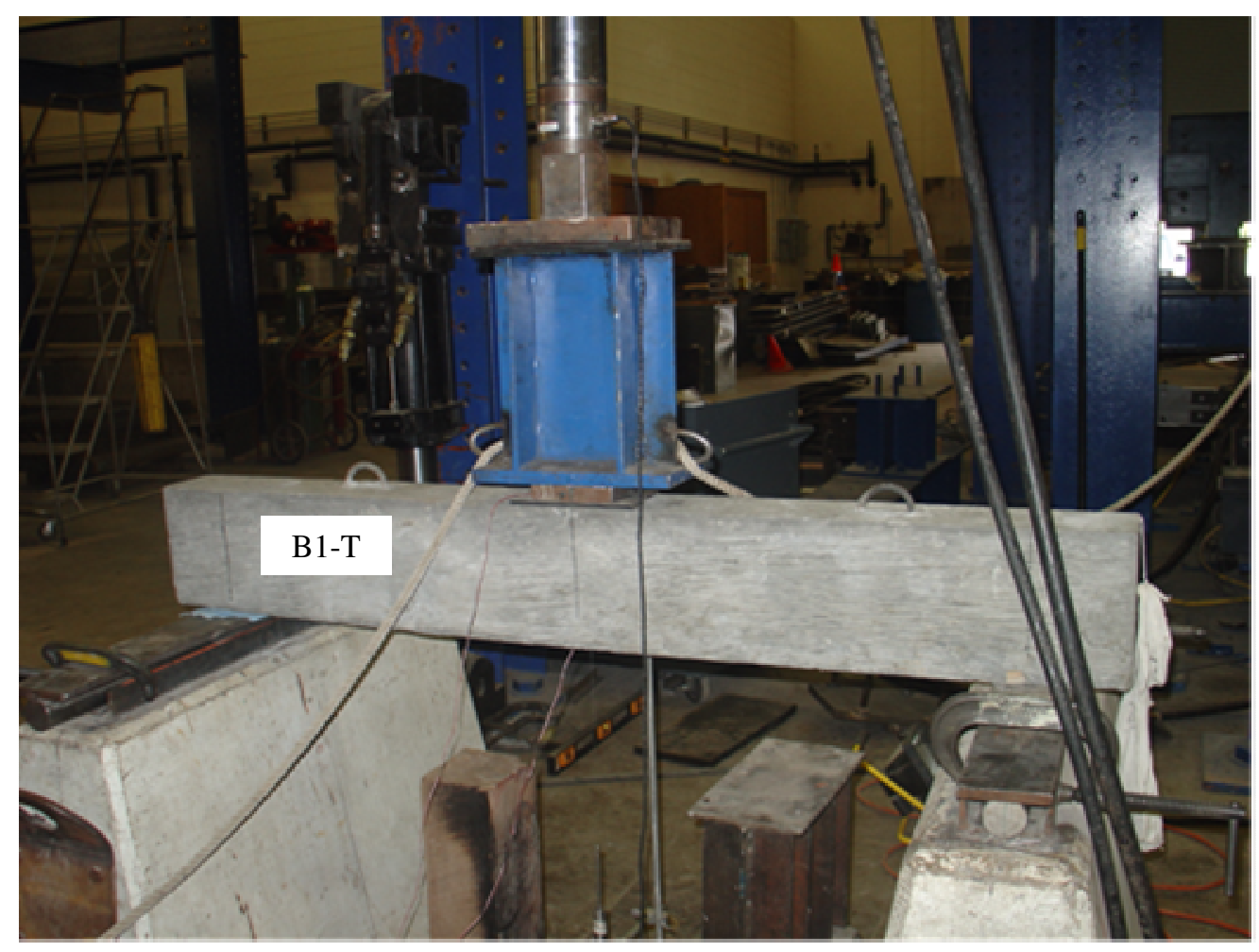

Figure 10-1 Three point bending setup

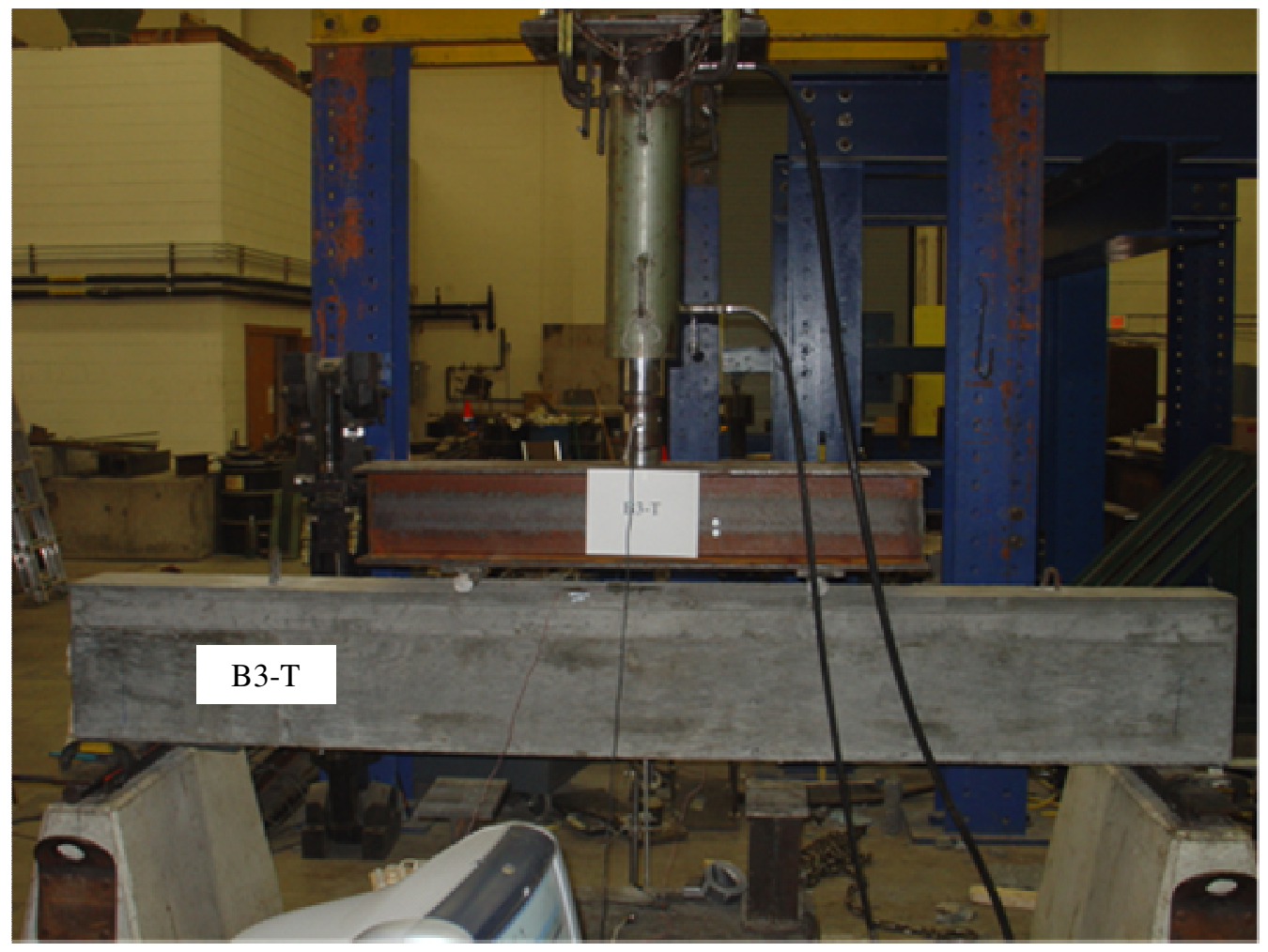

Figure 10-2 Four point bending setup 


\subsection{COMPRESSION TESTS ON CONCRETE CYLINDERS}

Compression cylinders were cast during beam casting and cured for 28 days with the beams. Cylinders were tested using UTM to evaluate their compressive strength (Table 10-2). The cylinders with 5000 psi strength correspond to $10 \mathrm{ft}$. length beams and 3500 psi correspond to $5 \mathrm{ft}$. length beams.

Table 10-2 Compressive strength of concrete cylinders

\begin{tabular}{|c|c|c|}
\hline $\begin{array}{c}\text { Diameter of } \\
\text { cylinder (inch) }\end{array}$ & $\begin{array}{c}\text { Load } \\
\text { (lb) }\end{array}$ & $\begin{array}{c}\text { Stress } \\
\text { (psi) }\end{array}$ \\
\hline 3 & 37200 & 5265.39 \\
\cline { 2 - 3 } & 34000 & 4812.46 \\
\hline Average & $\mathbf{3 5 6 0 0}$ & $\mathbf{5 0 3 8 . 9 3}$ \\
\hline Std Dev & $\mathbf{2 2 6 2 . 7 4}$ & $\mathbf{3 2 0 . 2 7}$ \\
\hline \% Std Dev & $\mathbf{6 . 3 6}$ & $\mathbf{6 . 3 6}$ \\
\hline \multirow{2}{*}{4} & 44000 & 3503.18 \\
\cline { 2 - 3 } & 41600 & 3312.10 \\
\hline Average & $\mathbf{4 2 8 0 0}$ & $\mathbf{3 4 0 7 . 6 4}$ \\
\hline Std Dev & $\mathbf{1 6 9 7 . 0 6}$ & $\mathbf{1 3 5 . 1 1}$ \\
\hline \% Std Dev & $\mathbf{3 . 9 6}$ & $\mathbf{3 . 9 7}$ \\
\hline
\end{tabular}

\subsection{SAMPLE CALCULATION FOR BEAM B2-T}

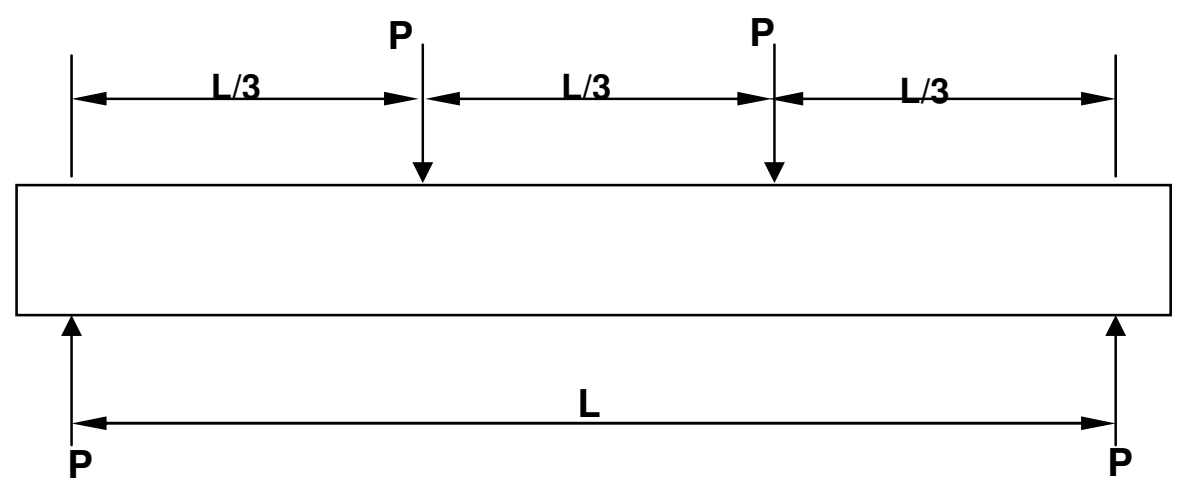

Figure 10-3 Schematic diagram of four point bending test 


\section{Properties of concrete}

Strength of concrete, $f_{c}^{\prime}=5000 \mathrm{psi}=5 \mathrm{ksi}$

Ultimate strain in concrete, $\varepsilon_{c u}=0.003$

Beam dimensions

Depth of the beam, $h=16$ in.

Width of the beam, $b=8$ in.

Span of beam, $L=9 \mathrm{ft}$. (6 in. overhang on each side)

\section{Properties of GFRP bar}

Guaranteed tensile strength of GFRP bar, $f_{f u}^{*}=130000 \mathrm{psi}=130 \mathrm{ksi}$

Guaranteed rupture strain of GFRP bar, $\mathcal{E}_{f u}^{*}=0.019$

Note:

Our intention is not to design and hence guaranteed tensile strength and strain are chosen without accounting for $3 \sigma$, where $\sigma$ is standard deviation.

Modulus of elasticity of GFRP bar, $E_{f}=4800 \mathrm{ksi}$

Environmental reduction factor, $C_{E}=1$ (for instantaneous testing purpose, for long-term

$$
\text { ACI } 440 \text { suggests } C_{E}=0.8 \text { ) }
$$

Rupture stress of GFRP bar, $f_{f u}=C_{E} f_{f u}^{*}=130 \mathrm{ksi}$

Rupture strain of GFRP bar, $\varepsilon_{f u}=C_{E} \mathcal{E}_{f u}^{*}=0.019$

Modulus of elasticity of concrete, $E_{c}=57000 \sqrt{f_{c}^{\prime}}$

$$
\begin{aligned}
& =57000 \sqrt{5000} \\
& =4030.51 \mathrm{ksi} \\
\beta_{1} & =0.85-0.05\left(\frac{f_{c}^{\prime}-4000}{1000}\right) \\
& =0.85-0.05\left(\frac{5000-4000}{1000}\right)=0.80
\end{aligned}
$$

Number of reinforcing bars $=2$

\# 4 bars are used as main reinforcement $=0.5 \mathrm{in}$.

Assume clear cover as 1 in., 
Estimated effective depth, $d=h-\operatorname{cov} e r-d_{b, \text { shear }}-\frac{d_{b}}{2}$

$$
\begin{aligned}
& =16-1-0.375-\frac{0.5}{2} \\
& =14.375 \mathrm{in} .
\end{aligned}
$$

$\underline{\text { To Find Depth of Neutral Axis Depth }}$

$$
\begin{aligned}
\frac{\varepsilon_{c u}}{c}=\frac{\varepsilon_{f u}}{d-c} \\
c=\frac{d \varepsilon_{c u}}{\varepsilon_{f u}+\varepsilon_{c u}} \\
=\frac{14.375 \times 0.003}{0.019+0.003} \\
=1.9602 \mathrm{in.} \\
a \quad=\beta_{1} c \\
=0.8 \times 1.9602=1.5682 \mathrm{in} .
\end{aligned}
$$

\section{$\underline{\text { To find moment }}$}

$$
\begin{aligned}
A_{f} & =\operatorname{No.bars}\left(\frac{\pi d^{2}}{4}\right) \\
& =2\left(\frac{\pi \times 0.5^{2}}{4}\right)=0.3927 \mathrm{in.}^{2} \\
\rho_{f} & =\frac{A_{f}}{b d} \\
& =\frac{0.3927}{8 \times 14.375}=0.0034 \\
& =A_{s} f_{y}(d-a / 2) \\
\mathrm{M}_{\mathrm{n}} & =0.3927 \times 130(14.375-1.5682 / 2) \\
& =57.819 \mathrm{kip}-\mathrm{ft}
\end{aligned}
$$

$\underline{\text { To find load }}$

$$
M=\frac{P L}{3}
$$




$$
P=\frac{3 M}{L}=\frac{3 \times 57.819}{9}=19.273 \text { kips }
$$

Total load $=2 P=2 \times 19.273=38.546$ kips

Theoretical

Experimental load $=38.61$ kips

$$
\frac{\text { Experimental load }}{\text { Theoretical load }}=38.61 / 38.546=1.08
$$

\subsection{DEFORMABILITY FACTOR}

Traditionally, energy absorption of steel reinforced concrete beams is indicated by ductility, which is defined as the ratio of deflection (or curvature or rotation) at ultimate to those values at yielding of steel. However, energy absorption of composite reinforced concrete beams is given by deformability factor, which is defined as the ratio of energy absorption (or area under moment curvature or load-deflection curve) at ultimate to energy absorption at limiting curvature value (GangaRao and Vijay, 1998). Limiting value of curvature is based on serviceability criteria of both deflection and crack width (hence, unified), (Vijay and GangaRao, 2001). ACI 318/318R-96 specified deflections and crack-width limits are shown below.

i. The serviceability deflection limit of 1/180 (ACI 318/318R-96)

ii. The crack-width limit of 0.016 in. (ACI 318/318R-96)

Other serviceability deflection limits such as 1/240, 1/360 etc. will improve the deformability factor, if deflections are the governing parameters as compared to crackwidth. For concrete beams reinforced with GFRP bars, 1/180 was found to be a better choice for unifying the two serviceability limit states of deflection and crack-width (Vijay and GangaRao, 2001).

Based on moment-curvature diagrams of over 50 FRP reinforced beams, Vijay and GangaRao (2001) experimentally determined that maximum unified curvature at a service load that satisfied both deflection and crack-width serviceability limits should be limited to $(0.005 / \mathrm{d})$ rad./in., where "d" is the effective depth of a concrete beam. Deformability factors for the beams tested in this research are provided in the Tables. 


\subsection{TEST RESULTS}

\subsubsection{BEAM WITH AND WITHOUT NANOCLAY (5 FT LONG)}

\section{Test/Specimen Details and Results}

Beams reinforced with 2- \#4 GFPR bars with and without nanoclay of size 5 in. $x 8$ in. $x$ 60 in. were tested in three point bending. Strains were measured using strain gages attached to the concrete and rebar. Deflection was measured in the mid span of the beam using an LVDT. Results from beams B1-T and B1-T-NC are presented in terms of maximum failure load, maximum moment, maximum deflection (recorded), and maximum crack width (recorded) in Table 10-3.

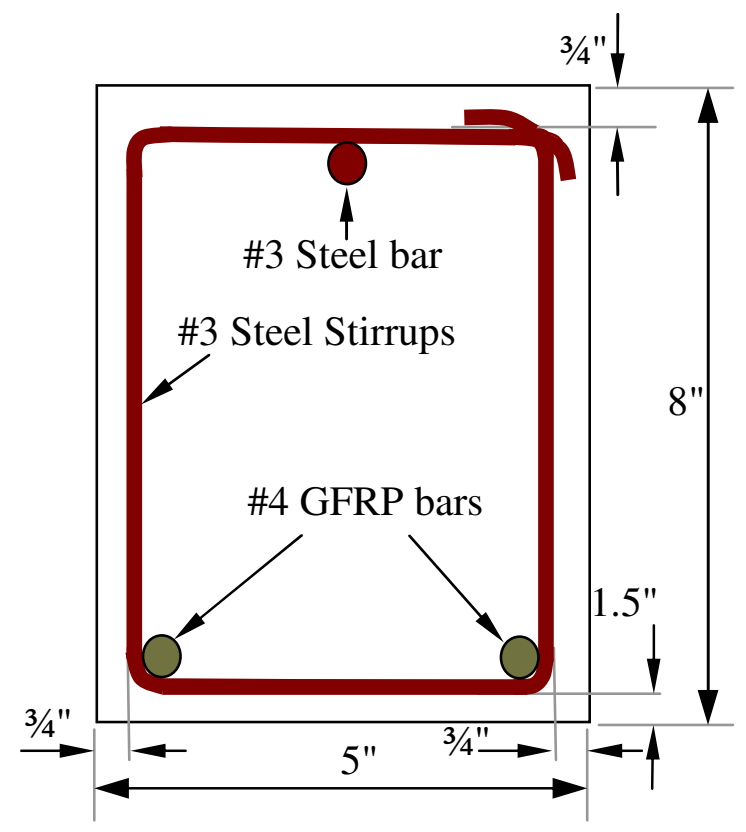

Figure 10-4 Schematic diagram of beams B1-T \& B1-T-NC

Table 10-3 Test results of beams B1-T \& B1-T-NC

\begin{tabular}{|c|c|c|c|c|}
\hline Beam & $\begin{array}{c}\text { Max Load } \\
\text { (recorded) } \\
\text { (kips) }\end{array}$ & $\begin{array}{c}\text { Max } \\
\text { moment } \\
\text { (recorded) } \\
\text { (kip-ft) }\end{array}$ & $\begin{array}{c}\text { Max } \\
\text { deflection } \\
\text { (recorded) } \\
\text { (inch) }\end{array}$ & $\begin{array}{c}\text { Max crack } \\
\text { width } \\
\text { (recorded) } \\
\text { (inch) }\end{array}$ \\
\hline B1-T & 16.37 & 17.05 & 1.62 & 0.0045 \\
\hline B1-T-NC & 14.84 & 15.46 & 1.49 & 0.003 \\
\hline
\end{tabular}




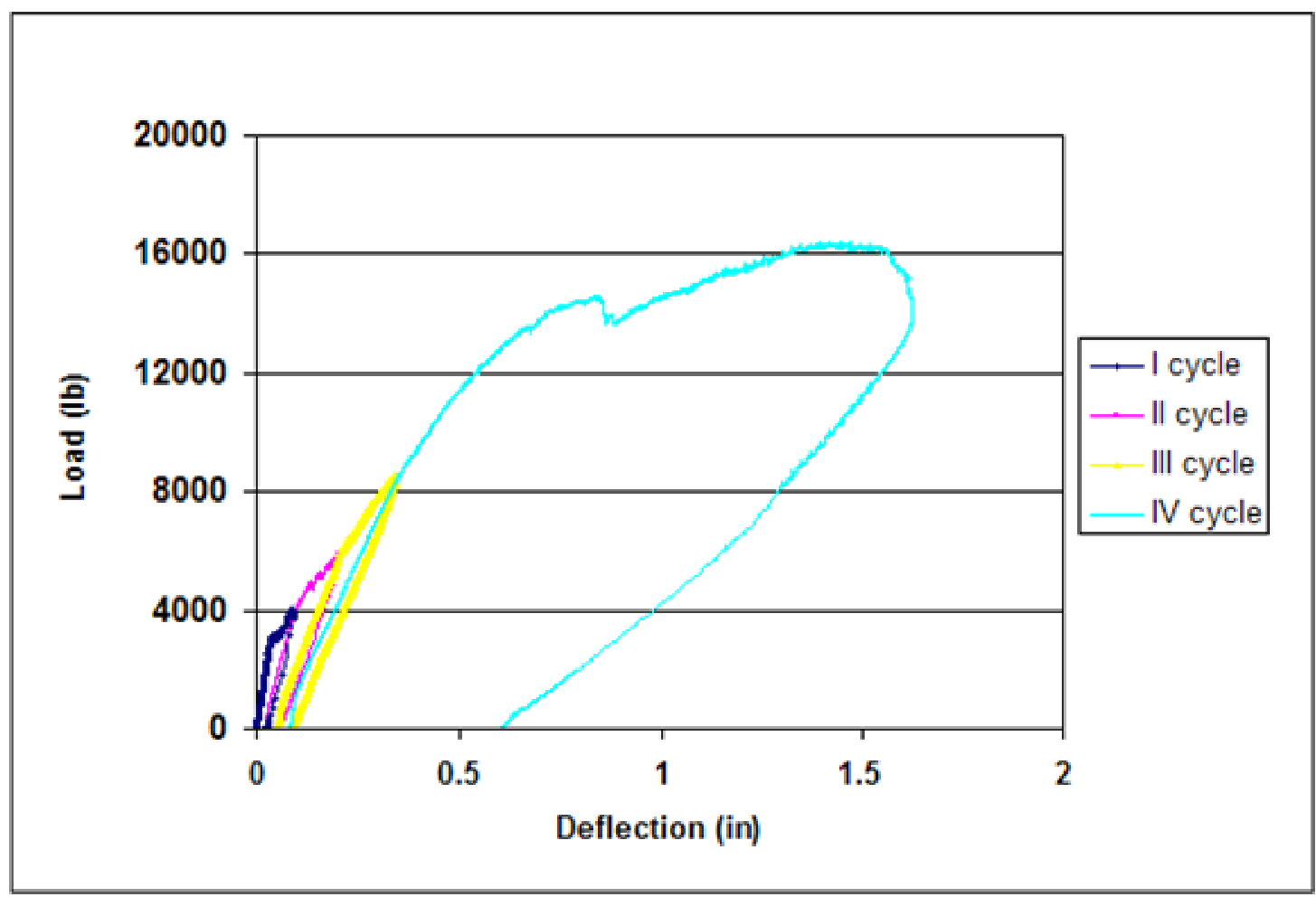

Figure 10-5 Load vs. deflection curve for beam B1-T

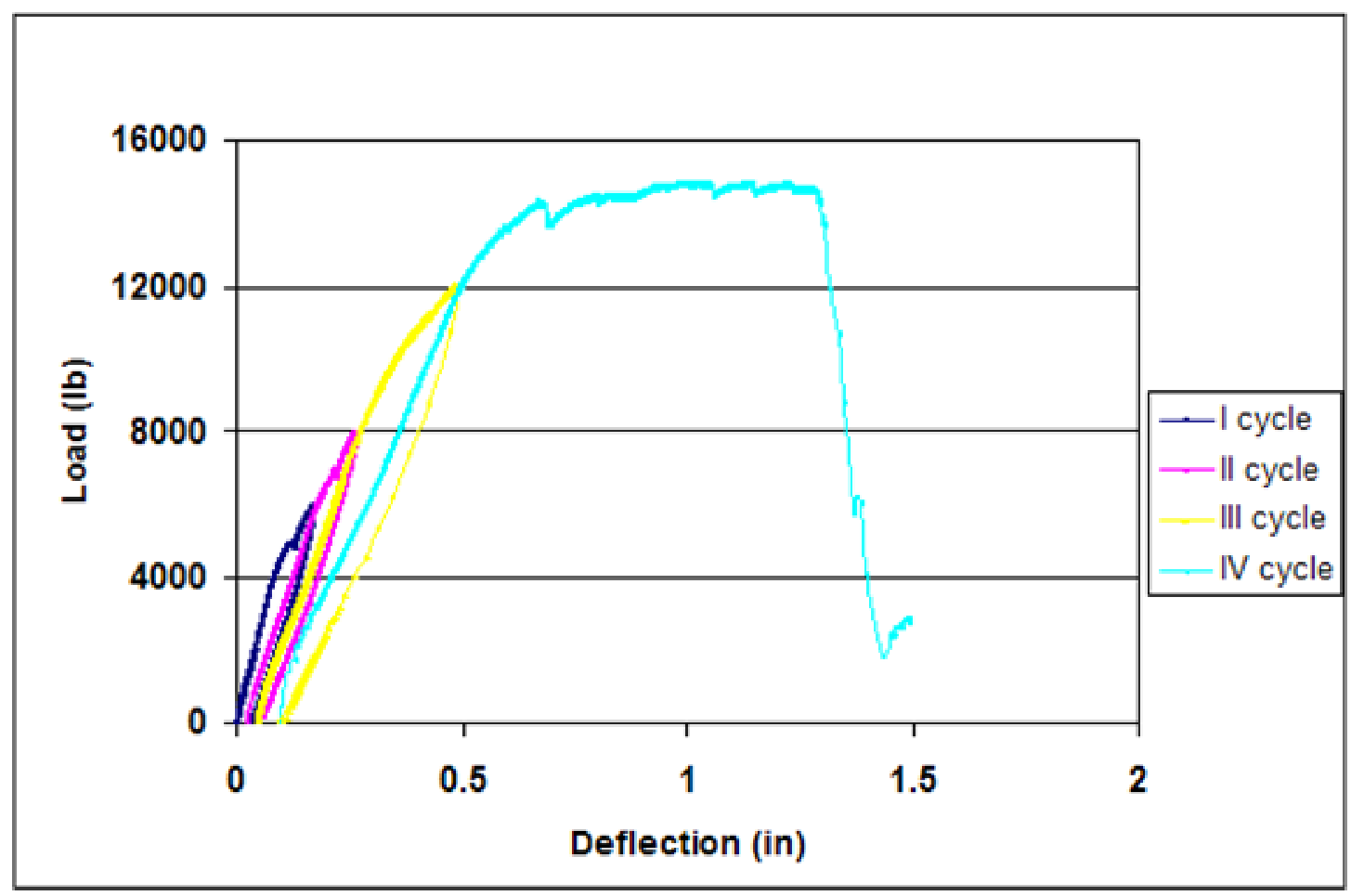

Figure 10-6 Load vs. deflection curve for beam B1-T-NC 


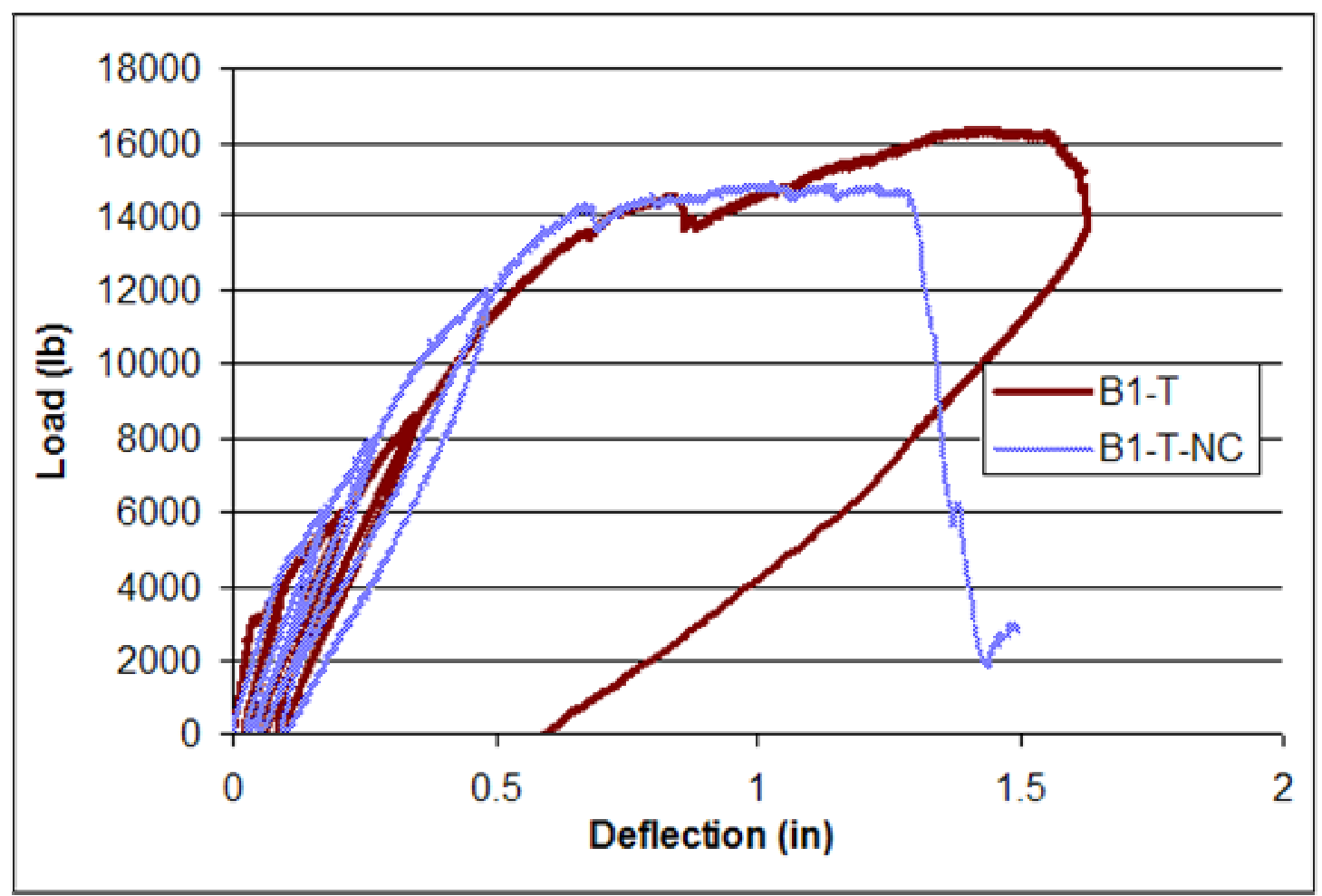

Figure 10-7 Comparison of load vs. deflection of beams B1-T and B1-T-NC

Experimental bending moment values of beams tested under three-point bending are compared with theoretical values based on bending theory for reinforced concrete beams in Table 10-4. In addition, ratio of experimental versus theoretical values of loads (moments) were calculated for comparison. Theoretical calculations for the beams are presented in Appendix C.

Ratio of experimental to theoretical load (moment) capacity were within $10 \%$ for concrete beams reinforced with GFRP bars (with and without nanoclay) tested under three point bending (Table 10-4).

Table 10-4 Max (Exptl./Theor) load (moment) ratios for beams B1-T \& B1-T-NC

\begin{tabular}{|c|c|c|c|c|c|c|}
\hline Beam & $\begin{array}{c}\text { Max } \\
\text { Load } \\
\text { (Exptl.) } \\
\text { (kips) }\end{array}$ & $\begin{array}{c}\text { Max } \\
\text { moment } \\
\text { (Exptl.) } \\
\text { (kip-ft) }\end{array}$ & $\begin{array}{c}\text { Max } \\
\text { Load } \\
\text { (Theor.) } \\
\text { (kips) }\end{array}$ & $\begin{array}{c}\text { Max } \\
\text { moment } \\
\text { (Theor.) } \\
\text { (kip-ft) }\end{array}$ & $\begin{array}{c}\text { Max } \\
\text { load (moment) } \\
\text { ratio } \\
\text { (Exptl./Theor) }\end{array}$ & $\begin{array}{l}\text { Deformability } \\
\text { factor }\end{array}$ \\
\hline B1-T & 16.37 & 17.05 & 17.92 & 18.67 & 0.94 & 14 \\
\hline B1-T-NC & 14.84 & 15.46 & 16.03 & 16.71 & 1.02 & 12 \\
\hline
\end{tabular}


Load at different serviceability deflection limits specified by ACI 318-02 are obtained from experimental results and compared in Table 10-5.

Table 10-5 Loads at different limiting deflection values of beams B1-T \& B1-T-NC

\begin{tabular}{|c|c|c|c|}
\hline \multirow{2}{*}{ Beam } & \multicolumn{3}{|c|}{ Load at deflection limit (kips) } \\
\cline { 2 - 4 } & $\mathbf{1 / 3 6 0}(\mathbf{0 . 1 6 6 7}$ in.) & $\mathbf{1} / \mathbf{2 4 0}(\mathbf{0 . 2 5 0}$ in.) & $\mathbf{1 / 1 8 0}(\mathbf{0 . 3 3 3}$ in.) \\
\hline B1-T & 5.26 & 6.76 & 8.40 \\
\hline B1-T-NC & 5.92 & 7.67 & 9.52 \\
\hline
\end{tabular}

The ratios of load at each deflection limit (1/360, 1/240, and 1/180) to maximum experimental load are presented in Table 10-6.

Table 10-6 Ratio of load at serviceability deflection to maximum load for the beams B1-T \& B1-C-NT

\begin{tabular}{|c|c|c|c|}
\hline \multirow{2}{*}{ Beam } & $\begin{array}{c}\text { Ratio of load at } \\
\text { deflection }(\mathbf{s p a n} / \mathbf{3 6 0}) \\
\text { to Max load }\end{array}$ & $\begin{array}{c}\text { Ratio of load at } \\
\text { (span/240) to Max } \\
\text { load }\end{array}$ & $\begin{array}{c}\text { Ratio of load at } \\
\text { deflection }(\mathbf{s p a n} / \mathbf{1 8 0}) \\
\text { to Max load }\end{array}$ \\
\cline { 2 - 4 } & $\mathbf{1 / 3 6 0}(\mathbf{0 . 1 6 6 7}$ in.) & $\mathbf{1 / 2 4 0}(\mathbf{0 . 2 5 0}$ in. $)$ & $\mathbf{1 / 1 8 0}(\mathbf{0 . 3 3 3}$ in. $)$ \\
\hline B1-T & 0.321 & 0.413 & 0.513 \\
\hline B1-T-NC & 0.398 & 0.517 & 0.642 \\
\hline
\end{tabular}

The ratios of load at limiting crack width (0.016 in.) to maximum load of beams are presented in Table 10-7.

Table 10-7 Load at crack width limit (0.016 in.) for the beams B1-T \& B1-T-NC

\begin{tabular}{|c|c|c|}
\hline Beam & $\begin{array}{c}\text { Load at limiting crack } \\
\text { width (0.016 in.) } \\
\text { (kips) }\end{array}$ & $\begin{array}{c}\text { Ratio of load at limiting } \\
\text { crack width (0.016 in.) } \\
\text { to max load }\end{array}$ \\
\hline B1-T & 3.60 & 0.219 \\
\hline B1-T-NC & 5.50 & 0.370 \\
\hline
\end{tabular}




\section{Discussion of Tests Results}

- Beam reinforced with bars without nanoclay (having higher tensile failure stress than those with nanoclay) carried higher failure load. It should be noted that bars with nanoclay had a lower tensile strength than bars without nanoclay (Chapter 5).

- Ratio of experimental to theoretical ultimate load (moment) capacities of the beams B1-T and B1-T-NC were 0.94 and 1.02, respectively (Table 10-4).

- Deformability factors of beams B1-T and B1-T-NC were 14 and 12, respectively (Table 10-4).

- Beam reinforced with bars without nanoclay showed lesser load than the beam reinforced with bars with nanoclay at same deflection and crack width value within $80 \%$ of ultimate load (Figure 10-7).

- Ratio of load at deflection limits and crack width limit to maximum load was higher for the beam reinforced with nanoclay.

\subsubsection{BEAM WITH \# 4 BARS WITH AND WITHOUT NANOCLAY (10 FT LONG)}

\section{Test/Specimen Details and Results}

Beams reinforced with 2- \#4 GFPR bars with and without nanoclay of size 8 in. $x 16$ in. $x$ 120 in. were tested in four point bending. Strains were measured using strain gages attached to the concrete and rebar. Deflection is measured in the mid span of the beam using an LVDT. Results from beams B2-T and B2-T-NC are presented in terms of maximum failure load, maximum moment, maximum deflection (recorded), and maximum crack width (recorded) in Table 10-8. 


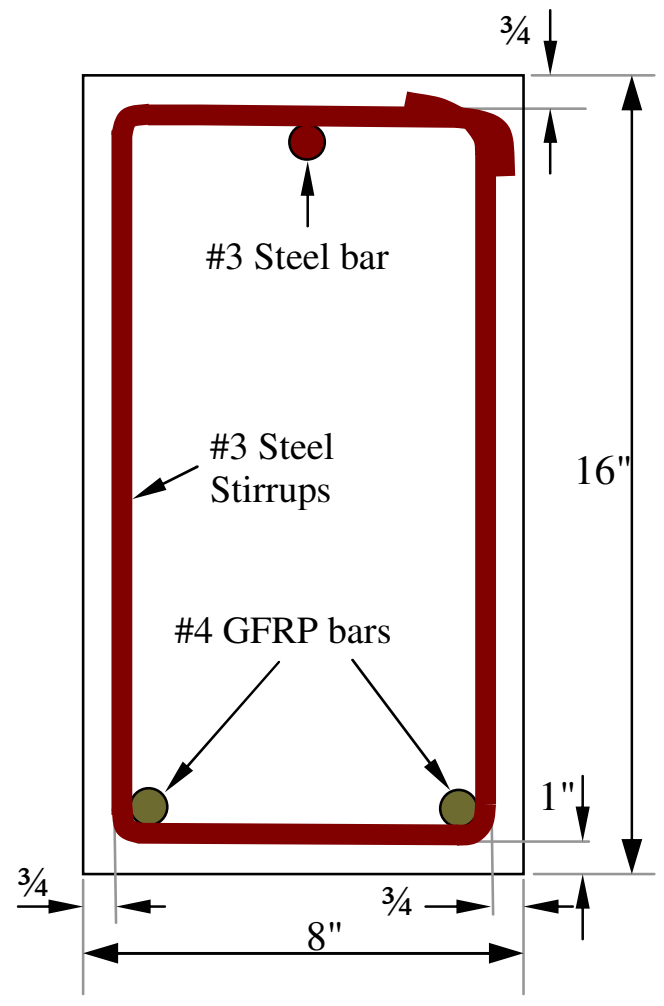

Figure 10-8 Schematic diagram of beam B2-T \& B2-T-NC

Table 10-8 Test results of beams B2-T \& B2-T-NC

\begin{tabular}{|c|c|c|c|c|}
\hline Beam & $\begin{array}{c}\text { Max Load } \\
\text { (recorded) } \\
\text { (kips) }\end{array}$ & $\begin{array}{c}\text { Max } \\
\text { moment } \\
\text { (recorded) } \\
\text { (kip-ft) }\end{array}$ & $\begin{array}{c}\text { Max } \\
\text { deflection } \\
\text { (recorded) } \\
\text { (inch) }\end{array}$ & $\begin{array}{c}\text { Max crack } \\
\text { width } \\
\text { (recorded) } \\
\text { (inch) }\end{array}$ \\
\hline B2-T & 38.61 & 57.915 & 2.21 & 0.0072 \\
\hline B2-T-NC & 27.78 & 41.67 & 1.52 & 0.0052 \\
\hline
\end{tabular}




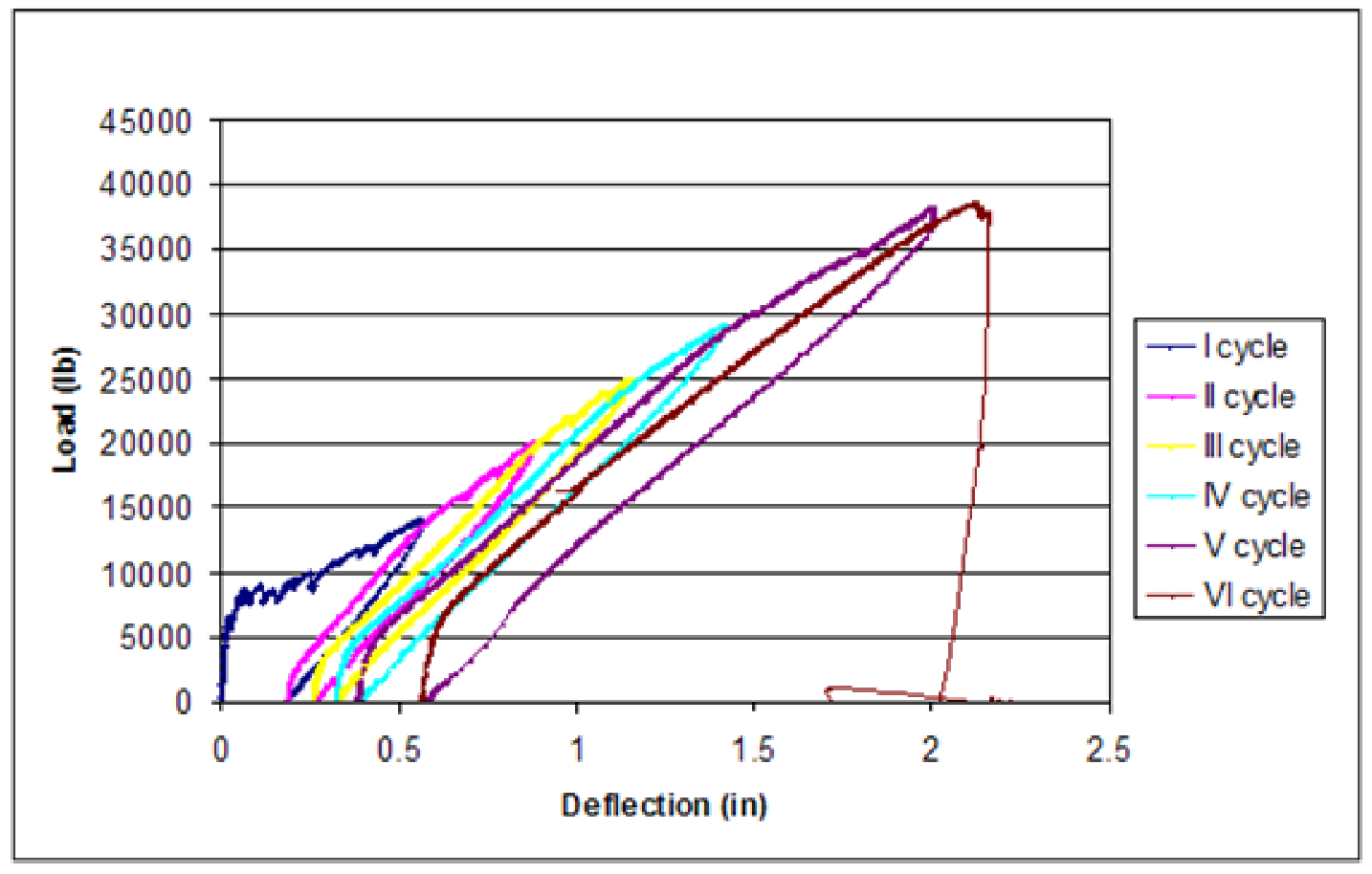

Figure 10-9 Load vs. deflection curve for beam B2-T

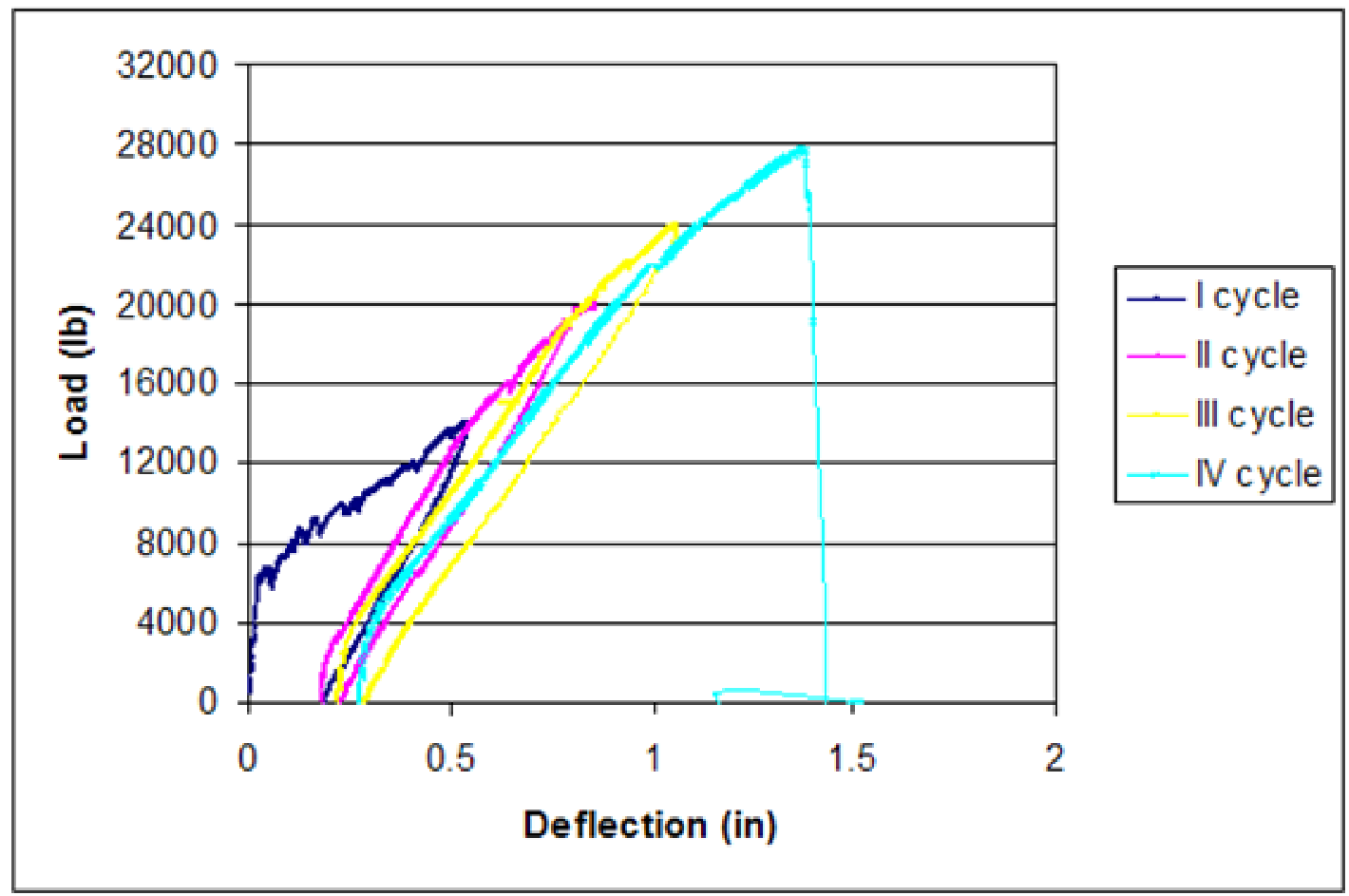

Figure 10-10 Load vs. deflection curve for beam B2-T-NC 


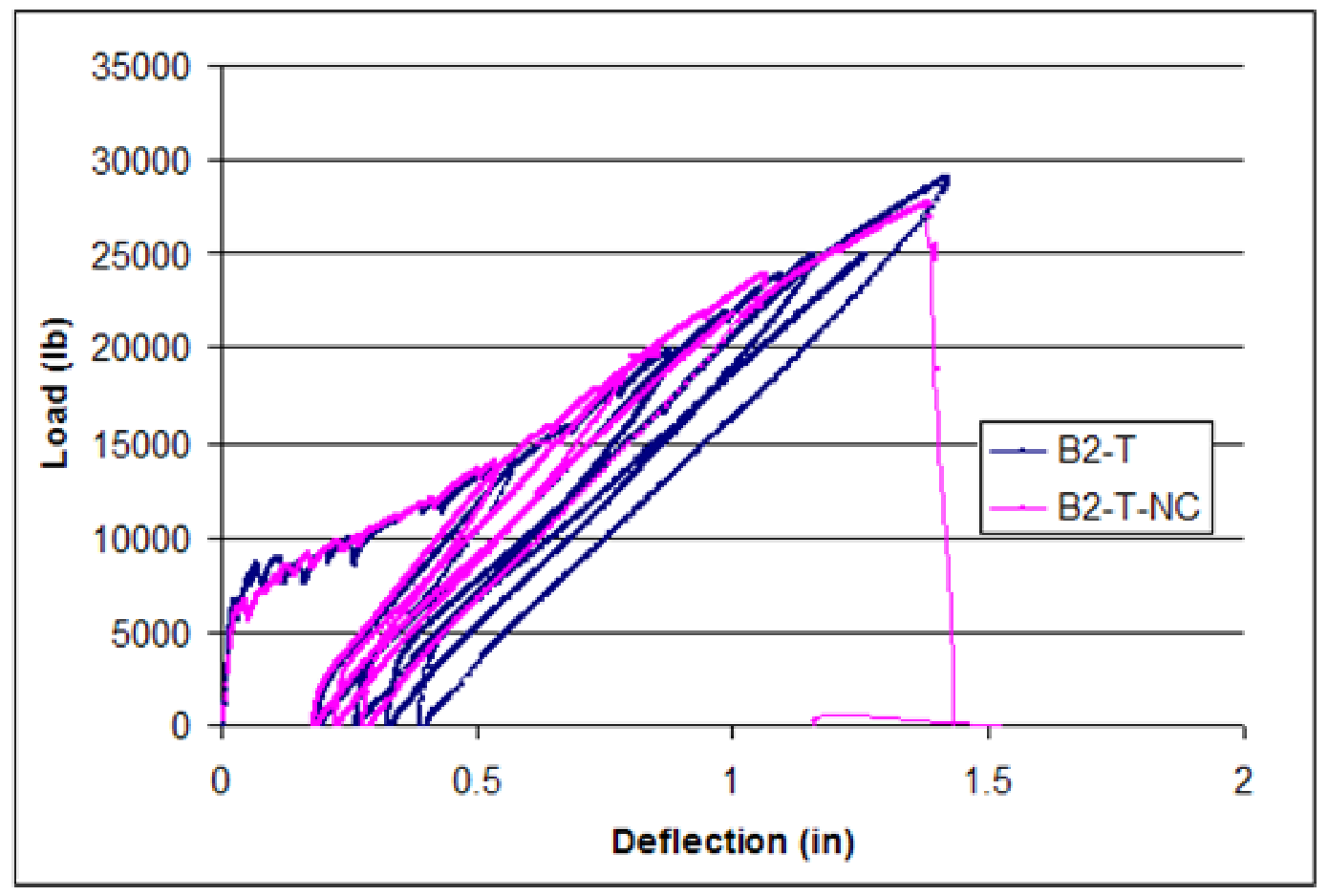

Figure 10-11 Comparison of load vs. deflection of beams B2-T and B2-T-NC (up to 30 kips)

Experimental bending moments of beams under four-point loads are compared with results from the bending theory for reinforced concrete beams in Table 10-9. In addition, ratio of experimental to theoretical values of loads (moments) were calculated for comparison. Sample theoretical calculations for the beam B2-T is shown in Section 10.4 and for other beams are presented in Appendix C.

Ratio of experimental to theoretical load (moment) capacity were within $10 \%$ for concrete beams reinforced with GFRP bars (with and without nanoclay) tested under four point bending (Table 10-9) loads.

Table 10-9 Max (Exptl./Theor) load (moment) ratios for beams B2-T \& B2-T-NC

\begin{tabular}{|c|c|c|c|c|c|c|}
\hline Beam & $\begin{array}{c}\text { Max } \\
\text { Load } \\
\text { (Exptl.) } \\
\text { (kips) }\end{array}$ & $\begin{array}{c}\text { Max } \\
\text { moment } \\
\text { (Exptl.) } \\
\text { (kip-ft) }\end{array}$ & $\begin{array}{c}\text { Max } \\
\text { Load } \\
\text { (Theor.) } \\
\text { (kips) }\end{array}$ & $\begin{array}{c}\text { Max } \\
\text { moment } \\
\text { (Theor.) } \\
\text { (kip-ft) }\end{array}$ & $\begin{array}{c}\text { Max load } \\
\text { (moment) } \\
\text { ratio } \\
\text { (Exptl./Theor) }\end{array}$ & $\begin{array}{c}\text { Deformability } \\
\text { factor }\end{array}$ \\
\hline B2-T & 38.61 & 57.915 & 35.58 & 53.37 & 1.08 & 7.88 \\
\hline B2-T-NC & 27.78 & 41.67 & 26.68 & 40.03 & 1.02 & 3.98 \\
\hline
\end{tabular}


Load at different serviceability deflection limits specified by ACI 318-02 are obtained from experimental results and compared in Table 10-10.

Table 10-10 Loads at different limiting deflection values of beams B2-T \& B2-T-NC

\begin{tabular}{|c|c|c|c|}
\hline \multirow{2}{*}{ Beam } & \multicolumn{3}{|c|}{ Load at deflection limit (kips) } \\
\cline { 2 - 4 } & $\mathbf{1 / 3 6 0}(\mathbf{0 . 3 3 3}$ in.) & $\mathbf{1 / 2 4 0}(\mathbf{0 . 5 0 0}$ in.) & $\mathbf{1 / 1 8 0}(\mathbf{0 . 6 6 7}$ in.) \\
\hline B2-T & 10.83 & 13.18 & 15.83 \\
\hline B2-T-NC & 11.05 & 13.26 & 16.47 \\
\hline
\end{tabular}

The ratios of load at each deflection limit (1/360, 1/240, and 1/180) to maximum experimental load are presented in Table 10-11.

Table 10-11 Ratio of load at serviceability deflection to maximum load for the beams B2-T \& B2-T-NC

\begin{tabular}{|c|c|c|c|}
\hline \multirow{2}{*}{ Beam } & $\begin{array}{c}\text { Ratio of load at } \\
\text { deflection }(\mathrm{span} / \mathbf{3 6 0}) \\
\text { to Max load }\end{array}$ & $\begin{array}{c}\text { Ratio of load at } \\
\text { deflection }(\mathrm{span} / \mathbf{2 4 0}) \\
\text { to Max load }\end{array}$ & $\begin{array}{c}\text { Ratio of load at } \\
\text { deflection }(\mathrm{span} / \mathbf{1 8 0}) \\
\text { to Max load }\end{array}$ \\
\cline { 2 - 4 } & $\mathbf{1 / 3 6 0}(\mathbf{0 . 3 3 3}$ in) & $\mathbf{1 / 2 4 0}(\mathbf{0 . 5 0 0}$ in) & $\mathbf{1 / 1 8 0}(\mathbf{0 . 6 6 7}$ in) \\
\hline B2-T & 0.280 & 0.341 & 0.410 \\
\hline B2-T-NC & 0.398 & 0.477 & 0.593 \\
\hline
\end{tabular}

The ratios of load at limiting crack width (0.016 in.) to maximum load of beams are presented in Table 10-12.

Table 10-12 Load at crack width limit (0.016 in.) for the beams B2-T \& B2-T-NC

\begin{tabular}{|c|c|c|}
\hline Beam & $\begin{array}{c}\text { Load at limiting crack } \\
\text { width }(\mathbf{0 . 0 1 6} \text { in.) } \\
\text { (kips) }\end{array}$ & $\begin{array}{c}\text { Ratio of load at limiting } \\
\text { crack width (0.016 in.) } \\
\text { to max load }\end{array}$ \\
\hline B2-T & 10.25 & 0.265 \\
\hline B2-T-NC & 10.00 & 0.360 \\
\hline
\end{tabular}




\section{Discussion of Tests Results}

- Beam reinforced with bars without nanoclay having higher tensile failure stress than those with nanoclay, carried higher failure load. It should be noted that bars with nanoclay had a lower tensile strength than bars without nanoclay (Chapter 5).

- Ratio of experimental to theoretical ultimate load (moment) capacities of beams B2-T and B2-T-NC were 1.08 and 1.02, respectively (Table 10-9).

- Deformability factors of beams B2-T and B2-T-NC were 7.88 and 3.98, respectively (Table 10-9).

- Beam reinforced with bars without nanoclay showed lesser load than the beam reinforced with bars with nanoclay at same deflection and crack-width value within $80 \%$ of ultimate load (Figure 10-11).

- Ratio of load at deflection limits and crack width limit to maximum load was higher for the beam reinforced with nanoclay.

\subsubsection{BEAM WITH \# 6 BARS WITH AND WITHOUT NANOCLAY (10 FT LONG)}

\section{Test/Specimen Details and Results}

Beams reinforced with 1- \#6 GFRP bars with and without nanoclay of size 8 in. $x 16$ in. $\mathrm{x}$ 120 in. were tested in four point bending. Strains were measured using strain gages attached to the concrete and rebar. Midspan deflections were measured using an LVDT. Results from beams B3-T and B3-T-NC are presented in terms of maximum failure load, maximum moment, maximum deflection (recorded), and maximum crack width (recorded) in Table 10-13 


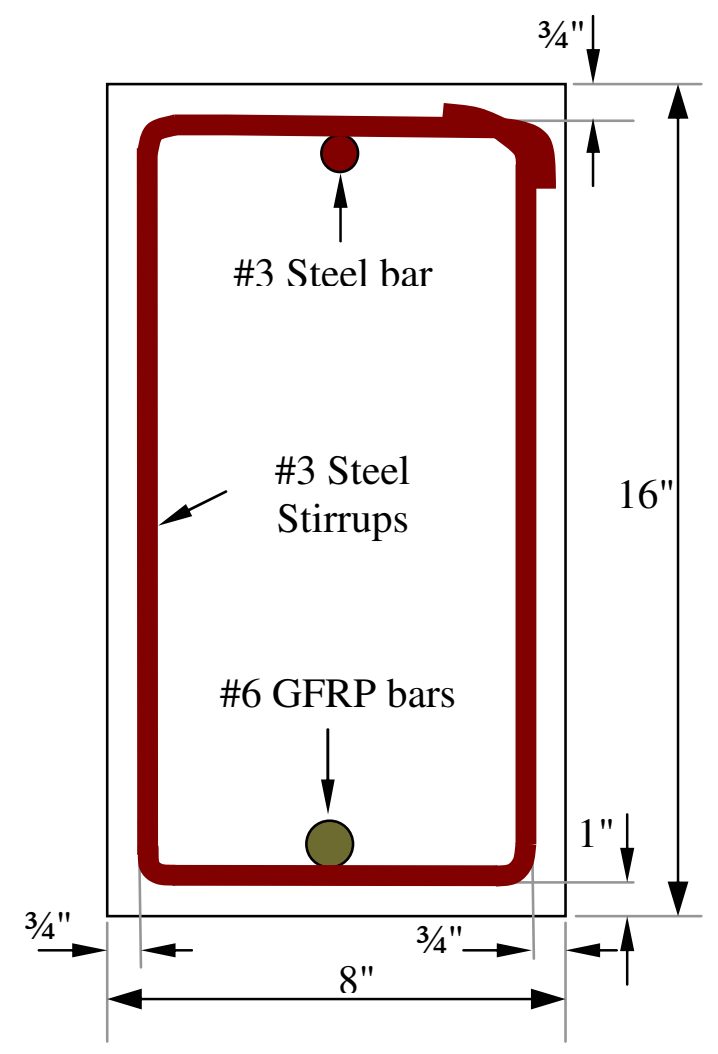

Figure 10-12 Schematic diagram of beam B3-T \& B3-T-NC

Table 10-13 Test results of beams B3-T \& B3-T-NC

\begin{tabular}{|c|c|c|c|c|}
\hline Beam & $\begin{array}{c}\text { Max Load } \\
\text { (recorded) } \\
\text { (kips) }\end{array}$ & $\begin{array}{c}\text { Max } \\
\text { moment } \\
\text { (recorded) } \\
\text { (kip-ft) }\end{array}$ & $\begin{array}{c}\text { Max } \\
\text { deflection } \\
\text { (recorded) } \\
\text { (inch) }\end{array}$ & $\begin{array}{c}\text { Max crack } \\
\text { width } \\
\text { (recorded) } \\
\text { (inch) }\end{array}$ \\
\hline B3-T & 30.02 & 45.03 & 2.25 & 0.008 \\
\hline B3-T-NC & 26.91 & 40.365 & 1.87 & 0.0052 \\
\hline
\end{tabular}




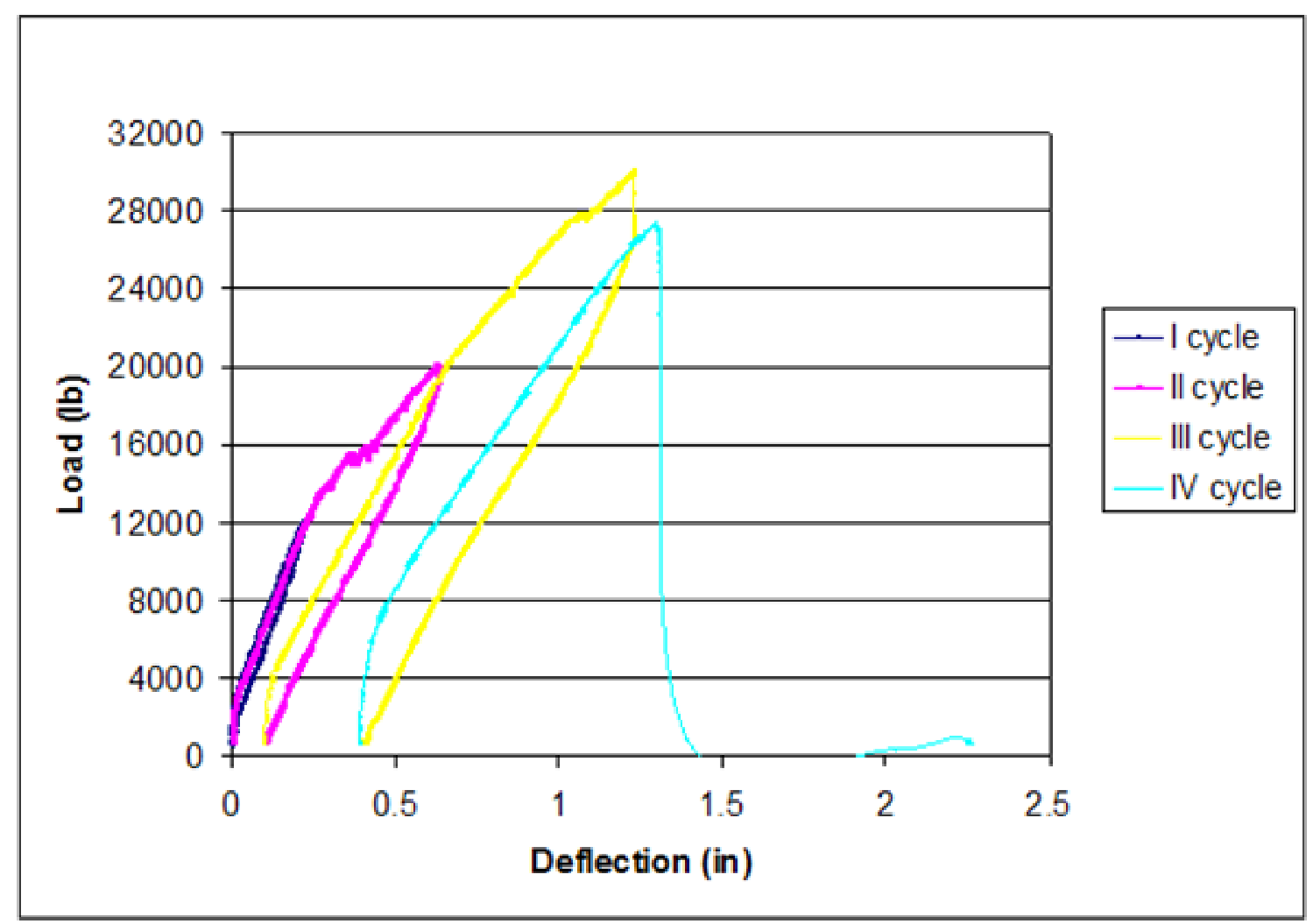

Figure 10-13 Load vs. deflection curve for beam B3-T

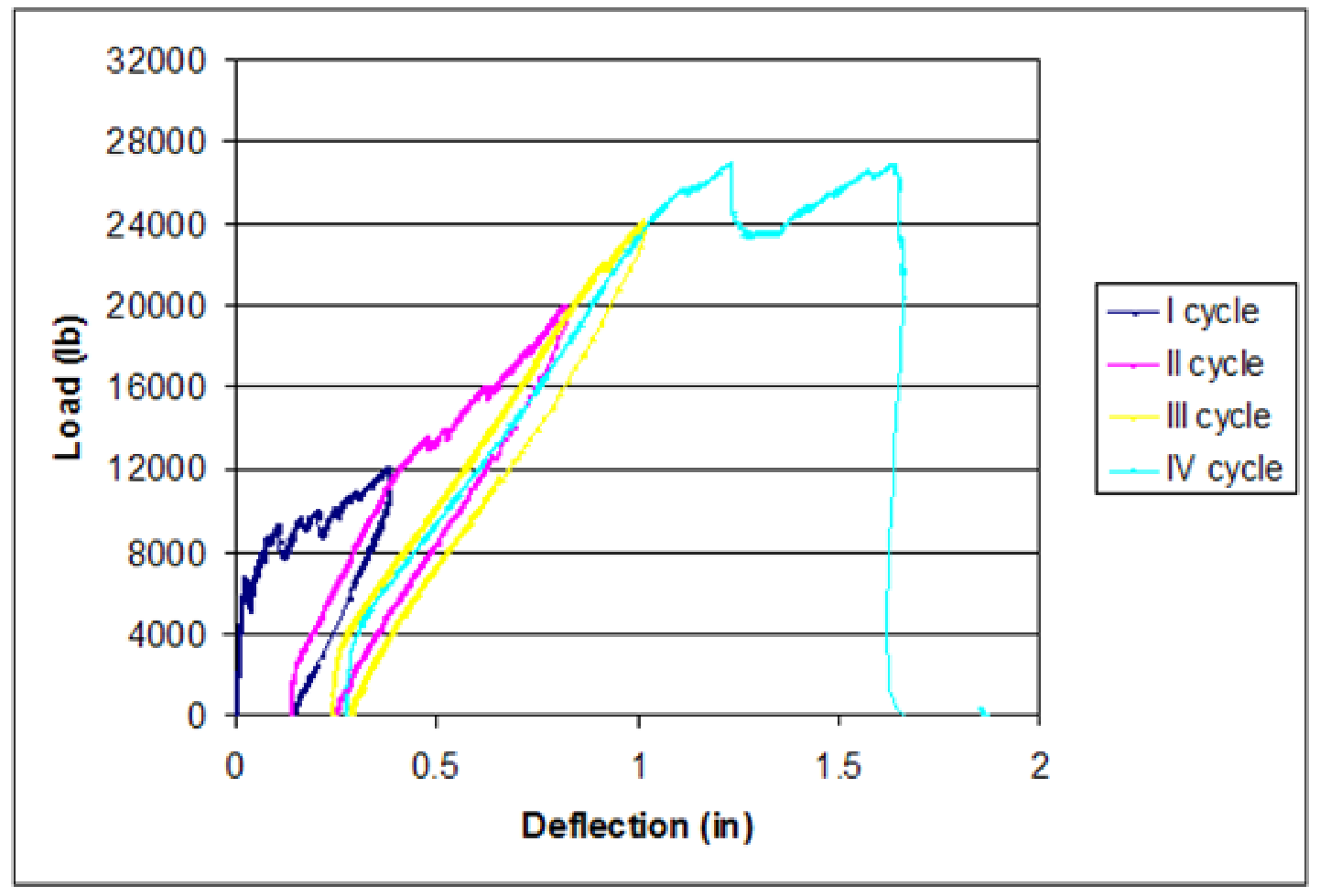

Figure 10-14 Load vs. deflection curve for beam B3-T-NC 
In Table 10-14, experimental bending moment values of beams under four-point loading are compared with results using the bending theory for reinforced concrete beams. In addition, ratio of experimental to theoretical values of loads (moments) were calculated for comparison purposes. Sample theoretical calculations for the beams are presented in Appendix C.

Ratio of experimental to theoretical load (moment) capacity were within $10 \%$ for concrete beams reinforced with GFRP bars (with and without nanoclay) tested under four point loading (Table 10-14).

Table 10-14 Max (Exptl./Theor ) load (moment) ratios for beams B3-T \& B3-T-NC

\begin{tabular}{|c|c|c|c|c|c|c|}
\hline Beam & $\begin{array}{c}\text { Max } \\
\text { Load } \\
\text { (Exptl.) } \\
\text { (kips) }\end{array}$ & $\begin{array}{c}\text { Max } \\
\text { moment } \\
\text { (Exptl.) } \\
\text { (kip-ft) }\end{array}$ & $\begin{array}{c}\text { Max } \\
\text { Load } \\
\text { (Theor.) } \\
\text { (kips) }\end{array}$ & $\begin{array}{c}\text { Max } \\
\text { moment } \\
\text { (Theor.) } \\
\text { (kip-ft) }\end{array}$ & $\begin{array}{c}\text { Max load } \\
\text { (moment)ratio } \\
\text { (Exptl./Theor) }\end{array}$ & $\begin{array}{l}\text { Deformability } \\
\text { factor }\end{array}$ \\
\hline B3-T & 30.02 & 45.03 & 31.41 & 47.12 & 0.96 & 17.88 \\
\hline B3-T-NC & 26.91 & 40.365 & 26.45 & 39.68 & 1.00 & 8.40 \\
\hline
\end{tabular}

Load at different serviceability deflection limits specified by ACI 318-02 are obtained from experimental results and compared in Table 10-15.

Table 10-15 Loads at different limiting deflection values of beams B3-T \& B3-T-NC

\begin{tabular}{|c|c|c|c|}
\hline \multirow{2}{*}{ Beam } & \multicolumn{3}{|c|}{ Load at deflection limit (kips) } \\
\cline { 2 - 4 } & $\mathbf{l} / \mathbf{3 6 0}(\mathbf{0 . 3 3 3}$ in.) & $\mathbf{l} / \mathbf{2 4 0}(\mathbf{0 . 5 0 0}$ in.) & $\mathbf{l} / \mathbf{1 8 0}(\mathbf{0 . 6 6 7}$ in.) \\
\hline B3-T & 14.83 & 17.51 & 20.36 \\
\hline B3-T-NC & 11.3 & 13.38 & 16.42 \\
\hline
\end{tabular}

The ratios of load at each deflection limit (1/360, 1/240, and 1/180) to maximum experimental load are presented in Table 10-16. 
Table 10-16 Ratio of load at serviceability deflection to maximum load for the beams B3-T \& B3-T-NC

\begin{tabular}{|c|c|c|c|}
\hline \multirow{2}{*}{ BEAM } & $\begin{array}{c}\text { Ratio of load at } \\
\text { deflection } \\
(\text { span/360) to Max } \\
\text { load }\end{array}$ & $\begin{array}{c}\text { Ratio of load at } \\
\text { deflection } \\
(\text { span/240) to Max } \\
\end{array}$ & $\begin{array}{c}\text { Ratio of load at } \\
\text { loflection }\end{array}$ \\
\cline { 2 - 4 } & $\mathbf{l} / \mathbf{3 6 0}(\mathbf{0 . 3 3 3}$ in. $)$ & $\mathbf{l} / \mathbf{2 4 0}(\mathbf{0 . 5 0 0}$ in. $)$ & $\mathbf{l} / \mathbf{1 8 0}(\mathbf{0 . 6 6 7}$ in. $)$ \\
\hline B3-T & 0.494 & 0.583 & 0.678 \\
\hline B3-T-NC & 0.420 & 0.497 & 0.610 \\
\hline
\end{tabular}

The ratios of load at limiting crack width (0.016 in.) to maximum load of beams are presented in Table 10-17.

Table 10-17 Load at crack width limit (0.016 in.) for the beams B3-T \& B3-T-NC

\begin{tabular}{|c|c|c|}
\hline Beam & $\begin{array}{c}\text { Load at limiting } \\
\text { crack width }(\mathbf{0 . 0 1 6} \text { in) } \\
\text { (kips) }\end{array}$ & $\begin{array}{c}\text { Ratio of load at limiting } \\
\text { crack width (0.016 in) } \\
\text { to max load }\end{array}$ \\
\hline B3-T & 6.50 & 0.2165 \\
\hline B3-T-NC & 8.20 & 0.3407 \\
\hline
\end{tabular}

\section{Discussion of Tests Results}

- Beams reinforced with bars without nanoclay having higher tensile failure stress than those with nanoclay carried higher failure load. It should be noted that bars with nanoclay had a lower tensile strength than the bars without nanoclay (Chapter 5).

- Ratio of experimental to theoretical ultimate load (moment) capacities of the beams B3-T and B3-T-NC were 0.96 and 1.00, respectively (Table 10-14).

- Deformability factors of beams B3-T and B3-T-NC were 17.88 and 8.4, respectively (Table 10-14). 


\subsection{SUMMARY AND CONCLUSION}

- Concrete beams reinforced with bars without nanoclay having higher tensile failure stress than those with nanoclay. It should be noted that bars with nanoclay had a lower tensile strength than bars without nanoclay (Chapter 5).

- Ratio of experimental to theoretical load (moment) capacity were within $10 \%$ for concrete beams reinforced with GFRP bars (with and without nanoclay) tested under three and four point bending.

- Beams reinforced with bars without nanoclay showed higher deformability factors compared to beams reinforced with bars with nanoclay for all the conditions.

- Beams reinforced with nanoclay GFRP bars showed similar or slightly better stiffness characteristics than those with regular GFRP bars (without nanoclay). Improved stiffness was evident from lower deflection and crack width for a given load within serviceability limits. It should be noted that GFRP bars with nanoclay exhibited slightly higher tensile stiffness than those without nanoclay. Conversely, at serviceability limit state of deflection (1/360, 1/240, and 1/180) and crack width $(0.016$ in), beams reinforced with nanoclay GFRP bars took up to $13.46 \%$ more load. 


\section{SUMMARY AND CONCLUSION}

\subsection{INTRODUCTION}

This chapter summarizes all the test methods carried out for this research. Test results from tension, shear, bond, moisture absorption, SEM, and beam flexure are summarized in Section 11-2 through 11-7.

\subsection{SUMMARY AND CONCLUSION- TENSION TESTS}

- \#4 bars with nanoclay showed $30.04 \%$ lower average stress as compared to \#4 bars without nanoclay (91.48 ksi vs. $130.76 \mathrm{ksi}$ ), which suggested that addition of nanoclay decreased the ultimate failure stress.

- Strength reduction in GFRP bars due to addition of nanoclay is attributed to:

$>$ Increase in resin viscosity, leading to increase in micro voids.

$>$ Reduction in bond strength between fibers and resin due to the presence of nanoclay that may locally affect the stress distribution.

$>$ Possible abrasion between fibers and nanoclay particles in the resin during pulling process that may create glass fiber surface imperfections under increased resin viscosity.

$>$ Increased resin viscosity leading to fiber twisting during pulling process, which was visually observed. This problem can be eliminated by using automatic pultrusion with sufficient fiber tension.

- GFRP bars with nanoclay exhibited better durability than those without nanoclay in all types of conditioning schemes (Table 5-9) considered in this research.

$>$ Maximum stress reduction after 9 months of water conditioning at room temperature without and with nanoclay were $11.77 \%$ and $0.85 \%$, respectively.

Maximum stress reduction after 9 months of water conditioning at $110^{\circ} \mathrm{F}$ with nanoclay was $16.56 \%$. Bars without nanoclay were not used for $110^{\circ} \mathrm{F}$ conditioning.

$>$ Maximum stress reduction after 9 months of water conditioning at $140^{\circ} \mathrm{F}$ without and with nanoclay were $36.51 \%$ and $15.40 \%$, respectively. 
Maximum stress reduction after 9 months of alkaline conditioning at room temperature without and with nanoclay were $15.31 \%$ and $10.77 \%$, respectively.

- Among different aging schemes, (water at room temperature, water at $110^{\circ} \mathrm{F}$, water at $140^{\circ} \mathrm{F}$, and alkaline solution at room temperature) water at elevated temperature of $140^{\circ} \mathrm{F}$ was found to be more severe on strength reduction followed by alkaline aging $\left(36.51 \%\right.$ without nanoclay vs. $15.40 \%$ with nanoclay at $140^{\circ} \mathrm{F}$ aging as compared to $15.31 \%$ without nanoclay and $10.77 \%$ with nanoclay at alkaline solution). Increase in temperature is known to accelerate both the glass fiber and matrix degradation.

Nanoclay was found to provide better durability with increasing temperature, which is attributed to bridging the difference in thermal compatibility between glass fiber $\left(5.3 \times 10^{-6} \mathrm{~m} / \mathrm{m} /{ }^{\circ} \mathrm{C}\right)$ and matrix $(56.8 \mathrm{x}$ $\left.10^{-6} \mathrm{~m} / \mathrm{m} /{ }^{\circ} \mathrm{C}\right)$.

$>$ Neat resin exfoliated with $4 \%$ nanoclay was found to have lower moisture absorption than neat resin without nanoclay (refer to Chapter 8). This needs to be verified for an extended duration.

- Flexure tests were conducted on GFRP bars with nanoclay subjected to no aging to verify the results obtained from the tension test (Appendix A). The maximum stress of GFRP bars from flexure test was $5.47 \%$ higher than the stress obtained from tension test (96.77 ksi vs. $91.48 \mathrm{ksi})$.

- Addition of nanoclay resulted in a reduction of ultimate failure stress in non-aged bars. However, better durability was noted in bars with nanoclay under different aging schemes.

- Effect of temperature on stress and stiffness - \#4 GFRP bar with $2 \%$ nanoclay subjected to $170^{\circ} \mathrm{F}$ for 5 days showed a strength reduction of $4.79 \%$ as compared to a identical bar (103.06 ksi vs. $108.24 \mathrm{ksi})$ and a stiffness reduction of $4.57 \%$ (4.81 ksi vs. $5.03 \mathrm{ksi})$.

- Effect of yield of glass fibers - \#6 GFRP bars with nanoclay manufactured with 113 Yields showed $0.5 \%$ higher strength than \#6 bars with nanoclay manufactured with 56 Yield rovings $(81.83 \mathrm{ksi}$ vs. $81.42 \mathrm{ksi})$. Therefore no 
discernable strength difference in bars manufactured with 56 and 113 Yield glass fiber rovings can be found from our test data.

- Bars without and with nanoclay extracted from concrete beams after flexure tests indicated $15.62 \%$ and $14.68 \%$ stress reduction, respectively as compared to nonaged specimens (Table 5-9). However, no definite conclusions are drawn because extraction of bars from the beams possibly resulted in fiber damage.

- \#6 bars with nanoclay showed 11\% lower average stress as compared to \#4 bars with nanoclay (81.42 ksi vs. $91.48 \mathrm{ksi}$ ). This was due to shear lag phenomenon in larger diameter bars as compared to smaller bars, where outer core fibers carry higher stress compared to inner fibers.

\subsection{SUMMARY AND CONCLUSION- SHEAR TESTS}

- \#4 bars with nanoclay showed 5.71\% lower (average) shear stress as compared to \#4 bars without nanoclay (24.77 ksi vs. $26.27 \mathrm{ksi}$ ) and \#6 bars with nanoclay showed $12.77 \%$ lower (average) stress as compared to \#6 bars without nanoclay (20.02 ksi vs. $22.95 \mathrm{ksi}$ ), which suggested that addition of nanoclay decreased the shear stress. Reduction in shear strength is attributed to reduction in interlaminar shear reduction in interfacial bond stress between fibers and resin.

- Shear stress reduction in GFRP bars due to addition of nanoclay is attributed to:

Increase in resin viscosity by nanoclay exfoliation, leading to increased micro voids.

$>$ Reduction in bond strength between fibers and resin due to the presence of nanoclay that may locally affect the stress distribution.

$>$ Possible abrasion between fibers and nanoclay particles in the resin during pulling process that may create glass fiber surface imperfections under increased resin viscosity.

- GFRP bar with nanoclay exhibited better durability than those without nanoclay in all types of conditioning schemes (Table 6-8) considered in this research.

Maximum stress reduction after 9 months of water conditioning at room temperature without and with nanoclay were $13.36 \%$ and $8.28 \%$, respectively. 
Maximum stress reduction after 9 months of water conditioning at $110^{\circ} \mathrm{F}$ with nanoclay was $11.75 \%$. Bars without nanoclay were not used for $110^{\circ} \mathrm{F}$ conditioning.

Maximum stress reduction after 9 months of water conditioning at $140^{\circ} \mathrm{F}$ without and with nanoclay were $20.14 \%$ and $19.94 \%$, respectively.

$>$ Maximum stress reduction after 9 months of alkaline conditioning at room temperature without and with nanoclay were $15.30 \%$ and $5.53 \%$, respectively.

- Among different aging schemes, (water at room temperature, water at $110^{\circ} \mathrm{F}$, water at $140^{\circ} \mathrm{F}$, and alkaline solution at room temperature) water at elevated temperature of $140^{\circ} \mathrm{F}$ was found to be more severe on shear stress reduction followed by alkaline aging $(20.14 \%$ without nanoclay vs. $19.94 \%$ with nanoclay at $140^{\circ} \mathrm{F}$ as compared to $15.30 \%$ without nanoclay and $5.53 \%$ with nanoclay at alkaline solution).

Nanoclay were found to provide better durability with increasing temperature, which is attributed to bridging the difference in thermal compatibility between glass fiber $\left(5.3 \times 10^{-6} \mathrm{~m} / \mathrm{m} /{ }^{\circ} \mathrm{C}\right)$ and matrix $(56.8 \mathrm{x}$ $\left.10^{-6} \mathrm{~m} / \mathrm{m} /{ }^{\circ} \mathrm{C}\right)$.

Neat resin exfoliated with nanoclay was found to have lower moisture absorption than neat resin without nanoclay (refer to Chapter 8).

- Addition of nanoclay resulted in a reduction of shear stress in non-aged bars. However, better durability was noted in bars with nanoclay under different aging schemes.

- Effect of Yield of glass fibers - \#6 bars manufactured with 113 Yield glass fiber rovings showed an increase in shear stress of $9.89 \%$ as compared to bars manufactured with 56 Yield glass fiber rovings (20.02 ksi vs. $22.00 \mathrm{ksi}$ ).

- \#4 Bars without and with nanoclay extracted from concrete beams after flexure tests indicated $5.94 \%$ and $5.49 \%$ stress reduction, respectively as compared to non-aged specimens (Table 6-8). \#6 Bars without and with nanoclay extracted from concrete beams after flexure tests indicated $2.79 \%$ and $2.40 \%$ stress 
reduction, respectively as compared to non-aged specimens (Table 6-8). However, no definite conclusions are drawn because extraction of bars from the beams possibly resulted in fiber damage.

- \#4 bars without nanoclay showed an increased shear stress of $12.64 \%$ over \#6 bars without nanoclay (26.27 ksi vs. 22.95 ksi). Similarly \#4 bars with nanoclay showed an increase shear stress of $19.18 \%$ over \#6 bars with nanoclay (24.77 ksi vs. $20.02 \mathrm{ksi})$.

\subsection{SUMMARY AND CONCLUSION- BOND TESTS}

- GFRP bar with nanoclay conditioned at different aging schemes showed higher bond strength than the original bond strength (Figure 7-5), because increase in stress was noted due to post curing of concrete and rebars. Increase in bond stress may be due to bar swelling also.

- Bond strength increase was noted with different conditioning schemes with nanoclay.

$>$ Water at room temperature up to 9 months $-4.86 \%$ increase

$>$ Water at $110^{\circ} \mathrm{F}$ up to 9 months $-1.10 \%$ increase

$>$ Water at $140^{\circ} \mathrm{F}$ up to 9 months $-2.27 \%$ increase

$>$ Alkaline solution at room temperature up to 9 months $-1.24 \%$ increase

- Such increase in bond strength up to $14 \%$ under 15 months of water and freezethaw conditioning for bars without nanoclay has been noted in other studies as well (Vijay and GangaRao, 1999). Results indicate that the addition of nanoclay helped in controlling the bar swelling and influenced corresponding bond stress development.

- Mechanisms that influence bond strength development are:

$>$ Swelling of the rebar

$>$ Interface between concrete and FRP bar

$>$ Interface between fibers within a bar 


\subsection{SUMMARY AND CONCLUSION - MOISTURE ABSORPTION}

- Neat resin without nanoclay had higher moisture pick up than the resin exfoliated with nanoclay.

- GFRP bar with nanoclay showed slightly higher moisture gain than bar without nanoclay.

- The results indicate possible pore and micro crack formation during fiber wetting and pulling process.

\subsection{SUMMARY AND CONCLUSION - SEM}

- Neat resin exfoliated with $4 \%$ nanoclay was selected as optimum clay content and used for all the bars manufactured in this research.

- Many of the GFRP bars without nanoclay exhibited pulling out of fibers near edges as compared to those with nanoclay.

- Bars subjected to $140^{\circ} \mathrm{F}$ and alkaline conditioning showed more number of fiber being pulled out and/or damaged from the matrix along the bar edges, which causes a reduction in bar strength.

\subsection{SUMMARY AND CONCLUSION - CONCRETE BEAM FLEXURE}

- Concrete beam reinforced with bars without nanoclay having higher tensile failure stress than those with nanoclay carried higher failure load. It should be noted that bars with nanoclay had a lower tensile strength than bars without nanoclay (Chapter5).

- Ratio of experimental to theoretical load (moment) capacity were within $10 \%$ for concrete beams reinforced with GFRP bars (with and without nanoclay) tested under three point bending.

- Concrete beams reinforced with nanoclay GFRP bars showed similar or slightly better stiffness characteristics than those with regular GFRP bars (without nanoclay). Improved stiffness was evident from lower deflection and crack width for a given load within serviceability limits. It should be noted that GFRP bars with nanoclay exhibited slightly higher tensile stiffness than those without nanoclay. Conversely, at serviceability limit state of deflection (1/360, 1/240, and 
1/180) and crack width (0.016 in), beams reinforced with nanoclay GFRP bars took up to $13.46 \%$ more load.

\subsection{RESEARCH SUMMARY OF TEST RESULTS}

Tension tests: \#4 bars with nanoclay showed $30.04 \%$ lesser average stress as compared to \#4 bars without nanoclay (91.48 ksi vs. $130.76 \mathrm{ksi}$ ), which suggested that addition of nanoclay decreased the ultimate failure stress. However, better durability was noted in bars with nanoclay under different aging schemes. Among different aging schemes, water at elevated temperature of $140^{\circ} \mathrm{F}$ was found to be more severe on strength reduction.

Shear tests: \#4 bars with nanoclay showed 5.71\% lesser average stress as compared to \#4 bars without nanoclay (24.77 ksi vs. $26.27 \mathrm{ksi}$ ), which suggested that addition of nanoclay decreased the shear stress. However, better durability was noted in bars with nanoclay under different aging schemes. Among different aging schemes, water at elevated temperature of $140^{\circ} \mathrm{F}$ was found to be more severe on strength reduction.

Bond tests: GFRP bar with nanoclay conditioned at different aging schemes showed higher bond strength than the original bond strength (Figure 7-5); increase in stress was noted due to post curing of concrete and rebars. Increase in stress might also happened because, of bar swelling.

Moisture absorption: Resin exfoliated with neat resin showed low moisture absorption than the neat resin without nanoclay.

SEM: Neat resin exfoliated with $4 \%$ nanoclay was selected as optimum clay content and used for all the bars manufacture thereafter. Bars subjected to $140^{\circ} \mathrm{F}$ and alkaline conditioning showed more number of fiber being pulled out and/or damaged from the matrix along the edges, which causes a reduction in bar strength.

Beam flexure: Beams reinforced with bars without nanoclay showed more strength than beams reinforced with bar with nanoclay because, bars without nanoclay had higher 
tensile strength than the bar with nanoclay. Beams reinforced with nanoclay GFRP bars showed better stiffness characteristics than those with regular GFRP bars. Ratio of load at deflection and crack width limit to maximum load was slightly higher for the beam reinforced with nanoclay.

\subsection{FUTURE RECOMMENDATION}

Following recommendations are made for future research:

1. FRP bars manufactured with resin exfoliated with different clay percent can be aged and tested.

2. Find optimum clay content for minimum strength reduction and better durability.

3. Study durability of different resin systems exfoliated with different percentage of nanoclay by using different type of fibers (such as: carbon and aramid). 


\section{REFERENCES}

1. Achillides, Z., and Pilakoutas, K., "Bond Behavior of Fiber Reinforced Polymer Bars under Direct Pullout Conditions," Journal of Composites for Construction, Volume 8, pp.173-181, 2004.

2. ACI 318R-02: Building Code Requirements for Reinforced Concrete and Commentary, American Concrete Institute.

3. ACI 440.1R-03: Guide for the Design and Construction of Concrete Reinforced with FRP Bars, American Concrete Institute.

4. Alsayed, S. and Alhozaimy, A., "Effect of High Temperature and Alkaline Solutions on the Durability of GFRP Bars," Proceedings of the First International Conference, CDCC'98, Montreal, Quebec, pp.623-634, 1998.

5. ASTM C234-91a, Standard Test Method for Comparing Concretes on the Basis of the Bond Developed with Reinforcing Steel.

6. ASTM C617-98, Standard Practice for Capping Cylindrical Concrete Specimens.

7. ASTM D 3916-02: Standard Test Method for Tensile Properties of Pultruded Glass Fiber Reinforced Plastic Rod.

8. Benmokrane, B., Chaallalt, O., and Masmoudi, R., "Glass fiber reinforced plastic (GFRP) rebars for concrete structures," Construction and Building Materials, Volume 9, No. 6, pp. 53-364, 1995.

9. Benmokrane, B., Wang, P., Ton-That, T.M., Ranman, H., and Robert, J.F., "Durability of Glass Fiber-Reinforced Polymer Reinforced Bars in Concrete Environment," Journal of Composites for Construction, pp.143-153, 2002.

10. Benmorkrane, B., and Masmoudi, R., "FRP C-bar as reinforcing rod for concrete structures," ACNBS-II, Montreal, Canada, pp. 181-188, 1996.

11. Christopher, I., and Meier, A., "Flammability Resistance of Phenolic Nanocomposites," Pittsburgh State University, Kansas, 2004.

12. Cosenza, E., Manfredi, G., Pecce, M., and Realfonzo, R., "Bond between Glass Fiber Reinforced Plastic Reinforcing Bars and Concrete - Experimental Analysis", Proceedings of $4^{\text {th }}$ International Symposium of Fiber Reinforced Polymer Reinforcement for Reinforced Concrete Structures (SP188), Eds Dolan C., Rizkalla S., and Nanni A., 1999. 
13. Fengge, G., "Clay/Polymer Composites: The Story,” Materials Today, Volume 7, pp. 50-55, November 2004.

14. GangaRao, H.V.S. and Faza, S.S. (1992), "Bending and Bond Behavior and Design of Concrete Beams Reinforced with Fiber Reinforced Plastic Rebars,” CFC-92-142, Submitted to WVDOH, Charleston, WV-23505.

15. Hay, J.N., and Shaw, S.J., “A Review of Nanocomposites 2000," Proceedings of the Nanocomposites 2000 Conference, Nov 2000, Brussels, Belgium. Farnborough, UK. http://www.nano.org.uk/nanocomposites_review.pdf

16. Katsuki, F., and Uomoto, T., "Prediction of Deterioration of FRP Rods Due to Alkali Attack," Non-metallic (FRP) Proceedings for Concrete Structures, pp.82-89, 1995.

17. Katz, A., "Bond Mechanism of FRP Rebars to Concrete," Materials and Structures, Volume 32, pp.761-768, 1999.

18. Kocaoza, S., Samaranayakeb, V.A., and Nannia, A., "Tensile characterization of glass FRP bars," Composites: Part B, Volume 36, pp.127-134, 2005.

19. Larralde, J., and Silva-Rodriguez, R., "Bond and Slip of FRP Rebars in Concrete," Journal of Materials in Civil Engineering, Volume 5, pp 30-41, 1993.

20. Larralde, J., Silva-Rodriguez, R., Burdette, J., and Harris, B., "Bond Tests of FRP Bars in Concrete," Journal of Testing and Evaluation, Volume 22, pp.351-359, 1994.

21. Mallick, P.K., "Fiber Reinforced Composite Materials, Manufacturing and Design," Marcel Dekker Inc., NY, 1993.

22. Malvar, L.J., "Tensile and bond properties of GFRP Rebars," ACI materials Journal, Volume 92, pp.276-285, 1995.

23. Micelli, F., Nanni, A., and La Tegola, A., "Effects of Conditioning Environments on GFRP Bars," 22nd SAMPE Europe International Conference, CNIT Paris, pp.1-13, 2001.

24. Pantuso, A., Spadea, G., and Swamy, R.N., "An Experimental Study on the Durability of GFRP Bars," Proceedings of Second International Conference on Composites in Infrastructure, ICCI'98, pp.476-487, 1998.

25. Phifer, S.P., and Lesko J.J., "Moisture Absorption and Strength Characterization of Hygrothermally Aged Neat and Clay Filled Vinyl Ester and Pultruded Vinyl Ester E- 
Glass Laminates," Proceedings of the First International Conference, CDCC 02, Montreal, Quebec, pp.485-497, 2001.

26. Prian, L., and Barkatt, A., "Degradation Mechanism of Fiber-reinforced Plastics and Its Implications to Prediction of Long-term Behavior," Journal of Materials Science, Volume 34, pp.3977-3989, 1999.

27. Sen, R., Mullins, G., and Salem, T., "Durability of E-Glass/Vinylester Reinforcement in Alkaline Solution,” ACI Structural Journal, Volume 99, pp.369-375, 2002.

28. Shah A.P., Moisture Diffusion Through Vinyl Ester/Clay Nanocomposites, Master's Thesis, West Virginia University, Morgantown, USA, 2001.

29. Shah, A.P., Gupta, R.K., GangaRao, H.V.S., and Powell, C.E., "Moisture Diffusion through Vinyl Ester Nanocomposites Made With Montmorillonite Clay," Polymer Engineering and Science, Vol. 42, No. 9, pp. 1852-1863, 2002.

30. Springer, G.S., Sanders, B.A., and Tung, R.W., "Environmental Effect on Glass Fiber Reinforced Polyester and Vinylester Composites," Environmental Effects on Composite Materials, Technomic Publishing Company, Inc., pp.126-144, 1981.

31. Subramaniyan, A.K., Bing, Q., Nakaima, D., and Sun, C.T., "Effect of nanoclay on compressive strength of glass fiber composites," Procedings of ASC, $18^{\text {th }}$ Annual Technical Conference, 2003.

32. Tannous, F. and Saadatmanesh, H., "Environmental Effect on the Mechanical Properties of E-Glass FRP Rebars," ACI Materials Journal, Volume 95, pp.87-100, 1998.

33. Theriault, M., and Benmokrane, B., "Effects of FRP reinforcement ration and concrete strength on flexural behavior of concrete beams," Journal of composites for construction, Volume 2, pp.7-15, 1998.

34. Timmerman, J.F., Hayes, B.S., and Seferis, J.C., "Nanoclay reinforcement effects on the cryogenic microcracking of carbon fiber/epoxy composites," Composites Science and Technology, Volume 62, pp.1249-1258, 2002.

35. Toutanji, H., and Yong, D., "Deflection and crack-width prediction of concrete beams reinforced with glass FRP rods," Construction and Building Materials, Volume 17, pp. 69-74, 2003. 
36. Tripathi, V.K., "Standardization of Test Methods for Property Evaluation of FRP Bars," Master thesis, West Virginia University, 186 pp, 2003.

37. Vijay, P.V., "Aging and Design of Concrete Members Reinforced With GFRP Bars," Ph.D. Dissertation, West Virginia University, 205 pp, 1999.

38. Vijay, P.V., and GangaRao, H.V.S., "Development of Fiber Reinforced Plastics for Highway Applications (Task A-2), Aging Behavior of Concrete Beams Reinforced with GFRP Bars," Final Report, WVDOH RP \# T-699-FRP-1, Chapter III, pp. 37 54, 1999.

39. Wu, W.P., "Thermo-mechanical Properties of fiber reinforced plastics (FRP) bars," Ph.D. Dissertation, West Virginia University, 292 pp, 1990.

40. Yano, K., Usuki, A., Okada, A., Kurauchi, T., and Kamigaito, O., "Synthesis and Properties of Polyimide-Clay Hybrid," Journal of Polymer Science. : Part A: Polymer Chemistry, 31, pp.2493-2498, 1993. 


\section{APPENDIX A}

\section{A.1. TEST RESULTS OF TENSION TESTS}

Table A-1 Test results of \#4 and \#6 bars with and without nanoclay subjected to no aging

\begin{tabular}{|c|c|c|c|c|c|c|}
\hline \multirow{2}{*}{$\begin{array}{c}\text { No of } \\
\text { months in } \\
\text { aging }\end{array}$} & \multirow{2}{*}{$\begin{array}{l}\text { Number of } \\
\text { specimens }\end{array}$} & \multirow{2}{*}{$\begin{array}{l}\text { Bar } \\
\text { size }\end{array}$} & \multicolumn{2}{|c|}{ Max stress (ksi) } & \multicolumn{2}{|c|}{ Stiffness (msi) } \\
\hline & & & $\begin{array}{l}\text { Without } \\
\text { nanoclay }\end{array}$ & $\begin{array}{c}\text { With } \\
\text { nanoclay }\end{array}$ & $\begin{array}{l}\text { Without } \\
\text { nanoclay }\end{array}$ & $\begin{array}{c}\text { With } \\
\text { nanoclay }\end{array}$ \\
\hline \multirow{16}{*}{0} & Bar 1 & \multirow{3}{*}{$\# 4$} & 128.75 & 87.51 & 4.53 & 4.74 \\
\hline & Bar 2 & & 133.62 & 95.82 & 4.62 & 4.89 \\
\hline & Bar 3 & & 129.87 & 91.12 & 4.32 & 4.40 \\
\hline & Average & & 130.76 & 91.48 & 4.49 & 4.68 \\
\hline & Std Dev & & 2.55 & 4.17 & 0.15 & 0.25 \\
\hline & \% Std Dev & & 1.95 & 4.55 & 3.43 & 5.37 \\
\hline & Bar 1 & \multirow{2}{*}{ \#6 } & - & 73.96 & - & 4.54 \\
\hline & Bar 2 & & - & 88.88 & - & 5.13 \\
\hline & Average & & - & 81.42 & - & 4.84 \\
\hline & Std Dev & & - & 10.55 & - & 0.42 \\
\hline & \% Std Dev & & - & 12.96 & - & 8.63 \\
\hline & Bar 1* & \multirow{2}{*}{ \#6 } & - & 74.19 & - & 5.15 \\
\hline & Bar 2* & & - & 89.47 & - & 4.45 \\
\hline & Average & & - & 81.83 & & 4.80 \\
\hline & Std Dev & & - & 10.80 & & 0.50 \\
\hline & \% Std Dev & & - & 13.20 & & 10.31 \\
\hline
\end{tabular}

*GFRP bars manufactured with 56 yield glass fiber rovings. Rest of the bars were manufactured with 113 Yield glass fiber rovings. 
Table A-2 Test results of \#4 and \#6 bars with and without nanoclay extracted from the concrete beams

\begin{tabular}{|c|c|c|c|c|c|c|}
\hline \multirow{2}{*}{$\begin{array}{c}\text { No of } \\
\text { months in } \\
\text { aging }\end{array}$} & \multirow{2}{*}{$\begin{array}{l}\text { Number of } \\
\text { specimens }\end{array}$} & \multirow{2}{*}{$\begin{array}{l}\text { Bar } \\
\text { size }\end{array}$} & \multicolumn{2}{|c|}{ Max stress (ksi) } & \multicolumn{2}{|c|}{ Stiffness (msi) } \\
\hline & & & $\begin{array}{l}\text { Without } \\
\text { nanoclay }\end{array}$ & $\begin{array}{c}\text { With } \\
\text { nanoclay }\end{array}$ & $\begin{array}{l}\text { Without } \\
\text { nanoclay }\end{array}$ & $\begin{array}{c}\text { With } \\
\text { nanoclay }\end{array}$ \\
\hline \multirow{7}{*}{2} & Bar 1 & \multirow{3}{*}{ \#4 } & 111.14 & 83.54 & 4.69 & 4.63 \\
\hline & Bar 2 & & 107.93 & 72.55 & 4.99 & 4.52 \\
\hline & Bar 3 & & 111.93 & - & 4.87 & - \\
\hline & Average & & 110.33 & 78.05 & 4.85 & 4.58 \\
\hline & Std Dev & & 2.12 & 7.77 & 0.15 & 0.08 \\
\hline & \% Std Dev & & 1.92 & 9.96 & 3.11 & 1.70 \\
\hline & Bar 1 & \#6 & 96.59 & 75.65 & 5.36 & 4.76 \\
\hline
\end{tabular}


Table A-3 Test results of \#4 bars with and without nanoclay aged in water at room temperature for 3,6 , and 9 months

\begin{tabular}{|c|c|c|c|c|c|}
\hline \multirow{2}{*}{$\begin{array}{c}\text { No of } \\
\text { months in } \\
\text { aging }\end{array}$} & \multirow{2}{*}{$\begin{array}{l}\text { Number of } \\
\text { specimens }\end{array}$} & \multicolumn{2}{|c|}{ Max stress (ksi) } & \multicolumn{2}{|c|}{ Stiffness (msi) } \\
\hline & & $\begin{array}{l}\text { Without } \\
\text { nanoclay }\end{array}$ & $\begin{array}{c}\text { With } \\
\text { nanoclay }\end{array}$ & $\begin{array}{l}\text { Without } \\
\text { nanoclay }\end{array}$ & $\begin{array}{c}\text { With } \\
\text { nanoclay }\end{array}$ \\
\hline \multirow{3}{*}{0} & Average & 130.76 & 91.48 & 4.49 & 4.68 \\
\hline & Std Dev & 2.55 & 4.17 & 0.15 & 0.25 \\
\hline & \% Std Dev & 1.95 & 4.55 & 3.43 & 5.37 \\
\hline \multirow{6}{*}{3} & Bar 1 & 114.44 & 89.24 & 4.67 & 4.94 \\
\hline & Bar 2 & 114.04 & 77.55 & 4.84 & 4.73 \\
\hline & Bar 3 & - & 100.92 & - & 4.88 \\
\hline & Average & 114.24 & 89.24 & 4.76 & 4.85 \\
\hline & Std Dev & 0.28 & 11.69 & 0.12 & 0.11 \\
\hline & \% Std Dev & 0.25 & 13.09 & 2.52 & 2.23 \\
\hline \multirow{6}{*}{6} & Bar 1 & 106.28 & 90.43 & 4.95 & 4.74 \\
\hline & Bar 2 & 116.63 & 74.51 & 4.94 & 4.74 \\
\hline & Bar 3 & - & 96.24 & - & 4.66 \\
\hline & Average & 111.46 & 87.06 & 4.95 & 4.71 \\
\hline & Std Dev & 7.32 & 11.25 & 0.01 & 0.05 \\
\hline & \% Std Dev & 6.57 & 12.92 & 0.14 & 0.98 \\
\hline \multirow{6}{*}{9} & Bar 1 & 115.47 & 101.86 & 5.00 & 4.66 \\
\hline & Bar 2 & 115.23 & 77.71 & 4.82 & 4.97 \\
\hline & Bar 3 & - & 92.54 & - & 4.98 \\
\hline & Average & 115.35 & 90.70 & 4.91 & 4.87 \\
\hline & Std Dev & 0.17 & 12.78 & 0.13 & 0.18 \\
\hline & $\%$ Std Dev & 0.15 & 13.43 & 2.59 & 3.74 \\
\hline
\end{tabular}


Table A-4 Test results of \#4 bars with nanoclay aged in water at $110^{\circ} \mathrm{F}$ for 3,6 , and 9 months

\begin{tabular}{|c|c|c|c|}
\hline $\begin{array}{c}\text { No of } \\
\text { months in } \\
\text { aging }\end{array}$ & $\begin{array}{l}\text { Number of } \\
\text { specimens }\end{array}$ & $\begin{array}{c}\text { Max stress of bars } \\
\text { with nanoclay } \\
\text { (ksi) }\end{array}$ & $\begin{array}{c}\text { Stiffness of bars } \\
\text { with nanoclay } \\
\text { (msi) }\end{array}$ \\
\hline \multirow{3}{*}{0} & Average & 91.48 & 4.68 \\
\hline & Std Dev & 4.17 & 0.25 \\
\hline & \% Std Dev & 4.55 & 5.37 \\
\hline \multirow{6}{*}{3} & Bar 1 & 70.02 & 4.21 \\
\hline & Bar 2 & 82.65 & 4.92 \\
\hline & Bar 3* & - & 4.88 \\
\hline & Average & 76.34 & 4.67 \\
\hline & Std Dev & 8.93 & 0.40 \\
\hline & \% Std Dev & 11.70 & 8.54 \\
\hline \multirow{6}{*}{6} & Bar 1 & 68.95 & 5.11 \\
\hline & Bar 2 & 82.20 & 4.75 \\
\hline & Bar 3 & 73.73 & 5.03 \\
\hline & Average & 74.96 & 4.96 \\
\hline & Std Dev & 6.71 & 0.19 \\
\hline & \% Std Dev & 8.95 & 3.81 \\
\hline \multirow{6}{*}{9} & Bar 1 & 53.48 & 4.97 \\
\hline & Bar 2 & 83.38 & 4.90 \\
\hline & Bar 3 & 92.14 & 4.86 \\
\hline & Average & 76.33 & 4.91 \\
\hline & Std Dev & 20.27 & 0.06 \\
\hline & \% Std Dev & 26.55 & 1.13 \\
\hline
\end{tabular}


Table A-5 Test results of bars with and without nanoclay aged in water at $140^{\circ} \mathrm{F}$ for 3,6 , and 9 months

\begin{tabular}{|c|c|c|c|c|c|}
\hline \multirow{2}{*}{$\begin{array}{c}\text { No of } \\
\text { months in } \\
\text { aging }\end{array}$} & \multirow{2}{*}{$\begin{array}{l}\text { Number of } \\
\text { specimens }\end{array}$} & \multicolumn{2}{|c|}{ Max stress (ksi) } & \multicolumn{2}{|c|}{ Stiffness (msi) } \\
\hline & & $\begin{array}{l}\text { Without } \\
\text { nanoclay }\end{array}$ & $\begin{array}{c}\text { With } \\
\text { nanoclay }\end{array}$ & $\begin{array}{l}\text { Without } \\
\text { nanoclay }\end{array}$ & $\begin{array}{c}\text { With } \\
\text { nanoclay }\end{array}$ \\
\hline \multirow{3}{*}{0} & Average & 130.76 & 91.48 & 4.49 & 4.68 \\
\hline & Std Dev & 2.55 & 4.17 & 0.15 & 0.25 \\
\hline & \% Std Dev & 1.95 & 4.55 & 3.43 & 5.37 \\
\hline \multirow{6}{*}{3} & Bar 1 & 95.22 & 77.24 & 4.99 & 4.61 \\
\hline & Bar 2 & 100.95 & 74.50 & 4.67 & 4.85 \\
\hline & Bar 3 & & 71.28 & & 4.50 \\
\hline & Average & 98.09 & 74.34 & 4.83 & 4.65 \\
\hline & Std Dev & 4.05 & 2.98 & 0.23 & 0.18 \\
\hline & \% Std Dev & 4.13 & 4.01 & 4.68 & 3.85 \\
\hline \multirow{6}{*}{6} & Bar 1 & 94.60 & 75.85 & 4.96 & 4.91 \\
\hline & Bar 2 & 87.93 & 74.12 & 4.63 & 5.04 \\
\hline & Bar 3 & - & 73.65 & - & 4.29 \\
\hline & Average & 91.27 & 74.54 & 4.80 & 4.75 \\
\hline & Std Dev & 4.72 & 1.16 & 0.23 & 0.40 \\
\hline & \% Std Dev & 5.17 & 1.55 & 4.87 & 8.44 \\
\hline \multirow{6}{*}{9} & Bar 1 & 81.76 & 76.17 & 4.92 & 4.72 \\
\hline & Bar 2 & 84.28 & 85.90 & 4.76 & 4.74 \\
\hline & Bar 3 & - & 70.09 & - & 4.67 \\
\hline & Average & 83.02 & 77.39 & 4.84 & 4.71 \\
\hline & Std Dev & 1.78 & 7.97 & 0.11 & 0.04 \\
\hline & \% Std Dev & 2.15 & 10.30 & 2.34 & 0.77 \\
\hline
\end{tabular}


Table A-6 Test results of bars with and without nanoclay aged in alkaline solution at room temperature for 3,6 , and 9 months

\begin{tabular}{|c|c|c|c|c|c|}
\hline \multirow{2}{*}{$\begin{array}{c}\text { No of } \\
\text { months in } \\
\text { aging }\end{array}$} & \multirow{2}{*}{$\begin{array}{l}\text { Number of } \\
\text { specimens }\end{array}$} & \multicolumn{2}{|c|}{ Max stress (ksi) } & \multicolumn{2}{|c|}{ Stiffness (msi) } \\
\hline & & $\begin{array}{l}\text { Without } \\
\text { nanoclay }\end{array}$ & $\begin{array}{c}\text { With } \\
\text { nanoclay }\end{array}$ & $\begin{array}{l}\text { Without } \\
\text { nanoclay }\end{array}$ & $\begin{array}{c}\text { With } \\
\text { nanoclay }\end{array}$ \\
\hline \multirow{3}{*}{0} & Average & 130.76 & 91.48 & 4.49 & 4.68 \\
\hline & Std Dev & 2.55 & 4.17 & 0.15 & 0.25 \\
\hline & \% Std Dev & 1.95 & 4.55 & 3.43 & 5.37 \\
\hline \multirow{6}{*}{3} & Bar 1 & 112.01 & 91.12 & 4.95 & 4.40 \\
\hline & Bar 2 & 113.73 & 98.80 & 4.63 & 4.89 \\
\hline & Bar 3 & - & 78.73 & - & 4.89 \\
\hline & Average & 112.87 & 89.55 & 4.79 & 4.73 \\
\hline & Std Dev & 1.22 & 10.13 & 0.23 & 0.28 \\
\hline & \% Std Dev & 1.08 & 11.31 & 4.72 & 5.98 \\
\hline \multirow{6}{*}{6} & Bar 1 & 108.16 & 74.20 & 4.68 & 4.95 \\
\hline & Bar 2 & 110.59 & 70.43 & 5.04 & 4.90 \\
\hline & Bar 3 & - & 92.55 & - & 4.67 \\
\hline & Average & 109.38 & 79.06 & 4.86 & 4.84 \\
\hline & Std Dev & 1.72 & 11.83 & 0.25 & 0.15 \\
\hline & \% Std Dev & 1.57 & 14.97 & 5.24 & 3.09 \\
\hline \multirow{6}{*}{9} & Bar 1 & 111.34 & 95.70 & 4.78 & 4.89 \\
\hline & Bar 2 & 110.13 & 70.74 & 4.66 & 5.02 \\
\hline & Bar 3 & - & 78.44 & - & 4.69 \\
\hline & Average & 110.74 & 81.63 & 4.72 & 4.87 \\
\hline & Std Dev & 0.86 & 12.78 & 0.08 & 0.17 \\
\hline & \% Std Dev & 0.77 & 15.66 & 1.80 & 3.42 \\
\hline
\end{tabular}




\section{A.2. FLEXURE TEST ON GFRP BAR WITH NANOCLAY}

Table A-7 Flexure test results of GFRP bars with nanoclay

\begin{tabular}{|c|c|c|c|}
\hline $\begin{array}{c}\text { No of } \\
\text { specimen }\end{array}$ & $\begin{array}{c}\text { Load } \\
\text { (lb) }\end{array}$ & $\begin{array}{c}\text { Moment } \\
\text { (lb-in) }\end{array}$ & $\begin{array}{c}\text { Tensile stress } \\
\text { (psi) }\end{array}$ \\
\hline Bar 1 & 450 & 1350 & 108870.97 \\
\hline Bar 2 & 400 & 1200 & 96774.19 \\
\hline Bar 3 & 350 & 1050 & 84677.42 \\
\hline Average & $\mathbf{4 0 0}$ & $\mathbf{1 2 0 0}$ & $\mathbf{9 6 7 7 4 . 1 9}$ \\
\hline Std Dev & $\mathbf{5 0}$ & $\mathbf{1 5 0}$ & $\mathbf{1 2 0 9 6 . 7 8}$ \\
\hline \% Std Dev & $\mathbf{1 2 . 5}$ & $\mathbf{1 2 . 5}$ & $\mathbf{1 2 . 5}$ \\
\hline
\end{tabular}

$$
\text { Moment of inertia, } \begin{aligned}
I & =\frac{\pi D^{4}}{64} \\
& =\frac{\pi \times 0.5^{4}}{64}=0.0031 \mathrm{in}^{4} \\
\text { Moment, } M & =\frac{P L}{4} \\
& =\frac{400 \times 12}{4}=1200 \mathrm{lb}-\mathrm{in}
\end{aligned}
$$

Tensile stress, $\sigma=\frac{M c}{I}$

$$
=\frac{1200 \times 0.25}{0.0031}=96774.19 \mathrm{psi}
$$

Tensile stress obtained for GFRP bars with nanoclay subjected to no aging from tension test and flexure test was $91.48 \mathrm{ksi}$ and $96.77 \mathrm{ksi}$, respectively. Tensile stress obtained from tension test was $5.78 \%$ lesser as compared to stress obtained from flexure test. 


\section{A.3. STRESS-STRAIN PLOTS FOR THE TENSION TEST}

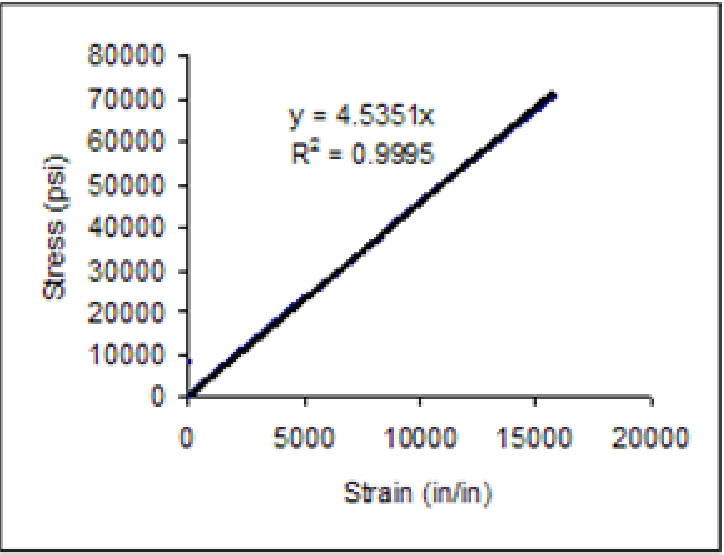

Bar 1

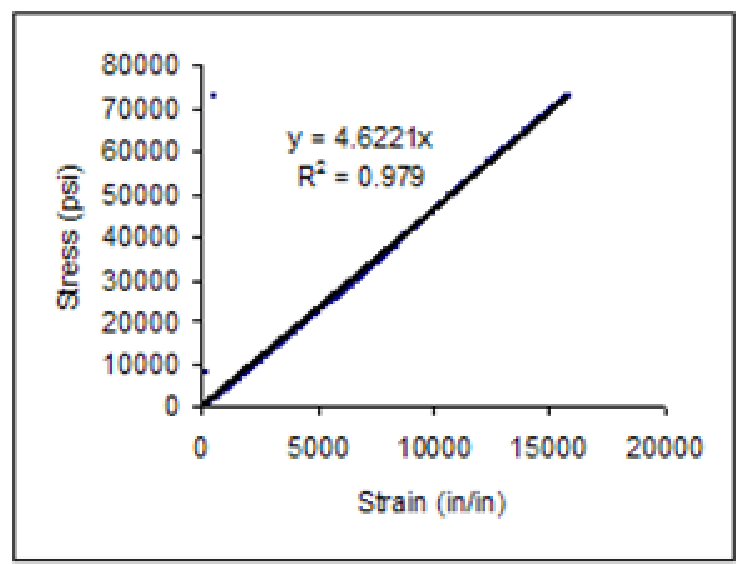

Bar 2

Figure A-1 Stress-strain plot of \#4 bars without nanoclay subjected to no aging (Table A-1)

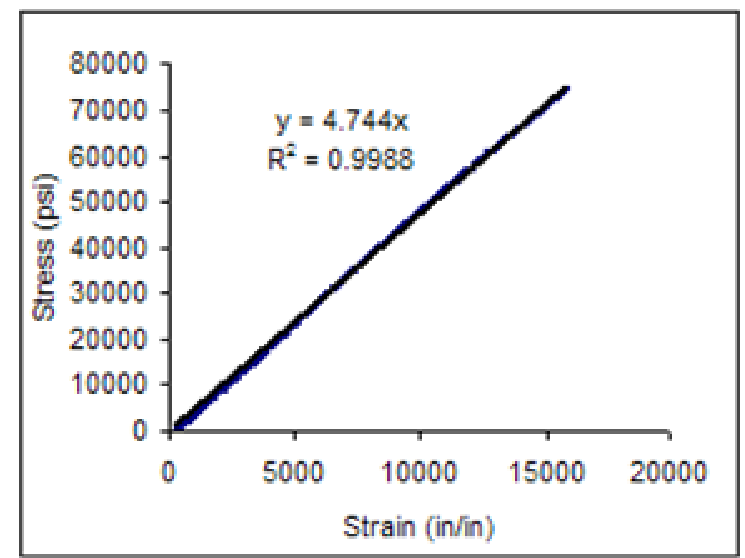

Bar 1

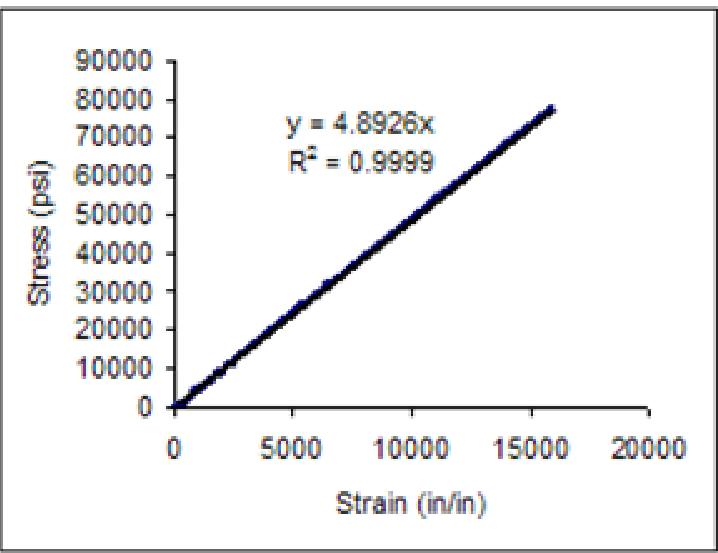

Bar 2

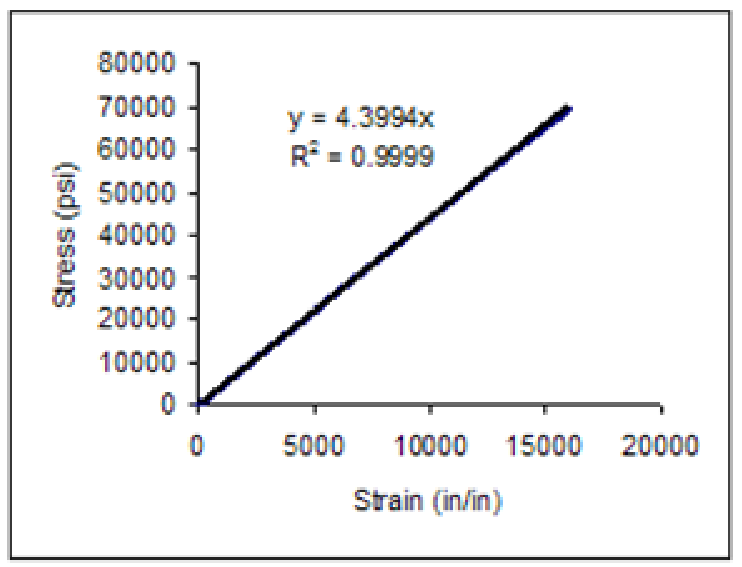

Bar 3

Figure A-2 Stress-strain plot of \#4 bars with nanoclay subjected to no aging (Table A-1) 


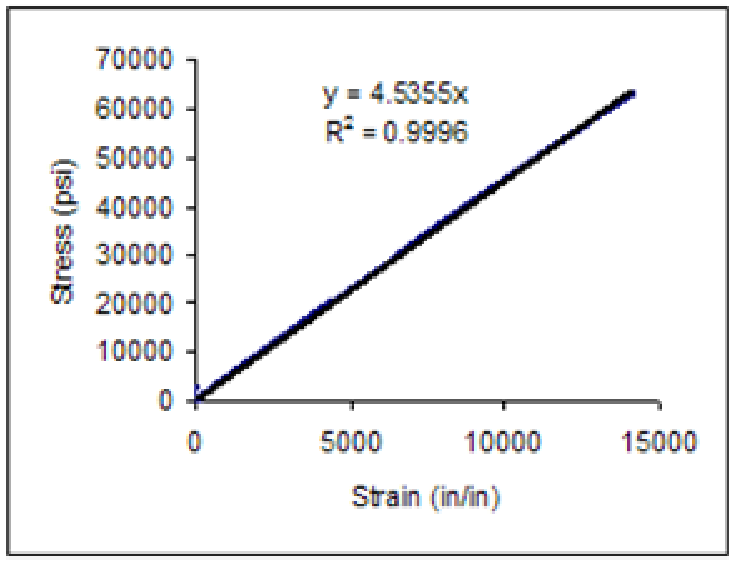

Bar 1

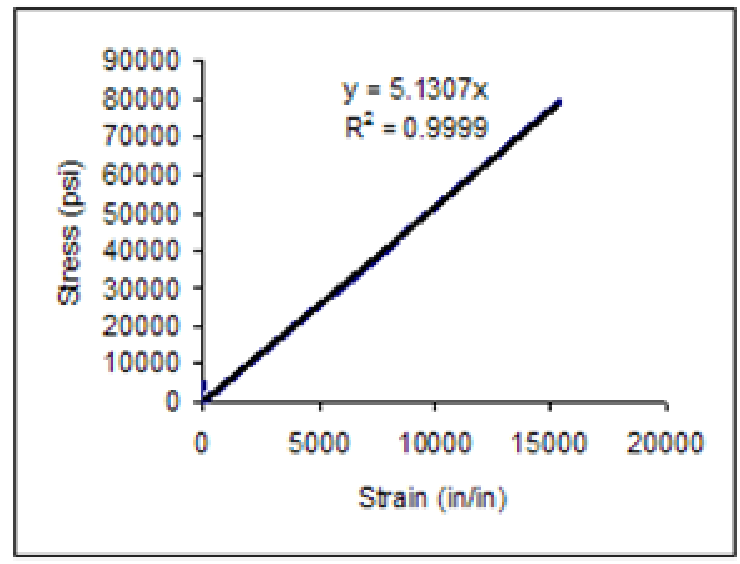

Bar 2

Figure A-3 Stress-strain plot of \#6 bars with nanoclay subjected to no aging (TableA-1)

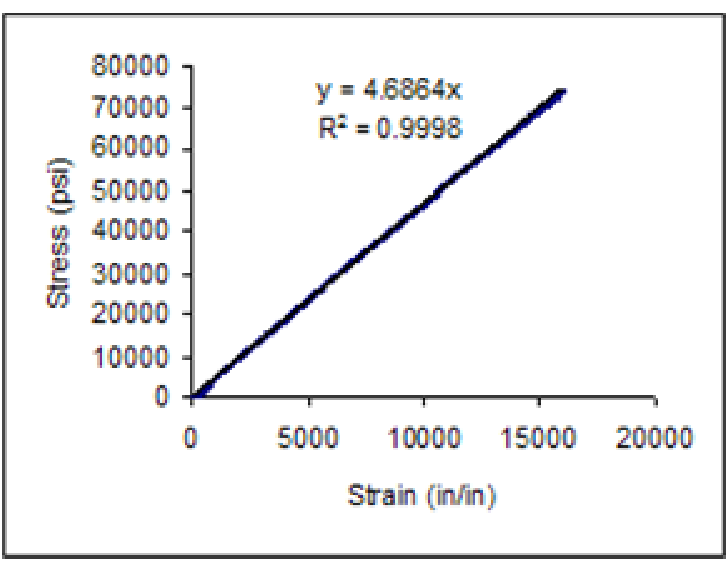

Bar 1

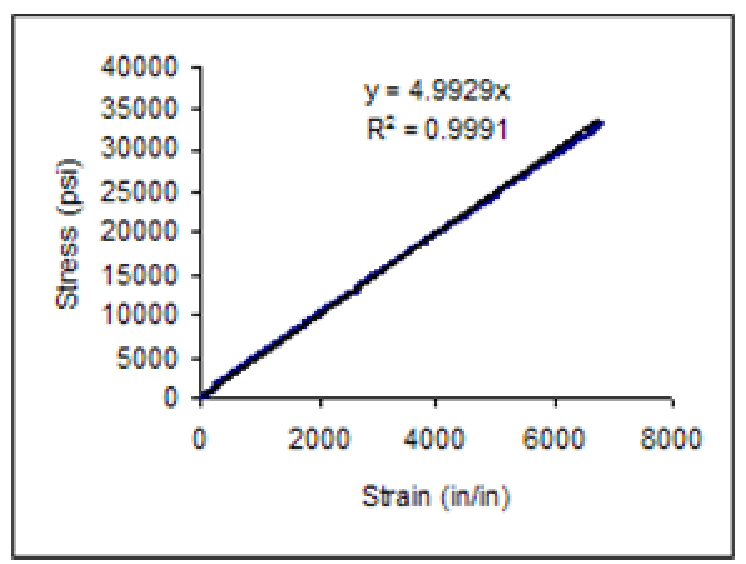

Bar 2

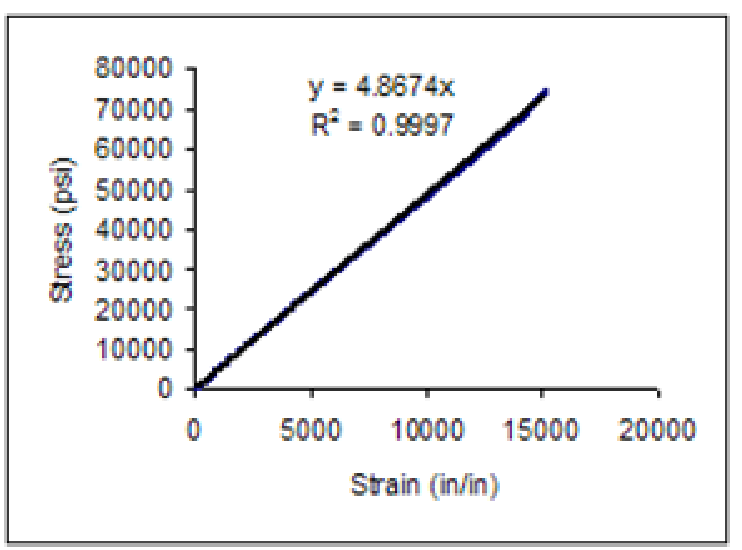

Bar 3

Figure A-4 Stress-strain plot of \#4 bars without nanoclay extracted from the concrete beam (Table A-2) 


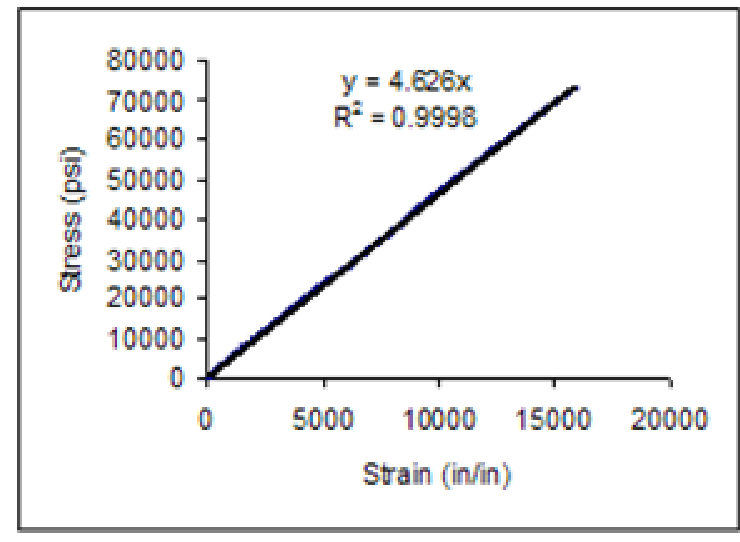

Bar 1

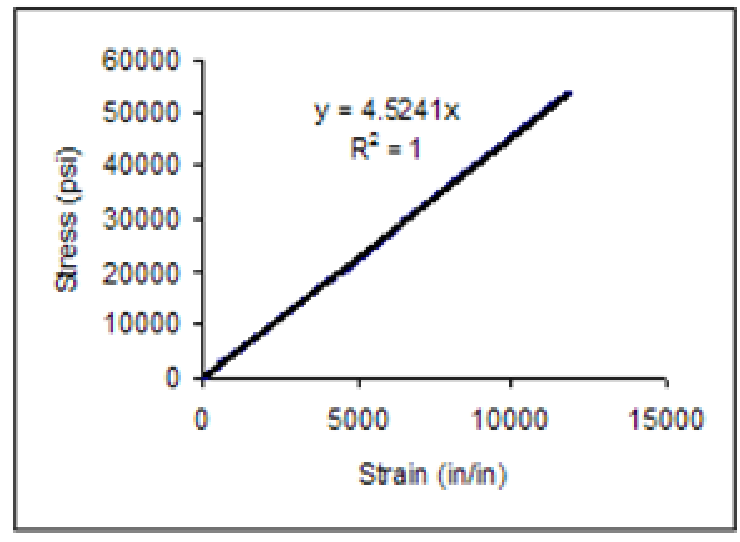

Bar 2

Figure A-5 Stress-strain plot of \#4 bars with nanoclay extracted from the concrete beam (Table A-2)

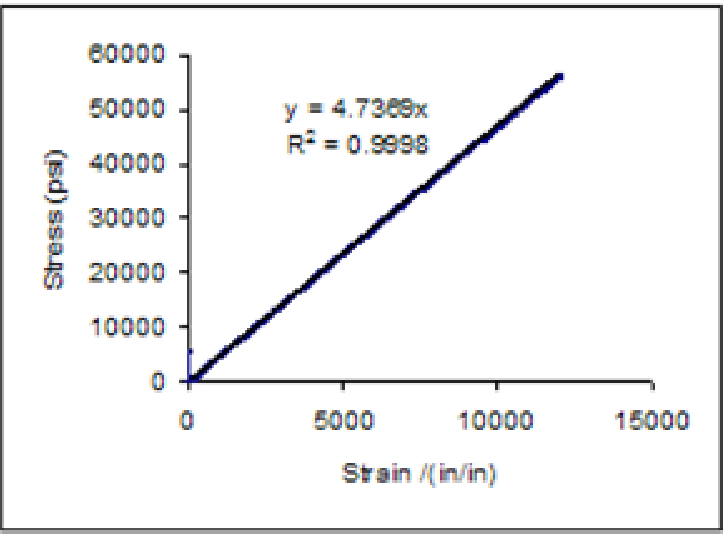

Bar 1

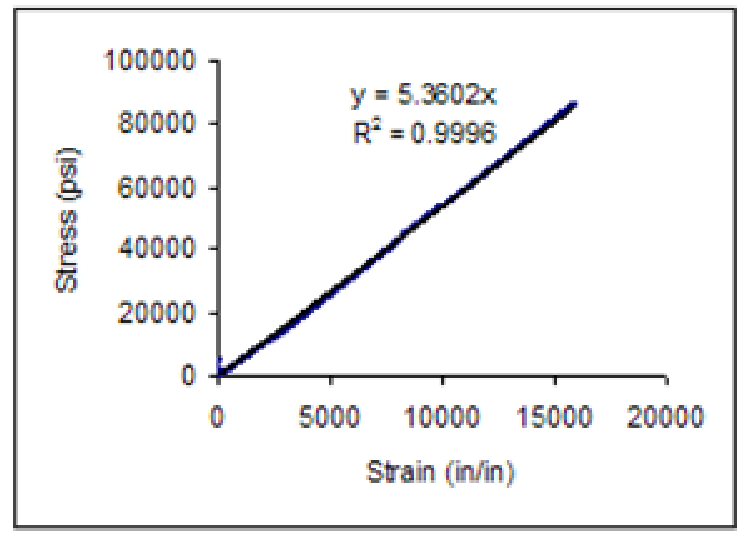

Bar 2

Figure A-6 Stress-strain plot of \#6 bars with and without nanoclay extracted from the concrete beam (Table A-2)

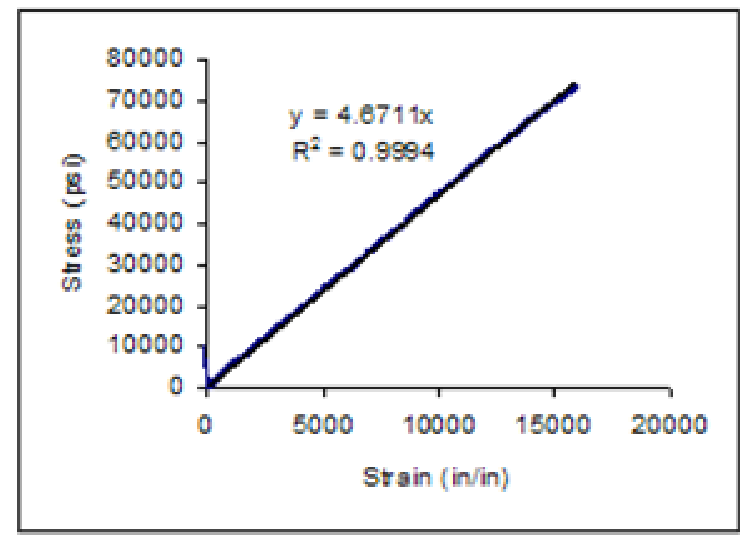

Bar 1

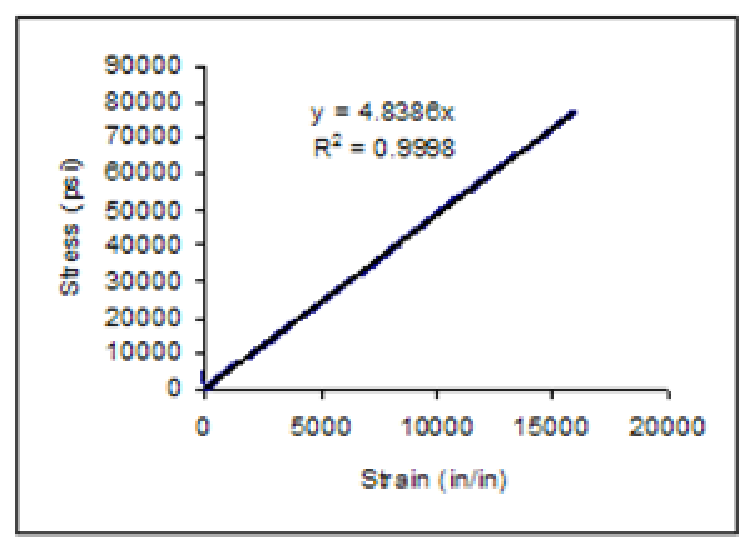

Bar 2

Figure A-7 Stress-strain plot of \#4 bars without nanoclay aged in water at room temperature for 3 months (Table A-3) 


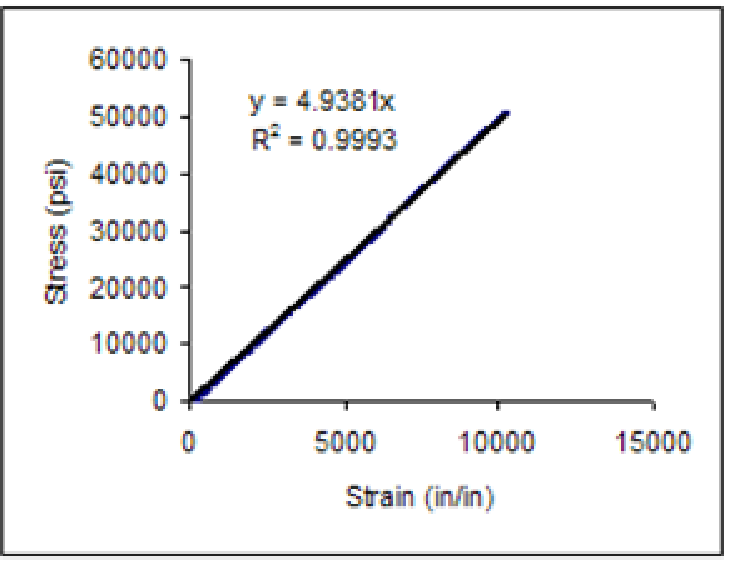

Bar 1

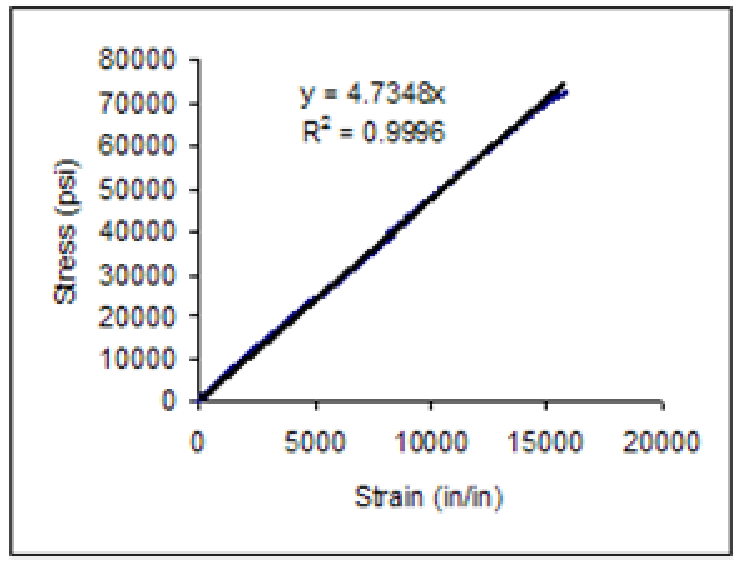

Bar 2

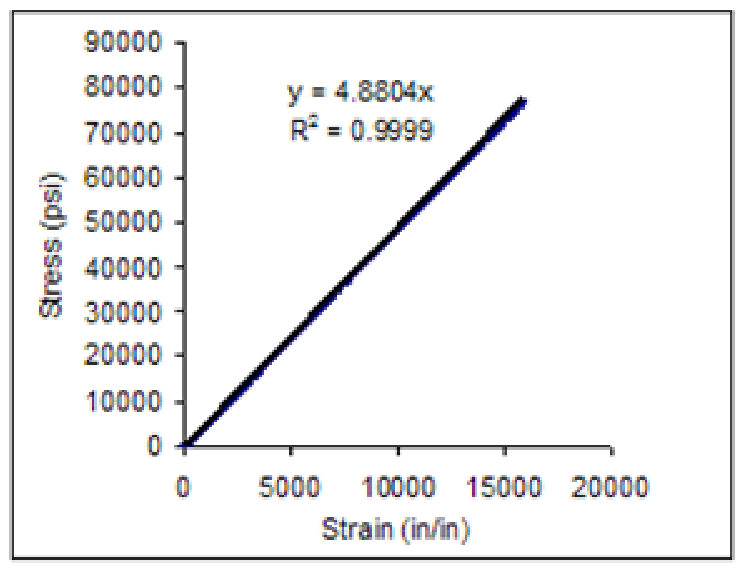

Bar 3

Figure A-8 Stress-strain plot of \#4 bars with nanoclay aged in water at room temperature for 3 months (Table A-3)

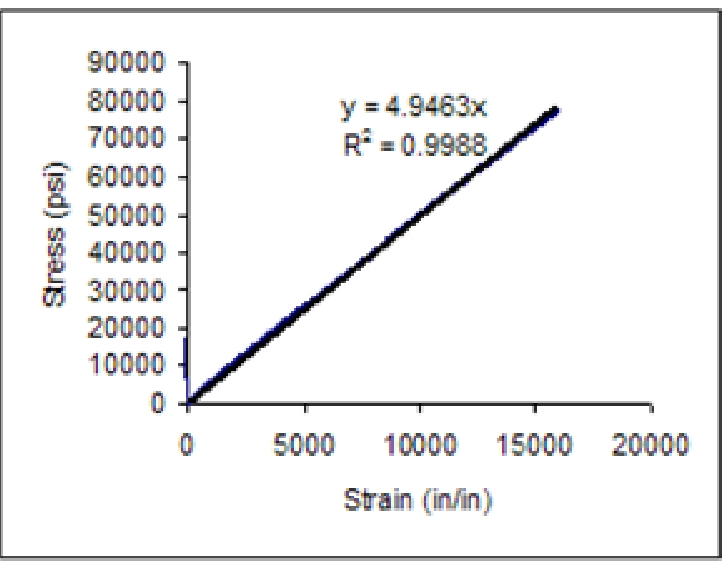

Bar 1

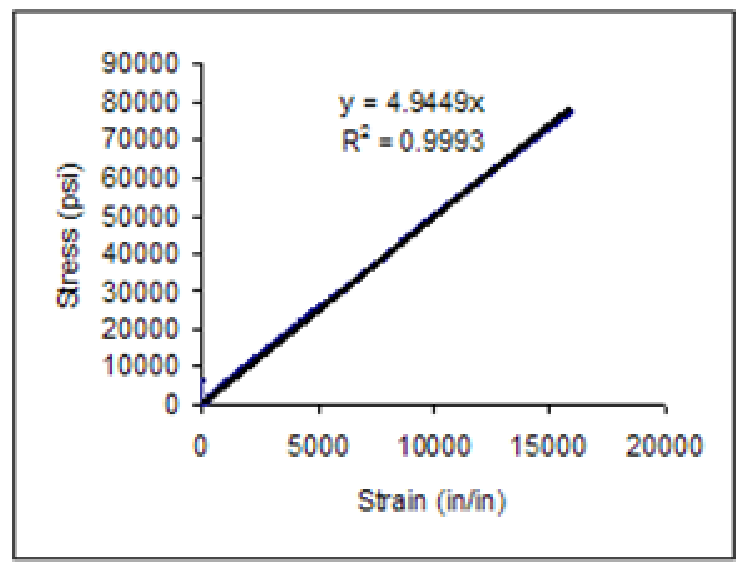

Bar 2

Figure A-9 Stress-strain plot of \#4 bars without nanoclay aged in water at room temperature for 6 months (Table A-3) 


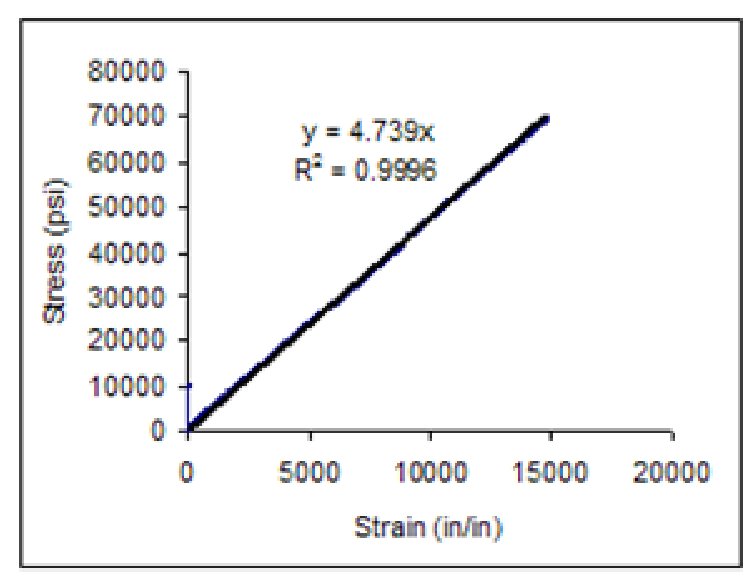

Bar 1

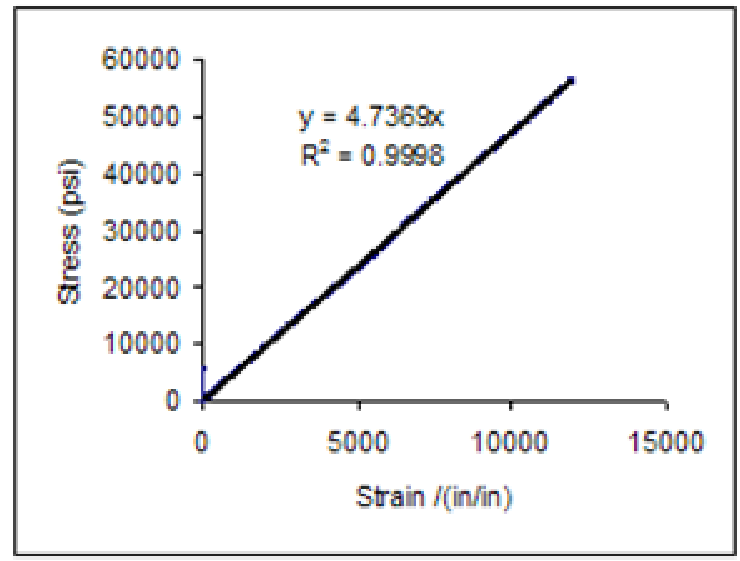

Bar 2

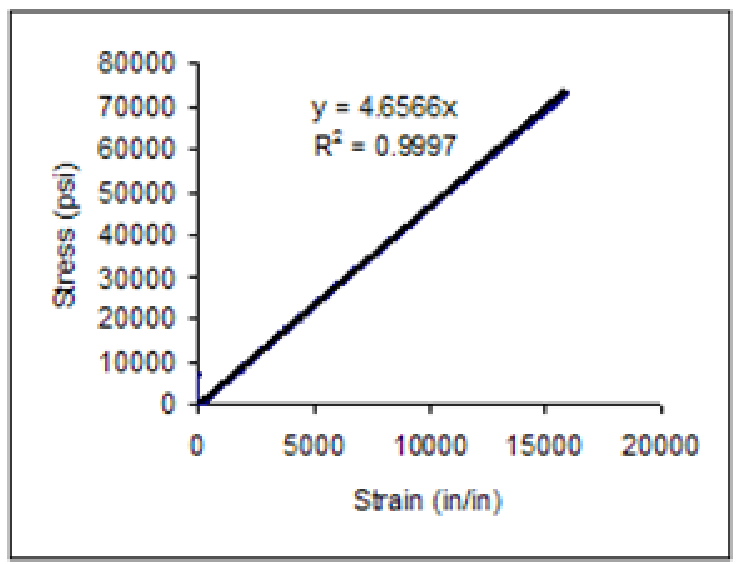

Bar 3

Figure A-10 Stress-strain plot of \#4 bars with nanoclay aged in water at room temperature for 6 months (Table A-3)

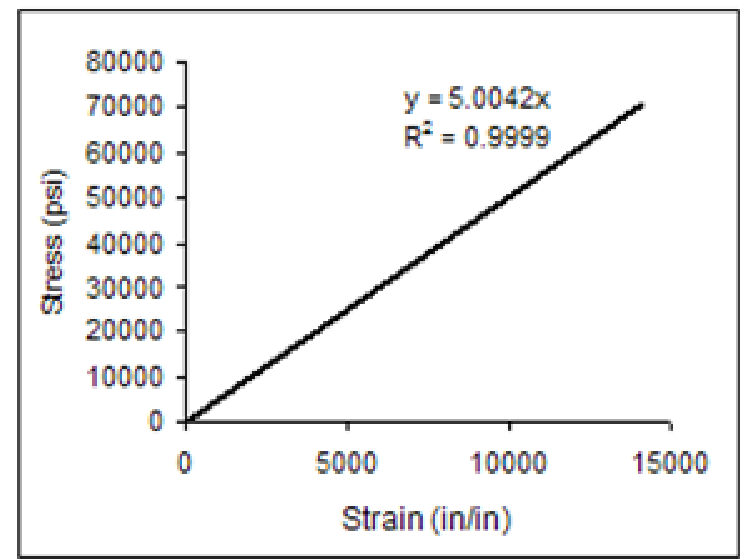

Bar 1

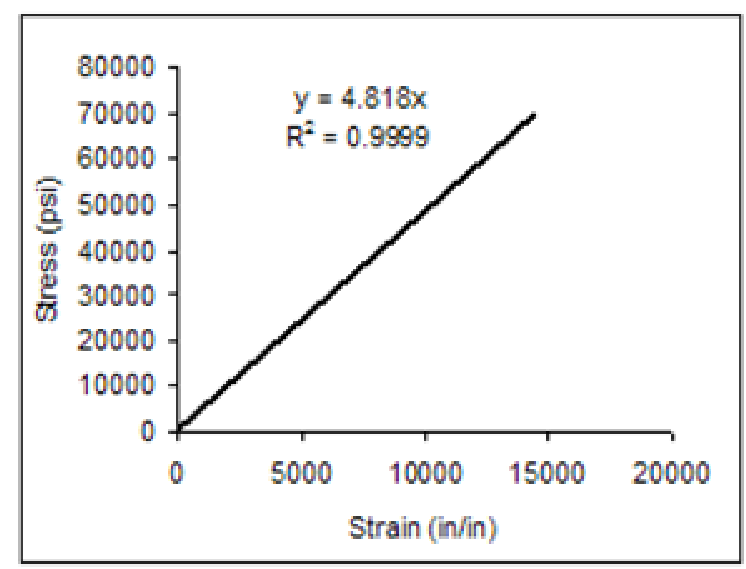

Bar 2

Figure A-11 Stress-strain plot of \#4 bars without nanoclay aged in water at room temperature for 9 months (Table A-3) 


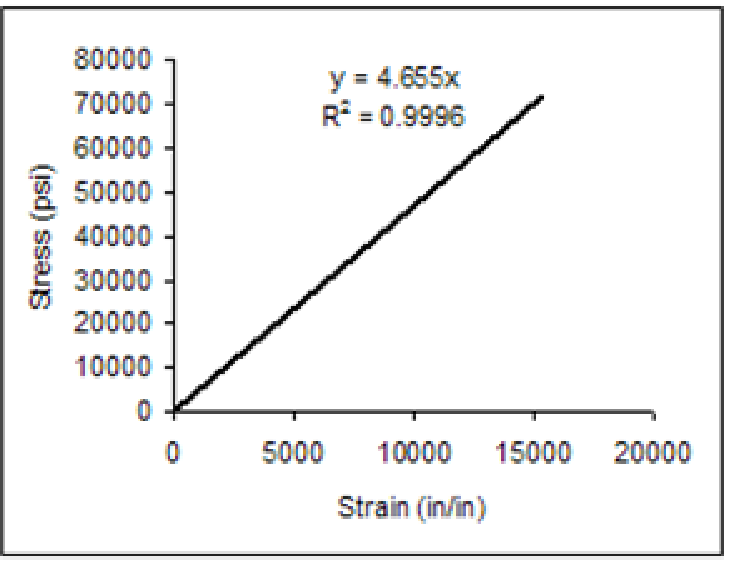

Bar 1

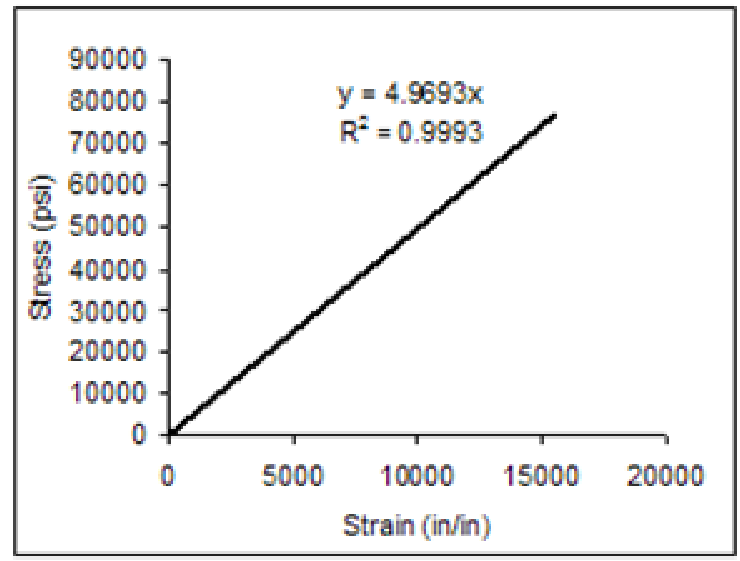

Bar 2

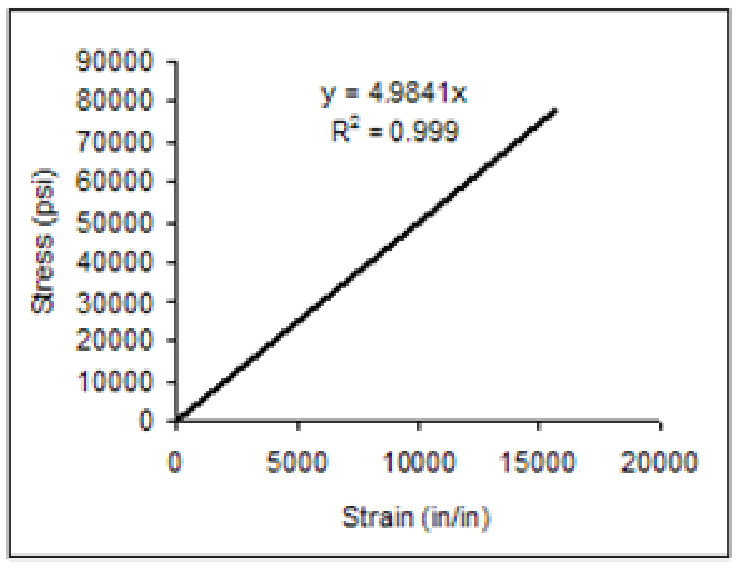

Bar 3

Figure A-12 Stress-strain plot of \#4 bars with nanoclay aged in water at room temperature for 9 months (Table A-3)

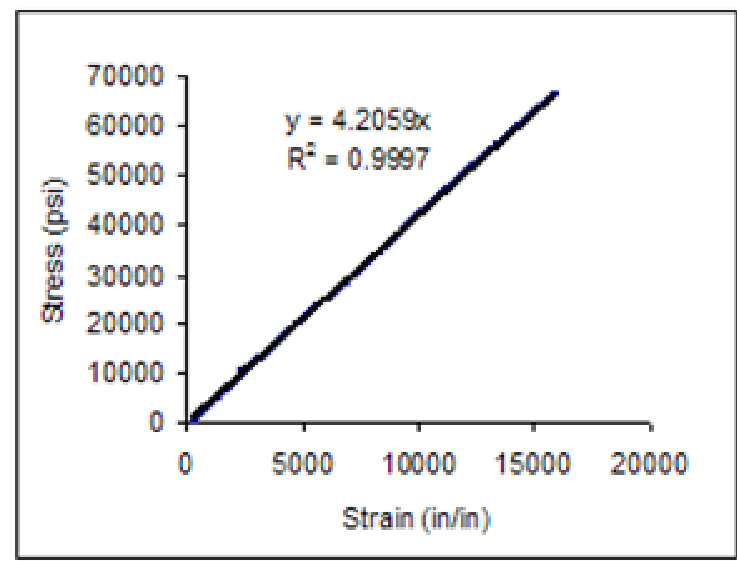

Bar 1

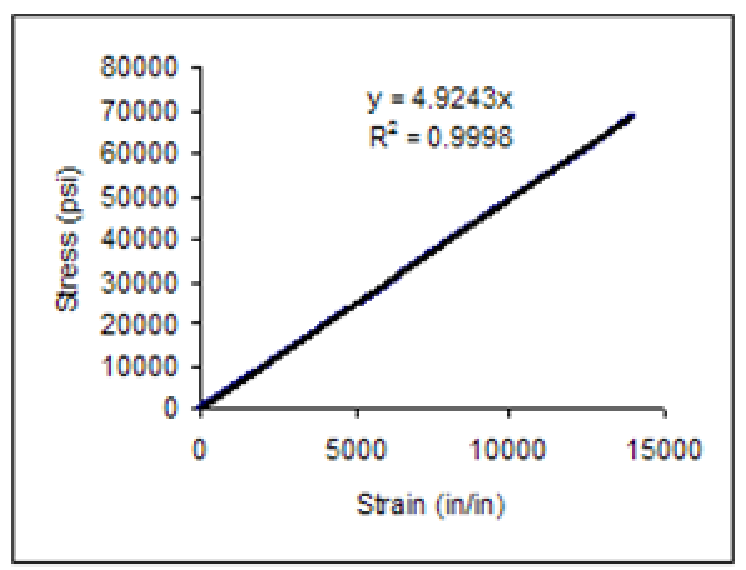

Bar 2 


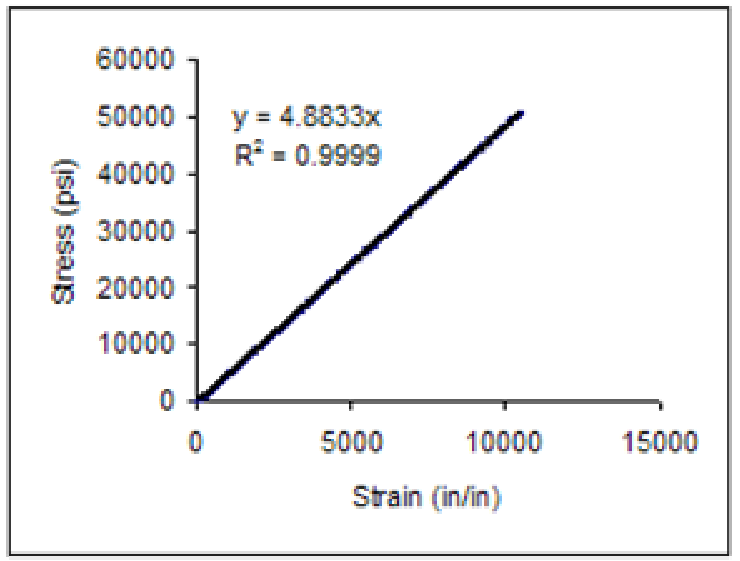

Bar 3

Figure A-13 Stress-strain plot of \#4 bars with nanoclay aged in water at $110^{\circ} \mathrm{F}$ for 3 months (Table A-4)

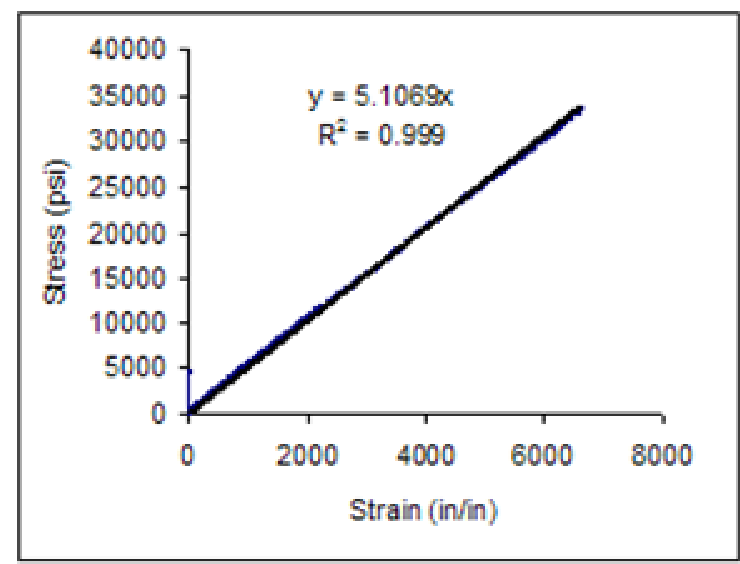

Bar 1

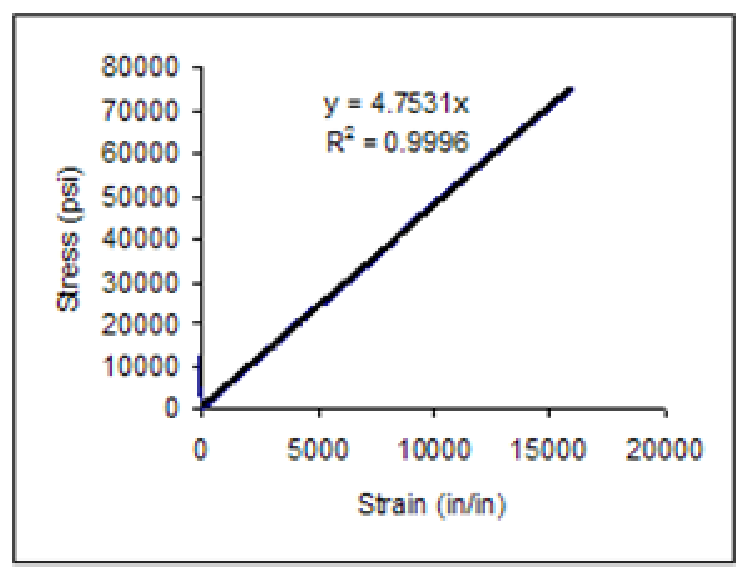

Bar 2

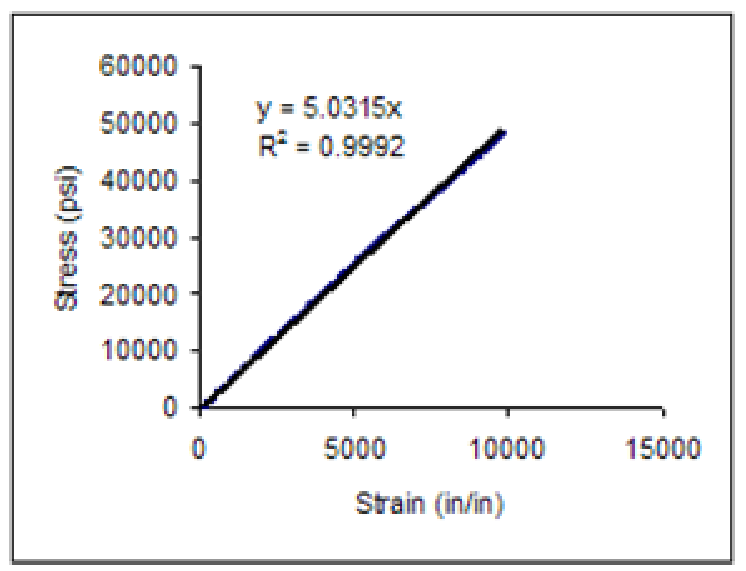

Bar 3

Figure A-14 Stress-strain plot of \#4 bars with nanoclay aged in water at $110^{\circ} \mathrm{F}$ for 6 months (Table A-4) 


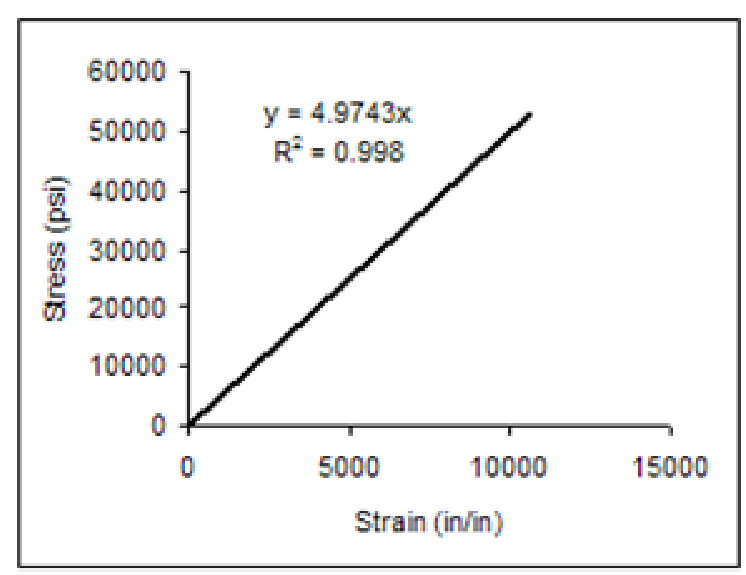

Bar 1

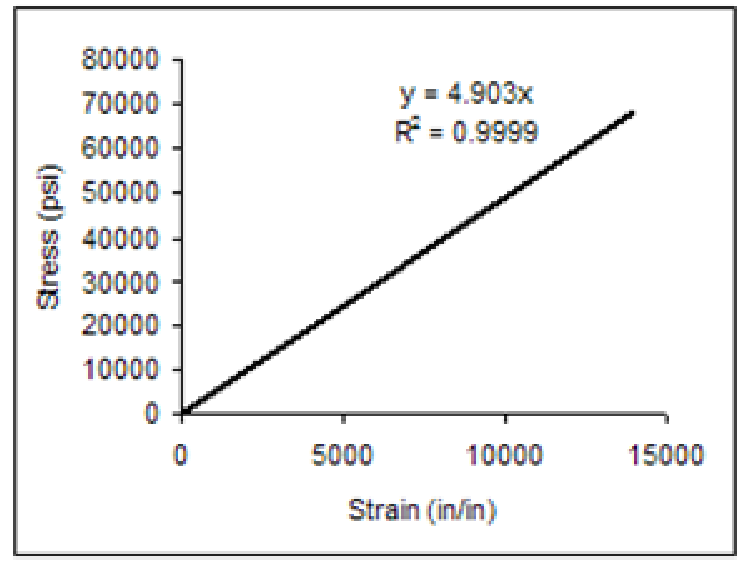

Bar 2

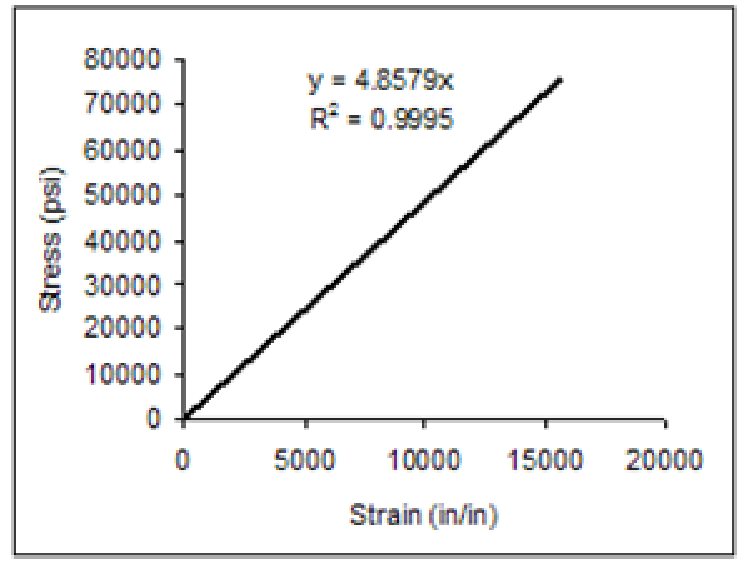

Bar 3

Figure A-15 Stress-strain plot of \#4 bars with nanoclay aged in water at $110^{\circ} \mathrm{F}$ for 9 months (Table A-4)

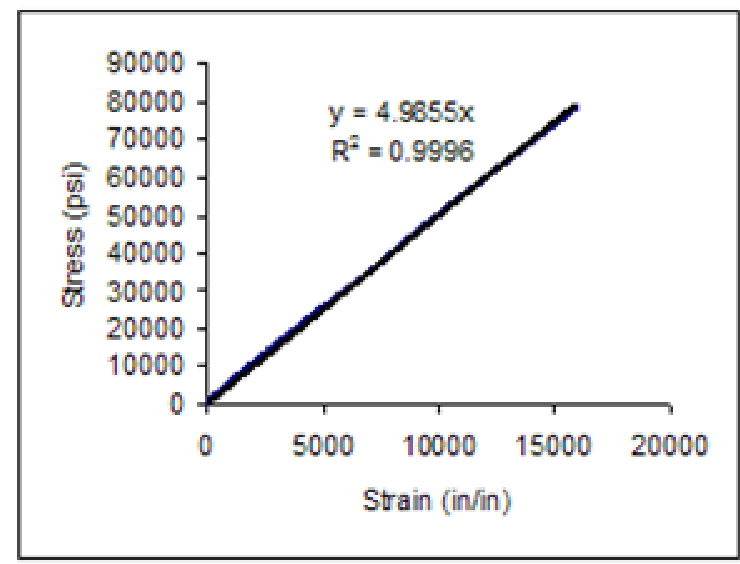

Bar 1

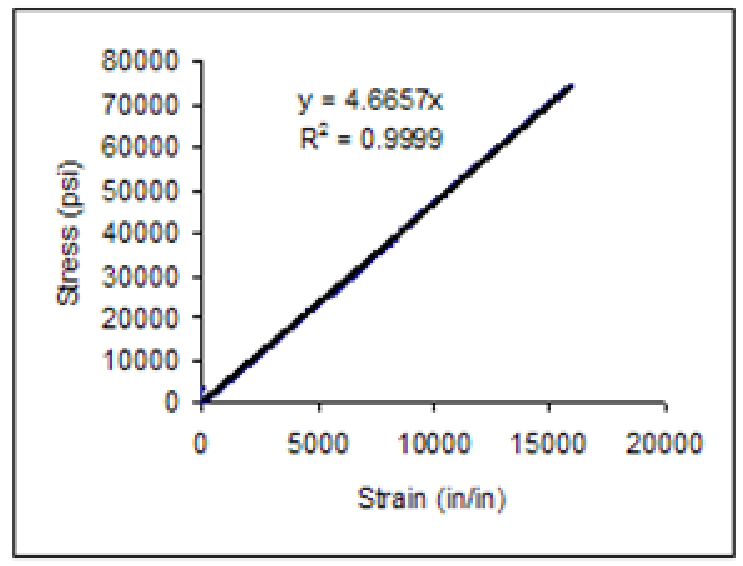

Bar 2

Figure A-16 Stress-strain plot of \#4 bars without nanoclay aged in water at $140^{\circ} \mathrm{F}$ for 3 months (Table A-5) 


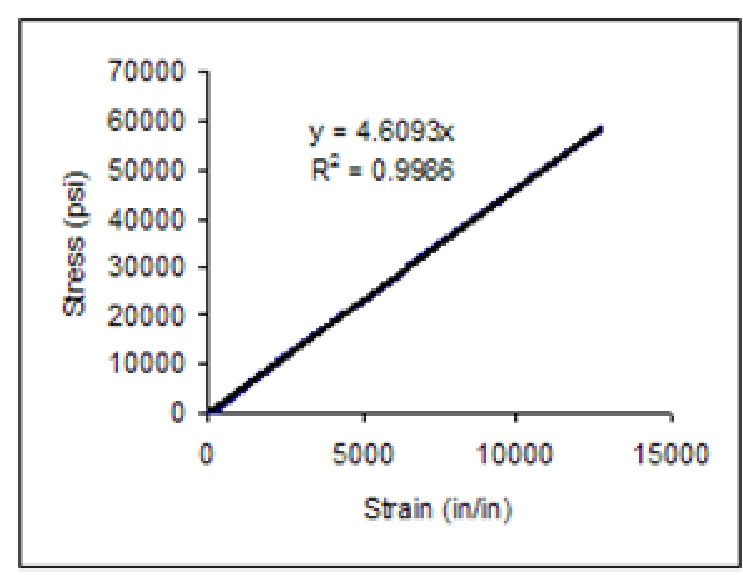

Bar 1

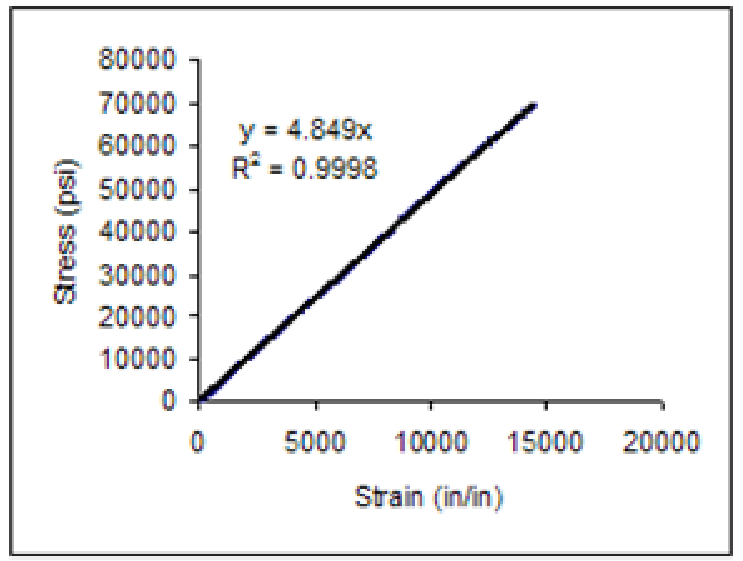

Bar 2

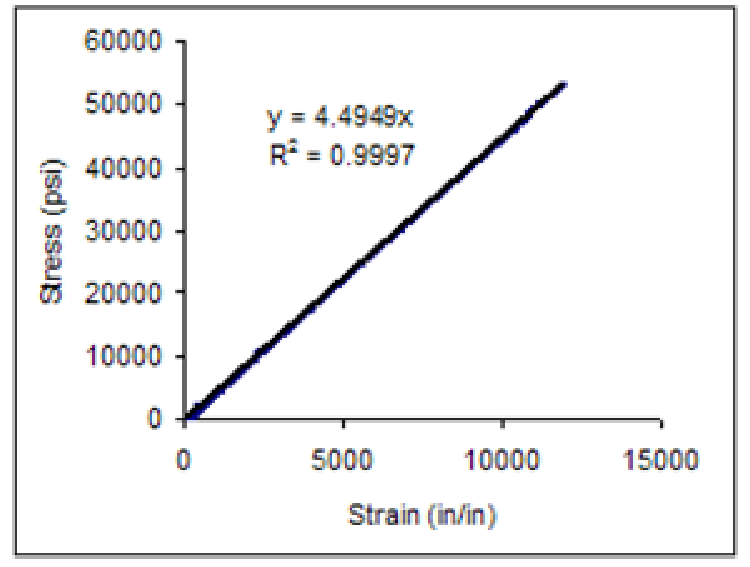

Bar 3

Figure A-17 Stress-strain plot of \#4 bars with nanoclay aged in water at $140^{\circ} \mathrm{F}$ for 3 months (Table A-5)

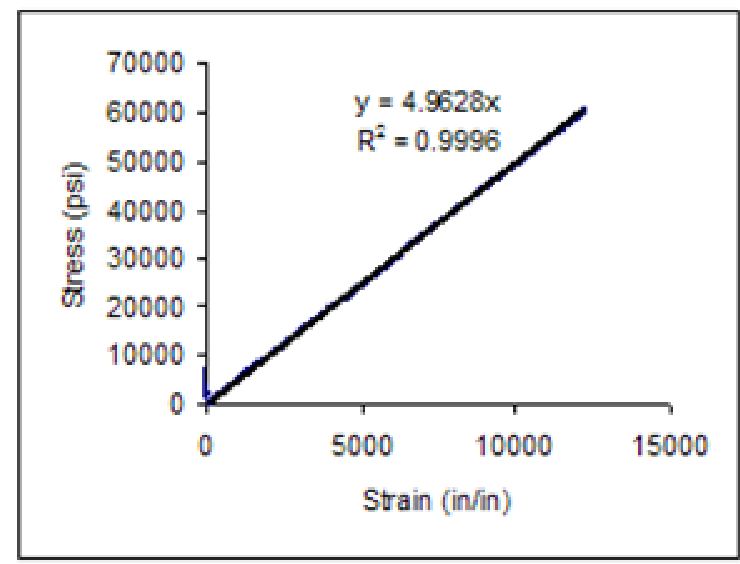

Bar 1

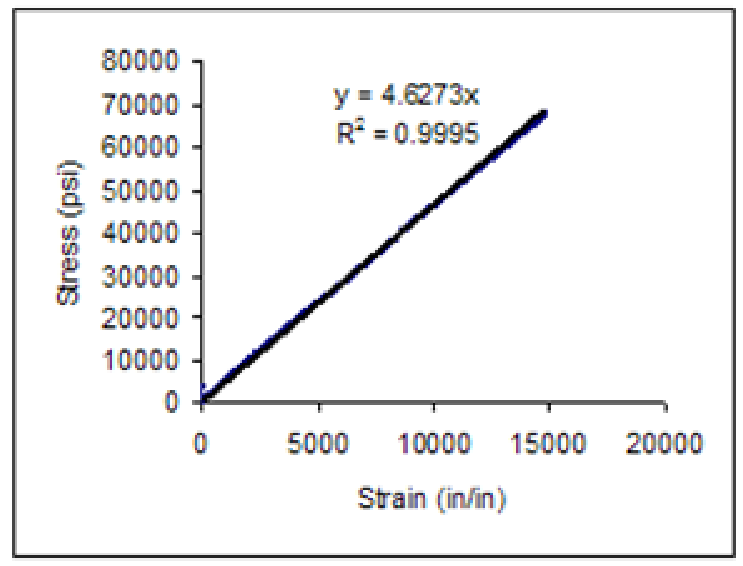

Bar 2

Figure A-18 Stress-strain plot of \#4 bars without nanoclay aged in water at $140^{\circ} \mathrm{F}$ for 6 months (Table A-5) 


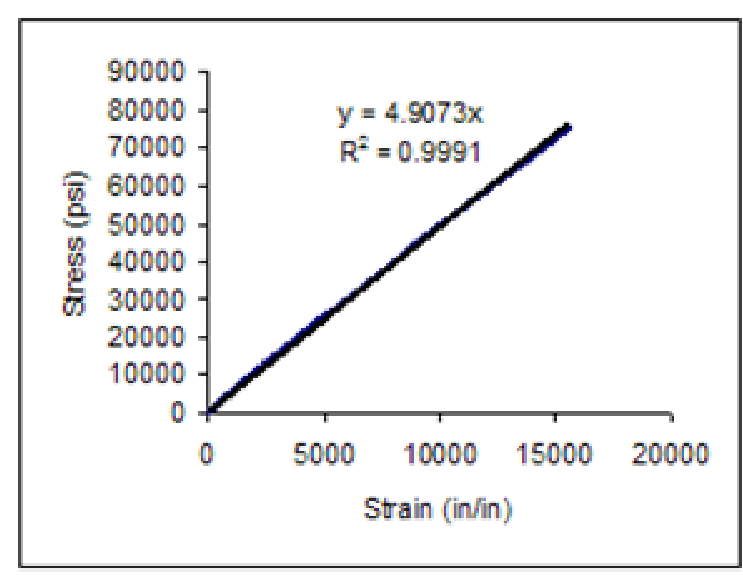

Bar 1

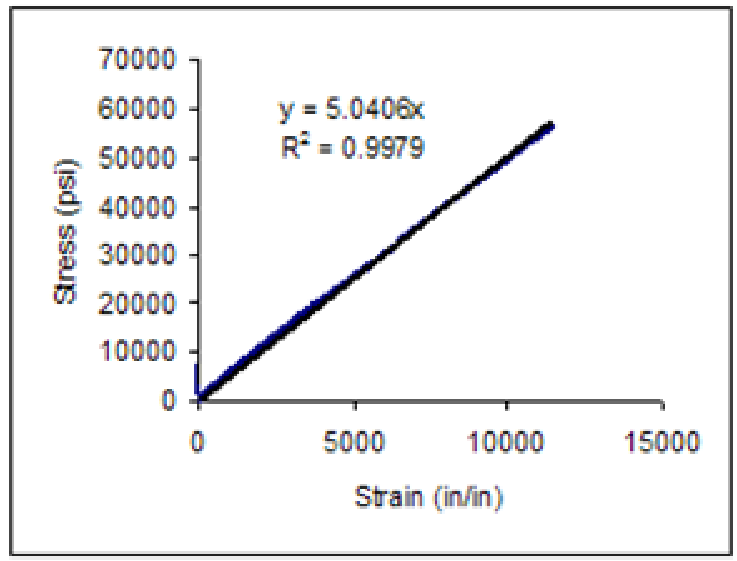

Bar 2

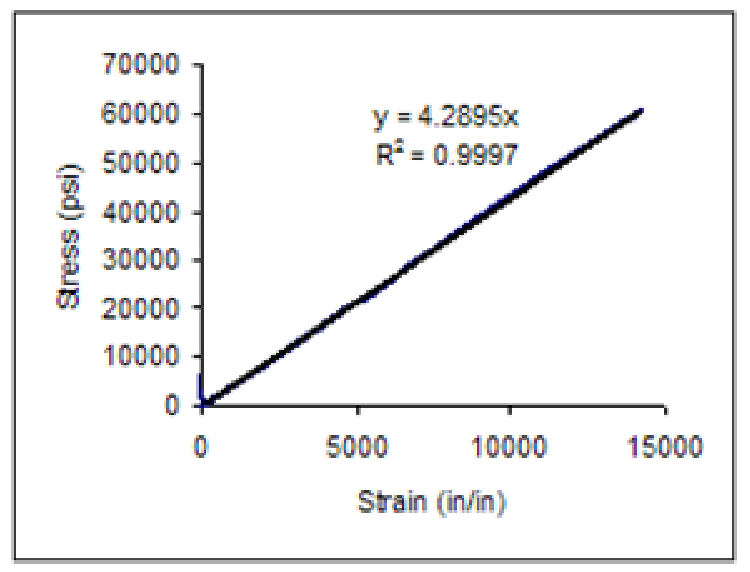

Bar 3

Figure A-19 Stress-strain plot of \#4 bars with nanoclay aged in water at $140^{\circ} \mathrm{F}$ for 6 months (Table A-5)

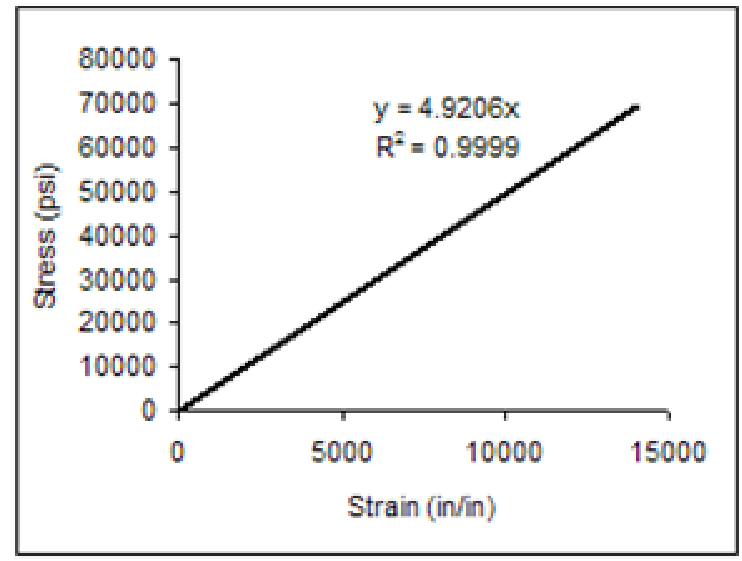

Bar 1

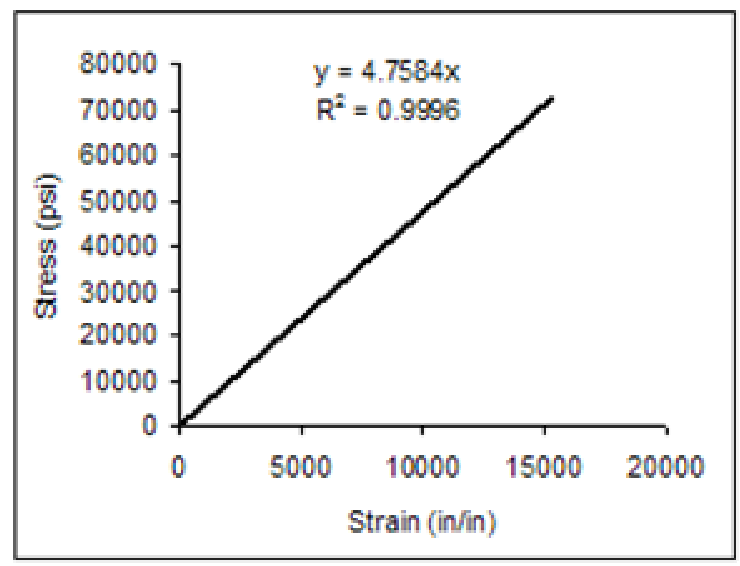

Bar 2

Figure A-20 Stress-strain plot of \#4 bars without nanoclay aged in water at $140^{\circ} \mathrm{F}$ for 9 months (Table A-5) 


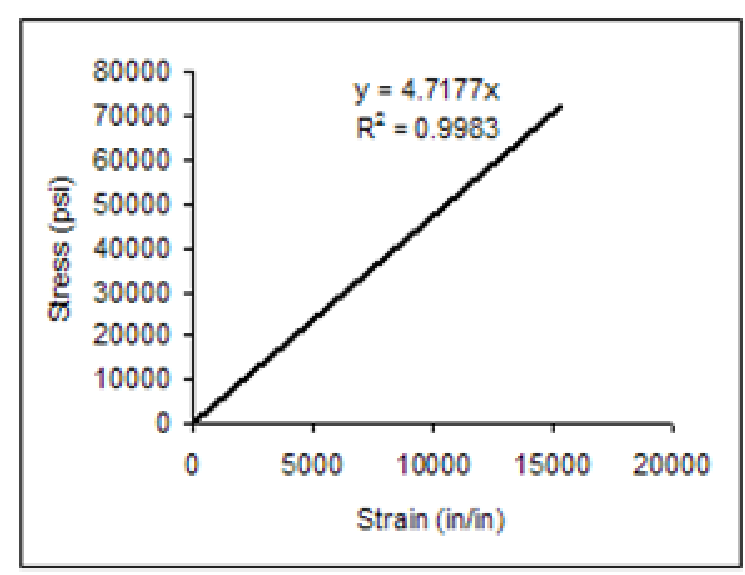

Bar 1

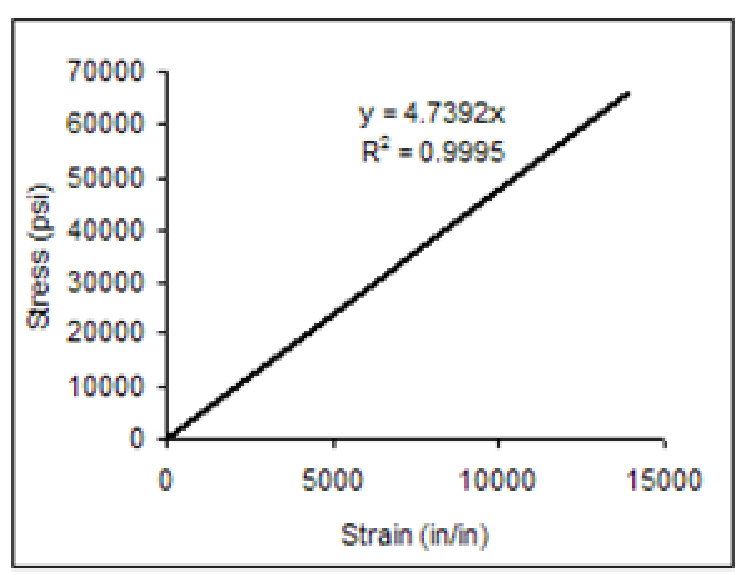

Bar 2

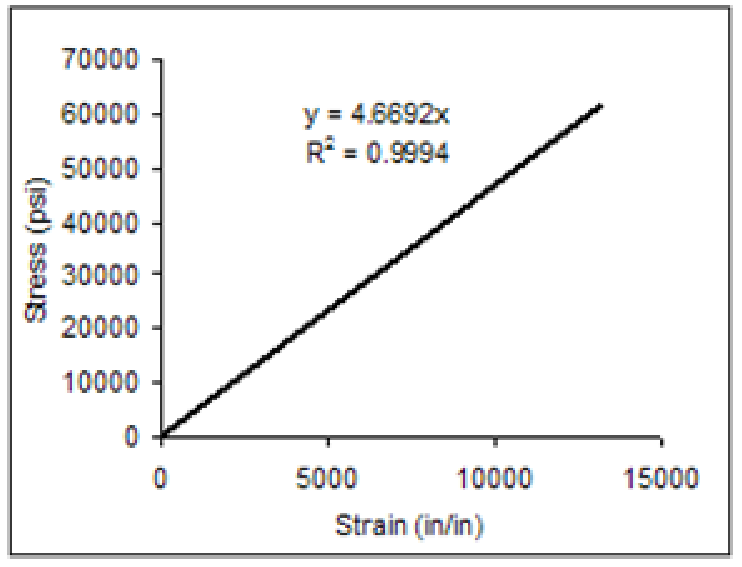

Bar 3

Figure A-21 Stress-strain plot of \#4 bars with nanoclay aged in water at $140^{\circ} \mathrm{F}$ for 9 months (Table A-5)

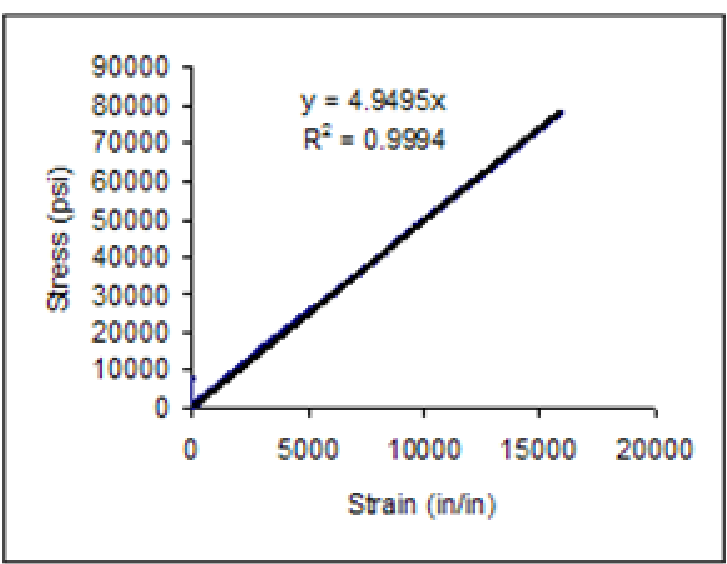

Bar 1

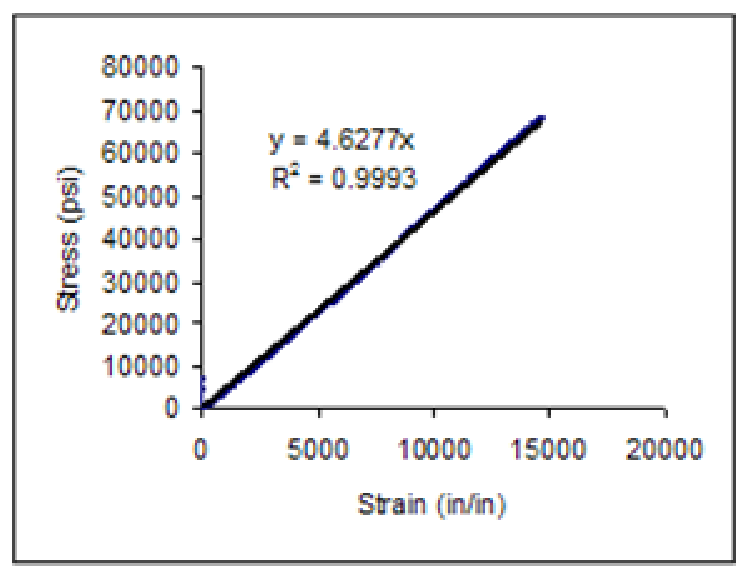

Bar 2

Figure A-22 Stress-strain plot of \#4 bars without nanoclay aged in alkaline solution at room temperature for 3 months (Table A-6) 


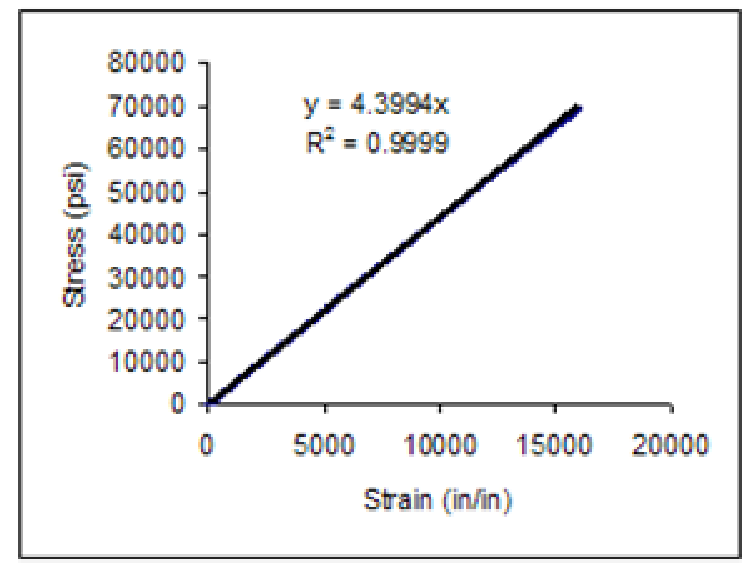

Bar 1

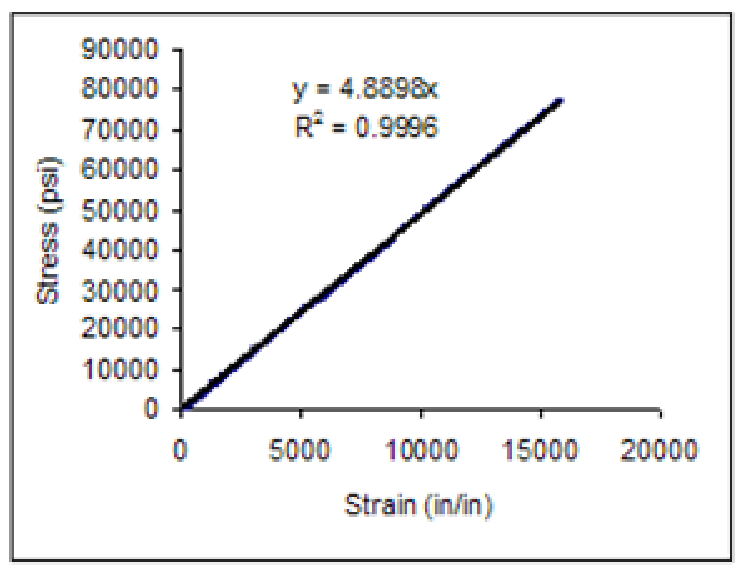

Bar 2

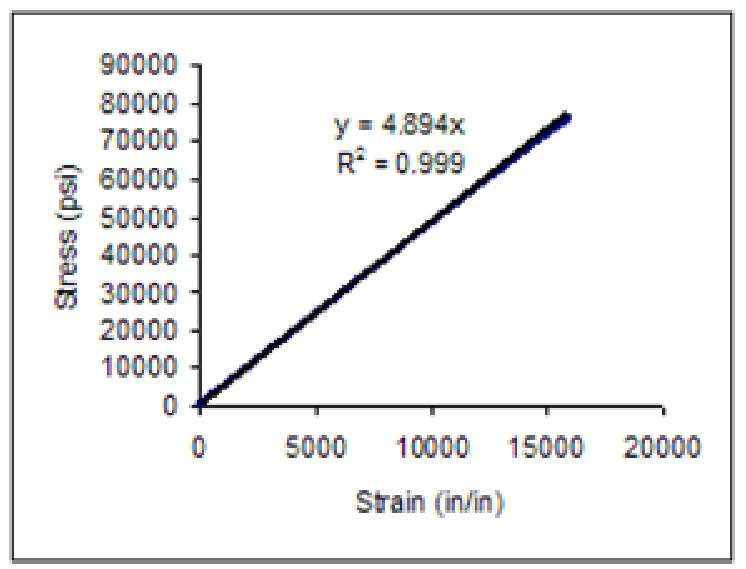

Bar 3

Figure A-23 Stress-strain plot of \#4 bars with nanoclay aged in alkaline solution at room temperature for 3 months (Table A-6)

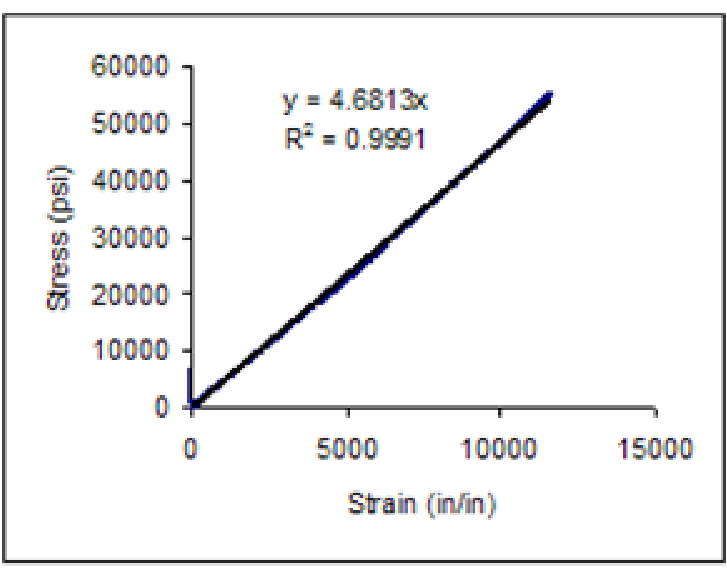

Bar 1

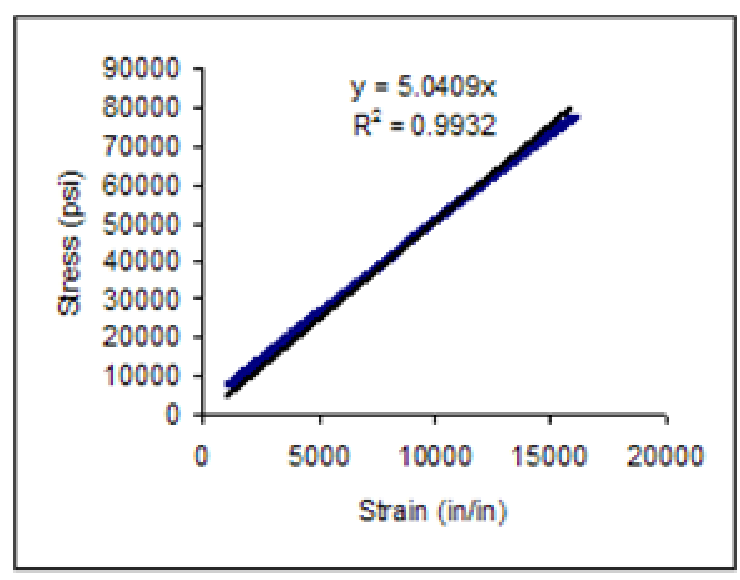

Bar 2 
Figure A-24 Stress-strain plot of \#4 bars without nanoclay aged in alkaline solution at room temperature for 6 months (Table A-6)

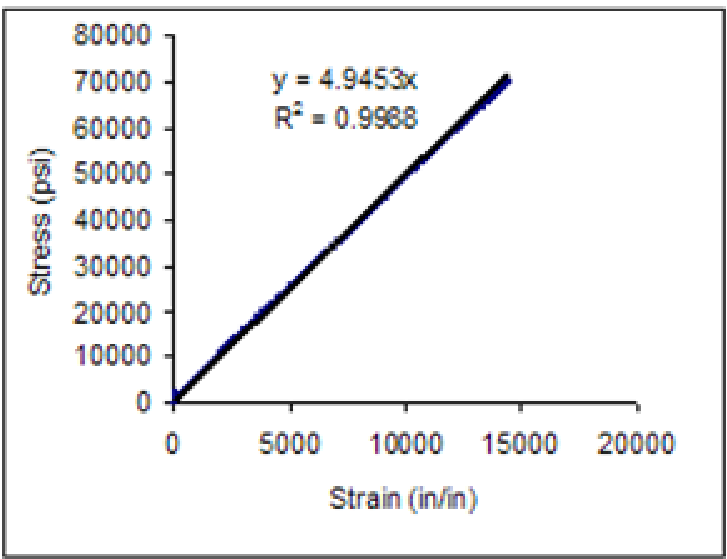

Bar 1

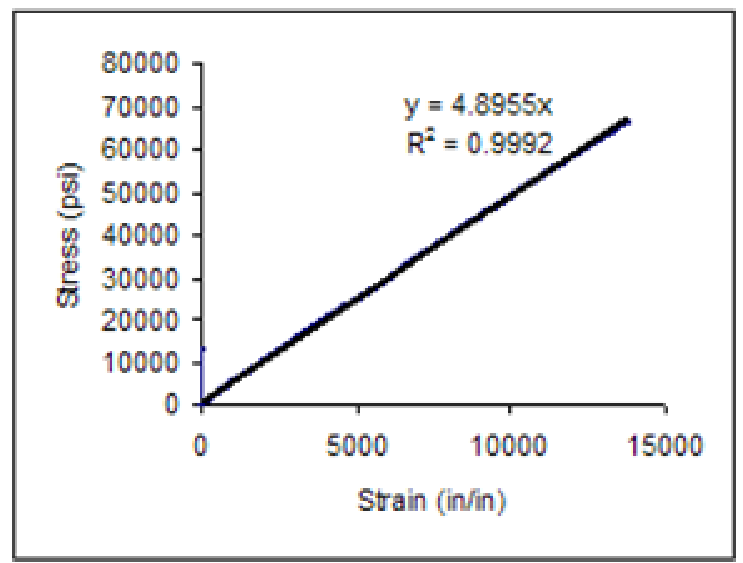

Bar 2

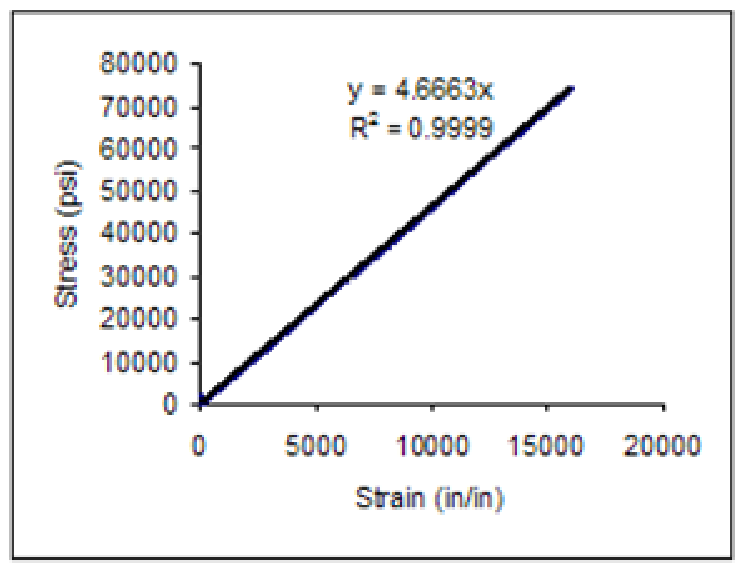

Bar 3

Figure A-25 Stress-strain plot of \#4 bars with nanoclay aged in alkaline solution at room temperature for 6 months (Table A-6)

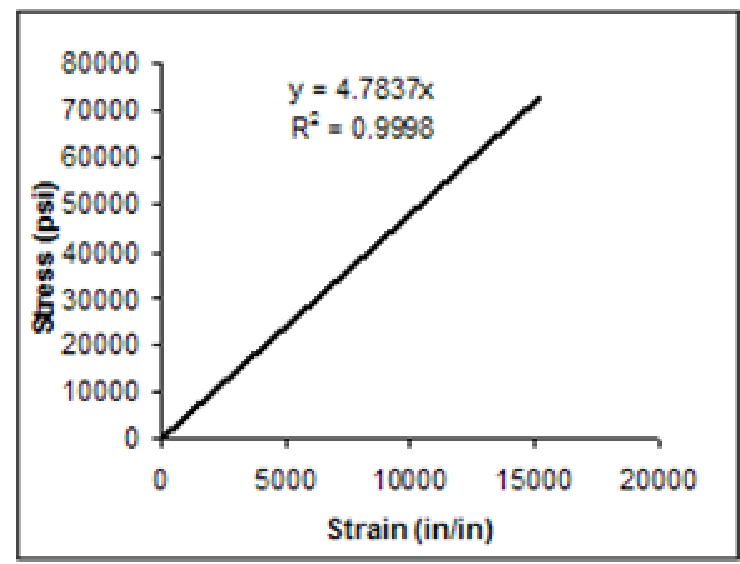

Bar 1

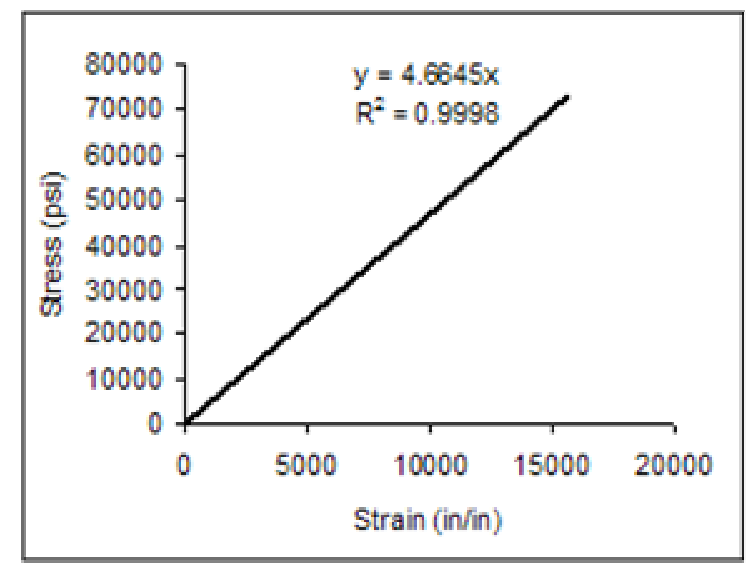

Bar 2

Figure A-26 Stress-strain plot of \#4 bars without nanoclay aged in alkaline solution at room temperature for 9 months (Table A-6) 


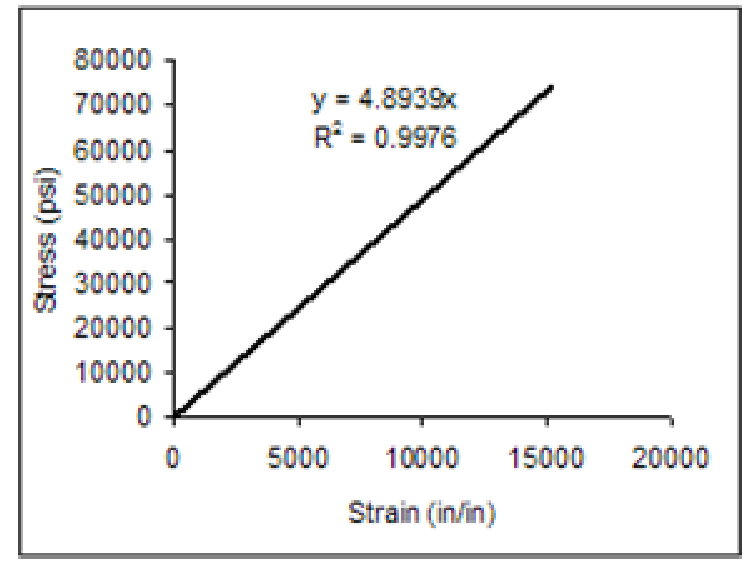

Bar 1

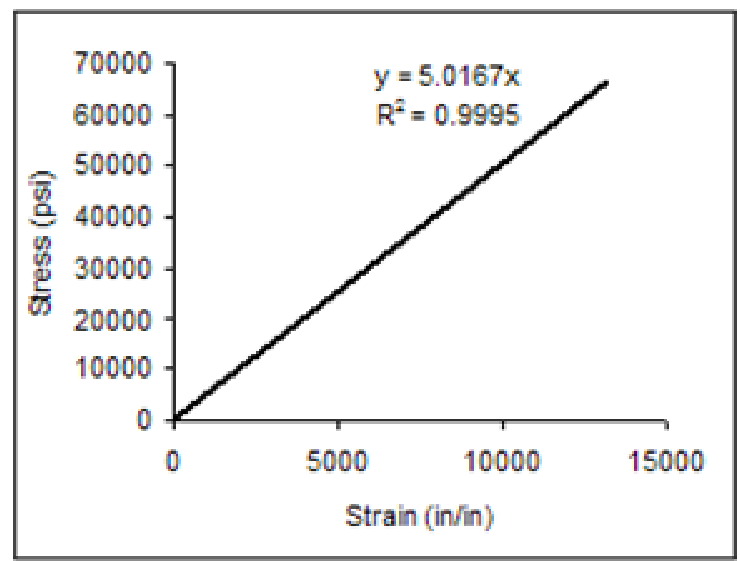

Bar 2

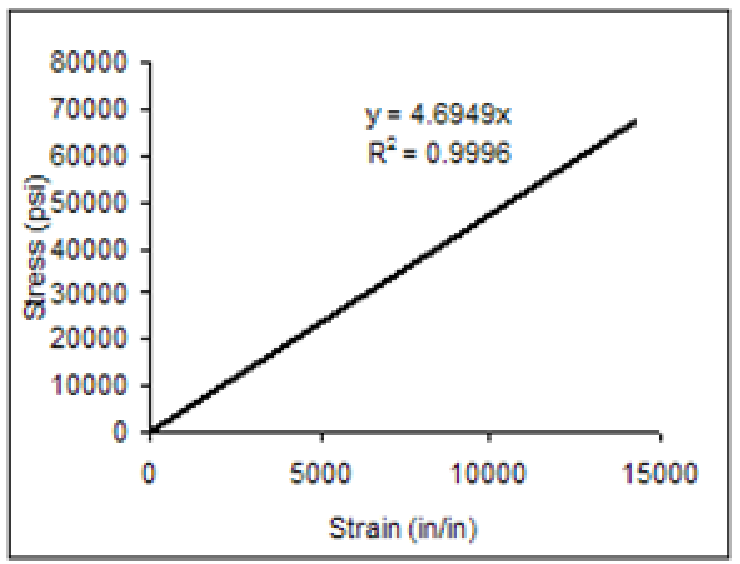

Bar 3

Figure A-27 Stress-strain plot of \#4 bars with nanoclay aged in alkaline solution at room temperature for 9 months (Table A-6) 


\section{APPENDIX B}

\section{B.1. TEST REULTS OF SHEAR TEST}

Table B-1 Test results of \#4 and \#6 bar with and without nanoclay subjected to no aging

\begin{tabular}{|c|c|c|c|c|c|}
\hline \multirow{2}{*}{$\begin{array}{c}\text { Number of } \\
\text { specimens }\end{array}$} & \multicolumn{2}{|c|}{$\begin{array}{c}\text { Shear stress of \#4 bars } \\
\text { (ksi) }\end{array}$} & \multicolumn{3}{c|}{ Shear stress of \#6 bars } \\
\cline { 2 - 6 } & without & with & without & \multicolumn{2}{c|}{ with nanoclay } \\
\cline { 3 - 6 } & nanoclay & nanoclay & nanoclay & $\mathbf{5 6}$ yield & 113 yield \\
\hline Bar 1 & 26.99 & 24.70 & 24.96 & 20.49 & 25.14 \\
\hline Bar 2 & 25.97 & 25.84 & 23.20 & 16.52 & 21.80 \\
\hline Bar 3 & 25.85 & 23.43 & 20.09 & 21.05 & 20.67 \\
\hline Bar 4 & - & 24.06 & 23.54 & 20.26 & 21.40 \\
\hline Bar 5 & - & 23.68 & - & 20.03 & 19.53 \\
\hline Bar 6 & - & 26.74 & - & 20.37 & 19.93 \\
\hline Bar 7 & - & 24.95 & - & 22.64 & 22.36 \\
\hline Bar 8 & - & - & - & 17.83 & 23.84 \\
\hline Bar 9 & - & - & - & 20.99 & 23.33 \\
\hline Average & $\mathbf{2 6 . 2 7}$ & $\mathbf{2 4 . 7 7}$ & $\mathbf{2 2 . 9 5}$ & $\mathbf{2 0 . 0 2}$ & $\mathbf{2 2 . 0 0}$ \\
\hline Std Dev & $\mathbf{0 . 6 2}$ & $\mathbf{1 . 1 9}$ & $\mathbf{2 . 0 5}$ & $\mathbf{1 . 8 1}$ & $\mathbf{1 . 8 6}$ \\
\hline \% Std Dev & $\mathbf{2 . 3 9}$ & $\mathbf{4 . 8 2}$ & $\mathbf{8 . 9 4}$ & $\mathbf{9 . 0 5}$ & $\mathbf{8 . 4 5}$ \\
\hline
\end{tabular}


Table B-2 Test results of bar with and without nanoclay aged in water at room temperature for 3,6 , and 9 months

\begin{tabular}{|c|c|c|c|c|c|c|}
\hline \multirow{2}{*}{$\begin{array}{c}\text { No. of } \\
\text { specimens }\end{array}$} & \multicolumn{2}{|c|}{$\begin{array}{c}\text { Shear stress of bars } \\
\text { aged for } 3 \text { month } \\
\text { (ksi) }\end{array}$} & \multicolumn{2}{|c|}{$\begin{array}{c}\text { Shear stress of bars } \\
\text { aged for } 6 \text { month } \\
\text { (ksi) }\end{array}$} & \multicolumn{2}{|c|}{$\begin{array}{c}\text { Shear stress of bars } \\
\text { aged for } 9 \text { month } \\
\text { (ksi) }\end{array}$} \\
\hline & $\begin{array}{l}\text { without } \\
\text { nanoclay }\end{array}$ & $\begin{array}{c}\text { with } \\
\text { nanoclay }\end{array}$ & $\begin{array}{l}\text { without } \\
\text { nanoclay }\end{array}$ & $\begin{array}{c}\text { with } \\
\text { nanoclay }\end{array}$ & $\begin{array}{l}\text { without } \\
\text { nanoclay }\end{array}$ & $\begin{array}{c}\text { with } \\
\text { nanoclay }\end{array}$ \\
\hline Bar 1 & 25.97 & 25.59 & 23.69 & 23.51 & 22.93 & 22.37 \\
\hline Bar 2 & 25.21 & 22.28 & 26.36 & 23.26 & 23.18 & 23.68 \\
\hline Bar 3 & 24.19 & 23.81 & 24.33 & 22.80 & 22.16 & 23.95 \\
\hline Bar 4 & - & 25.97 & - & 24.83 & - & 20.53 \\
\hline Bar 5 & - & 25.02 & - & 24.20 & - & 23.16 \\
\hline Bar 6 & - & 22.54 & - & 23.18 & - & 22.63 \\
\hline Average & 25.13 & 24.20 & 24.79 & 23.63 & 22.76 & 22.72 \\
\hline Std Dev & 0.89 & 1.57 & 1.40 & 0.75 & 0.53 & 1.23 \\
\hline \% Std dev & 3.56 & 6.48 & 5.64 & 3.18 & 2.33 & 5.42 \\
\hline
\end{tabular}

Table B-3 Test results on bar with and without nanoclay aged in water at $110^{\circ} \mathrm{F}$ for 3,6 , and 9 months

\begin{tabular}{|c|c|c|c|}
\hline $\begin{array}{c}\text { No. of } \\
\text { specimens }\end{array}$ & $\begin{array}{c}\text { Shear stress of } \\
\text { bars with } \\
\text { nanoclay aged for } \\
\text { 3 month (ksi) }\end{array}$ & $\begin{array}{c}\text { Shear stress of bars } \\
\text { with nanoclay aged } \\
\text { for 6 month (ksi) }\end{array}$ & $\begin{array}{c}\text { Shear stress of bars } \\
\text { with nanoclay aged } \\
\text { for 9 month (ksi) }\end{array}$ \\
\hline Bar 1 & 21.07 & 21.01 & 23.18 \\
\hline Bar 2 & 21.65 & 22.03 & 20.64 \\
\hline Bar 3 & 23.25 & 24.07 & 24.33 \\
\hline Bar 4 & 21.16 & 22.67 & 19.75 \\
\hline Bar 5 & 21.01 & 21.52 & 22.93 \\
\hline Bar 6 & 24.98 & 21.40 & $\mathbf{2 1 . 8 6}$ \\
\hline Average & $\mathbf{2 2 . 1 9}$ & $\mathbf{2 2 . 1 2}$ & $\mathbf{1 . 8 5}$ \\
\hline Std Dev & $\mathbf{1 . 6 1}$ & $\mathbf{1 . 1 2}$ & $\mathbf{8 . 0 7}$ \\
\hline \% Std dev & $\mathbf{7 . 2 4}$ & $\mathbf{5 . 0 4}$ & \\
\hline
\end{tabular}


Table B-4 Test results on bar with and without nanoclay aged in water at $140^{\circ} \mathrm{F}$ for 3,6 , and 9 months

\begin{tabular}{|c|c|c|c|c|c|c|}
\hline \multirow{2}{*}{$\begin{array}{c}\text { No. of } \\
\text { specimens }\end{array}$} & \multicolumn{2}{|c|}{$\begin{array}{c}\text { Shear stress of bars } \\
\text { aged for 3 month }\end{array}$} & \multicolumn{2}{c|}{$\begin{array}{c}\text { Shear stress of bars } \\
\text { aged for 6 month }\end{array}$} & \multicolumn{2}{c|}{$\begin{array}{c}\text { Shear stress of bars } \\
\text { aged for 9 month } \\
\text { (ksi) }\end{array}$} \\
\cline { 2 - 7 } & $\begin{array}{c}\text { without } \\
\text { nanoclay }\end{array}$ & $\begin{array}{c}\text { with } \\
\text { nanoclay }\end{array}$ & $\begin{array}{c}\text { without } \\
\text { nanoclay }\end{array}$ & $\begin{array}{c}\text { with } \\
\text { nanoclay }\end{array}$ & $\begin{array}{c}\text { without } \\
\text { nanoclay }\end{array}$ & $\begin{array}{c}\text { with } \\
\text { nanoclay }\end{array}$ \\
\hline Bar 1 & 22.41 & 23.01 & 21.35 & 21.01 & 21.40 & 20.25 \\
\hline Bar 2 & 21.01 & 21.59 & 21.20 & 20.63 & 20.64 & 19.75 \\
\hline Bar 3 & 21.90 & 19.86 & 20.83 & 19.10 & 20.89 & 19.62 \\
\hline Bar 4 & - & 19.66 & - & 19.74 & - & 19.11 \\
\hline Bar 5 & - & 20.12 & - & 19.99 & - & 20.51 \\
\hline Bar 6 & - & 19.51 & - & 19.87 & - & 19.75 \\
\hline Average & $\mathbf{2 1 . 7 7}$ & $\mathbf{2 0 . 6 3}$ & $\mathbf{2 1 . 1 3}$ & $\mathbf{2 0 . 0 6}$ & $\mathbf{2 0 . 9 8}$ & $\mathbf{1 9 . 8 3}$ \\
\hline Std Dev & $\mathbf{0 . 7 1}$ & $\mathbf{1 . 3 8}$ & $\mathbf{0 . 2 7}$ & $\mathbf{0 . 6 8}$ & $\mathbf{0 . 3 9}$ & $\mathbf{0 . 4 9}$ \\
\hline \% Std dev & $\mathbf{3 . 2 6}$ & $\mathbf{6 . 7 3}$ & $\mathbf{1 . 2 6}$ & $\mathbf{3 . 3 8}$ & $\mathbf{1 . 8 6}$ & $\mathbf{2 . 4 9}$ \\
\hline
\end{tabular}

Table B-5 Test results on bar with and without nanoclay aged in alkaline solution at room temperature for 3,6 , and 9 months

\begin{tabular}{|c|c|c|c|c|c|c|}
\hline \multirow{2}{*}{$\begin{array}{c}\text { No. of } \\
\text { specimens }\end{array}$} & \multicolumn{2}{|c|}{$\begin{array}{c}\text { Shear stress of bars } \\
\text { aged for 3 month }\end{array}$} & \multicolumn{2}{c|}{$\begin{array}{c}\text { Shear stress of bars } \\
\text { aged for 6 month }\end{array}$} & \multicolumn{2}{c|}{$\begin{array}{c}\text { Shear stress of bars } \\
\text { aged for 9 month } \\
\text { (ksi) }\end{array}$} \\
\cline { 2 - 8 } & $\begin{array}{c}\text { without } \\
\text { nanoclay }\end{array}$ & $\begin{array}{c}\text { with } \\
\text { nanoclay }\end{array}$ & $\begin{array}{c}\text { without } \\
\text { nanoclay }\end{array}$ & $\begin{array}{c}\text { with } \\
\text { nanoclay }\end{array}$ & $\begin{array}{c}\text { without } \\
\text { nanoclay }\end{array}$ & $\begin{array}{c}\text { with } \\
\text { nanoclay }\end{array}$ \\
\hline Bar 1 & 24.32 & 23.09 & 23.31 & 22.06 & 21.91 & 23.57 \\
\hline Bar 2 & 24.57 & 20.58 & 19.23 & 23.56 & 22.68 & 21.91 \\
\hline Bar 3 & 21.65 & 24.57 & 24.20 & 24.89 & 22.17 & 22.80 \\
\hline Bar 4 & - & 20.73 & - & 22.53 & - & 24.97 \\
\hline Bar 5 & - & 23.02 & - & 21.85 & - & 22.66 \\
\hline Bar 6 & - & 22.82 & - & 23.85 & - & 24.56 \\
\hline Average & $\mathbf{2 3 . 5 1}$ & $\mathbf{2 2 . 4 6}$ & $\mathbf{2 2 . 2 4}$ & $\mathbf{2 3 . 1 2}$ & $\mathbf{2 2 . 2 5}$ & $\mathbf{2 3 . 4 0}$ \\
\hline Std Dev & $\mathbf{1 . 6 2}$ & $\mathbf{1 . 5 4}$ & $\mathbf{2 . 6 5}$ & $\mathbf{1 . 1 8}$ & $\mathbf{0 . 3 9}$ & $\mathbf{1 . 1 6}$ \\
\hline \% Std dev & $\mathbf{6 . 9 0}$ & $\mathbf{6 . 8 4}$ & $\mathbf{1 1 . 9 0}$ & $\mathbf{5 . 1 0}$ & $\mathbf{1 . 7 5}$ & $\mathbf{4 . 9 5}$ \\
\hline
\end{tabular}


Table B-6 Test results of \#4 and \#6 bar with and without nanoclay extracted from concrete beams

\begin{tabular}{|c|c|c|c|c|}
\hline \multirow{2}{*}{$\begin{array}{c}\text { Number of } \\
\text { specimens }\end{array}$} & \multicolumn{2}{|c|}{$\begin{array}{c}\text { Shear stress of \#4 bars } \\
\text { (ksi) }\end{array}$} & \multicolumn{2}{c|}{ Shear stress of \#6 bars } \\
\cline { 2 - 5 } & without & with & without & with \\
nanoclay & nanoclay & nanoclay & nanoclay \\
\hline Bar 1 & 23.55 & 21.77 & 22.43 & 21.11 \\
\hline Bar 2 & 25.08 & 20.50 & 20.03 & 20.37 \\
\hline Bar 3 & 23.55 & 22.41 & 23.26 & 18.47 \\
\hline Bar 4 & 27.25 & 23.43 & 23.50 & 18.22 \\
\hline Bar 5 & 23.43 & 23.55 & - & - \\
\hline Bar 6 & 25.85 & 25.59 & - & - \\
\hline Bar 7 & 22.03 & 24.83 & - & - \\
\hline Bar 8 & 25.21 & 22.03 & - & - \\
\hline Bar 9 & 26.48 & 24.45 & - & - \\
\hline Bar 10 & - & 25.59 & - & - \\
\hline Average & $\mathbf{2 4 . 7 1}$ & $\mathbf{2 3 . 4 1}$ & $\mathbf{2 2 . 3 1}$ & $\mathbf{1 9 . 5 4}$ \\
\hline Std Dev & $\mathbf{1 . 6 9}$ & $\mathbf{1 . 7 2}$ & $\mathbf{1 . 5 8}$ & $\mathbf{1 . 4 2}$ \\
\hline \% Std Dev & $\mathbf{6 . 8 3}$ & $\mathbf{7 . 3 5}$ & $\mathbf{7 . 1 0}$ & $\mathbf{7 . 2 6}$ \\
\hline
\end{tabular}




\section{B.2. BOND TEST RESULTS}

Table B-7 Test results of \#4 and \#6 bars with and without nanoclay subjected to no aging

\begin{tabular}{|c|c|c|c|c|c|c|}
\hline \multirow{2}{*}{$\begin{array}{l}\text { No of } \\
\text { months } \\
\text { in aging }\end{array}$} & \multirow{2}{*}{$\begin{array}{l}\text { Number of } \\
\text { specimens }\end{array}$} & \multirow{2}{*}{$\begin{array}{l}\text { Bar } \\
\text { size }\end{array}$} & \multicolumn{2}{|c|}{ Max load (lb) } & \multicolumn{2}{|c|}{ Bond stress (psi) } \\
\hline & & & $\begin{array}{l}\text { Without } \\
\text { nanoclay }\end{array}$ & $\begin{array}{c}\text { With } \\
\text { nanoclay }\end{array}$ & $\begin{array}{l}\text { Without } \\
\text { nanoclay }\end{array}$ & $\begin{array}{c}\text { With } \\
\text { nanoclay }\end{array}$ \\
\hline \multirow{12}{*}{$\mathbf{0}$} & Bar 1 & \multirow{3}{*}{ \#4 } & 8153.75 & 8259.78 & 1730.28 & 1752.78 \\
\hline & Bar 2 & & 7928.08 & 7975.53 & 1682.39 & 1692.46 \\
\hline & Bar 3 & & - & 8279.62 & - & 1756.99 \\
\hline & Average & & 8040.91 & 8171.64 & 1706.34 & 1734.08 \\
\hline & Std Dev & & 159.58 & 170.13 & 33.86 & 36.10 \\
\hline & \% Std Dev & & 1.98 & 2.08 & 1.98 & 2.08 \\
\hline & Bar 1 & \multirow{3}{*}{ \#6 } & - & 12634.34 & - & 1788.30 \\
\hline & Bar 2 & & - & 12244.00 & - & 1733.05 \\
\hline & Bar 3 & & - & 13125.64 & - & 1857.84 \\
\hline & Average & & - & 12667.99 & - & 1793.06 \\
\hline & Std Dev & & - & 441.783 & - & 62.53 \\
\hline & \% Std Dev & & - & 3.49 & - & 3.49 \\
\hline
\end{tabular}


Table B-8 Test results of \#4 bars with and without nanoclay aged in water at room temperature, water at $110^{\circ} \mathrm{F}$, and water at $140^{\circ} \mathrm{F}$

\begin{tabular}{|c|c|c|c|c|c|c|c|}
\hline \multirow{2}{*}{$\begin{array}{c}\text { No of } \\
\text { months } \\
\text { in } \\
\text { aging }\end{array}$} & \multirow[b]{2}{*}{$\begin{array}{c}\text { No of } \\
\text { specimens }\end{array}$} & \multicolumn{3}{|c|}{ Max load (lb) } & \multicolumn{3}{|c|}{ Bond stress (psi) } \\
\hline & & $\begin{array}{c}\text { Water } \\
\text { at } \\
\text { room } \\
\text { temp }\end{array}$ & $\begin{array}{c}\text { Water } \\
\text { at } 110^{\circ} \mathrm{F} \\
\text { temp }\end{array}$ & $\begin{array}{c}\text { Water at } \\
140^{\circ} \mathrm{F} \\
\text { temp }\end{array}$ & $\begin{array}{c}\text { Water } \\
\text { at room } \\
\text { temp }\end{array}$ & $\begin{array}{c}\text { Water } \\
\text { at } \\
110^{\circ} \mathrm{F} \\
\text { temp }\end{array}$ & $\begin{array}{c}\text { Water } \\
\text { at } \\
140^{\circ} \mathrm{F} \\
\text { temp }\end{array}$ \\
\hline \multirow{3}{*}{ 0 } & Average & 8171.64 & 8171.64 & 8171.64 & 1734.08 & 1734.08 & 1734.08 \\
\hline & Std Dev & 170.13 & 170.13 & 170.13 & 36.10 & 36.10 & 36.10 \\
\hline & \% Std Dev & 2.08 & 2.08 & 2.08 & 2.08 & 2.08 & 2.08 \\
\hline \multirow{5}{*}{3} & Bar 1 & 8655.34 & 8878.26 & 7325.13 & 1836.72 & 1884.98 & 1555.23 \\
\hline & Bar 2 & 8468.21 & 8602.67 & 8745.39 & 1797.01 & 1826.47 & 1856.77 \\
\hline & Average & 8561.78 & 8740.47 & 8035.26 & 1816.87 & 1855.73 & 1706.00 \\
\hline & Std Dev & 132.32 & 194.87 & 1004.27 & 28.08 & 41.37 & 213.22 \\
\hline & \% Std Dev & 1.55 & 2.23 & 12.50 & 1.55 & 2.23 & 12.50 \\
\hline \multirow{5}{*}{6} & Bar 1 & 8639.79 & 8750.38 & 8879.43 & 1834.35 & 1857.83 & 1885.23 \\
\hline & Bar 2 & 8142.18 & 8756.31 & 8817.87 & 1728.70 & 1859.09 & 1872.16 \\
\hline & Average & 8390.98 & 8753.35 & 8848.65 & 1781.53 & 1858.46 & 1878.70 \\
\hline & Std Dev & 351.86 & 4.20 & 43.53 & 74.71 & 0.89 & 9.24 \\
\hline & \% Std Dev & 4.19 & 0.05 & 0.49 & 4.19 & 0.05 & 0.49 \\
\hline \multirow{5}{*}{9} & Bar 1 & 8345.05 & 8129.50 & 8037.12 & 1771.73 & 1726.01 & 1706.39 \\
\hline & Bar 2 & 8783.27 & 8384.88 & 8668.39 & 1864.81 & 1780.23 & 1840.42 \\
\hline & Average & 8564.16 & 8257.19 & 8352.76 & 1818.27 & 1753.12 & 1773.41 \\
\hline & Std Dev & 309.87 & 180.58 & 446.38 & 65.82 & 38.34 & 94.77 \\
\hline & \% Std Dev & 3.62 & 2.19 & 5.34 & 3.62 & 2.19 & 5.34 \\
\hline
\end{tabular}


Table B-9 Test results of \#4 bars with nanoclay aged in alkaline solution at room temperature

\begin{tabular}{|c|c|c|c|}
\hline $\begin{array}{l}\text { No of } \\
\text { months } \\
\text { in } \\
\text { aging }\end{array}$ & $\begin{array}{c}\text { No of } \\
\text { specimens }\end{array}$ & $\begin{array}{l}\text { Max load of bars in } \\
\text { alkaline solution at } \\
\text { room temp } \\
\text { (lb) }\end{array}$ & $\begin{array}{l}\text { Bond stress of bars } \\
\text { in alkaline solution } \\
\text { at room temp } \\
\text { (psi) }\end{array}$ \\
\hline \multirow{3}{*}{$\mathbf{0}$} & Average & 8171.64 & 1734.08 \\
\hline & Std Dev & 170.13 & 36.10 \\
\hline & \% Std Dev & 2.08 & 2.08 \\
\hline \multirow{5}{*}{3} & Bar 1 & 8817.87 & 1872.16 \\
\hline & Bar 2 & 8277.78 & 1757.47 \\
\hline & Average & 8547.78 & 1814.82 \\
\hline & Std Dev & 381.97 & 81.10 \\
\hline & \% Std Dev & 4.47 & 4.47 \\
\hline \multirow{5}{*}{6} & Bar 1 & 8771.67 & 1862.35 \\
\hline & Bar 2 & 8371.60 & 1777.41 \\
\hline & Average & 8571.64 & 1819.88 \\
\hline & Std Dev & 282.89 & 60.06 \\
\hline & \% Std Dev & 3.30 & 3.30 \\
\hline \multirow{5}{*}{9} & Bar 1 & 8597.27 & 1825.32 \\
\hline & Bar 2 & 8129.46 & 1726.00 \\
\hline & Average & 8363.37 & 1755.66 \\
\hline & Std Dev & 330.79 & 70.23 \\
\hline & \% Std Dev & 3.96 & 3.96 \\
\hline
\end{tabular}




\section{APPENDIX C}

\section{C.1. THEORETICAL DESIGN OF BEAMS}

\section{C.1.1 CALCULATION FOR BEAM B1-T}

Properties of Concrete

Strength of concrete, $f_{c}^{\prime}=3400 \mathrm{psi}=3.4 \mathrm{ksi}$

Ultimate strain in concrete, $\varepsilon_{c u}=0.003$

Beam Dimensions

Depth of the beam, $h=8$ in.

Width of the beam, $b=5$ in.

Span of beam, $L=4.1667 \mathrm{ft}$. (5 in. overhang on each side)

\section{Properties of GFRP Bar}

Guaranteed tensile strength of GFRP bar, $f_{f u}^{*}=110000 \mathrm{psi}=110 \mathrm{ksi}$

Guaranteed rupture strain of GFRP bar, $\mathcal{E}_{f u}^{*}=0.019$

Note:

Our intention is not to design and hence guaranteed tensile strength and strain are chosen without accounting for $3 \sigma$, where $\sigma$ is standard deviation.

Modulus of elasticity of GFRP bar, $E_{f}=4800 \mathrm{ksi}$

Environmental reduction factor, $C_{E}=1$ (for instantaneous testing purpose, for long-term

$$
\text { ACI } 440 \text { suggests } C_{E}=0.8 \text { ) }
$$

Rupture stress of GFRP bar, $f_{f u}=C_{E} f_{f u}^{*}=110 \mathrm{ksi}$

Rupture strain of GFRP bar, $\varepsilon_{f u}=C_{E} \mathcal{E}_{f u}^{*}=0.019$

Modulus of elasticity of concrete, $E_{c}=57000 \sqrt{f_{c}^{\prime}}$

$$
\begin{aligned}
& =57000 \sqrt{3400} \\
& =3323.64 \mathrm{ksi} \\
\beta_{1} & =0.85-0.05\left(\frac{f_{c}^{\prime}-4000}{1000}\right) \\
& =0.85-0.05\left(\frac{3400-4000}{1000}\right)=0.85
\end{aligned}
$$

Number of reinforcing bars $=2$

\# 4 bars are used as main reinforcement $=0.5$ in. 
Assume clear cover as 2 in.

Estimated effective depth, $d=h-\operatorname{cov} e r-d_{b, \text { shear }}-\frac{d_{b}}{2}$

$$
\begin{aligned}
& =8-2-0.375-\frac{0.5}{2} \\
& =5.375 \mathrm{in} .
\end{aligned}
$$

$\underline{\text { To Find Depth of Neutral Axis Depth }}$

$$
\begin{aligned}
\frac{\mathcal{E}_{c u}}{c}=\frac{\mathcal{\varepsilon}_{f u}}{d-c} \\
c=\frac{d \varepsilon_{c u}}{\varepsilon_{f u}+\varepsilon_{c u}} \\
=\frac{5.375 \times 0.003}{0.019+0.003} \\
=0.7329 \mathrm{in} . \\
=\beta_{l} c \\
=0.85 \times 0.7329=0.6320 \mathrm{in} .
\end{aligned}
$$

$\underline{\text { To Find Moment }}$

$$
\begin{aligned}
A_{f} & =\operatorname{No.bars}\left(\frac{\pi d^{2}}{4}\right) \\
& =2\left(\frac{\pi \times 0.5^{2}}{4}\right)=0.3927 \mathrm{in.}^{2} \\
\rho_{f} & =\frac{A_{f}}{b d} \\
& =\frac{0.3927}{5 \times 5.375}=0.0146 \\
\mathrm{M}_{\mathrm{n}} & =A_{s} f_{y}(d-a / 2) \\
& =0.3927 \times 110(5.375-0.6320 / 2) \\
& =18.227 \mathrm{kip}-\mathrm{ft}
\end{aligned}
$$


$\underline{\text { To Find Load }}$

$$
\begin{aligned}
& M=\frac{P L}{4} \\
& P=\frac{4 M}{L}=\frac{4 \times 18.227}{4.1667}=17.498 \mathrm{kips}
\end{aligned}
$$

Theoretical load $=17.498$ kips

Experimental load $=16.37 \mathrm{kips}$

$$
\frac{\text { Experimental load }}{\text { Theoretical load }}=\frac{16.37}{17.50}=0.94
$$

\section{C.1.2. CALCULATION FOR BEAM B1-T-NC}

Properties of Concrete

Strength of concrete, $f_{c}^{\prime}=3400 \mathrm{psi}=3.4 \mathrm{ksi}$

Ultimate strain in concrete, $\varepsilon_{c u}=0.003$

$\underline{\text { Beam Dimensions }}$

Depth of the beam, $h=8$ in.

Width of the beam, $b=5 \mathrm{in}$.

Span of beam, $L=4.1667 \mathrm{ft}$. ( 5 in. overhang on each side)

\section{Properties of GFRP Bar}

Guaranteed tensile strength of GFRP bar, $f_{f u}^{*}=91500 \mathrm{psi}=91.5 \mathrm{ksi}$

Guaranteed rupture strain of GFRP bar, $\mathcal{E}_{f u}^{*}=0.019$

Note:

Our intention is not to design and hence guaranteed tensile strength and strain are chosen without accounting for $3 \sigma$, where $\sigma$ is standard deviation.

Modulus of elasticity of GFRP bar, $E_{f}=4800 \mathrm{ksi}$

Environmental reduction factor, $C_{E}=1$ (for instantaneous testing purpose, for long-term

$$
\text { ACI } 440 \text { suggests } C_{E}=0.8 \text { ) }
$$

Rupture stress of GFRP bar, $f_{f u}=C_{E} f_{f u}^{*}=91.5 \mathrm{ksi}$

Rupture strain of GFRP bar, $\varepsilon_{f u}=C_{E} \mathcal{E}_{f u}^{*}=0.019$

Modulus of elasticity of concrete, $E_{c}=57000 \sqrt{f_{c}^{\prime}}$ 


$$
\begin{aligned}
& =57000 \sqrt{3400} \\
& =3323.64 \mathrm{ksi} \\
\beta_{1} & =0.85-0.05\left(\frac{f_{c}^{\prime}-4000}{1000}\right) \\
& =0.85-0.05\left(\frac{3400-4000}{1000}\right)=0.85
\end{aligned}
$$

Number of reinforcing bars $=2$

\# 4 bars are used as main reinforcement $=0.5 \mathrm{in}$.

Assume clear cover as 2 in.

Estimated effective depth, $d=h-\operatorname{cov} e r-d_{b, s h e a r}-\frac{d_{b}}{2}$

$$
\begin{aligned}
& =8-2-0.375-\frac{0.5}{2} \\
& =5.375 \mathrm{in} .
\end{aligned}
$$

$\underline{\text { To Find Depth of Neutral Axis Depth }}$

$$
\begin{aligned}
\frac{\mathcal{E}_{c u}}{c}=\frac{\varepsilon_{f u}}{d-c} \\
c=\frac{d \varepsilon_{c u}}{\varepsilon_{f u}+\varepsilon_{c u}} \\
=\frac{5.375 \times 0.003}{0.019+0.003} \\
=0.7329 \mathrm{in.} \\
a \quad=\beta_{l} c \\
=0.85 \times 0.7329=0.6320 \mathrm{in} .
\end{aligned}
$$

$\underline{\text { To Find Moment }}$

$$
\begin{aligned}
A_{f} & =\operatorname{No.bars}\left(\frac{\pi d^{2}}{4}\right) \\
& =2\left(\frac{\pi \times 0.5^{2}}{4}\right)=0.3927 \mathrm{in} .^{2}
\end{aligned}
$$




$$
\begin{aligned}
\rho_{f} & =\frac{A_{f}}{b d} \\
& =\frac{0.3927}{5 \times 5.375}=0.0146 \\
\mathrm{M}_{\mathrm{n}} \quad & =A_{s} f_{y}(d-a / 2) \\
& =0.3927 \times 91.5(5.375-0.6320 / 2) \\
& =15.162 \mathrm{kip}-\mathrm{ft}
\end{aligned}
$$

$\underline{\text { To Find Load }}$

$$
\begin{aligned}
& M=\frac{P L}{4} \\
& P=\frac{4 M}{L}=\frac{4 \times 15.162}{4.1667}=14.555 \mathrm{kips}
\end{aligned}
$$

Theoretical load $=14.555 \mathrm{kips}$

Experimental load $=14.84$ kips

$$
\frac{\text { Experimental load }}{\text { Theoretical load }}=\frac{14.84}{14.56}=1.02
$$

\section{C.1.3. CALCULATION FOR BEAM B2-T}

\section{Properties of Concrete}

Strength of concrete, $f_{c}^{\prime}=5000 \mathrm{psi}=5 \mathrm{ksi}$

Ultimate strain in concrete, $\boldsymbol{\varepsilon}_{c u}=0.003$

\section{Beam Dimensions}

Depth of the beam, $h=16$ in.

Width of the beam, $b=8$ in.

Span of beam, $L=9 \mathrm{ft}$. ( $6 \mathrm{in}$. overhang on each side)

\section{Properties of GFRP Bar}

Guaranteed tensile strength of GFRP bar, $f_{f u}^{*}=130000 \mathrm{psi}=130 \mathrm{ksi}$

Guaranteed rupture strain of GFRP bar, $\varepsilon_{f u}^{*}=0.019$

Note: 
Our intention is not to design and hence guaranteed tensile strength and strain are chosen without accounting for $3 \sigma$, where $\sigma$ is standard deviation.

Modulus of elasticity of GFRP bar, $E_{f}=4800 \mathrm{ksi}$

Environmental reduction factor, $C_{E}=1$ (for instantaneous testing purpose, for long-term ACI 440 suggests $C_{E}=0.8$ )

Rupture stress of GFRP bar, $f_{f u}=C_{E} f_{f u}^{*}=130 \mathrm{ksi}$

Rupture strain of GFRP bar, $\varepsilon_{f u}=C_{E} \varepsilon_{f u}^{*}=0.019$

Modulus of elasticity of concrete, $E_{c}=57000 \sqrt{f_{c}^{\prime}}$

$$
\begin{aligned}
& =57000 \sqrt{5000} \\
& =4030.51 \mathrm{ksi} \\
\beta_{1} & =0.85-0.05\left(\frac{f_{c}^{\prime}-4000}{1000}\right) \\
& =0.85-0.05\left(\frac{5000-4000}{1000}\right)=0.80
\end{aligned}
$$

Number of reinforcing bars $=2$

\# 4 bars are used as main reinforcement $=0.5$ in.

Assume clear cover as 1 in.

Estimated effective depth, $d=h-\operatorname{cov} e r-d_{b, s h e a r}-\frac{d_{b}}{2}$

$$
\begin{aligned}
& =16-1-0.375-\frac{0.5}{2} \\
& =14.375 \mathrm{in} .
\end{aligned}
$$

To Find Depth of Neutral Axis Depth

$$
\begin{aligned}
\frac{\mathcal{E}_{c u}}{c} & =\frac{\mathcal{E}_{f u}}{d-c} \\
c & =\frac{d \varepsilon_{c u}}{\varepsilon_{f u}+\varepsilon_{c u}} \\
& =\frac{14.375 \times 0.003}{0.019+0.003} \\
& =1.9602 \mathrm{in} .
\end{aligned}
$$




$$
\begin{aligned}
a \quad & =\beta_{1} c \\
& =0.8 \times 1.9602=1.5682 \mathrm{in} .
\end{aligned}
$$

$\underline{\text { To Find Moment }}$

$$
\begin{aligned}
A_{f} & =\operatorname{Nobars}\left(\frac{\pi d^{2}}{4}\right) \\
& =2\left(\frac{\pi \times 0.5^{2}}{4}\right)=0.3927 \mathrm{in.}^{2} \\
\rho_{f} & =\frac{A_{f}}{b d} \\
& =\frac{0.3927}{8 \times 14.375}=0.0034 \\
& =A_{s} f_{y}(d-a / 2) \\
\mathrm{M}_{\mathrm{n}} & =0.3927 \times 130(14.375-1.5682 / 2) \\
& =57.819 \mathrm{kip}-\mathrm{ft}
\end{aligned}
$$

$\underline{\text { To Find Load }}$

$$
\begin{aligned}
& M=\frac{P L}{3} \\
& P=\frac{3 M}{L}=\frac{3 \times 57.819}{9}=19.273 \mathrm{kips}
\end{aligned}
$$

Total load $=2 P=2 \times 19.273=38.546$ kips

Theoretical

Experimental load $=38.61$ kips

$$
\frac{\text { Experimental load }}{\text { Theoretical load }}=\frac{38.61}{38.55}=1.08
$$

\section{C.1.4. CALCULATION FOR BEAM B2-T-NC}

$\underline{\text { Properties of Concrete }}$ 
Strength of concrete, $f_{c}^{\prime}=5000 \mathrm{psi}=5 \mathrm{ksi}$

Ultimate strain in concrete, $\varepsilon_{c u}=0.003$

$\underline{\text { Beam Dimensions }}$

Depth of the beam, $h=16$ in.

Width of the beam, $b=8 \mathrm{in}$.

Span of beam, $L=9 \mathrm{ft}$. (6 in. overhang on each side)

Properties of GFRP Bar

Guaranteed tensile strength of GFRP bar, $f_{f u}^{*}=91500 \mathrm{psi}=91.5 \mathrm{ksi}$

Guaranteed rupture strain of GFRP bar, $\mathcal{E}_{f u}^{*}=0.019$

Note:

Our intention is not to design and hence guaranteed tensile strength and strain are chosen without accounting for $3 \sigma$, where $\sigma$ is standard deviation.

Modulus of elasticity of GFRP bar, $E_{f}=4800 \mathrm{ksi}$

Environmental reduction factor, $C_{E}=1$ (for instantaneous testing purpose, for long-term ACI 440 suggests $\left.C_{E}=0.8\right)$

Rupture stress of GFRP bar, $f_{f u}=C_{E} f_{f u}^{*}=91.5 \mathrm{ksi}$

Rupture strain of GFRP bar, $\varepsilon_{f u}=C_{E} \mathcal{E}_{f u}^{*}=0.019$

Modulus of elasticity of concrete, $E_{c}=57000 \sqrt{f_{c}^{\prime}}$

$$
\begin{aligned}
& =57000 \sqrt{5000} \\
& =4030.51 \mathrm{ksi} \\
\beta_{1} & =0.85-0.05\left(\frac{f_{c}^{\prime}-4000}{1000}\right) \\
& =0.85-0.05\left(\frac{5000-4000}{1000}\right)=0.80
\end{aligned}
$$

Number of reinforcing bars $=2$

\# 4 bars are used as main reinforcement $=0.5 \mathrm{in}$.

Assume clear cover as 1 in.

Estimated effective depth, $d=h-\operatorname{cov} e r-d_{b, \text { shear }}-\frac{d_{b}}{2}$ 


$$
\begin{aligned}
& =16-1-0.375-\frac{0.5}{2} \\
& =14.375 \mathrm{in} .
\end{aligned}
$$

To Find Depth of Neutral Axis Depth

$$
\begin{aligned}
\frac{\varepsilon_{c u}}{c}=\frac{\varepsilon_{f u}}{d-c} \\
c=\frac{d \varepsilon_{c u}}{\varepsilon_{f u}+\varepsilon_{c u}} \\
=\frac{14.375 \times 0.003}{0.019+0.003} \\
=1.9602 \mathrm{in.} \\
a \quad=\beta_{1} c \\
=0.8 \times 1.9602=1.5682 \mathrm{in} .
\end{aligned}
$$

\section{$\underline{\text { To Find Moment }}$}

$$
\begin{aligned}
A_{f} & =\text { No.bars }\left(\frac{\pi d^{2}}{4}\right) \\
& =2\left(\frac{\pi \times 0.5^{2}}{4}\right)=0.3927 \mathrm{in.}^{2} \\
\rho_{f} & =\frac{A_{f}}{b d} \\
& =\frac{0.3927}{8 \times 14.375}=0.0034 \\
\mathrm{M}_{\mathrm{n}} & =A_{s} f_{y}(d-a / 2) \\
& =0.3927 \times 91.5(14.375-1.5682 / 2) \\
& =40.6957 \mathrm{kip}-\mathrm{ft}
\end{aligned}
$$

$\underline{\text { To Find Load }}$

$$
M=\frac{P L}{3}
$$




$$
P=\frac{3 M}{L}=\frac{3 \times 40.6957}{9}=13.5652 \mathrm{kips}
$$

Total load $=2 P=2 \times 13.5652=27.13 \mathrm{kips}$

Theoretical load $=27.13 \mathrm{kips}$

Experimental load $=27.78$ kips

$$
\frac{\text { Experimental load }}{\text { Theoretical load }}=\frac{27.78}{27.13}=1.02
$$

\section{C.1.5. CALCULATION FOR BEAM B3-T}

\section{Properties of Concrete}

Strength of concrete, $f_{c}^{\prime}=5000 \mathrm{psi}=5 \mathrm{ksi}$

Ultimate strain in concrete, $\varepsilon_{c u}=0.003$

\section{$\underline{\text { Beam Dimensions }}$}

Depth of the beam, $h=16 \mathrm{in}$.

Width of the beam, $b=8 \mathrm{in}$.

Span of beam, $L=9 \mathrm{ft}$. (6 in. overhang on each side)

\section{Properties of GFRP Bar}

Guaranteed tensile strength of GFRP bar, $f_{f u}^{*}=96590 \mathrm{psi}=96.59 \mathrm{ksi}$

Guaranteed rupture strain of GFRP bar, $\mathcal{E}_{f u}^{*}=0.019$

Note:

Our intention is not to design and hence guaranteed tensile strength and strain are chosen without accounting for $3 \sigma$, where $\sigma$ is standard deviation.

Modulus of elasticity of GFRP bar, $E_{f}=4800 \mathrm{ksi}$

Environmental reduction factor, $C_{E}=1$ (for instantaneous testing purpose, for long-term

$$
\text { ACI } 440 \text { suggests } C_{E}=0.8 \text { ) }
$$

Rupture stress of GFRP bar, $f_{f u}=C_{E} f_{f u}^{*}=96.59 \mathrm{ksi}$

Rupture strain of GFRP bar, $\varepsilon_{f u}=C_{E} \mathcal{E}^{*}{ }_{f u}=0.019$

Modulus of elasticity of concrete, $E_{c}=57000 \sqrt{f_{c}^{\prime}}$

$$
\begin{aligned}
& =57000 \sqrt{5000} \\
& =4030.51 \mathrm{ksi}
\end{aligned}
$$




$$
\begin{aligned}
\beta_{1} & =0.85-0.05\left(\frac{f_{c}^{\prime}-4000}{1000}\right) \\
& =0.85-0.05\left(\frac{5000-4000}{1000}\right)=0.80
\end{aligned}
$$

Number of reinforcing bars $=1$

\# 4 bars are used as main reinforcement $=0.75 \mathrm{in}$.

Assume clear cover as $1 \mathrm{in}$.

Estimated effective depth, $d=h-\operatorname{cov} e r-d_{b, \text { shear }}-\frac{d_{b}}{2}$

$$
\begin{aligned}
& =16-1-0.375-\frac{0.75}{2} \\
& =14.25 \mathrm{in} .
\end{aligned}
$$

\section{To Find Depth of Neutral Axis Depth}

$$
\begin{aligned}
\frac{\varepsilon_{c u}}{c}=\frac{\varepsilon_{f u}}{d-c} \\
c=\frac{d \varepsilon_{c u}}{\varepsilon_{f u}+\varepsilon_{c u}} \\
=\frac{14.25 \times 0.003}{0.019+0.003} \\
=1.9432 \mathrm{in.} \\
a \quad=\beta_{1} c \\
=0.8 \times 1.9432=1.5546 \mathrm{in} .
\end{aligned}
$$

\section{$\underline{\text { To Find Moment }}$}

$$
\begin{aligned}
A_{f} & =\text { No.bars }\left(\frac{\pi d^{2}}{4}\right) \\
& =\left(\frac{\pi \times 0.75^{2}}{4}\right)=0.4418 \text { in. }^{2} \\
\rho_{f} & =\frac{A_{f}}{b d}
\end{aligned}
$$




$$
\begin{aligned}
&=\frac{0.4418}{8 \times 14.25}=0.0039 \\
& \mathrm{M}_{\mathrm{n}} \quad=A_{s} f_{y}(d-a / 2) \\
&=0.4418 \times 96.59(14.25-1.5546 / 2) \\
&=47.9092 \mathrm{kip}-\mathrm{ft}
\end{aligned}
$$

$\underline{\text { To Find Load }}$

$$
\begin{aligned}
& M=\frac{P L}{3} \\
& P=\frac{3 M}{L}=\frac{3 \times 47.9092}{9}=15.9697 \mathrm{kips}
\end{aligned}
$$

Total load $=2 P=2 \times 15.9697=31.9395$ kips

Theoretical load $=31.94$ kips

Experimental load $=30.02$ kips

$$
\frac{\text { Experimental load }}{\text { Theoretical load }}=\frac{30.02}{31.94}=0.94
$$

\section{C.1.6. CALCULATION FOR BEAM B3-T-NC}

\section{Properties of Concrete}

Strength of concrete, $f_{c}^{\prime}=5000 \mathrm{psi}=5 \mathrm{ksi}$

Ultimate strain in concrete, $\varepsilon_{c u}=0.003$

\section{$\underline{\text { Beam Dimensions }}$}

Depth of the beam, $h=16$ in.

Width of the beam, $b=8 \mathrm{in}$.

Span of beam, $L=9 \mathrm{ft}$. (6 in. overhang on each side)

Properties of GFRP Bar

Guaranteed tensile strength of GFRP bar, $f_{f u}^{*}=81420 \mathrm{psi}=81.42 \mathrm{ksi}$

Guaranteed rupture strain of GFRP bar, $\mathcal{E}_{f u}^{*}=0.019$

Note: 
Our intention is not to design and hence guaranteed tensile strength and strain are chosen without accounting for $3 \sigma$, where $\sigma$ is standard deviation.

Modulus of elasticity of GFRP bar, $E_{f}=4800 \mathrm{ksi}$

Environmental reduction factor, $C_{E}=1$ (for instantaneous testing purpose, for long-term ACI 440 suggests $C_{E}=0.8$ )

Rupture stress of GFRP bar, $f_{f u}=C_{E} f_{f u}^{*}=81.42 \mathrm{ksi}$

Rupture strain of GFRP bar, $\varepsilon_{f u}=C_{E} \varepsilon_{f u}^{*}=0.019$

Modulus of elasticity of concrete, $E_{c}=57000 \sqrt{f_{c}^{\prime}}$

$$
\begin{aligned}
& =57000 \sqrt{5000} \\
& =4030.51 \mathrm{ksi} \\
\beta_{1} & =0.85-0.05\left(\frac{f_{c}^{\prime}-4000}{1000}\right) \\
& =0.85-0.05\left(\frac{5000-4000}{1000}\right)=0.80
\end{aligned}
$$

Number of reinforcing bars $=1$

\# 4 bars are used as main reinforcement $=0.75$ in .

Assume clear cover as 1 in.

Estimated effective depth, $d=h-\operatorname{cov} e r-d_{b, \text { shear }}-\frac{d_{b}}{2}$

$$
\begin{aligned}
& =16-1-0.375-\frac{0.75}{2} \\
& =14.25 \mathrm{in} .
\end{aligned}
$$

To Find Depth of Neutral Axis Depth

$$
\begin{aligned}
\frac{\mathcal{E}_{c u}}{c} & =\frac{\mathcal{E}_{f u}}{d-c} \\
c & =\frac{d \varepsilon_{c u}}{\varepsilon_{f u}+\varepsilon_{c u}} \\
& =\frac{14.25 \times 0.003}{0.019+0.003} \\
& =1.9432 \mathrm{in} .
\end{aligned}
$$




$$
\begin{aligned}
a \quad & =\beta_{1} c \\
& =0.8 \times 1.9432=1.5546 \mathrm{in} .
\end{aligned}
$$

$\underline{\text { To Find Moment }}$

$$
\begin{array}{rl}
A_{f} & =\operatorname{No.bars}\left(\frac{\pi d^{2}}{4}\right) \\
& =\left(\frac{\pi \times 0.75^{2}}{4}\right)=0.4418 \mathrm{in.}^{2} \\
\rho_{f} & =\frac{A_{f}}{b d} \\
& =\frac{0.4418}{8 \times 14.25}=0.0039 \\
& =A_{s} f_{y}(d-a / 2) \\
\mathrm{M}_{\mathrm{n}} & 0.4418 \times 81.42(14.25-1.5546 / 2) \\
& =40.3848 \mathrm{kip}-\mathrm{ft}
\end{array}
$$

$\underline{\text { To Find Load }}$

$$
\begin{aligned}
& M=\frac{P L}{3} \\
& P=\frac{3 M}{L}=\frac{3 \times 40.3848}{9}=13.4616 \mathrm{kips}
\end{aligned}
$$

Total load $=2 P=2 \times 13.4616=26.9332 \mathrm{kips}$

Theoretical load $=26.93 \mathrm{kips}$

Experimental load $=26.91 \mathrm{kips}$

$$
\frac{\text { Experimental load }}{\text { Theoretical load }}=\frac{26.91}{26.93}=1.00
$$




\section{APPEDNDIX D}

\section{D.1. DIFFERENTIAL SCANNING CALORIMETRY (DSC)}

DSC tests were conducted on four samples with and without nanoclay subjected to 0 and 9 months of aging at $140^{\circ} \mathrm{C}$. Glass transition $\left(\mathrm{T}_{\mathrm{g}}\right)$ temperature of samples with and without nanoclay was determined from the average midpoint value of the glass transition temperature of DSC scans.

The onset and end of glass transition for each specimen was determined using the software provided with the DSC instrument and the glass transition zone was analyzed. Graphs of heat flow Vs temp are shown in Figures D-1 to D-4.

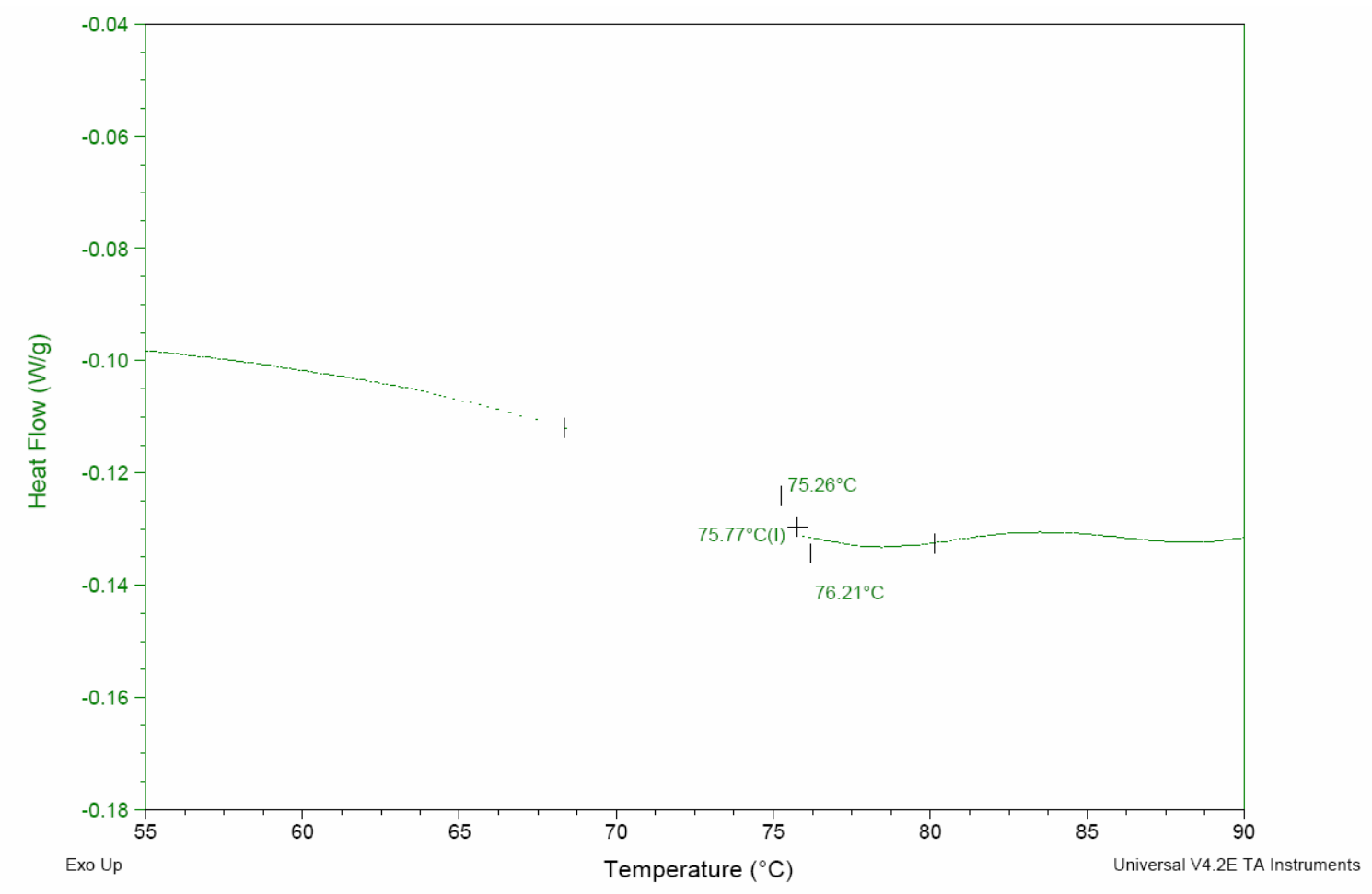

Figure D-1 Glass transition temperature plot for sample without nanoclay subjected to no aging 


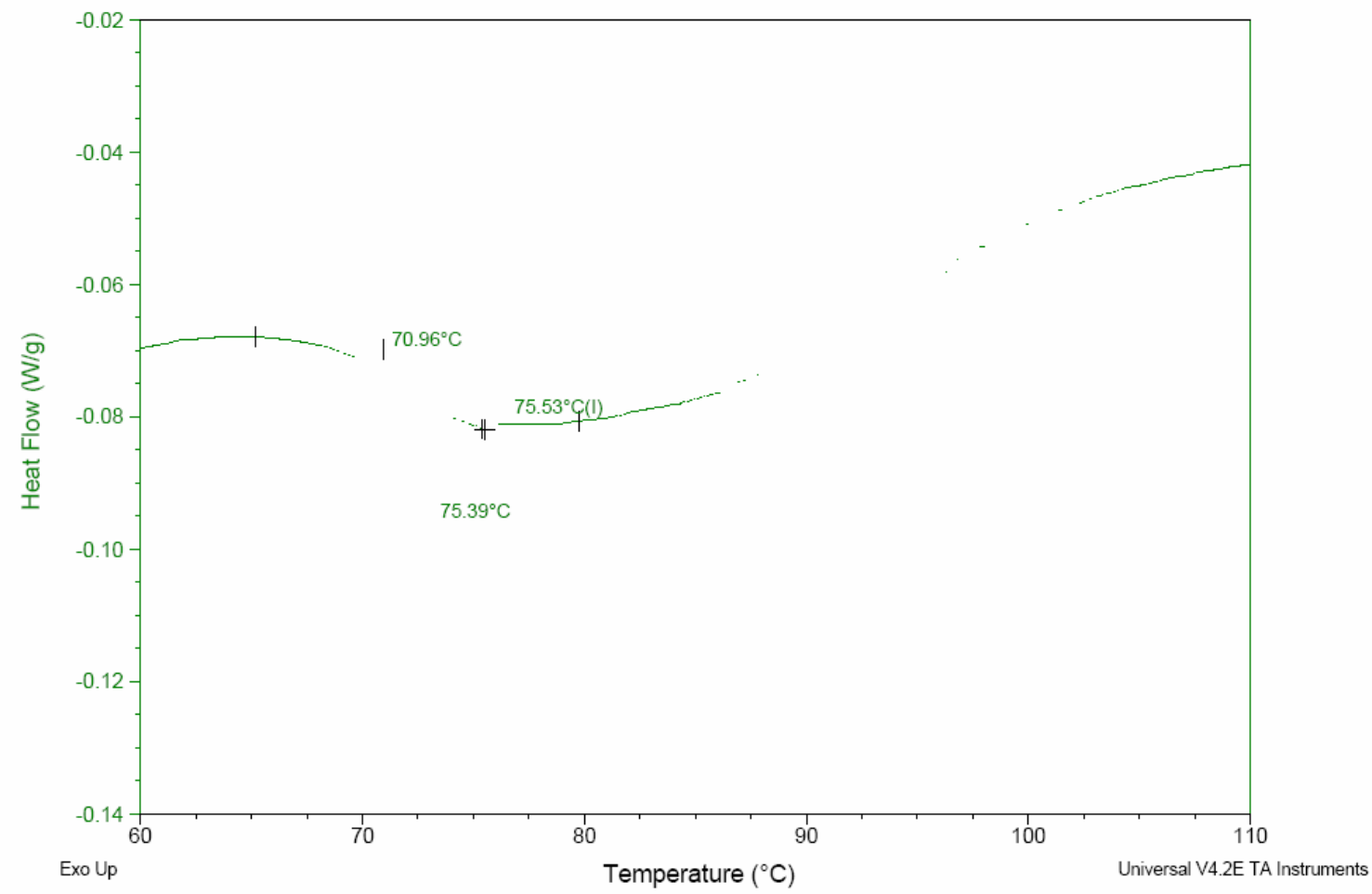

Figure D-2 Glass transition temperature plot for sample with nanoclay subjected to no aging

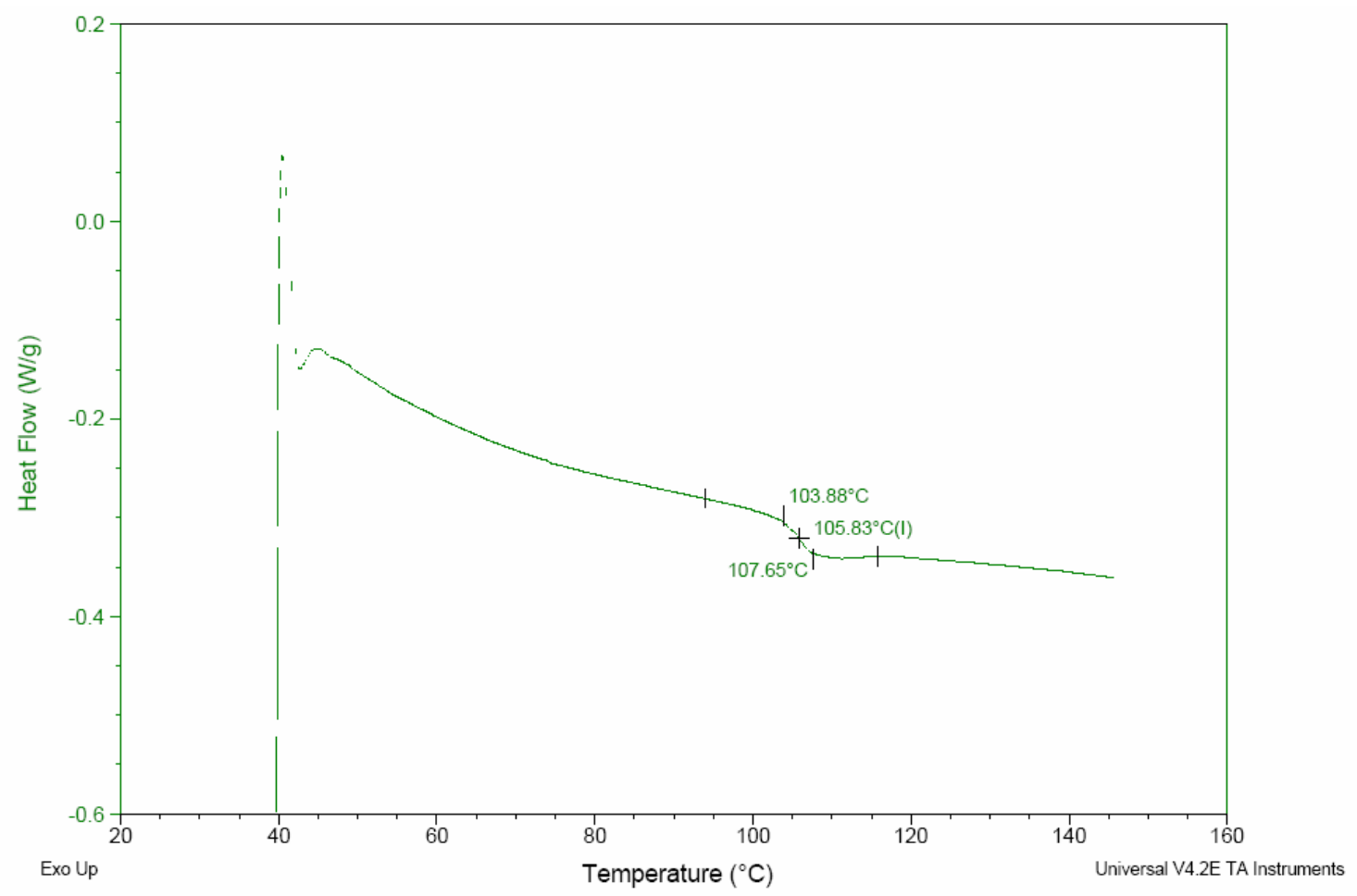

Figure D-3 Glass transition temperature plot for sample without nanoclay subjected to 9 months of aging at $140^{\circ} \mathrm{C}$ 


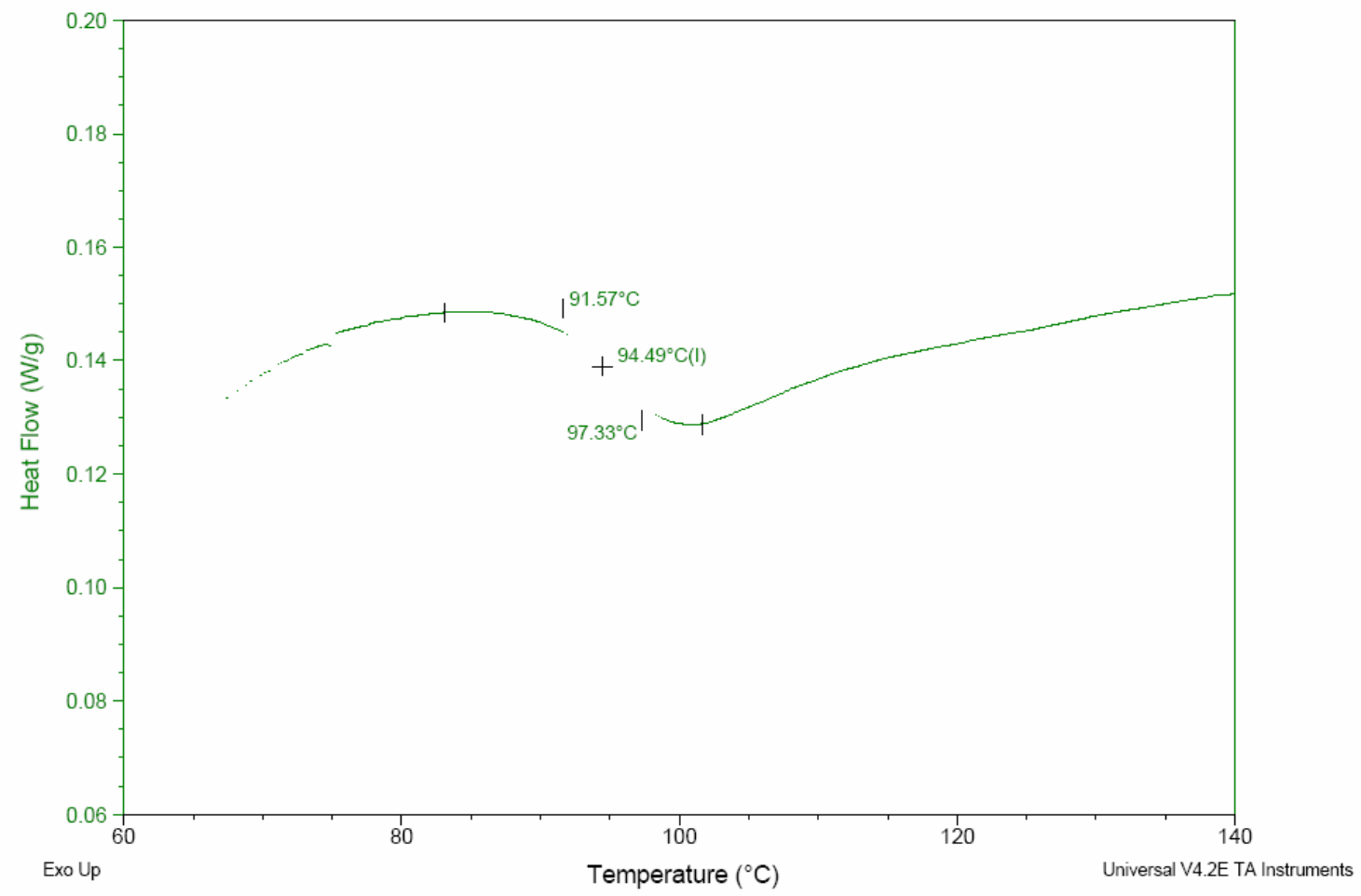

Figure D-4 Glass transition temperature plot for sample with nanoclay subjected to 9 months of aging at $140^{\circ} \mathrm{C}$

Table D-1 Glass transition temperature of samples with and without nanoclay

\begin{tabular}{|c|c|c|c|c|c|}
\hline $\begin{array}{c}\text { No of } \\
\text { months }\end{array}$ & Nanoclay & $\begin{array}{c}\text { Onset } \\
\text { temperature } \\
\text { of }\left(\mathbf{T}_{\mathbf{g}}\right) \\
\left({ }^{\circ} \mathbf{C}\right)\end{array}$ & $\begin{array}{c}\text { End } \\
\text { temperature } \\
\text { of }\left(\mathbf{T}_{\mathrm{g}}\right) \\
\left({ }^{\circ} \mathrm{C}\right)\end{array}$ & $\begin{array}{c}\text { Breadth } \\
\text { of } \\
\text { transition } \\
\left.{ }^{\circ} \mathrm{C}\right)\end{array}$ & $\begin{array}{c}\text { Average } \\
\text { temperature } \\
\left(\mathbf{T}_{\mathrm{g}}\right) \\
\left({ }^{\circ} \mathrm{C}\right)\end{array}$ \\
\hline \multirow{2}{*}{0} & No & 75.26 & 76.21 & 0.95 & 75.77 \\
\hline & Yes & 70.96 & 75.39 & 4.43 & 75.53 \\
\hline \multirow{2}{*}{9} & No & 103.88 & 107.65 & 3.77 & 105.83 \\
\hline & yes & 91.57 & 97.33 & 5.76 & 94.49 \\
\hline
\end{tabular}




\section{D.2. CONCLUSION}

1. Samples without nanoclay have an average $\mathrm{T}_{\mathrm{g}}$ of $75.77^{\circ} \mathrm{C}$ and $105.83^{\circ} \mathrm{C}$ at 0 and 9 months of aging respectively.

2. Samples with nanoclay have an average $\mathrm{T}_{\mathrm{g}}$ of $75.53^{\circ} \mathrm{C}$ and $94.49^{\circ} \mathrm{C}$ at 0 and 9 months of aging respectively.

3. Samples with nanoclay had relatively lower $T_{g}$ which indicates that post curing (aging related) process is slower as compared to samples without nanoclay. This phenomenon explains relatively larger reduction in tensile and shear strength of GFRP bars with nanoclay as compared to those without nanoclay after 9 months of aging. This phenomenon is explained by Fengge (2004), where intercalation of clays with the precursor of a thermosetting polymer changes the functionality of the polymer. This change in functionality affects the extent of cross-linking and lowers the glass transition temperature $\mathrm{T}_{\mathrm{g}}$. 